UNIVERSIDAD NACIONAL DE LA PLATA

FACULTAD DE CIENCIAS NATURALES Y MUSEO

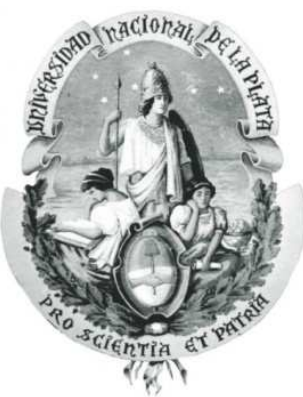

\title{
HISTORIA NATURAL Y ECOLOGÍA DE LOS OFIDIOS (REPTILIA: SERPENTES) DE LAS SIERRAS AUSTRALES \\ DE LA PROVINCIA DE BUENOS AIRES, ARGENTINA
}

\author{
AUTOR \\ DiEgo O. DI PIETRO \\ DIRECTOR \\ JORGE D. WILLIAMS \\ CODIRECTOR \\ MARIO R. CABRERA
}

LUGAR DE TRABAJO

Sección Herpetología, División Zoología Vertebrados

FCNYM - UNLP 
Dedicado a mis padres

Silvia J. Ferrari y Omar O. Di Pietro 


\section{AGRADECIMIENTOS}

Deseo expresar mi agradecimiento a las numerosas personas e instituciones que participaron, directa o indirectamente, de este proyecto. En primer lugar a mis directores, Jorge Williams y Mario Cabrera, por sus invalorables consejos y permanente incentivo para llevar adelante este trabajo. A la Facultad de Ciencias Naturales y Museo por brindarme la posibilidad de realizar el doctorado y a la División Zoología Vertebrados por facilitarme el espacio donde llevar a cabo mi trabajo. A mis compañeros de la Sección Herpetología, Leandro Alcalde, Federico Kacoliris, Sergio Rosset, Camila Kass, Belén Semeñiuk, Melina Velasco y Laura Triviño por su ayuda permanente y desinteresada. Al jurado, Alejandro Giraudo, Margarita Chiaraviglio y María Laura de Wysiecki, por dedicarme parte de su tiempo, por su disposición y sugerencias que mejoraron la calidad de la tesis. A Diego Barrasso, Santiago Nenda, Rodrigo Cajade, Sebastián Lyons, Sebastián Gomes, Cristian Delgado, Fernando Duran, Nahuel De Santis, Ignacio Garcia y Samanta Cairo por la colaboración prestada durante las tareas de campo, colección y fotografía del material. A Germán Moreira, Leopoldo Alvarez y Mariano Lucia por la asistencia brindada en la determinación de las presas consumidas por las serpientes. A Juan Manuel Di Pietro, Matías Grecco, Luis Fajre, Lucas Pomi, Marcos Salvatore, Mariano Lelli, Leandro D’Elia, Agustín Solari, Ariel Paracampo, Javier Negrete, Ignacio Gould, Matías Baviera, Andrés Lavore, Cristian Larsen, Ignacio Perez Nuñes y Carlos Grillo por su amistad y colaboración; especialmente a Marcela Quetglas por su infinita paciencia. A los curadores de las colecciones, Julián Faivovich (MACN, Buenos Aires) y Sonia Kretzschmar (FML, Tucumán), por el préstamo de ejemplares. Al Organismo Provincial para el Desarrollo Sostenible (OPDS, Buenos Aires) por los permisos de investigación y colecta. A mis compañeros de la Cátedra Zoología III Vertebrados (FCNyM, UNLP), principalmente, por tanta amistad. Deseo expresar también mi reconocimiento al Consejo Nacional de Investigaciones Científicas y Técnicas (CONICET) y a la Comisión de Investigaciones Científicas de la provincia de Buenos Aires (CIC) por las becas que posibilitaron este estudio. 


\section{CONTENIDOS}

Resumen 6

Abstract.

Capítulo 1. Introducción general

Composición faunística comparativa. 12

Estructura de la comunidad 14

Estrategias de forrajeo 16

Modelos de distribución 17

Áreas prioritarias para la conservación 19

Objetivo general . 22

Objetivos específicos 22

Hipótesis.

Capítulo 2. Composición taxonómica y similitud biogeográfica de la comunidad de serpientes

Introducción 24

Metodología 24

Área de estudio 24

Obtención de datos 26

Resultados 30

Composición faunística 30

Patrones de distribución y abundancia.. 32

Comparación con otras regiones. 37

Discusión 43

Composición faunística 43

Patrones de distribución y abundancia. 46

Comparación con otras regiones. 51 
Capítulo 3. Relaciones tróficas y espaciales de la comunidad de serpientes

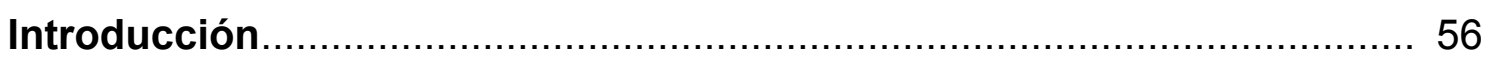

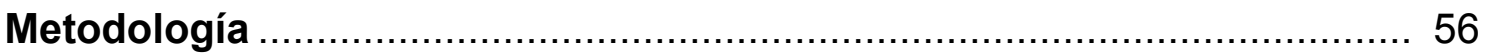

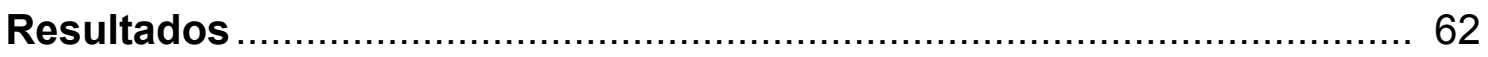

Análisis de la dieta de las especies ............................................. 62

Análisis del microhábitat de las especies ............................................... 74

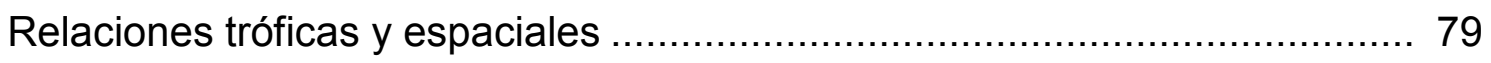

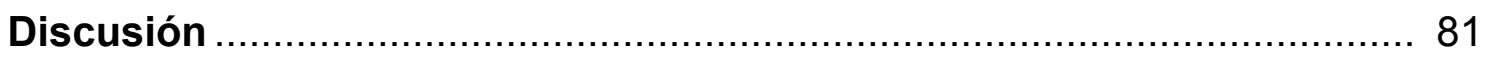

Composición de la dieta ................................................................. 81

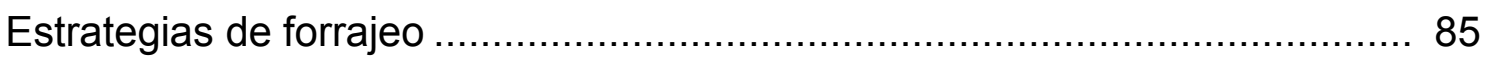

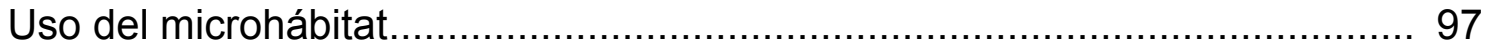

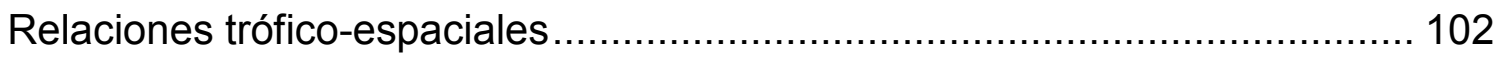

Capítulo 4. Áreas prioritarias para la conservación de la comunidad de serpientes

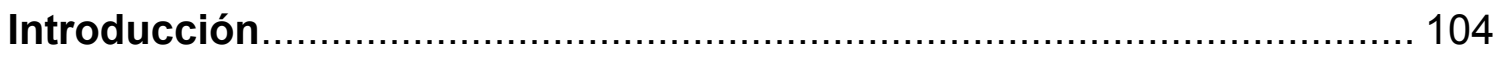

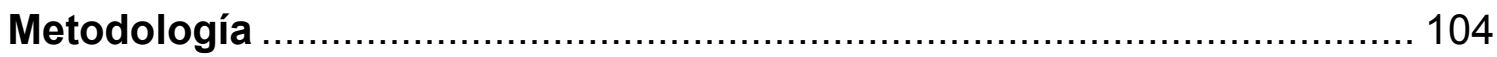

Modelos de distribución potencial ...................................................... 104

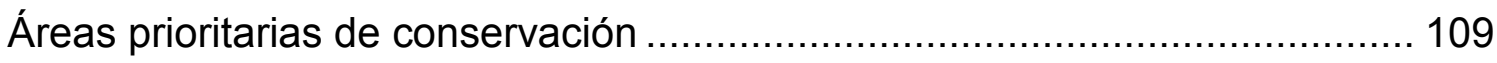

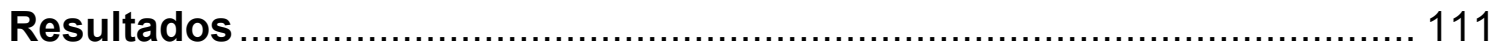

Modelos de distribución potencial ...................................................... 111

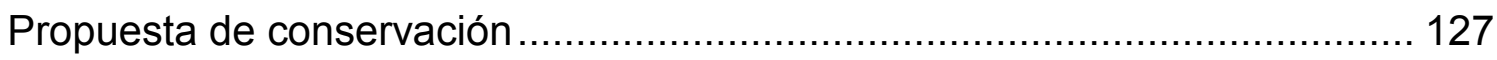

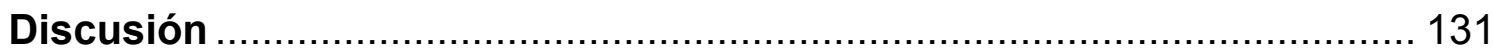

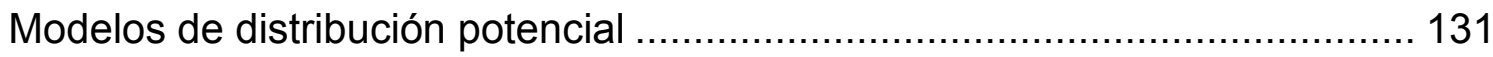

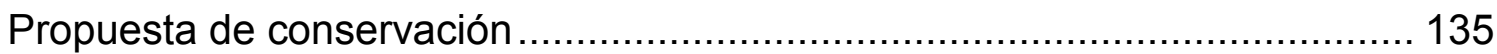

Capítulo 5. Conclusiones

Composicion taxonómica y similitud biogeográfica ................................... 138

Relaciones tróficas y espaciales ................................................... 139

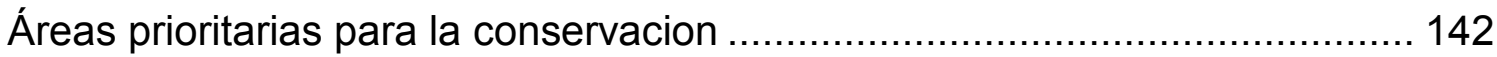




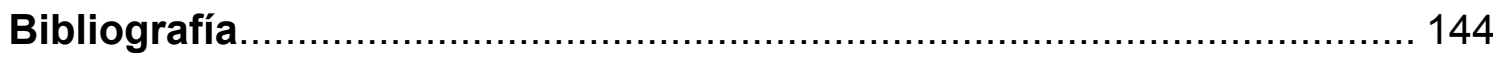

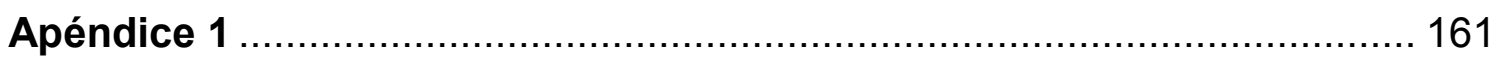

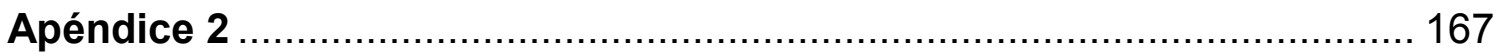

\section{Índice de tablas y figuras}

\section{Tabla $\mathbf{N}^{\circ}$}

Capítulo 2.

2.1. Cantidad de ejemplares examinados por partido

2.2. Ocurrencia de serpientes de presencia confirmada (en las 11 regiones comparadas)

2.3. Coeficiente de Semejanza Biogeográfica (CBR) entre las regiones comparadas.

2.4. Abundancia relativa de las serpientes en las Sierras bonaerenses

2.5. Abundancia relativa de las serpientes en las Sierras bonaerenses, agrupadas según sus hábitos primarios

2.6. Riqueza específica, posición geográfica y principales características ambientales (en las 11 regiones comparadas).

Capítulo 3.

3.1. Dieta de Epictia australis 63

3.2. Dieta de Erythrolamprus poecilogyrus sublineatus. 65

3.3. Dieta de Lygophis elegantissimus 68

3.4. Dieta de Philodryas patagoniensis 70

3.5. Dieta de Bothrops alternatus 72

3.6. Relaciones interespecíficas 80

3.7. Valores de solapamiento de MacArthur y Levins (1967) para la proporción de las presas, volumen de las presas y microhábitats 81

3.8. Amplitud del nicho, diversidad de presas, tipo de dieta, estrategias de forrajeo y selectividad. 97

3.9. Amplitud del nicho, diversidad espacial, tipo de microhábitat y selectividad 101

Capítulo 4.

4.1. Variables ambientales empleadas para construir los modelos de distribución 105 
4.2. Resultados del análisis de correlación espacial realizado con las variables ambientales 113

4.3. Resultados obtenidos durante el modelaje con el algoritmo de máxima entropía 114

Figura $\mathbf{N}^{\circ}$

Capítulo 2.

2.1. Área de estudio - Localidades de origen del material estudiado 32

2.2. Frecuencia porcentual de los ejemplares examinados 33

2.3. Patrones generales de distribución 36

2.4. Distribución altitudinal de la comunidad de serpientes 37

2.5. Dendrograma según los CBR empleando UPGMA y el Índice de Similitud de Bray-Curtis 42

Capítulo 3.

3.1. Determinación de la dieta

3.2. Principales tipos de hábitats/microhábitats utilizados por las serpientes en las Sierras de Ventania 59

3.3. Determinación de la muestra mínima para Epictia australis 62

3.4. Índice de importancia de las categorías de presas consumidas por Epictia australis. 63

3.5. Determinación de la muestra mínima para Erythrolamprus poecilogyrus sublineatus ....

3.6. Índice de importancia de las categorías de presas consumidas por Erythrolamprus poecilogyrus sublineatus. 66

3.7. Determinación de la muestra mínima para Lygophis elegantissimus. 67

3.8. Índice de importancia de las categorías de presas consumidas por Lygophis elegantissimus. 68

3.9. Determinación de la muestra mínima para Philodryas patagoniensis . 69

3.10. Índice de importancia de las categorías de presas consumidas por Philodryas patagoniensis 70

3.11. Determinación de la muestra mínima para Bothrops alternatus. 72

3.12. Índice de importancia de las categorías de presas consumidas por Bothrops alternatus 73

3.13. Microhábitats utilizados por Epictia australis 74

3.14. Microhábitats utilizados por Erythrolamprus poecilogyrus sublineatus... 75 
3.15. Microhábitats utilizados por Lygophis elegantissimus ......................... 76

3.16. Microhábitats utilizados por Philodryas patagoniensis ......................... 77

3.17. Microhábitats utilizados por Bothrops alternatus ................................. 78

3.18. Epictia australis regurgitando huevos/larvas de hormigas.................... 87

3.19. Depredación de Erythrolamprus poecilogyrus sublineatus sobre

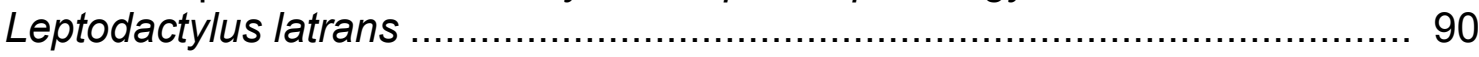

3.20. Depredación de Lygophis elegantissimus sobre Hypsiboas pulchellus.. 92

3.21. Depredación en cautiverio de Lygophis elegantissimus sobre Melanophryniscus montevidensis

Capítulo 4.

4.1. Área seleccionada en la provincia de Buenos Aires para generar los modelos de distribución potencial ......................................................... 106

4.2. Modelo de distribución potencial de Bothrops alternatus ......................... 115

4.3. Modelo de distribución potencial de Bothrops ammodytoides................. 116

4.4. Modelo de distribución potencial de Epictia australis ................................ 117

4.5. Modelo de distribución potencial de Erythrolamprus poecilogyrus

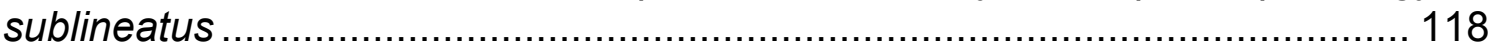

4.6. Modelo de distribución potencial de Lygophis anomalus ....................... 119

4.7. Modelo de distribución potencial de Lygophis elegantissimus ................ 120

4.8. Modelo de distribución potencial de Oxyrhopus rhombifer rhombifer....... 121

4.9. Modelo de distribución potencial de Philodryas patagoniensis................ 122

4.10. Modelo de distribución potencial de Xenodon dorbignyi ........................ 123

4.11. Aporte de las variables ambientales a los modelos de distribución potencial 126

4.12. Curvas de respuesta de las especies empleando solo la variable altitud como predictor de la distribución. 127

4.13. Modelo de áreas prioritarias para la conservación basado en el algoritmo $A B F$ de Zonation 129

4.14. Modelo de áreas prioritarias para la conservación basado en el algoritmo CAZ de Zonation 130 


\section{RESUMEN}

En este trabajo fueron analizados diversos aspectos de la composición faunística, historia natural, ecología y distribución espacial de la comunidad de serpientes de las Sierras Australes de la provincia de Buenos Aires, o Sierras de Ventania, con el propósito de establecer prioridades de conservación.

El área de muestreo comprendió los partidos de Puan, Saavedra, Tornquist, Cnel. Suárez y Cnel. Pringles, abarcando la totalidad de la unidad orográfica del sudoeste bonaerense (entre los $37^{\circ} 31^{\prime} \mathrm{S}, 62^{\circ} 50^{\prime} \mathrm{W}$ y $38^{\circ} 23^{\prime} \mathrm{S}$, $61^{\circ} 13^{\prime}$ W). Los datos fueron obtenidos entre Febrero de 2010 y Marzo de 2014, las serpientes fueron colectadas manualmente mediante búsqueda activa por tiempo limitado. Para complementar los datos fueron revisados ejemplares depositados en colecciones de museos.

Entre los resultados obtenidos se determinó que la comunidad de serpientes está compuesta por 15 especies y subespecies. Las más frecuentes fueron, Erythrolamprus poecilogyrus sublineatus, Lygophis elegantissimus, Bothrops alternatus, Epictia australis y Philodryas patagoniensis, el resto de las especies resultaron poco frecuentes. Los partidos y localidades del centro del área de estudio presentaron mayor cantidad de registros y de ejemplares que los partidos y localidades periféricas. La riqueza específica de las Sierras de Ventania se correspondió con el resto de las regiones comparadas. La mayor similitud biogeográfica de las Sierras de Ventania se presentó con las Dunas Costeras, con las Sierras de Balcarce y Mar del Plata y con las Sierras Bayas. Estas regiones formaron un agrupamiento bien definido en base a sus ofiofaunas.

Epictia australis presentó una dieta especialista mediante una estrategia de forrajeo activo con elevada selectividad por los huevos y larvas de formícidos (Pheidole sp.). Erythrolamprus poecilogyrus sublineatus presentó una dieta generalista, pero con tendencia hacia la especialización, mediante una estrategia de forrajeo activo con moderada selectividad por los anfibios (en general). Lygophis elegantissimus presentó una dieta especialista mediante una estrategia de forrajeo activo con elevada selectividad por larvas y adultos de anfibios (Hypsiboas pulchellus). Philodryas patagoniensis presentó una dieta 
generalista, pero con tendencia hacia la especialización, mediante una estrategia de forrajeo activo con moderada selectividad por las arañas (Lycosa sp.). Bothrops alternatus presentó una dieta especialista mediante una estrategia de forrajeo pasivo con elevada selectividad por los roedores (en general). Epictia australis presentó una especialización en el uso del sustrato con elevada selectividad por el tipo de microhábitat (bajo rocas sueltas sobre tierra). Erythrolamprus poecilogyrus sublineatus y Lygophis elegantissimus presentaron hábitos generalistas en el uso del sustrato, pero con tendencia hacia la especialización, con moderada selectividad por el tipo de microhábitat (arroyos y sus bordes). Philodryas patagoniensis presentó una especialización en el uso del sustrato con elevada selectividad por el tipo de microhábitat (pastizal en general). Bothrops alternatus presentó hábitos generalistas en el uso del sustrato, pero con tendencia hacia la especialización, con moderada selectividad por el tipo de microhábitat (pastizal en general). Se registró un bajo solapamiento en la proporción y volumen de las presas consumidas y un elevado solapamiento en el microhábitat utilizado.

Los modelos de distribución potencial obtenidos revelaron una capacidad predictiva elevada. Al proyectarlos en el espacio geográfico se observaron dos patrones de distribución: (1) el hábitat apropiado es elevado en el ambiente serrano y el intraserrano, y disminuye gradualmente hacia el ambiente periserrano y la llanura circundante y (2) el hábitat apropiado es elevado en la llanura circundante y el ambiente periserrano y disminuye hacia el ambiente serrano y el intraserrano. La altitud resultó la variable más informativa para la construcción de los modelos de distribución, seguida de la temperatura máxima del mes más cálido y la mínima del más frio. Las mejores áreas para la conservación de la comunidad de serpientes abarcaron una superficie de $4176 \mathrm{~km}^{2}$. En la propuesta empleando el algoritmo $A B F$ las áreas de mayor importancia para la conservación se distribuyeron asociadas a las Sierras de Ventania, mientras que empleando el algoritmo CAZ estas áreas también se distribuyeron en las mencionadas sierras, aunque con menor superficie de extensión a expensas de ampliar el área prioritaria a sectores particulares de la llanura circundante. La propuesta empleando $A B F$ fue considerada la mejor opción para conservar la comunidad de serpientes. 
Independientemente del algoritmo de remoción de celdas empleado, solo el $2,2 \%$ de estas áreas prioritarias están representadas en el sistema actual de Áreas Naturales Protegidas.

En conclusión, en base a la comunidad de serpientes, las Sierras de Ventania forman parte del dominio Pampásico. Las especies analizadas utilizan nichos complementarios, con una alta superposición en una dimensión del nicho (microhábitat) y una baja superposición en otra (proporción y volumen de las presas), lo que permite que coexistan en simpatría (y/o sintopía) evitando la exclusión competitiva. Un incremento en las Áreas Naturales Protegidas sería necesario, debido a que las áreas protegidas existentes en las Sierras de Ventania son poco efectivas en la protección de la comunidad de serpientes. 
ABSTRACT

In this work, aspects of faunal composition, natural history, ecology and spatial distribution of the snake community in the Sierras Australes of Buenos Aires province, or Sierras de Ventania, were analyzed in order to establish conservation priorities.

The sampling area included the partidos of Puan, Saavedra, Tornquist, Cnel. Suárez and Cnel. Pringles, covering the entire orographic unit of southwestern bonaerense (between $37^{\circ} 31^{\prime} \mathrm{S}, 62^{\circ} 50^{\prime} \mathrm{W}$ and $38^{\circ} 23^{\prime} \mathrm{S}, 61^{\circ} 13^{\prime}$ W). Data were obtained between February 2010 and March 2014, and the snakes were collected manually by active search for a limited amount of time. To supplement data, specimens from museum collections were reviewed.

The present study determined that the snake community is composed of 15 species and subspecies. The most frequent species were Erythrolamprus poecilogyrus sublineatus, Lygophis elegantissimus, Bothrops alternatus, Epictia australis and Philodryas patagoniensis, while the rest of species were less frequent. The central partidos and localities (with respect to the study area) have more records of species and specimens than the peripheral partidos and localities. Species richness of the Sierras de Ventania corresponds to that of other regions compared. The highest biogeographic similarity of the Sierras de Ventania resulted to be with the Coastal Dunes, Sierras de Balcarce and Mar del Plata, and Sierras Bayas. These regions form a well-defined group based on their ophiofaunas.

Epictia australis presented a specialist diet characterized by a strategy of widely foraging with high selectivity for eggs and larvae of formicids (Pheidole sp.). Erythrolamprus poecilogyrus sublineatus presented a generalist diet, but with a tendency to specialization, through a strategy of widely foraging with moderate selectivity for amphibians (in general). Lygophis elegantissimus presented a specialist diet through a strategy of widely foraging with high selectivity for larvae and adult amphibians (Hypsiboas pulchellus). Philodryas patagoniensis presented a generalist diet, but with a tendency to specialization, through a strategy of widely foraging with moderate selectivity for spiders (Lycosa sp.). Bothrops alternatus displayed a specialist diet through a strategy 
of sit-and-wait foraging with high selectivity for rodents (in general). Epictia australis displayed a specialization in the use of the substrate with high selectivity for the type of microhabitat (under loose rocks on earth). Erythrolamprus poecilogyrus sublineatus and Lygophis elegantissimus displayed generalist habits in the use of the substrate, with a tendency to specialization and moderate selectivity for the type of microhabitat (streams and their edges). Philodryas patagoniensis displayed a specialization in the use of the substrate with high selectivity for the type of microhabitat (pastureland in general). Bothrops alternatus possessed generalist habits in the use of the substrate, with a tendency to specialization and moderate selectivity for the type of microhabitat (pastureland in general). Low overlap in the proportion and volume of prey consumed and high overlap in the microhabitats used were recorded.

The inferred potential distribution models revealed a high predictive capacity. When projecting these models in the geographical space, two distribution patterns were observed: (1) suitable habitat is high at the serrano and intraserrano environment, and gradually decreases towards the periserrano environment and the surrounding plain; and (2) suitable habitat is high at the surrounding plain and the periserrano environment and decreases towards the serrano and intraserrano environment. The altitude resulted to be the most informative variable for the construction of distribution models, followed by the maximum temperature of the warmest month and the minimum of the coldest. The best areas for conservation of the snake community covered an area of $4176 \mathrm{~km}^{2}$. When using the $A B F$ algorithm, the most important areas for conservation were distributed over the Sierras de Ventania, while using the $C A Z$ algorithm these areas were also distributed in these sierras but with less surface extension at the expense of expanding the priority area for particular sectors of the surrounding plain. The $A B F$ proposal was considered the best option to conserve the snake community. Independently of the cell removal algorithm employed, only $2.2 \%$ of these priority areas are represented in the current system of Protected Natural Areas.

In conclusion, based on the snake community, the Sierras de Ventania form part of the Pampásico domain. The analyzed species use complementary 
niches with high overlap in one dimension of the niche (microhabitats) and a low overlap in another (proportion and volume of preys), which allows their existence in sympatry (and/or syntopy) avoiding competitive exclusion. An increase in Protected Natural Areas would be necessary, because the existing protected areas in the Sierras de Ventania are ineffective in protecting the snake community. 


\section{INTRODUCCIÓN GENERAL}

\section{Composición faunística comparativa}

Los censos faunísticos de un país o región cualquiera constituyen una suerte de "código de la naturaleza", como paso previo e indispensable para un ensayo racional de aprovechamiento de las riquezas naturales y de su adecuada conservación (Ringuelet y Arámburu 1957). Las primeras referencias a la fauna de serpientes de la República Argentina se remontan a 1861 cuando Burmeister enumera los vertebrados del país (según Abalos y Mischis 1975). A partir de allí, se suceden muchos trabajos en los que se va plasmando progresivamente el conocimiento sobre la diversidad de las serpientes argentinas (Koslowsky 1896, Berg 1898, Serié 1915, 1921, 1936, Peters y Orejas Miranda 1970, Abalos y Mischis 1975, Cei 1986, 1993, Williams y Francini 1991, Giraudo y Scrocchi 2002). Se destaca el trabajo de Peters y Orejas Miranda (1970), que actualizó la sistemática de los ofidios neotropicales, y que junto con la obra de Cei $(1986,1993)$ sobre reptiles argentinos, son motivo permanente de consultas. Además, sobresalen las "checklists" de Williams y Francini (1991) y Giraudo y Scrocchi (2002), que proporcionaron una lista completa de las serpientes argentinas, con referencias concretas sobre su nomenclatura y distribución geográfica, y que sirvieron de base para evaluar su estado de conservación (Scrocchi et al. 2000, Giraudo et al. 2012).

Con referencia a la provincia de Buenos Aires, la fauna de serpientes ha sido ampliamente estudiada (Marelli 1924, Ringuelet y Arámburu 1957, Gallardo 1977, Miranda et al. 1983, Varela de Olmedo y Carrizo 1987, Williams 1991, Giambelluca 2015). Sin embargo, y como sucede con las referencias bibliográficas mencionadas para el país, muy pocos de estos trabajos citan el material en que se basan, y cuando lo hacen no aclaran los números de colección, lo que impide reubicar los ejemplares. Como tempranamente indica Scrocchi (1991), la ausencia de "vouchers" es muy notable en la mayoría de los trabajos no sistemáticos y obliga a confiar en el principio de autoridad personal. Se debe destacar el trabajo de Williams (1991), que proporcionó una lista completa de las serpientes de la provincia, con referencias puntuales sobre su 
distribución geográfica por partidos. Este fue el primer esfuerzo serio aplicado a revisar la diversidad de las serpientes bonaerenses.

Con respecto a las Sierras Australes de la provincia de Buenos Aires o Sierras de Ventania, área abarcada en el presente estudio, las menciones sobre ofidios se restringen al trabajo pionero de Koslowsky (1895), donde enumera siete especies y subespecies de serpientes. El resto de las referencias se corresponden a revisiones de especies o géneros particulares (Cranwell 1942, Barrio 1961, Barrio y Miranda 1966, Thomas 1976, Lema 1984 , Scrocchi 1990, Scrocchi y Viñas 1991, Scrocchi y Cruz 1993), citas zoogeográficas aisladas (Couturier y Grisolía 1989, Viñas et al. 1989) y trabajos generales sobre distribución de serpientes en la Argentina (por ej. Giraudo et al. 2012).

De acuerdo con Ringuelet (1961), el ajuste entre unidades zoo y fitogeográficas es algo esperable y hasta deseable. De hecho, la mayor parte de los intentos zoogeográficos en cuanto a los reptiles argentinos han estado regidos por las divisiones fitogeográficas de base (por ej. Cabrera 1993, 1995, 2001). En todos sus esquemas, Ringuelet $(1955,1961)$ y Ringuelet y Arámburu (1957) consideran que, en la provincia de Buenos Aires, la zona desde el río Colorado hasta las Sierras de Ventania, inclusive, presenta vinculación faunística con el Monte de La Pampa y forman parte del dominio Central. No obstante, desde el punto de vista fitogeográfico y biogeográfico las Sierras de Ventania quedan comprendidas en la provincia Pampeana (Cabrera 1976, 1994, Morrone 2001).

Una comunidad, en sentido amplio, está integrada por todos los organismos que viven juntos en un hábitat particular, es decir que comprende la totalidad del componente biótico de un ecosistema (Pianka 1973). En la práctica, es imposible el estudio de comunidades enteras, por lo tanto, muchos biólogos han adoptado el criterio de MacArthur (1971), quien al referirse al estudio de una comunidad considera lícito incluir a "cualquier grupo de organismos relacionados que viven uno cerca del otro y acerca del cual es interesante hablar". El estudio de este conjunto se realiza con frecuencia en relación con grupos taxonómicos definidos, denominados taxocenosis, 
taxocomunidad o ensambles (ver Basso 1990). De hecho, Vitt y Vangilder (1983) afirmaron estar convencidos que los patrones relacionados a la historia natural y ecología de serpientes simpátricas solo pueden ser interpretados cuando las especies son estudiadas al mismo tiempo y en una misma área restringida.

La comparación entre comunidades de serpientes puede resultar complejo cuando se relacionan diferentes ambientes y áreas, y cuando existen diferencias en los métodos de muestreo realizados, sumado a la dificultad de hallar ofidios en el campo, debido a la baja densidad que generalmente presentan, y que la mayoría de las especies son cripticas y muchas de ellas tienen hábitos desconocidos (Martins y Oliveira 1998, Bernarde y Abe 2006, Sawaya et al. 2008). Adicionalmente, algunas variables como la posición geográfica (latitud y altitud), temperatura, precipitaciones y tipo de vegetación, influencian la riqueza de especies en las comunidades de serpientes (Vitt 1987). Además de estas variables, los factores históricos también son responsables de la composición de serpientes en una región dada, como la disminución de los Colubridae y los Dipsadinae y el aumento de los Xenodontinae con el aumento de la latitud sur, junto a las limitaciones morfológicas y fisiológicas que permiten a una especie sobrevivir en un determinado ambiente (Cadle y Greene 1993).

\section{Estructura de la comunidad}

Las interacciones entre las especies, tales como competencia y depredación, son consideradas como los mecanismos responsables de las estructuras observadas en comunidades y como sinónimo de partición de recursos (Schoener 1974). Sin embargo, la gran cantidad de especies que interactúan en una comunidad herpetológica complejizan el conocimiento de su ecología (Heyer 1988), aceptándose ampliamente que si bien la competencia es importante, factores que operan independientemente de las interacciones interespecíficas actúan en forma conjunta en el modelado de la estructura comunitaria (Toft 1985, Cadle y Greene 1993). 
La utilización de recursos en una comunidad está íntimamente vinculada con el concepto de nicho ecológico (sensu Hutchinson 1957) y ha sido común que, en estudios sobre el papel funcional desempeñado por las distintas unidades organísmicas, se seleccionaran tres dimensiones principales del nicho: alimentación, hábitat y tiempo de actividad, de este modo el análisis de la utilización de recursos en comunidades animales se aproxima a características reales y puede ser razonablemente bien descripto (Pianka 1973, 1975, 1982, Schoener 1974, Toft 1980, 1981,1985, Jaksic et al. 1981).

Recientemente, se ha sugerido que las diferencias históricas entre las especies representan un papel determinante en las comunidades, indicándose que algunas estructuras previamente atribuidas a las interacciones interespecíficas del presente pueden tener una base filogenética (Cadle y Greene 1993) y que parte de la variación ecológica entre las especies de grupos taxonómicamente diversos, como se considera a las serpientes, puede ser filogenética o evolutivamente estable, mostrando así una marcada relación entre la utilización de recursos, la morfología y la estructura taxonómica (Thorpe et al.1994, Vitt y Zani 1996), aunque la evidencia cuantitativa aún es escasa (Vitt y Zani 1998). De hecho, Vitt y Pianka (2005) plantearon que la partición de recursos en las comunidades puede estar afectada por las habilidades competitivas actuales de las especies, que retienen diferencias ancestrales. Según estos autores, los efectos históricos (o filogenéticos) son mayores y las interacciones son menores entre especies filogenéticamente distantes, mientras que los efectos históricos son mínimos y las interacciones son mayores entre especies filogenéticamente similares que comparten el mismo ambiente.

Los datos disponibles sobre la ecología de comunidades de serpientes, en relación con otros escamados como las lagartijas, son generalmente escasos, debido a que las serpientes son menos abundantes, más crípticas y con frecuencia presentan los estómagos vacíos (Goodyear y Pianka 2008). Sin embargo, la partición de recursos en forma de alimentación, hábitat, y tiempo de actividad ha sido documentada en diversas comunidades de serpientes (por ej. Henderson 1974a, White y Kolb 1974, Yanosky 1989, Martins y Oliveira 1998, Luiselli 2006, Goodyear y Pianka 2008, Bellini et al. 2015). 
En una revisión sobre la partición de recursos en comunidades de anfibios y reptiles, Toft (1985) determinó que el hábitat es la dimensión del nicho más particionada en la mayoría de los taxa, excepto en las serpientes (y larvas de anfibios) donde la dieta es la dimensión más importante en la reducción del solapamiento ecológico entre las especies. Estos datos coinciden con las menciones previas sobre la importancia de la depredación en la divergencia ecológica de las comunidades de serpientes (Arnold 1972, Schoener 1977). Luiselli (2006) revisó la literatura publicada sobre la partición de recursos en comunidades de serpientes, desde la revisión de Toft, y concluyó que la dieta es el recurso más particionado en el $56,8 \%$ de los estudios. Cabe mencionar, nuevamente, que la partición de recursos en cualquier grupo de organismos puede no ser solo consecuencia de la competencia por sí sola, las comunidades están influenciadas por otros factores como: la variación en las limitaciones fisiológicas y morfológicas, la respuesta a los depredadores (Toft 1985) y las limitaciones históricas (Brooks y McLennan 1991, Cadle y Greene 1993).

\section{Estrategias de forrajeo}

La teoría del forrajeo óptimo establece que un depredador será más eficiente cuando tome decisiones que le permitan maximizar la tasa neta de alimento ingerido mientras forrajea. El beneficio obtenido a partir del consumo de una presa estará en función del valor energético neto que provee la presa y el tiempo invertido en la captura. Así los depredadores optimizarán su forrajeo al discriminar entre los tipos de presa, en términos del valor energético y tiempo invertido, eligiendo la presa más adecuada (Perry y Pianka 1997). Los modos de forrajeo se encuentran más relacionados con el linaje filogenético que con las adaptaciones ecológicas como respuesta a las presas (Cooper 1995, Schwenk 1995). Los tipos de dieta (especialista o generalista) y sus gradientes se hallan relacionados con la estrategia de forrajeo empleada por el depredador para capturar las presas. Pianka (1966) define dos estrategias con características opuestas, los forrajeros activos (widely foraging) que buscan activamente las presas, y los forrajeros pasivos (sit and wait) que esperan en 
un sitio de emboscada el paso de las presas. Por lo tanto, una dieta de tipo generalista se relaciona, en parte, con una estrategia de forrajeo pasiva, mientras que una de tipo especialista lo hace con la estrategia de forrajeo activa. Sin embargo, las variaciones entre los dos tipos de dieta muestran un "continuo" entre los extremos de las estrategias de forrajeo (ver Huey y Pianka 1981). Por lo general, los modos de forrajeo y las tácticas empleadas en detectar a las presas están correlacionadas: los forrajeros pasivos dependen de la visión y/o la termorrecepción (foseta loreal) para detectar presas móviles, mientras que los forrajeros activos dependen de la quimiorrecepción (órgano vomeronasal), ya que suelen buscar presas que se encuentran escondidas (Cooper 1994, Schwenk 1995). De esto se desprende que los estrategas pasivos sean en general crípticos y capturen al acecho confundiéndose con su entorno. Por el contrario, los forrajeros activos suelen ser bastante conspicuos al ojo humano, por sus diseños vistosos y porque además suelen moverse mucho para encontrar a sus presas (Huey y Pianka 1981).

\section{Modelos de distribución}

El conocimiento detallado sobre la distribución geográfica y ecológica de las especies es fundamental en la planificación de la conservación, así como para comprender los determinantes ecológicos y evolutivos que intervienen en los patrones de diversidad (Elith et al. 2006, Ferrier y Guisan 2006). Originalmente, las áreas de distribución se construían en un mapa tomando como referencia la localización de los registros puntuales y trazando polígonos alrededor de ellos, de manera que se generan mapas dicotómicos indicando directamente la ausencia o presencia de la especie en cuestión. Algunos ejemplos son el método "a mano alzada" y el método areográfico (Rapoport 1975, Zunino y Zullini 1995). Otro método, como el cartográfico, consiste en emplear cuadrículas sobre un mapa y rellenar aquellas donde se encuentran las localidades de una especie (Rapoport 1975). Este método, aunque fue ampliamente utilizado, presenta limitaciones conocidas al no proveer información sobre qué fracción de la celda está siendo realmente ocupada por la especie (Pleguezuelos et al. 2002). 
La generalización de los Sistemas de Información Geográfica y el desarrollo de técnicas estadísticas aplicadas y robustas ha permitido en los últimos años la expansión de herramientas para el análisis de los patrones espaciales de las especies, los modelos de distribución (revisado en Mateo et al. 2011). La construcción de modelos de distribución de especies es, esencialmente, un proceso de clasificación (Guisan y Zimmermann 2000). La variable dependiente es dicotómica (presencia/ausencia) y las independientes pueden ser cuantitativas (por ej. temperatura, precipitaciones, altitud) 0 nominales (por ej. uso del suelo, vegetación, centros urbanos). Los métodos implicados son clasificadores que deben generar un valor numérico para cada punto del terreno. Dicho valor refleja la idoneidad de presencia de la especie en función de los valores locales de las variables independientes (Mateo et al. 2011).

Los modelos de distribución han recibido diferentes denominaciones en función de sus múltiples aplicaciones e interpretaciones (Peterson 2006). Algunos autores los consideran modelos de idoneidad, y representan la distribución potencial de la especie, entendiendo esto como el espacio donde podría estar presente la especie en función de sus características ambientales (Felicísimo et al. 2005). Otros, optan por describirlos como modelos del hábitat potencial, afirmando que el concepto de hábitat puede ser aplicado a la descripción de la asociación entre los organismos y los factores ambientales, entienden, por lo tanto, que la mayoría de las aproximaciones empleadas en modelización ecológica son ejercicios descriptivos de modelización del hábitat de una determinada especie (Kearney 2006). Por último, la mayoría de los trabajos prefieren denominarlos modelos de nicho ecológico (Pulliam 2000, Araújo y Guisan 2006, Sillero et al. 2010), que representa la combinación de condiciones ecológicas que la especie puede tolerar (sensu Grinnell 1917). Los modelos de distribución que se basan principalmente en el nicho ecológico, predicen la disponibilidad ambiental para las especies como una función de las variables ambientales empleadas, representando así una aproximación empírica o matemática de dicho nicho (Phillips et al. 2006). Se denomina nicho fundamental al conjunto de todas las condiciones que permiten la supervivencia de las especies, mientras que un nicho realizado es aquel que las especies 
ocupan en realidad (Guisan y Zimmermann 2000, Phillips et al. 2006). En la mayoría de los casos, el nicho realizado puede ser más pequeño que el nicho fundamental, debido a la influencia humana, interacciones bióticas y/o barreras geográficas que dificultan la dispersión y colonización (Phillips et al. 2006, Elith et al. 2006). La distribución inferida a partir del nicho fundamental se denomina distribución potencial, y es necesaria para tener un conocimiento relativo sobre los patrones de distribución de las especies (Phillips et al. 2006). Asimismo, el modelado a nivel comunidad combina datos de muchas especies y produce información adicional sobre los patrones espaciales en la distribución de la diversidad a nivel de la comunidad en conjunto, además de, a nivel de las especies individuales (Ferrier y Guisan 2006).

Con diversas aplicaciones y herramientas las serpientes fueron empleadas como objeto de estudio en el modelaje de la distribución y el hábitat (ver Jenkins et al. 2009). La utilidad del algoritmo de máxima entropía (Maxent) fue ampliamente probada en el modelado de la distribución geográfica de diversas especies de serpientes neotropicales (por ej. Urbina-Cardona 2008, Paredes-García et al. 2011, Rivera et al. 2011, Mesquita et al. 2013, Nori et al. 2013a, González-Maya et al. 2014). Asimismo, los modelos de distribución y hábitat son herramientas importantes para evaluar el estado de conservación de las serpientes, considerando que la pérdida y fragmentación del hábitat son algunas de las causas fundamentales en la disminución de sus poblaciones a nivel mundial (Gibbons et al. 2000, Jenkins et al. 2009, Reading et al. 2010).

\section{Áreas prioritarias para la conservación}

Muchas personas se preocupan por la contaminación, el efecto invernadero y la capa de ozono, pero no advierten la perdida de la biodiversidad, un fenómeno cuyo avance actual está provocando una verdadera crisis (Crisci et al. 2000). De hecho, la tasa actual de extinción de plantas y animales, debido a las actividades humanas, es más de mil veces superior a las tasas típicas de toda la historia de la vida en la Tierra (Pimm et al. 1995). Las propuestas de áreas prioritarias para la conservación a gran escala, como las áreas de endemismos de aves (Stattersfield et al. 1998), los 
"hotspots" de riqueza (Myers et al. 2000), las ecorregiones (Olson et al. 2001), los centros de extinciones inminentes (Ricketts et al. 2005), así como las prioridades globales de conservación, han sido una vía efectiva para distribuir los fondos destinados para la conservación de la biodiversidad (Brooks et al. 2006). No obstante, la ordenación espacial del territorio a una escala más fina es indispensable para optimizar las acciones de conservación y manejo en el terreno, ante la rápida destrucción del hábitat y los alarmantes pronósticos de cambios en el clima mundial (Bruner et al. 2001, Seymour et al. 2001, Ricketts et al. 2005, Kremen et al. 2008). En este sentido, el criterio de áreas claves para la biodiversidad ha sido propuesto para identificar, mediante criterios cuantitativos y a escala local, aquellos sitios con mayor concentración de especies amenazadas e irremplazables (Eken et al. 2004, Langhammer et al. 2007).

La red global de Áreas Naturales Protegidas (ANP) fue creciendo en superficie de forma sostenida desde 1992, aumentando un promedio de $2,5 \%$ por año (Butchart et al. 2010). Las ANP actualmente ocupan casi 17 millones de $\mathrm{km}^{2}$ en todo el mundo (cerca de $19 \%$ de la superficie terrestre) pero solo cerca del 5,8\% está estrictamente destinado a proteger la biodiversidad (Jenkins y Joppa 2009). Las ANP son una de las principales herramientas para la conservación, aunque muchas de éstas no cumplen con los propósitos de su creación al no haber sido diseñadas en función de las especies que desean conservar (Pressey 1994, Bruner et al. 2001, Sutherland et al. 2010). Esto sucede debido a que las ANP han sido delimitadas a partir de elementos antrópicos (como carreteras, caminos, vías del ferrocarril), turísticos o geográficos (como ríos, montañas) que no necesariamente delimitan los hábitats y las condiciones propicias para las especies, que son sus objetivos de conservación (Küper et al. 2004). Por lo tanto, la adición de nuevas áreas prioritarias para la conservación al sistema de ANP debe ser cuidadosamente planificada para maximizar la representación de la biodiversidad y garantizar su persistencia futura (Araújo y Williams 2000).

Como tempranamente indica Gallardo (1973, 1980b), las serpientes cumplen funciones ecológicas muy importantes al controlar las poblaciones de roedores, ranas, otras serpientes, lagartos y aves. De hecho, en los últimos 
años, fueron consideradas muy buenas especies subrogadas de la biodiversidad, incluso, fueron señaladas como el nuevo organismo modelo en investigaciones ecológicas y de conservación (ver Shine y Bonnet 2000, Mullin y Seigel 2009). Adicionalmente, las ANP juegan un rol fundamental para su preservación, ya que la mayoría de las personas las mata cuando las encuentra, debido al exacerbado temor cultural y bajo la presunción de que todas las serpientes son peligrosas (Dodd 1993, Giraudo 2001, Arzamendia y Giraudo 2004, 2012).

Numerosos estudios han estado dirigidos a facilitar la selección óptima de reservas, empleando criterios cuantitativos para su delimitación y definidas de acuerdo con la calidad de los hábitats desde el punto de vista de las especies (por ej. Urbina-Cardona 2008, Urbina-Cardona y Loyola 2008, UrbinaCardona y Flores-Villela 2010, Milanovich et al. 2010, Rissler y Smith 2010, Nori et al. 2013b). Asimismo, se han diseñado algoritmos de priorización espacial para delimitar de forma eficiente y objetiva estos sitios (por ej. Rebelo 1994, Moilanen et al. 2005, Moilanen 2007). Entre los algoritmos de priorización espacial empleados con más éxito en los últimos años se encuentran los brindados por Zonation (ver Moilanen et al. 2014). Este programa constituye un marco para la selección de reservas al identificar de forma cuantitativa áreas 0 paisajes que son importantes para resguardar la calidad y conectividad de los hábitats de múltiples especies (Moilanen et al. 2014). El uso de Zonation en la selección de áreas prioritarias para la conservación de la biodiversidad, muestra grandes ventajas al permitir integrar hábitats de alta calidad para un gran número de taxones y reconocer de forma directa áreas núcleo de su distribución geográfica de acuerdo con un valor jerárquico de importancia (Kremen et al. 2008). Estudios recientes lo han utilizado para priorizar áreas de conservación con diferentes organismos y en diferentes regiones del mundo (por ej. Kremen et al. 2008, Leathwick et al. 2008, 2010, Fiorella et al. 2010, Carroll 2010, Tognelli et al. 2011, Corbalán et al 2011, Leach et al. 2013). Sin embargo, se desconoce en la actualidad su empleo en la selección de reservas empleando a los ofidios como modelo. 


\section{Objetivo general}

- Determinar la composición faunística, distribución espacial, y aspectos de la historia natural y ecología de la comunidad de serpientes de las Sierras Australes de la provincia de Buenos Aires, con el propósito de contar con la información suficiente para sugerir pautas de conservación.

\section{Objetivos específicos}

- $\quad$ Conocer la composición de la comunidad de serpientes.

- Determinar los patrones de distribución y abundancia de las especies.

- $\quad$ Establecer las afinidades biogeográficas de la comunidad de serpientes mediante la comparación con otras regiones.

- Determinar diferentes aspectos de la ecología trófica (dieta, estrategias de forrajeo) y espacial (uso del microhábitat).

- Determinar el solapamiento del nicho trófico-espacial de la comunidad de serpientes.

- Completar los vacíos existentes en los patrones de distribución y estimar el hábitat de ocurrencia para cada especie.

- Determinar las variables ambientales que modelan los patrones de distribución de las especies.

- Generar propuestas para la conservación de la comunidad de serpientes.

- Determinar la efectividad del sistema actual de Áreas Naturales Protegidas (Parque Provincial Ernesto Tornquist y Reserva Privada Sierras Grandes). 


\section{Hipótesis}

- En base a la comunidad de serpientes, las Sierras Australes de la provincia de Buenos Aires forman parte del dominio Pampásico.

- La utilización diferencial de los recursos permite que las especies coexistan en simpatría evitando la exclusión competitiva. Por lo tanto, las especies analizadas particionan la dieta y comparten el espacio.

- Las Áreas Naturales Protegidas existentes en el área de estudio son poco efectivas para la protección de la comunidad de serpientes. 


\section{COMPOSICIÓN TAXONÓMICA Y SIMILITUD BIOGEOGRÁFICA DE LA COMUNIDAD DE SERPIENTES}

\section{INTRODUCCIÓN}

En este capítulo se establece la composición faunística y los patrones de distribución y abundancia de las especies. Se determinan las afinidades biogeográficas de la comunidad de serpientes mediante la comparación con otras regiones cercanas.

\section{METODOLOGÍA}

\section{Área de estudio}

Localización geográfica (Figura 2.1): En el sudoeste de la provincia de Buenos Aires, República Argentina, entre los $37^{\circ} 31^{\prime} \mathrm{S}, 62^{\circ} 50^{\prime} \mathrm{W}$ y $38^{\circ} 23^{\prime} \mathrm{S}$, $61^{\circ} 13^{\prime} \mathrm{W}$, se desarrolla una unidad orográfica que también constituye una provincia geológica, la primera se denomina Sierras Australes, mientras que a la segunda le corresponde el nombre de Sierras de Ventania (Sellés-Martínez 2001). Esta unidad orográfica, formada por cordones sub-paralelos, alcanza los $170 \mathrm{~km}$ de longitud en dirección NW-SE, un ancho máximo de $65 \mathrm{~km}$, y una

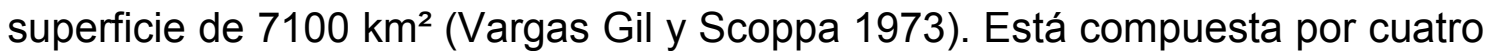
cordones principales: las Sierras de Cura Malal, de la Ventana, de las Tunas y de Pillahuincó, con alturas máximas sobre el nivel del mar de 1015, 1243, 650 y 550 metros, respectivamente.

Datos climáticos: El clima es templado, con una temperatura promedio anual de $14{ }^{\circ} \mathrm{C}$ y una precipitación promedio anual de $800 \mathrm{~mm}$ (Burgos 1968). Dentro del área serrana existe un gradiente altitudinal de temperatura, la cual disminuye $6,9^{\circ} \mathrm{C} / 1000 \mathrm{~m}$ (Kristensen y Frangi 1995a, b). Estos autores estudiaron los efectos de la topografía sobre el clima y diferenciaron cinco mesoclimas que difieren en su temperatura, insolación y humedad. Asimismo, las precipitaciones aumentan con la altitud, desde $745 \mathrm{~mm}$ en la base hasta 828 mm en la cumbre (Pérez y Frangi 2000). 
Geología: El área estudiada está constituida por rocas paleozoicas fuertemente plegadas (Harrington 1947). A ellas, se suman conglomerados rojos terciarios muy cementados y materiales cuaternarios, que incluyen rodados pleistocenos, sedimentos arcillosos, loessoides y limos, con intercalaciones de tosca. El relieve actual se debe a levantamientos intermitentes que comenzaron en el Terciario superior (Harrington 1980). En la región fueron descriptos cuatro ambientes geoedafológicos: serrano, intraserrano (valle serrano), periserrano y de llanura (Cappannini et al. 1971). En términos productivos, los ambientes intraserrano y serrano se destinan a la ganadería pastoril, utilizando los pastizales naturales como recurso forrajero, y los ambientes periserranos y de llanura se destinan principalmente a la implantación de praderas o cultivos de granos (Frangi y Barrera 1996). Los suelos se han desarrollado a partir de sedimentos loéssicos que cubrieron los faldeos de las sierras, mientras que el basamento, compuesto por granito y riolitas, de edad precámbrica y en parte paleozoica, aflora en varios sectores, debido al intenso plegamiento que sufrió (Cappannini et al. 1971, Vargas Gil y Scopa 1973). Las características del plegamiento y la disposición final del basamento, originó hacia el sudoeste, laderas con pendientes muy pronunciadas y abundante afloramiento rocoso, mientras que las laderas ubicadas hacia el noreste presentan pendientes más suaves, permitiendo la deposición de loess (ver Lizzi et al. 2007).

Vegetación: La vegetación de las sierras fue descripta por Cabrera (1976) para el Distrito Pampeano Austral (Provincia Fitogeográfica Pampeana, Dominio Chaqueño, Región Neotropical). Se identificaron en la región más de 400 taxones vegetales, con varios endemismos (ver De la Sota 1967, Frangi y Bottino 1995, Frangi y Barrera 1996). Frangi y Bottino (1995) realizaron un completo estudio de la vegetación de la zona y reconocieron seis complejos de vegetación casmofítica de los afloramientos rocosos, siete comunidades de pastizales y tres de matorrales. Estos autores indican que los pastizales del ambiente serrano están dominados por Briza subaristata, y flechillas de los géneros Stipa y Piptochaetium, y que los prados de altura están dominados por Festuca pampeana y F. ventanicola, donde aparece Sorghastrum pellitum como especie co-dominante. En los pastizales periserranos e intraserranos 
dominan los pajonales de Stipa caudata y S. ambigua (Tussock). En algunos sectores se encuentran comunidades arbustivas, principalmente de Eupatorium buniifolium y Discaria americana. En los cursos de agua y sus márgenes dominan los carrizales (Phragmites australis), las cortaderas (Cortaderia selloana), la paja colorada (Paspalum quadrifarium) y los bosques de sauces (Salix humboldtiana y $S$. fragilis), entre otras especies. Esta región ha sido considerada como un área valiosa para la conservación de los pastizales naturales (Bilenca y Miñarro 2004). En el área de Sierra de la Ventana se ha forestado en mayor frecuencia con pinos (por ej. Pinus halapensis y $P$. radiata) y en menor medida con otras especies, como cedros (por ej. Cedrus deorata y C. atlantica), olmos (por ej. Ulmus pumila), aromos (por ej. Acacia dealbata y A. trinervis) y eucaliptus (por ej. Eucalyptus viminalis y E. rostrata). Además de las forestaciones con pinos, merece un comentario aparte la naturalización de la retama (Spartium junceum) en los márgenes de algunos arroyos, formando matorrales densos de conspicua floración amarilla.

\section{Obtención de datos}

Composición faunística: Para determinar la composición de serpientes del área de estudio se obtuvieron datos de diversas fuentes, como muestreos propios y revisión de ejemplares depositados en museos. Las serpientes se colectaron en el periodo comprendido entre Febrero de 2010 hasta Marzo de 2014. Fueron realizadas 15 campañas de prospección herpetológica, con una duración de siete días cada una, durante los siguientes meses del año: Febrero de 2010, Noviembre de 2010, Diciembre de 2010, Enero de 2011, Marzo de 2011, Octubre de 2011, Noviembre de 2011, Enero de 2012, Marzo de 2012, Septiembre de 2012, Noviembre de 2012, Enero de 2013, Marzo de 2013, Noviembre de 2013 y Marzo de 2014. Se utilizaron los métodos de captura directa comúnmente empleados en los muestreos de ofidios, búsqueda activa por tiempo limitado o procedimiento de tiempo restringido (ver Campbell y Christman 1982, Scrocchi y Kretzschmar 1996, Manzanilla y Péfaur 2000). Los ejemplares fueron colectados manualmente por tres observadores en el campo, mediante el recorrido diario de una transecta de 4000 a $5000 \mathrm{~m}$ de longitud y 
durante un periodo aproximado de seis horas de búsqueda exhaustiva. E diseño del muestreo consistió de visitas regulares a tres estaciones fijas: La estación 1 se ubicó en el Cerro Cura Malal Grande (3743' S, 62¹3' W) Partido de Saavedra, correspondiente a la Sierra de Cura Malal; la estación 2 en el

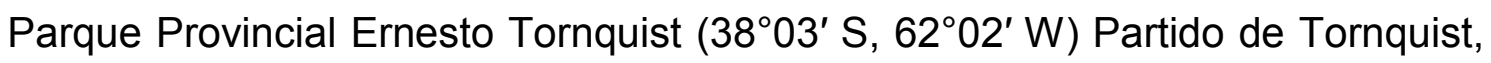
correspondiente a la Sierra de la Ventana; y la estación 3 en Villa ArcadiaSierra de la Ventana $\left(38^{\circ} 08^{\prime} \mathrm{S}, 61^{\circ} 48^{\prime} \mathrm{W}\right.$ ) límite de los Partidos de Coronel Suarez y Tornquist, correspondiente a la Sierra de las Tunas y de Pillahuincó (Figura 2.1). Con esta metodología fueron cumplidas un total de 2016 horashombre de muestreo de ofidios. Adicionalmente, se efectuaron visitas no regulares a otras localidades de los Partidos serranos de Puan (Puan), Saavedra (por ej. Saavedra, Pigüé), Coronel Suárez (por ej. D’Orbignyi, Cura Malal), Tornquist (por ej. Saldungaray, Villa Ventana) y Coronel Pringles (por ej. Las Mostazas, Pillahuincó) con un total de 672 horas-hombre de muestreo (Figura 2.1).

Para generar información complementaria se realizaron colectas de ejemplares atropellados (o en actividad) sobre carreteras y caminos rurales, mediante el recorrido en vehículo a velocidades bajas y constantes (aprox. 50 $\mathrm{km} / \mathrm{h}$ ), donde se recorrieron aproximadamente $4500 \mathrm{~km}$ (ver Campbell y Christman 1982 por metodología). Se transitaron principalmente las RP72, 76, 85,52 , y la RN33. Solo fueron colectados los ejemplares hallados en actividad o en muy buen estado de preservación. Además, se revisaron los ejemplares depositados en las siguientes colecciones herpetológicas: Centro Nacional de Investigaciones lológicas (ex CENAI, actualmente MACN), Museo Argentino de Ciencias Naturales "Bernardino Rivadavia" (MACN, Buenos Aires) y Museo de La Plata (MLP.R, MLP.JW, Buenos Aires). También se recibieron datos de catálogo de ejemplares depositados en la Fundación Miguel Lillo (FML, Tucumán).

Para determinar los patrones de distribución (latitudinal y altitudinal) de las serpientes se georreferenciaron los registros de campo utilizando GPS Garmin eTrex Vista, y las coordenadas de localidades de museos se obtuvieron mediante el programa Google Earth Pro. Los mapas de distribución de las especies fueron realizados utilizando un Sistema de Información Geográfica 
mediante el programa DIVA-GIS versión 7.5 (Hijmans et al. 2012). Para evidenciar la existencia de diferencias significativas en la distribución altitudinal de la comunidad de serpientes se realizó una prueba de Kruskal-Wallis y posteriormente para identificar las especies que presentaron dichas diferencias se realizó una comparación por pares de Mann-Whitney con ajuste de Bonferroni, utilizando el programa PAST versión 3.04 (Hammer et al. 2001).

Se emplearon las técnicas usuales para la fijación y conservación de los ejemplares (Pisani y Villa 1974, Scrocchi y Kretzschmar 1996). Se realizó el procedimiento de eutanasia por inyección intracardíaca de 0,05-0,1 ml de pentotal sódico. Los ejemplares fueron fijados mediante inyección de formol neutro al $10 \%$ e inmediata inmersión en el mismo durante 48-72 horas, para posteriormente ser transportados al laboratorio y conservados en alcohol etílico al $70 \%$. Para dicho procedimiento se contó con los permisos de investigación y colecta por parte del Organismo Provincial para el Desarrollo Sostenible, Buenos Aires (OPDS, Disposición N003/2011). Los ejemplares coleccionados en este estudio fueron depositados en la Colección de Reptiles del Museo de La Plata (MLP.R, ver Apéndice 1).

Similitud biogeográfica: Para determinar la similitud biogeográfica del área de estudio se realizaron comparaciones con otras regiones en base a sus ofiofaunas. Los datos de las regiones comparadas se obtuvieron de la revisión exhaustiva de la literatura. Solo se consideraron las listas de serpientes de presencia confirmada y se adicionaron las citas zoogeografías con idéntica localidad. A continuación se enumeran las regiones y localidades comparadas y la fuente de información (de norte a sur): (1) Noreste bonaerense (NE), Baradero, Bella Vista, Cañuelas, Lincoln, Parque Pereyra Iraola (Berazategui, Ensenada, Florencio Varela y La Plata) y San Fernando (Gallardo 1980a, Scrocchi y Giraudo 1997, Di Pietro y Nenda 2007); (2) Parque Regional, Forestal y Botánico Rafael de Aguiar (PRA), San Nicolás (Voglino et al. 2001); (3) Reserva Natural Otamendi (RNO), Campana (Pereira y Haene 2003); (4) Reserva Natural Punta Lara (RNPL), Berazategui y Ensenada (Saibene et al. 2012); (5) Parque Costero del Sur (PCS), Magdalena y Punta Indio (Gallardo 1987, Nenda y Di Pietro 2009, Williams y Kacoliris 2009); (6) Depresión del Salado (DS), Gral. Alvear, Gral. Lavalle, Las Flores, Libres del Sud y Monte 
(Gallardo 1976, Nenda y Di Pietro 2009); (7) Sierras Bayas (SB), Olavarría (Nágera 1915, Barrio 1961); (8) Sierras de Balcarce y Mar del Plata (SBM), Balcarce y General Pueyrredón (Vega y Bellagamba 1990, Barrio 1961); (9) Dunas costeras (DC), Partido de la Costa, Punta Médanos, Reserva Municipal Faro Querandí, Reserva Natural Mar Chiquita, Mar del Sur, Dunas entre Necochea y Pehuen-Có (Kacoliris et al. 2006, Celsi et al. 2008); (10) Sierras de Ventania (SV) (Koslowsky 1895, Couturier y Grisolia 1989, Viñas et al. 1989, presente estudio); (11) Sierras de Lihué Calel (SLC), Parque Nacional Lihué Calel, Lihué Calel, La Pampa (Tiranti y Avila 1997, obs. pers.). No fueron consideradas las especies de presencia probable y/o dudosa y aquellas que presentan un único registro aislado en Buenos Aires sin localidad específica de colecta. Por ejemplo, Amerotyphlops brongersmianus (Dixon y Hendricks 1979), Erythrolamprus almadensis (Ringuelet y Aramburu 1957, Gallardo 1980a), Xenodon merremii (Vuoto 1996), Hydrodynastes gigas (Voglino et al. 2001) y Tantilla melanocephala (Ramos et al. 2013), entre otras especies.

Se calculó el Coeficiente de Semejanza Biogeográfica (CBR):

$$
\mathrm{CBR}=2 \mathrm{C} /(\mathrm{Na}+\mathrm{Nb})
$$

donde, $C$ es la cantidad de taxones comunes a dos $a, b$ regiones comparadas, $\mathrm{Na}$ es el total de especies y subespecies en la primera región y $\mathrm{Nb}$ es el total de especies y subespecies para la segunda región del par. EI CBR es un índice de similitud basado en datos binarios (presencia/ausencia) y es adoptado aquí por tratarse de un coeficiente robusto, utilizado en trabajos previos sobre herpetofauna neotropical (por ej. Duellman 1979, 1990, Cabrera 1993, 1995, 2001). Sobre la matriz de similitud biogeográfica obtenida en base al CBR se obtuvo un dendrograma mediante el algoritmo UPGMA (Unweighted Pair Group Method with Arithmetic Mean) y el índice de similitud de Bray-Curtis, con el programa PAST versión 3.04 (Hammer et al. 2001). 


\section{RESULTADOS}

\section{Composición faunística}

Se obtuvieron 376 ejemplares pertenecientes a 15 especies y subespecies, nueve géneros y tres familias de serpientes procedentes del área de estudio (Figura 2.1; ver Apéndice 1 para datos de colección y Apéndice 2 para fotografías de las especies). La clasificación de la taxocomunidad fue tomada de Adalsteinsson et al. (2009) para los Leptotyphlopidae, Zaher et al. (2009) y Grazziotin et al. (2012) para los Dipsadidae y Campbell y Lamar (2004) y Carrasco et al. (2012) para los Viperidae, la cual se transcribe a continuación:

\section{SERPENTES Linnaeus 1758}

Familia Leptotyphlopidae Stejneger 1891

Subfamilia Epictinae Hedges, Adalsteinsson y Branch 2009

Tribu Epictini Hedges, Adalsteinsson y Branch 2009

Género Epictia Gray 1845

Epictia australis (Freiberg y Orejas Miranda 1968)

Epictia munoai (Orejas Miranda 1961)

Familia Dipsadidae Bonaparte 1838

Subfamilia Xenodontinae Bonaparte 1845

Tribu Elapomorphini Jan 1862

Género Phalotris Cope 1862

Phalotris bilineatus (Duméril, Bibron y Duméril 1854)

Tribu Philodryadini Cope 1886

Género Philodryas Wagler 1830 
Philodryas aestiva subcarinata Boulenger 1902

Philodryas agassizii (Jan 1863)

Philodryas patagoniensis (Girard 1857)

Tribu Pseudoboini Bailey 1967

Género Oxyrhopus Wagler 1830

Oxyrhopus rhombifer rhombifer (Duméril, Bibron y Duméril 1854)

Género Paraphimophis Zaher, Grazziotin, Murphy, Scrocchi, Altamirano, Benavides, Zhang y Bonatto 2012

Paraphimophis rustica (Cope 1878)

Tribu Xenodontini Bonaparte 1845

Género Erythrolamprus Boie 1826

Erythrolamprus poecilogyrus sublineatus (Cope 1860)

Género Lygophis Fitzinger 1843

Lygophis anomalus (Günther 1858)

Lygophis elegantissimus (Koslowsky 1895)

Género Xenodon Boie 1826

Xenodon dorbignyi (Duméril, Bibron y Duméril 1854)

Xenodon semicinctus (Duméril, Bibron y Duméril 1854)

Familia Viperidae Oppel 1811

Subfamilia Crotalinae Oppel 1811

Género Bothrops Wagler 1824

Bothrops alternatus (Duméril, Bibron y Duméril 1854)

Bothrops ammodytoides (Leybold 1873) 


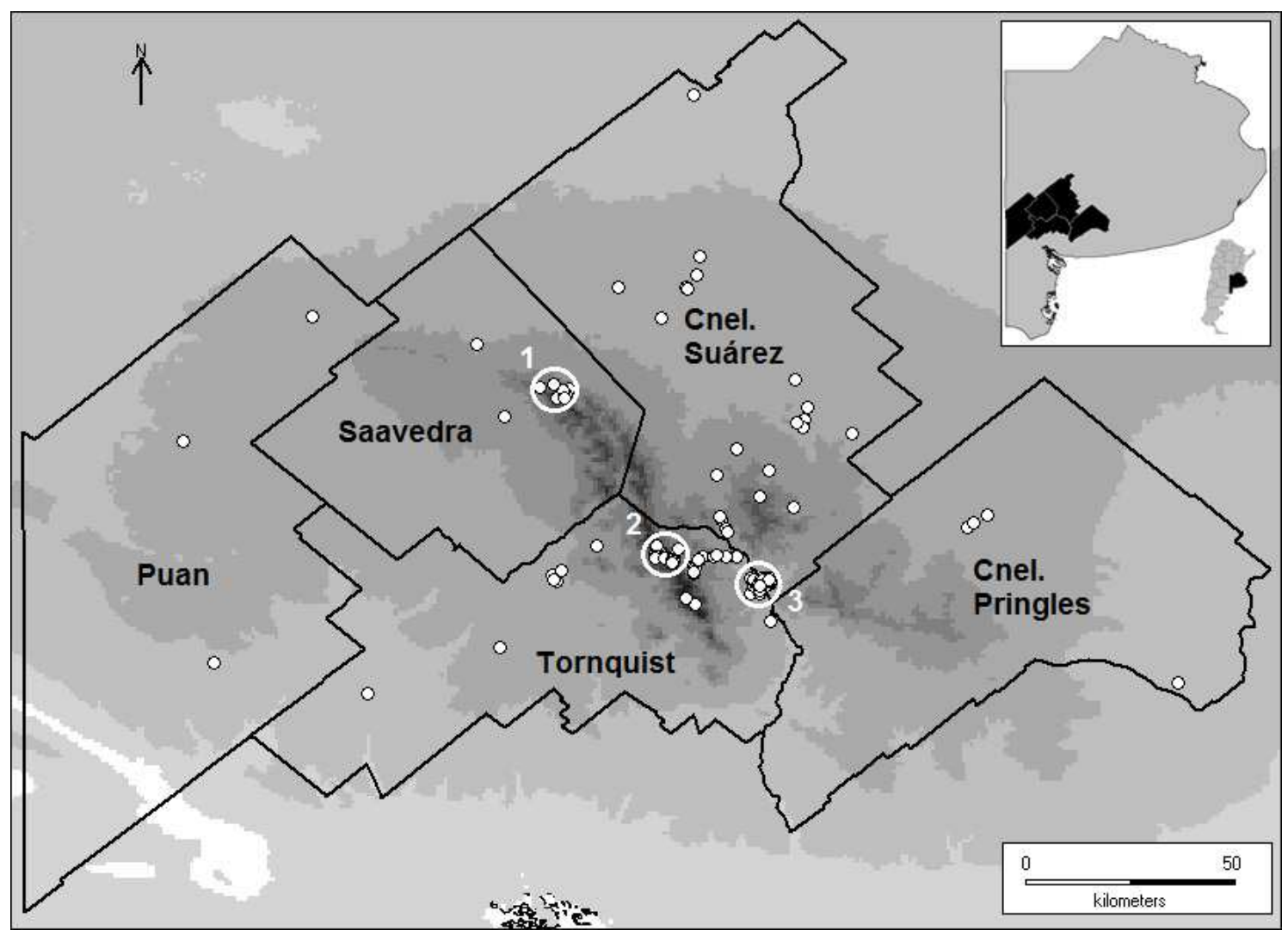

Figura 2.1. Área de estudio - Localidades de origen del material estudiado. Los números indican las estaciones de muestreo fijas: $1=$ Cerro Cura Malal Grande $\left(37^{\circ} 43^{\prime} \mathrm{S}, 62^{\circ} 13^{\prime} \mathrm{W}\right), 2=$ Parque Provincial Ernesto Tornquist $\left(38^{\circ} 03^{\prime} \mathrm{S}, 62^{\circ} 02^{\prime} \mathrm{W}\right)$ y $3=$ Villa Arcadia - Sierra de la Ventana $\left(38^{\circ} 08^{\prime} \mathrm{S}, 61^{\circ} 48^{\prime} \mathrm{W}\right)$.

\section{Patrones de distribución y abundancia}

Independientemente del método utilizado para la obtención de los datos, las especies y subespecies más frecuentes, que representan juntas el $81,6 \%$ del total de ejemplares $(\mathrm{n}=376)$, fueron Erythrolamprus poecilogyrus sublineatus (22,9\%), Lygophis elegantissimus (18,6\%), Bothrops alternatus $(15,4 \%)$, Epictia australis $(13,3 \%)$ y Philodryas patagoniensis $(11,4 \%)$. El resto de las especies resultaron poco frecuentes (<6\%, Figura 2.2).

La cantidad de especies y de ejemplares por partido no es equitativa. Los partidos y localidades del centro del área serrana e intraserrana presentan mayor cantidad de registros (Tabla 2.1) respecto a la periferia (periserrana y llanura circundante). El partido de Tornquist presenta registros de las 15 especies y subespecies de Ventania, mientras que Coronel Suárez y Saavedra 
presentan 10 y nueve especies, respectivamente. Los partidos de Coronel Pringles y Puan presentan escasos registros de serpientes (Tabla 2.1, ver Apéndice 1 para detalles de localidades).

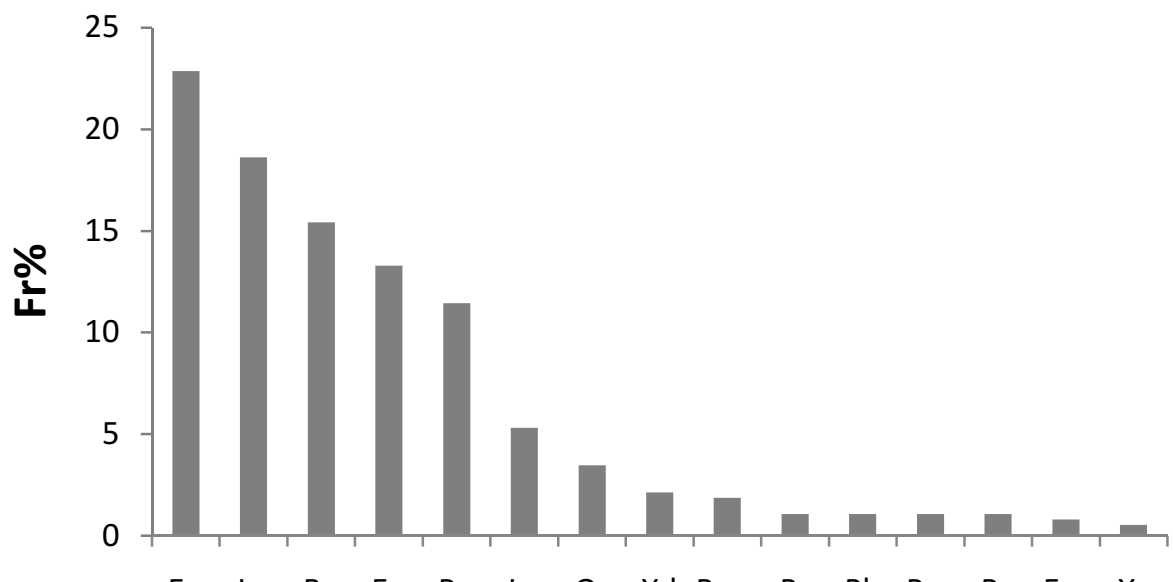

\section{Especies}

Figura 2.2. Frecuencia porcentual ( $\mathrm{Fr} \%)$ de los ejemplares examinados de Erythrolamprus poecilogyrus sublineatus (Ep), Lygophis elegantissimus (Le), Bothrops alternatus (Ba), Epictia australis (Ea), Philodryas patagoniensis (Pp), Lygophis anomalus (Le), Oxyrhopus rhombifer rhombifer (Or), Xenodon dorbignyi (Xd), Bothrops ammodytoides (Bam), Paraphimophis rustica $(\mathrm{Pr})$, Phalotris bilineatus (Pb), Philodryas aestiva subcarinata (Pas), Philodryas agassizii (Pa), Epictia munoai (Em) y Xenodon semicinctus (Xs). 
Tabla 2.1. Cantidad de ejemplares examinados por partido. Ver referencias en Figura 2.2.

\begin{tabular}{cccccccc}
\hline ESPECIES & Cnel. Pringles & Cnel. Suárez & Puan & Saavedra & Tornquist & Sin localidad & TOTAL \\
\hline Ea & - & 18 & 2 & 1 & 29 & - & $\mathbf{5 0}$ \\
Em & - & 1 & - & 1 & 1 & - & $\mathbf{3}$ \\
Ep & 1 & 23 & - & 2 & 60 & - & $\mathbf{8 6}$ \\
$\mathrm{La}$ & 2 & 17 & - & - & 1 & - & $\mathbf{2 0}$ \\
$\mathrm{Le}$ & 1 & 30 & - & 2 & 35 & 2 & $\mathbf{7 0}$ \\
$\mathrm{Or}$ & - & 2 & - & 3 & 8 & - & $\mathbf{1 3}$ \\
$\mathrm{Pr}$ & - & 1 & - & 1 & 2 & - & $\mathbf{4}$ \\
$\mathrm{Pb}$ & - & - & - & - & 4 & - & $\mathbf{4}$ \\
$\mathrm{Pas}$ & - & - & - & - & 4 & - & $\mathbf{4}$ \\
$\mathrm{Pa}$ & - & - & - & - & 4 & - & $\mathbf{4}$ \\
$\mathrm{Pp}$ & - & 18 & - & 5 & 20 & - & $\mathbf{4 3}$ \\
$\mathrm{Xd}$ & - & 1 & - & 1 & 6 & - & $\mathbf{8}$ \\
$\mathrm{Xs}$ & - & - & - & - & 2 & - & $\mathbf{2}$ \\
$\mathrm{Ba}$ & - & $\mathbf{7}$ & - & 2 & 49 & - & $\mathbf{5 8}$ \\
$\mathrm{Bam}$ & - & - & 2 & - & 5 & - & $\mathbf{7}$ \\
\hline TOTAL & $\mathbf{4}$ & $\mathbf{1 1 8}$ & $\mathbf{4}$ & $\mathbf{1 8}$ & $\mathbf{2 3 0}$ & $\mathbf{2}$ & $\mathbf{3 7 6}$ \\
\hline
\end{tabular}

Varios congéneres fueron hallados en sintopía en el área de estudio. Entre los Leptotyphlopidae, las especies del género Epictia son simpátricas en los partidos de Cnel. Suárez, Saavedra y Tornquist. Epictia australis además fue registrada en el partido de Puan. El área de sintopía estricta entre estas especies fue hallada durante los muestreos en la localidad de Villa Arcadia, Cnel. Suárez y probablemente en la localidad vecina de Sierra de la Ventana, Tornquist en base a ejemplares de museos (Figura 2.3 A). Entre los Dipsadidae, Erythrolamprus poecilogyrus sublineatus presenta una extensa distribución en el área de estudio y fue hallada en todos los partidos serranos, excepto en Puan (Figura $2.3 \mathrm{~B}$ ). Las especies del género Lygophis son simpátricas en los partidos de Cnel. Pringles, Cnel. Suárez y Tornquist. Lygophis elegantissimus además fue hallada en el partido de Saavedra. El área de sintopía estricta entre estas especies fue registrada durante los muestreos de campo al noreste del sistema serrano, en el arroyo Las Tunas, Cnel. Suárez y en el arroyo Pillahuincó, Cnel. Pringles, y probablemente en otras localidades y parajes del partido de Cnel. Suárez (por ej. Cnel. Suárez, Estancia El Triunfo y Estancia El Relincho) en base a ejemplares de museos (Figura $2.3 \mathrm{C}$ ). Oxyrhopus rhombifer rhombifer y Paraphimophis rustica fueron registradas en 
los partidos de Cnel. Suárez, Saavedra y Tornquist; Phalotris bilineatus presenta escasos registros exclusivos del partido de Tornquist (Figura 2.3 D), como sucede con otras especies (por ej. Philodryas a. subcarinata, P. agassizii y Xenodon semicinctus). Las tres especies del género Philodryas son simpátricas en el partido de Tornquist. Philodryas patagoniensis además fue hallada en los partidos de Cnel. Suárez y Saavedra. El área de sintopía estricta entre estas especies no fue determinada durante los muestreos, sin embargo se puede realizar una aproximación comparando los ejemplares de museos. Las tres especies presentan registros procedentes de la localidad de Sierra de la Ventana. Philodryas patagoniensis y $P$. agassizii fueron halladas en el Parque Provincial Ernesto Tornquist, y $P$. patagoniensis y $P$. a. subcarinata en los alrededores de la localidad de Villa Ventana (Figura 2.3 E). Las especies del género Xenodon son simpátricas en el partido de Tornquist. Xenodon dorbignyi además fue registrada en los partidos de Cnel. Suárez y Saavedra. Estas especies no fueron registradas en sintopía estricta en el área de estudio (Figura $2.3 \mathrm{~B}$ ). Entre los Viperidae, las especies del género Bothrops son simpátricas en el partido de Tornquist. Bothrops alternatus habita también los partidos de Cnel. Suárez y Saavedra, y B. ammodytoides el partido de Puan. El área de sintopía estricta entre estas especies fue registrada en la localidad de Tornquist durante los muestreos de campo, y probablemente en la localidad de Sierra de la Ventana en base a ejemplares de museos (Figura 2.3 F). 


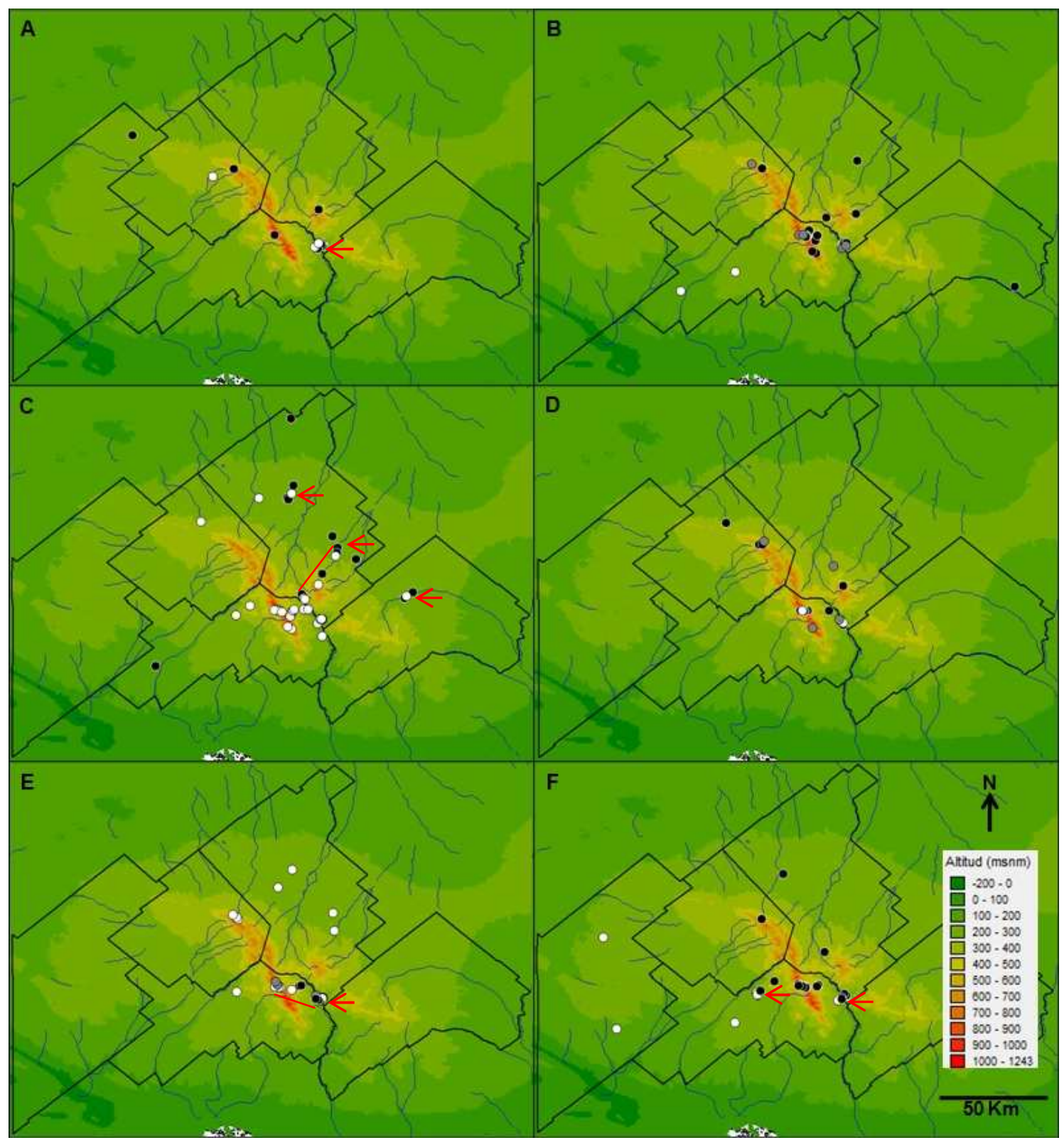

Figura 2.3. Patrones generales de distribución: A Epictia australis (Círculos negros) y E. munoai (Círculos blancos); B Erythrolamprus poecilogyrus sublineatus (Círculos negros), Xenodon dorbignyi (Círculos grises) y X. semicinctus (Círculos blancos); C Lygophis anomalus (Círculos negros) y L. elegantissimus (Círculos blancos); D Oxyrhopus rhombifer rhombifer (Círculos negros), Paraphimophis rustica (Círculos grises) y Phalotris bilineatus (Círculos blancos); E Philodryas aestiva subcarinata (Círculos negros), $P$. agassizii (Círculos grises) y $P$. patagoniensis (Círculos blancos); F Bothrops alternatus (Círculos negros) y B. ammodytoides (Círculos blancos). Las flechas rojas indican el área de sintopía estricta entre congéneres. 
La prueba de Kruskal-Wallis indica que existen diferencias significativas en la distribución altitudinal de la comunidad de serpientes $(H=64,31, p=$ 1,258E-08). En base a la comparación por pares de Mann-Whitney se observaron dichas diferencias significativas ( $p \leq 0,05$ con ajuste de Bonferroni) entre Epictia australis, que habita preferentemente la porción basal de las sierras, y Erythrolamprus poecilogyrus sublineatus, Lygophis elegantissimus, Oxyrhopus rhombifer rhombifer, Philodryas patagoniensis y Bothrops alternatus que son frecuentes a mayor altitud. Similarmente, Lygophis anomalus, que también frecuenta la porción basal, presenta diferencias significativas con Lygophis elegantissimus, Oxyrhopus rhombifer rhombifer y Bothrops alternatus. El resto de las especies y subespecies de la comunidad de serpientes no presentaron diferencias significativas en su distribución altitudinal (Figura 2.4).

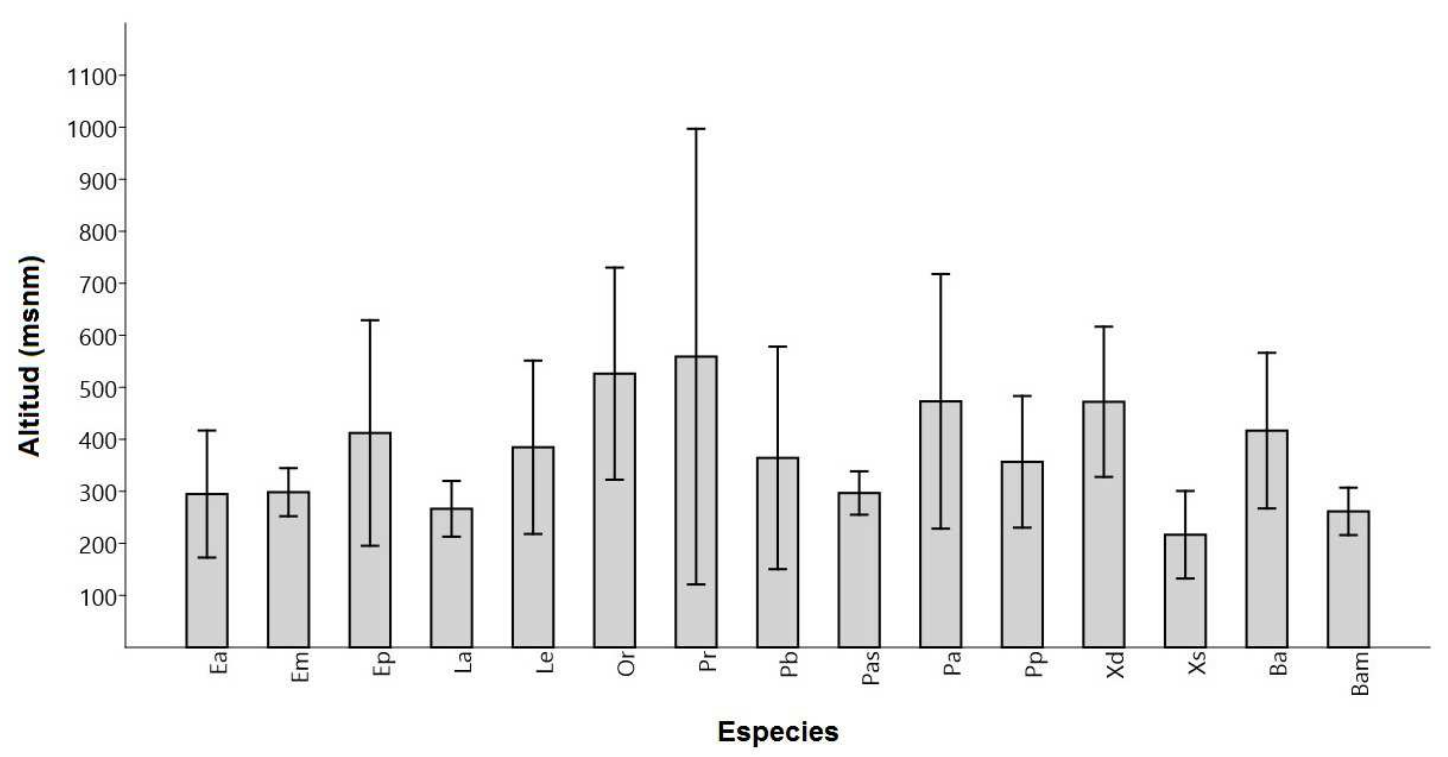

Figura 2.4. Distribución altitudinal de la comunidad de serpientes (promedio y desvío estándar). Ver referencias de las especies en Figura 2.2.

\section{Comparación con otras regiones}

La riqueza específica de las Sierras de Ventania se corresponde con el resto de las regiones comparadas (Tabla 2.2). El Noreste bonaerense presenta mayor número de especies y subespecies de serpientes de presencia 
confirmada $(n=17)$, seguido de las Sierras de Ventania y el Parque Costero del Sur en la provincia de Buenos Aires y de las Sierras de Lihué Calel en La Pampa $(n=15)$. En el resto de las regiones la riqueza específica disminuye levemente (por ej. 14 especies en la R.N. Punta Lara y 13 especies en las Dunas Costeras, Tabla 2.2). Ninguna especie se distribuye en todas las regiones comparadas en el presente estudio. Philodryas patagoniensis fue registrada en todas las regiones excepto en el Parque Rafael de Aguiar. Si se consideran solo las regiones y localidades de la provincia de Buenos Aires, Bothrops alternatus, Erythrolamprus poecilogyrus sublineatus, Lygophis anomalus y Paraphimophis rustica se encuentran ampliamente distribuidas (presentes en todas las regiones). Mientras que, otras especies presentan una distribución restringida a una región particular (Tabla 2.2), como Psomophis obtusus en el Noreste bonaerense, Lygophis elegantissimus en las Sierras de Ventania, y Rena unguirostris, Bothrops diporus, Micrurus pyrrhocryptus, Boiruna maculata, Erythrolamprus sagittifer sagittifer, Oxyrhopus rhombifer bachmanni, Philodryas psamophidea psamophidea, Philodryas trilineata y Pseudotomodon trigonatus en las Sierras de Lihué Calel, La Pampa. El resto de las regiones comparadas en el presente estudio no presentan especies propias (Tabla 2.2).

En la Tabla 2.3 se presentan las relaciones establecidas por el Coeficiente de Semejanza Biogeográfica (CBR). La mayor similitud biogeográfica de las Sierras de Ventania se presenta con las Dunas Costeras $(C B R=0,85)$, con las Sierras de Balcarce y Mar del Plata $(C B R=0,84)$ y, un poco menos, con las Sierras Bayas $(C B R=0,75)$. Todas las especies y subespecies de serpientes halladas en estas regiones (excepto Thamnodynastes hypoconia citada en las Dunas costeras) se encuentran representadas en las Sierras de Ventania (Tabla 2.2). El Noreste bonaerense presenta elevados valores de similitud biogeográfica con la Reserva Natural Punta Lara $(C B R=0,9)$ y con el Parque Costero del Sur $(C B R=0,87)$. Las especies y subespecies de serpientes registradas en estas regiones (excepto Taeniophallus poecilopogon citada en el Parque Costero del Sur) se encuentran representadas en el Noreste bonaerense (Tabla 2.2). El Parque Rafael de Aguiar presenta elevados valores de similitud biogeográfica con la 
Reserva Natural Punta Lara $(C B R=0,78)$ y con la Reserva Natural Otamendi $(\mathrm{CBR}=0,7)$. Mientras que la Reserva Natural Otamendi presenta elevados valores de similitud biogeográfica con la Depresión del Salado (CBR =0,77), con la Reserva Natural Punta Lara $(C B R=0,72)$ y con el Parque Rafael de Aguiar $(C B R=0,7)$. La Reserva Natural Punta Lara presenta elevados valores de similitud biogeográfica con el Noreste bonaerense (CBR $=0,9)$, con el Parque Costero del Sur (CBR =0,82), con el Parque Rafael de Aguiar (CBR = $0,78)$ y con la Reserva Natural Otamendi $(C B R=0,72)$. El Parque Costero del Sur presenta elevados valores de similitud biogeográfica con el Noreste bonaerense $(C B R=0,87)$, con la Reserva Natural Punta Lara $(C B R=0,82)$, con la Depresión del Salado $(\mathrm{CBR}=0,8)$ y con las Dunas Costeras $(\mathrm{CBR}=$ 0,71). La Depresión del Salado presenta elevados valores de similitud biogeográfica con el Parque Costero del Sur $(C B R=0,8)$ y con la Reserva Natural Otamendi $(C B R=0,77)$. Las Sierras Bayas presentan elevados valores de similitud biogeográfica con las Sierras de Balcarce y Mar del Plata (CBR = $0,9)$, con las Dunas Costeras (CBR $=0,81)$ y con las Sierras de Ventania (CBR $=0,75)$. Mientras que, las Sierras de Balcarce y Mar del Plata presentan elevados valores de similitud biogeográfica con las Sierras Bayas (CBR =0,9), con las Sierras de Ventania $(\mathrm{CBR}=0,84)$ y con las Dunas Costeras $(\mathrm{CBR}=$ 0,83). Las Dunas Costeras presentan elevados valores de similitud biogeográfica con las Sierras de Ventania $(C B R=0,85)$, de Balcarce y Mar del Plata $(C B R=0,83)$, Bayas $(C B R=0,81)$ y en menor grado con el Parque Costero del Sur $(C B R=0,71)$. Por otra parte, todas las regiones comparadas de la provincia de Buenos Aires presentan muy bajos valores de similitud biogeográfica con las Sierras de Lihué Calel, La Pampa (Tabla 2.3). La mayor similitud biogeográfica de esta región se presenta con las Sierras de Ventania $(\mathrm{CBR}=0,4)$. Estas regiones comparten seis especies y subespecies de serpientes (Tabla 2.2 y 2.3 ).

El dendrograma obtenido mediante la técnica de agrupamiento por ligamiento promedio no ponderado (UPGMA) para los valores del CBR (Figura 2.5) revela que las Sierras de Lihué Calel, La Pampa, se separan de las regiones de la provincia de Buenos Aires a muy bajos niveles de similitud. Las restantes localidades conforman dos grupos bien definidos; uno integrado por 
las regiones vinculadas a la cuenca Paranoplatense y del Salado (Noreste bonaerense, Reserva Natural Punta Lara, Parque Costero del Sur, Parque Rafael de Aguiar, Reserva Natural Otamendi y Depresión del Salado), y otro integrado por las regiones serranas y de la costa atlántica (Sierras de Ventania, Sierras de Balcarce y Mar del Plata, Sierras Bayas y Dunas Costeras). El coeficiente de correlación obtenido para este análisis $(0,97)$ sugiere una buena representación de las relaciones establecidas entre las localidades. 
Tabla 2.2. Ocurrencia de serpientes de presencia confirmada (en las 11 regiones comparadas). Referencias: Noreste bonaerense (NE), Parque Rafael de Aguiar (PRA), Reserva Natural Otamendi (RNO), Reserva Natural Punta Lara (RNPL), Parque Costero del Sur (PCS), Depresión del Salado (DS), Sierras Bayas (SB), Sierras de Balcarce y Mar del Plata (SBM), Dunas Costeras (DC), Sierras de Ventania (SV) y Sierras de Lihué Calel, La Pampa (SLC). Ver localidades particulares y fuente de información en la Metodología.

\begin{tabular}{|c|c|c|c|c|c|c|c|c|c|c|c|}
\hline ESPECIES & NE & PRA & RNO & RNPL & PCS & DS & SB & SBM & DC & sv & SLC \\
\hline Epictia australis & & & & & & & & & & $\mathbf{x}$ & $\mathbf{x}$ \\
\hline Epictia munoai & $\mathbf{x}$ & & & $\mathbf{x}$ & $\mathbf{x}$ & & $\mathbf{x}$ & $\mathbf{x}$ & $\mathbf{x}$ & $\mathbf{x}$ & \\
\hline Rena unguirostris & & & & & & & & & & & $\mathbf{x}$ \\
\hline Bothrops alternatus & $\mathbf{x}$ & $\mathbf{x}$ & $\mathbf{x}$ & $\mathbf{x}$ & $\mathbf{x}$ & $\mathbf{x}$ & $\mathbf{x}$ & $\mathbf{x}$ & $\mathbf{x}$ & $\mathbf{x}$ & \\
\hline Bothrops ammodytoides & & & & & & & $\mathbf{x}$ & $\mathbf{x}$ & $\mathbf{x}$ & $\mathbf{x}$ & $\mathbf{x}$ \\
\hline Bothrops diporus & & & & & & & & & & & $\mathbf{x}$ \\
\hline Micrurus pyrrhocryptus & & & & & & & & & & & $\mathbf{x}$ \\
\hline Boiruna maculata & & & & & & & & & & & $\mathbf{x}$ \\
\hline Erythrolamprus jaegeri coralliventris & $\mathbf{x}$ & $\mathbf{x}$ & & $\mathbf{x}$ & & & & & & & \\
\hline Erythrolamprus pocilogyrus sublineatus & $x$ & $\mathbf{x}$ & $\mathbf{x}$ & $x$ & $\mathbf{x}$ & $\mathbf{x}$ & $\mathbf{x}$ & $\mathbf{x}$ & $\mathbf{x}$ & $\mathbf{x}$ & \\
\hline Erythrolamprus sagittifer sagittifer & & & & & & & & & & & $\mathbf{x}$ \\
\hline Erythrolamprus semiaureus & $\mathbf{x}$ & $\mathbf{x}$ & $\mathbf{x}$ & $\mathbf{x}$ & $\mathbf{x}$ & & & & & & \\
\hline Helicops infrataeniatus & $\mathbf{x}$ & $\mathbf{x}$ & & $\mathbf{x}$ & $\mathbf{x}$ & & & & & & \\
\hline Helicops leopardinus & $\mathbf{x}$ & $\mathbf{x}$ & & $\mathbf{x}$ & $\mathbf{x}$ & & & & & & \\
\hline Lygophis anomalus & $\mathbf{x}$ & $\mathbf{x}$ & $\mathbf{x}$ & $\mathbf{x}$ & $\mathbf{x}$ & $\mathbf{x}$ & $\mathbf{x}$ & $\mathbf{x}$ & $\mathbf{x}$ & $\mathbf{x}$ & \\
\hline Lygophis elegantissimus & & & & & & & & & & $\mathbf{x}$ & \\
\hline Oxyrhopus rhombifer bachmanni & & & & & & & & & & & $\mathbf{x}$ \\
\hline Oxyrhopus rhombifer rhombifer & & & & & & & $\mathbf{x}$ & $\mathbf{x}$ & $\mathbf{x}$ & $\mathbf{x}$ & \\
\hline Paraphimophis rustica & $x$ & $\mathbf{x}$ & $\mathbf{x}$ & $\mathbf{x}$ & $\mathbf{x}$ & $\mathbf{x}$ & $\mathbf{x}$ & $\mathbf{x}$ & $\mathbf{x}$ & $\mathbf{x}$ & \\
\hline Phalotris bilineatus & $x$ & & & & $\mathbf{x}$ & & & $\mathbf{x}$ & $\mathbf{x}$ & $\mathbf{x}$ & $\mathbf{x}$ \\
\hline Philodryas aestiva subcarinata & $\mathbf{x}$ & & $\mathbf{x}$ & $\mathbf{x}$ & $\mathbf{x}$ & $x$ & & & $x$ & $\mathbf{x}$ & \\
\hline Philodryas agassizii & & & & & & & & $\mathbf{x}$ & & $\mathbf{x}$ & $\mathbf{x}$ \\
\hline Philodryas patagoniensis & $\mathbf{x}$ & & $\mathbf{x}$ & $\mathbf{x}$ & $\mathbf{x}$ & $\mathbf{x}$ & $\mathbf{x}$ & $\mathbf{x}$ & $\mathbf{x}$ & $\mathbf{x}$ & $x$ \\
\hline Philodryas psamophidea psamophidea & & & & & & & & & & & $\mathbf{x}$ \\
\hline Philodryas trilineata & & & & & & & & & & & $\mathbf{x}$ \\
\hline Pseudotomodon trigonatus & & & & & & & & & & & $x$ \\
\hline Psomophis obtusus & $\mathbf{x}$ & & & & & & & & & & \\
\hline Taeniophallus poecilopogon & & & & & $\mathbf{x}$ & $\mathbf{x}$ & & & & & \\
\hline Thamnodynastes hypoconia & $\mathbf{x}$ & $\mathbf{x}$ & $\mathbf{x}$ & $x$ & $\mathbf{x}$ & $\mathbf{x}$ & & & $\mathbf{x}$ & & \\
\hline Thamnodynastes strigatus & $\mathbf{x}$ & & & $\mathbf{x}$ & & & & & & & \\
\hline Tomodon ocellatus & $\mathbf{x}$ & & & $\mathbf{x}$ & $\mathbf{x}$ & $\mathbf{x}$ & & & & & \\
\hline Xenodon dorbignyi & $\mathbf{x}$ & & & & $\mathbf{x}$ & $x$ & $\mathbf{x}$ & $\mathbf{x}$ & $\mathbf{x}$ & $\mathbf{x}$ & \\
\hline Xenodon semicinctus & & & & & & & & & $\mathbf{x}$ & $\mathbf{x}$ & $\mathbf{x}$ \\
\hline TOTAL DE ESPECIES & 17 & 9 & 8 & 14 & 15 & 10 & 9 & 11 & 13 & 15 & 15 \\
\hline
\end{tabular}


Tabla 2.3. Coeficiente de Semejanza Biogeográfica (CBR) entre las regiones comparadas. Número de especies en común (subrayado), total de especies (diagonal negrita) y coeficiente de semejanza biogeográfica (cursiva). Ver referencias en la Tabla 2.2.

$\begin{array}{lccccccccccc} & \text { NE } & \text { PRA } & \text { RNO } & \text { RNPL } & \text { PCS } & \text { DS } & \text { SB } & \text { SBM } & \text { DC } & \text { SV } & \text { SLC } \\ \text { NE } & \mathbf{1 7} & \underline{9} & \underline{8} & \frac{14}{4} & \frac{14}{4} & \underline{9} & \underline{7} & \underline{8} & \underline{10} & \underline{9} & \underline{2} \\ \text { PRA } & 0,69 & \mathbf{9} & \underline{6} & \underline{9} & \underline{8} & \underline{5} & \underline{4} & \underline{4} & \underline{5} & \underline{4} & \underline{0} \\ \text { RNO } & 0,64 & 0,7 & \mathbf{8} & \underline{8} & \underline{8} & \underline{7} & \underline{5} & \underline{5} & \underline{7} & \underline{6} & \underline{1} \\ \text { RNPL } & 0,9 & 0,78 & 0,72 & \mathbf{1 4} & \underline{12} & \underline{8} & \underline{6} & \underline{6} & \underline{8} & \underline{7} & \underline{1} \\ \text { PCS } & 0,87 & 0,66 & 0,69 & 0,82 & \mathbf{1 5} & \underline{10} & \underline{7} & \underline{8} & \underline{10} & \underline{9} & \underline{2} \\ \text { DS } & 0,66 & 0,52 & 0,77 & 0,66 & 0,8 & \mathbf{1 0} & \underline{6} & \underline{6} & \underline{8} & \underline{7} & \underline{1} \\ \text { SB } & 0,53 & 0,44 & 0,58 & 0,52 & 0,58 & 0,63 & \mathbf{9} & \underline{9} & \underline{9} & \underline{9} & \underline{2} \\ \text { SBM } & 0,57 & 0,4 & 0,52 & 0,48 & 0,61 & 0,57 & 0,9 & \mathbf{1 1} & \underline{10} & \underline{11} & \underline{4} \\ \text { DC } & 0,66 & 0,45 & 0,66 & 0,59 & 0,71 & 0,69 & 0,81 & 0,83 & \mathbf{1 3} & \underline{12} & \underline{4} \\ \text { SV } & 0,56 & 0,33 & 0,52 & 0,48 & 0,6 & 0,56 & 0,75 & 0,84 & 0,85 & \mathbf{1 5} & \underline{6} \\ \text { SLC } & 0,12 & 0 & 0,08 & 0,06 & 0,13 & 0,08 & 0,16 & 0,3 & 0,28 & 0,4 & \mathbf{1 5}\end{array}$

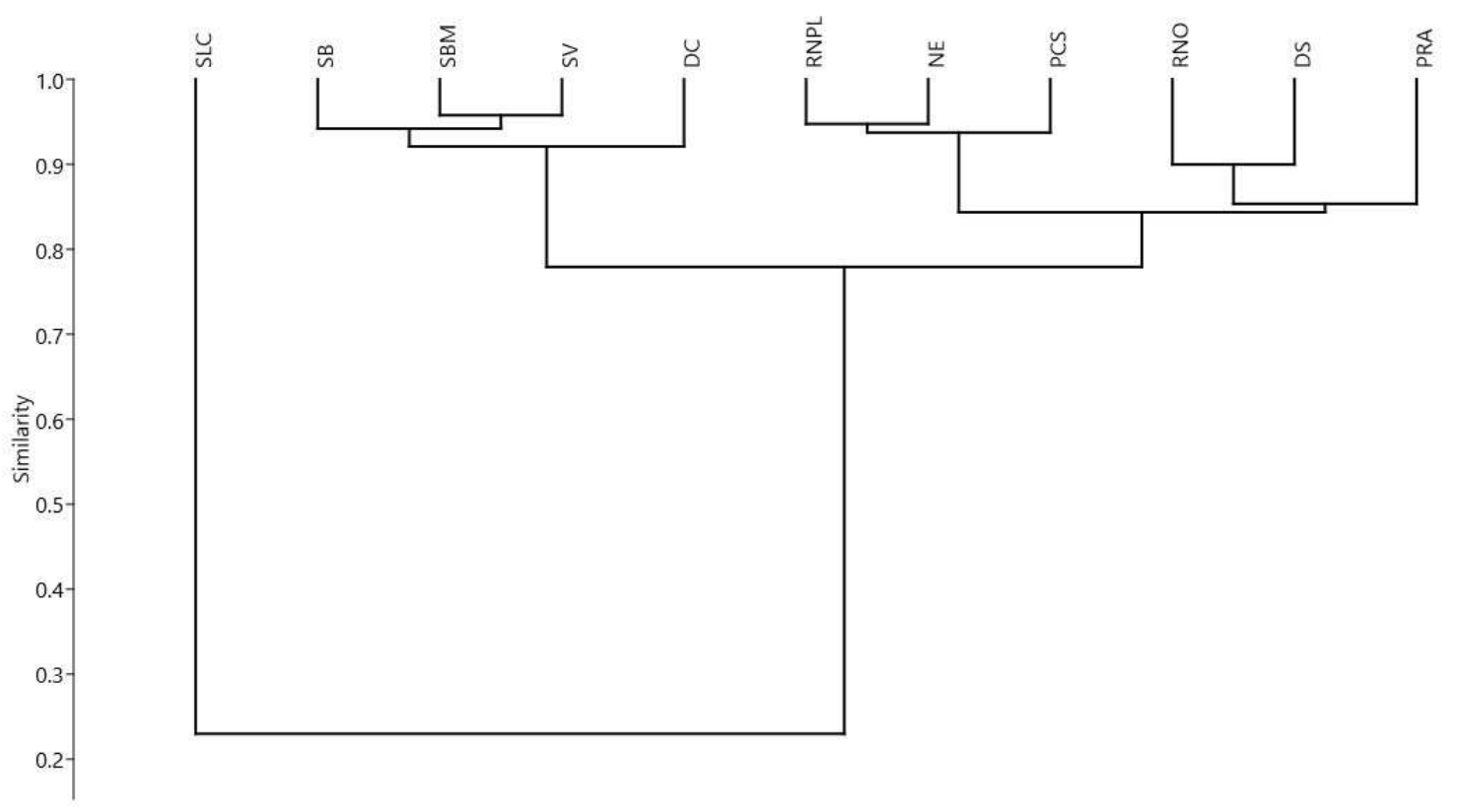

Figura 2.5. Dendrograma según los CBR empleando UPGMA y el Índice de Similitud de BrayCurtis. Ver referencias en la Tabla 2.2. 


\section{DISCUSIÓN}

\section{Composición faunística}

La fauna de serpientes de la provincia de Buenos Aires, Argentina, ha sido ampliamente estudiada (Marelli 1924, Ringuelet y Arámburu 1957, Gallardo 1977, Miranda et al. 1983, Varela de Olmedo y Carrizo 1987, Williams 1991, Giambelluca 2015). Lamentablemente, muy pocos de estos trabajos citan el material en que se basan y cuando lo hacen no aclaran los números de colección, lo que impide reubicar los ejemplares. Con respecto al área de Sierras de Ventania, Koslowsky (1895) en un trabajo pionero sobre herpetología argentina (ver Williams 2013) enumera siete especies de serpientes. Posteriormente, Couturier y Grisolía (1989) confirman la presencia de Philodryas aestiva subcarinata y Viñas et al. (1989) confirman la presencia de Philodryas agassizii. Resulta prudente aclarar aquí que estas dos especies no fueron observadas durante el periodo de muestreo, los ejemplares mencionados en el presente estudio provienen de la revisión de museos. En el caso de $P$. agassizii la rareza actual de la especie en áreas de pastizales ha sido vinculada con las modificaciones antrópicas (Marques et al. 2006, Winck et al. 2007, Giraudo et al. 2011). El resto de los trabajos sobre ofidios en el área de Sierra de la Ventana se corresponden a revisiones de especies o géneros particulares (por ej. Barrio y Miranda 1966, Thomas 1976, Lema 1984, Scrocchi 1990, Scrocchi y Viñas 1991, Scrocchi y Cruz 1993) y trabajos generales sobre distribución de serpientes en la Argentina (por ej. Abalos y Mischis 1975, Williams y Francini 1991, Giraudo y Scrocchi 2002). Los resultados obtenidos en este estudio permiten confirmar la presencia de 15 especies y subespecies de serpientes, que corresponden al $50 \%$ del total de ofidios citados para la provincia de Buenos Aires y al $11 \%$ del total citado para la República Argentina (ver Giraudo et al. 2012 y literatura allí mencionada). Aquí, se presenta ampliada considerablemente después de 120 años una lista de serpientes para la región.

Los siguientes taxones mencionados en las Sierras de Ventania y cercanías no fueron considerados parte de la comunidad de serpientes por tratarse de especies de presencia dudosa o marginal: 
"Boas" - Koslowsky (1895) menciona en base a relatos de pobladores locales la existencia de boas en las Sierras de Ventania (Estancia Las Vertientes). De igual forma, Gallardo (1977) menciona hallazgos ocasionales de grandes serpientes en Bolívar y Coronel Suárez. Los registros más cercanos son de Boa constrictor occidentalis Philippi 1873 en las Sierras de Lihué Calel, La Pampa (Orrego Aravena 1971, 1979). Sin embargo, Tiranti y Avila (1997) consideran que la especie debe ser excluida de la lista actual de reptiles de La Pampa. Siguiendo el criterio de estos autores, es muy probable la existencia de Boa constrictor occidentalis en tiempos históricos, pero actualmente la especie ya no existe en estas latitudes.

Bothrops diporus Cope 1862 - En la provincia de Buenos Aires esta especie fue mencionada (sin datos de localidades) por Serié $(1921,1936)$ y para el dominio central por Ringuelet y Arámburu (1957). Scanferla y Nenda (2005) confirman con material de referencia (MACN 1468) la presencia de Bothrops diporus en Sierra de la Ventana. Durante la revisión de la colección del MACN fue examinado este ejemplar y presenta los caracteres de coloración y escamación citados por Nágera (1915), Barrio y Miranda (1966) y de Roodt et al. (2012) para las poblaciones de B. alternatus presentes en las sierras del sur bonaerense, lo que probablemente llevó a estos autores a la incorrecta identificación.

Erythrolamprus semiaureus (Cope 1862) - Koslowsky (1895) menciona haber colectado cuatro ejemplares de esta especie en Sierra de la Ventana, como Rhadinaea fusca (Cope) Blgr. Actualmente estos ejemplares se encuentran perdidos en la Colección Herpetológica del MLP, donde Koslowsky generalmente depositaba el material colectado (Williams obs. pers.). Esta especie actualmente habita el noreste bonaerense hasta aproximadamente la bahía de Samborombón (ver Williams 1991, Williams y Scrocchi 1994) y no fue registrada durante los muestreos o la revisión de colecciones.

Micrurus pyrrhocryptus (Cope 1862) - En la provincia de Buenos Aires fue mencionada (sin datos de localidades) por Marelli (1924), y para los dominios subtropical, noroeste del pampásico y central por Ringuelet y Arámburu (1957). Ningún otro autor considera probable la presencia de corales 
en esta provincia (por ej. Williams 1991, Cei 1993, Giraudo et al. 2012). En la Colección de Herpetología del MLP se encuentra depositado un ejemplar, determinado como M. pyrrhocryptus (MLP.JW.958) y colectado en la localidad de Sierra de la Ventana, lo que confirmaría parcialmente y con material de referencia las observaciones efectuadas por Marelli (1924) y Ringuelet y Arámburu (1957). Sin embargo, al no hallar esta especie durante los muestreos de campo, sumado a la presunta ausencia del taxón en la provincia de Buenos Aires, se considera preliminarmente de presencia dudosa.

Philodryas olfersii (Lichtenstein 1823) - Koslowsky (1895) menciona haber colectado cuatro ejemplares de esta especie en Sierra de la Ventana. Actualmente estos ejemplares se encuentran extraviados en la Colección Herpetológica del MLP, donde Koslowsky generalmente depositaba el material colectado durante sus campañas (Williams obs. pers.). Posteriormente, Koslowsky (1896) no considera a Philodryas olfersii en Buenos Aires y sí menciona a Philodryas aestiva, que fue citada formalmente en el área de Sierra de la Ventana por Couturier y Grisolia (1989). Probablemente Koslowsky (1895) no identificó como válida la especie Philodryas aestiva (Duméril, Bibron y Duméril 1854) descripta años antes de su trabajo.

Philodryas psammophidea psammophidea Günther 1872 - Ringuelet y Arámburu (1957) mencionan a esta especie para el dominio pampásico y central de la provincia de Buenos Aires. Estudios posteriores no consideran a la especie en el territorio bonaerense (ver Gallardo 1977, Miranda et al. 1983, Varela de Olmedo y Carrizo 1987, Williams 1991, Giambelluca 2015). En la revisión del género, Thomas (1976) presenta un mapa de distribución de $P$. p. psammophidea con ejemplares procedentes del noreste de la provincia de Buenos Aires. Sin embargo, en el material examinado no figuran los acrónimos y localidades. Probablemente en base a estas menciones, Giraudo y Scrocchi (2002) y Giraudo et al. (2012) consideran la presencia de la especie en la provincia de Buenos Aires (sin datos de localidades). Aquí, se confirma con material de referencia (MACN 24796) la presencia la $P$. p. psammophidea en la provincia de Buenos Aires (Partido de Villarino, Laguna de Chasicó, $38^{\circ} 37^{\prime} 14^{\prime \prime} \mathrm{S}, 63^{\circ} 4^{\prime} 33^{\prime \prime} \mathrm{W}$ ) aproximadamente $130 \mathrm{~km}$ al sudoeste de la localidad 
de Sierra de la Ventana, por lo que se considera de presencia marginal en el sistema serrano.

Philodryas trilineata (Burmeister 1861) - Esta especie no fue mencionada previamente para el territorio bonaerense (ver Giraudo et al. 2012 y literatura allí citada). En un trabajo, aún en preparación (Nenda y Di Pietro en prep.), se confirma con material de referencia (MACN 3238, 3244 y 3246) la presencia de $P$. trilineata en la provincia de Buenos Aires (Partido de Villarino, Nicolás Levalle, Salinas Chicas o Salinas Las Barrancas, 3851'08"S, 6253'01"W) aproximadamente $123 \mathrm{~km}$ al sudoeste de localidad de Sierra de la Ventana, por lo que se considera de presencia marginal en el sistema serrano.

Philodryas varia (Jan 1863) - Esta especie tiene una compleja historia taxonómica (ver Laurent 1973, Thomas et al. 1977, Thomas y Johnson 1984), entre los sinónimos de $P$. varia figura un Philodryas werneri Müller 1926, representado por dos ejemplares juveniles cuya procedencia sería Sierra de Cura Malal, provincia de Buenos Aires. Thomas (1976) indica el área de simpatría Philodryas patagoniensis - P. varia en base a estos ejemplares. De acuerdo con Cei (1993) se considera improbable la subsistencia de una población de $P$. varia en el sur de la provincia de Buenos Aires.

Pseudotomodon trigonatus (Leybold 1873) - En la provincia de Buenos Aires, Miranda et al. (1983) confirman por primera vez la presencia de esta especie (sin referencia al material) para la localidad de Médanos, partido de Villarino (38 $\left.49^{\prime} 43^{\prime \prime S}, 62^{\circ} 41^{\prime} 37^{\prime \prime W}\right)$, aproximadamente $110 \mathrm{~km}$ al sudoeste de la localidad de Sierra de la Ventana, por lo que se considera de presencia marginal en el sistema serrano.

\section{Patrones de distribución y abundancia}

Realizar comparaciones entre comunidades de serpientes puede resultar complejo cuando se relacionan diferentes ambientes y áreas, y cuando existen diferencias en los métodos de muestreo empleados, sumado a la relativa dificultad de hallar ofidios en el campo, debido a la baja densidad que generalmente presentan y a que la mayoría de las especies son crípticas y 
muchas tienen hábitos desconocidos (ver por ej. Martins y Oliveira 1998, Bernarde y Abe 2006, Sawaya et al. 2008). Probablemente debido a esto no fueron hallados en la literatura estudios que traten en detalle la abundancia relativa de serpientes bonaerenses, y las menciones al respecto generalmente provienen de observaciones casuales o anecdóticas. Por lo tanto, para realizar algunas comparaciones sobre la frecuencia de las serpientes, fueron hallados solo dos estudios que indican la cantidad de ejemplares colectados, asumiendo esto como una medida de la abundancia relativa (Sierras de Tandilia: Nágera 1915, Vega y Bellaganba 1990).

Independientemente del método de muestreo empleado, las especies y subespecies más abundantes en las Sierras de Ventania fueron, en orden de importancia, Erythrolamprus poecilogyrus sublineatus, Lygophis elegantissimus, Bothrops alternatus, Epictia australis y Philodryas patagoniensis. El resto de las especies resultaron relativamente poco frecuentes. Comparando estos resultados con dos estudios efectuados en las Sierras de Tandilia se observan algunas diferencias que se detallan a continuación. En las Sierras de Balcarce y Mar del Plata (Vega y Bellagamba 1990), donde se realizó una colecta de ejemplares limitada por tiempo (150 horas), la especie más abundante fue Epictia munoai (Tabla 2.4); mientras que en las Sierras de Ventania esta especie es poco frecuente, siendo $E$. australis el Leptotyphlopidae más abundante. Estas diferencias en la abundancia podrían explicarse debido a la competencia interespecífica, ya que ambas especies habitan en sintopía estricta en las Sierras de Ventania. Situación similar ocurre con Lygophis elegantissimus y L. anomalus (ver más abajo), hallándose ésta última especie con bajos valores de abundancia en las Sierras de Ventania, a pesar de ser de hallazgo frecuente en gran parte del territorio bonaerense (obs. pers.). En las Sierras Bayas (Nágera 1915), donde se realizó una colecta de ejemplares por encuentros ocasionales o accidentales, la especie más abundante fue Philodryas patagoniensis (Tabla 2.4); estos valores se corresponden a los observados en las Sierras de Ventania donde $P$. patagoniensis presenta relativamente elevados valores de abundancia. Además de estas especies, Xenodon dorbignyi es relativamente frecuente en las Sierras de Tandilia, tanto en las Sierras Bayas como en las Sierras de 
Balcarce y Mar del Plata (Tabla 2.4); y presenta bajos valores de abundancia en las Sierras de Ventania. Según Koslowsky (1895), en el área de Sierra de la Ventana $X$. dorbignyi presenta temporadas de elevada abundancia y otras donde se registran muy pocos ejemplares, mientras que Gallardo (1970) indica que esta especie prefiere suelos arenosos y no habita el sudoeste bonaerense. Estas observaciones podrían explicar la baja frecuencia de la especie durante el periodo de muestreo. Todo parece indicar que, algunas especies consideradas comunes y de amplia distribución no se presentan con los mismos niveles de abundancia en las diferentes localidades bonaerenses, incluso están ausentes en algunas zonas. Por ejemplo, varias especies citadas para "toda la provincia" como, Oxyrhopus rhombifer rhombifer, Phalotris bilineatus y Xenodon semicinctus, entre otras (ver Miranda et al. 1983, Varela de Olmedo y Carrizo 1987, Williams 1991) presentaron una distribución más restringida en este estudio.

Considerando los ensambles faunísticos funcionales (ver Jaksic 1981, Di Fonzo de Abalos y Bucher 1983, Yanosky 1989) las especies más abundantes en las Sierras de Ventania presentaron hábitos semiacuáticos; mientras que en las Sierras de Tandilia las especies más abundantes presentaron hábitos fosoriales (Sierras de Balcarce y Mar del Plata) o terrestres (Sierras Bayas) (Tabla 2.5). Resulta interesante destacar la elevada abundancia de especies de hábitos semiacuáticos en las Sierras de Ventania, a pesar de que el ambiente acuático se encuentra escasamente representado en superficie en la región serrana (Kristensen y Frangi 1995b). 
Tabla 2.4. Abundancia relativa (\%) de las serpientes en las Sierras bonaerenses (SV= presente estudio; SBM= Vega y Bellagamba 1990; SB= Nágera 1915). Con rojo se indican las especies de mayor abundancia.

\begin{tabular}{lccc}
\hline ESPECIES & SV & SBM & SB \\
\hline Erythrolamprus poecilogyrus sublineatus & 22,9 & 5,7 & 10 \\
Lygophis elegantissimus & 18,6 & - & - \\
Bothrops alternatus & 15,4 & 7,5 & 5 \\
Epictia australis & 13,3 & - & - \\
Philodryas patagoniensis & 11,4 & 1,9 & 45 \\
Lygophis anomalus & 5,3 & 1,9 & 5 \\
Oxyrhopus rhombifer rhombifer & 3,5 & 3,8 & 5 \\
Xenodon dorbignyi & 2,1 & 7,5 & 15 \\
Bothrops ammodytoides & 1,9 & - & - \\
Paraphimophis rustica & 1,1 & 3,8 & 5 \\
Phalotris bilineatus & 1,1 & 3,8 & - \\
Philodryas aestiva subcarinata & 1,1 & - & - \\
Philodryas agassizii & 1,1 & 1,9 & - \\
Epictia munoai & 0,8 & 62,3 & 10 \\
Xenodon semicinctus & 0,5 & - & - \\
\hline TOTAL DE EJEMPLARES & 376 & 53 & 20 \\
\hline
\end{tabular}

Tabla 2.5. Abundancia relativa (\%) de las serpientes en las Sierras bonaerenses, agrupadas según sus hábitos primarios. Con rojo se indican los hábitos mejor representados. Ver referencias en Tabla 2.4 .

\begin{tabular}{cccc}
\hline HÁBITOS & VE & SBM & SB \\
\hline Semiacuático & 46,8 & 7,5 & 15 \\
Terrestre & 31,9 & 15,1 & 55 \\
Fosorial & 14,1 & 62,3 & 10 \\
Semifosorial & 7,2 & 15,1 & 20 \\
\hline
\end{tabular}

Con respecto a los patrones de distribución de las serpientes en las Sierras de Ventania, la cantidad de especies y de ejemplares por partido no resultó equitativa. Las localidades del centro del área de estudio, con elevada proporción de ambiente serrano e intraserrano, poseen mayor cantidad de registros y de ejemplares de serpientes (riqueza y abundancia) respecto a las localidades periféricas, con elevada proporción de ambiente periserrano y de llanura. Solo en el partido de Tornquist habitan en simpatría las 15 especies y subespecies presentes en el área de estudio. La mayor cantidad de especies y 
de ejemplares registrados en el área serrana e intraserrana podría estar relacionado con las diferencias significativas halladas en la distribución altitudinal de la comunidad de serpientes, ya que la mayoría de las especies son frecuentes en altitudes intermedias. Otra opción, no excluyente, sería debido a las diferencias en la utilización de los distintos ambientes en términos productivos, ya que la zona serrana e intraserrana se destina a la ganadería pastoril, utilizándose los pastizales naturales como recurso forrajero, mientras que el ambiente periserrano y de llanura se destina principalmente a la implantación de praderas para la ganadería y además al cultivo (Frangi y Barrera 1996), con mayores consecuencias para las serpientes, ya que la perdida y fragmentación del hábitat son algunas de las causas más importantes en la declinación de sus poblaciones (Gibbons et al. 2000).

El limite austral en la distribución geográfica de diversas especies de serpientes (por ej. Epictia munoai, Erythrolamprus poecilogyrus sublineatus, Lygophis anomalus, Philodryas aestiva subcarinata, Bothrops alternatus) alcanza las Sierras de Ventania y alrededores (Williams 1991, presente estudio). Se presenta aquí la primer evidencia de sintopía estricta entre Epictia munoai - E. australis, Lygophis anomalus - L. elegantissimus y Bothrops alternatus - B. ammodytoides en base a observaciones personales en el campo. No se consideran las áreas de sintopía obtenidas mediante localidades de museos para evitar posibles errores en la georreferencia. En la provincia de Buenos Aires, Epictia australis fue mencionada como un endemismo parcial de las Sierras de Ventania (Scrocchi 1990, Williams 1991). Mientras que Epictia munoai presenta una extensa distribución, alcanzando el este de la provincia de Buenos Aires, y fue considerada de presencia marginal en el área de estudio (ver mapa en Cei 1986, 1993). Orejas Miranda (1961) en la descripción original de E. munoai menciona un paratipo procedente de Sierra de la Ventana (ver Apéndice 1). El área de sintopía estricta entre estas especies fue hallada durante los muestreos al este del sistema serrano, en la localidad de Villa Arcadia, Cnel. Suárez, donde fueron registradas ambas especies en actividad en el mismo tipo de microhábitat. Similarmente, Lygophis elegantissimus representa un endemismo de las Sierras de Ventania (Williams y Scrocchi 1994, Di Pietro et al. 2012), mientras que, L. anomalus presenta una extensa 
distribución, alcanzando el noreste de la provincia de Buenos Aires, y también fue considerada de presencia marginal en el área de estudio (ver mapa en Dixon 1985). De hecho, Cranwell (1942) presenta un mapa de distribución de ambas especies en la provincia de Buenos Aires y deja planteado el interesante aspecto zoogeográfico con interrogantes en las zonas de contacto. Se debe mencionar que estas especies fueron consideradas, previa revisión del grupo "anomalus" (sensu Dixon 1985), como sinónimos (Marelli 1924, Amaral 1926, Peters y Orejas Miranda 1970) o subespecies (Gallardo 1970, 1977). El área de sintopía estricta fue registrada durante los muestreos al noreste del sistema serrano, en el arroyo Las Tunas, Cnel. Suárez y en el arroyo Pillahuincó, Cnel. Pringles, donde fueron halladas ambas especies en actividad en el mismo tipo de microhábitat. Finalmente, las distribuciones de Bothrops alternatus y $B$. ammodytoides en la provincia de Buenos Aires se superponen en las regiones serranas (ver Barrio 1961). De hecho, Koslowsky (1895) tempranamente indica que ambas especies habitan el área de Sierra de la Ventana, aunque solo enumera a $B$. alternatus. Durante los muestreos de campo, el área de sintopía estricta fue registrada al sudoeste del sistema serrano en la localidad de Tornquist, Tornquist, donde fueron registradas ambas especies en actividad en el mismo tipo de microhábitat.

\section{Comparación con otras regiones}

Como fue mencionado anteriormente, las comparaciones entre las especies registradas en diferentes comunidades de serpientes son complejas por diversos factores, como las diferencias en el tamaño del área de estudio, el esfuerzo y los métodos de muestreo empleados (ver por ej. Martins y Oliveira 1998, Bernarde y Abe 2006, Sawaya et al. 2008). Además, algunas variables como la posición geográfica (latitud y altitud), temperatura, precipitación y tipo de vegetación influencian la riqueza de especies en las comunidades de serpientes (ver Vitt 1987). Estas características, en las 11 regiones comparadas en el presente estudio, se presentan resumidas en la Tabla 2.6. La riqueza específica de las Sierras de Ventania está dentro de los valores observados en las regiones comparadas. La disminución de la riqueza 
específica, con el aumento de la latitud sur y la disminución de la temperatura media anual (Vitt 1987) se evidencia, aunque sutilmente, al comparar el Noreste bonaerense y el resto de las regiones. Dos localidades ubicadas al norte de la provincia de Buenos Aires, el Parque Rafael de Aguiar y la Reserva Natural Otamendi (Voglino et al. 2001, Pereira y Haene 2003, respectivamente) presentaron baja riqueza específica, comparados con el Noreste bonaerense de Gallardo (1980a). En estas dos localidades, otros factores deben estar influenciando el menor número de especies en relación con la latitud, como las diferencias en el tamaño del área muestreada (Tabla 2.6). Otra interpretación sería debido a la falta de relevamientos, ya que en estos trabajos se presentaron mayor cantidad de especies dudosas o probables que confirmadas. Como fue mencionado previamente por Gallardo (1977), en la provincia de Buenos Aires las dos zonas con mayor riqueza de ofidios (y de reptiles en general) corresponden al Noreste bonaerense y las Sierras de Ventania. En esta última región otros factores deben estar influenciando la elevada riqueza específica en relación con la latitud, como la mayor altitud. Situación similar podría ocurrir en las Sierras de Lihué Calel, con la mayor altitud y el tipo de vegetación (Tabla 2.6). Además de estas variables, factores históricos también son responsables de la composición de serpientes en una región dada, como la disminución de los Colubridae y los Dipsadinae y el aumento de los Xenodontinae con el aumento de la latitud sur, junto a las limitaciones morfológicas y fisiológicas que permiten a una especie sobrevivir en un determinado ambiente (Cadle y Greene 1993). Esta tendencia, al igual que la riqueza específica, es notable al comparar con regiones distantes. Por ejemplo, en la región de Manaos, Brasil (Martins y Oliveira 1998) fueron registradas 66 especies de serpientes y entre los Colubroidea (sensu Zaher et al. 2009) el $28,5 \%$ de las especies son Colubridae, el $24,5 \%$ son Dipsadinae y el 46,9\% son Xenodontinae; en el Bagual, Argentina (Yanosky et al. 1989, Scrocchi y Giraudo 2005) fueron registradas 33 especies y entre los Colubroidea el $10,7 \%$ son Colubridae, el $10,7 \%$ son Dipsadinae y el $78,5 \%$ son Xenodontinae; mientras que en las regiones comparadas en el presente estudio la riqueza específica no supera las 17 especies, y están ausentes los Colubridae y los Dipsadinae, y los Colubroidea están representados exclusivamente por los Xenodontinae. 
Tabla 2.6. Riqueza específica, posición geográfica y principales características ambientales (en las 11 regiones comparadas). Referencias: Reg. = Regiones y localidades con listas de serpientes, Spp. $=$ Total de especies confirmadas, Ap. $(\mathrm{m})=$ Altitud promedio, Aa. $(\mathrm{ha})=$ Área aproximada, $\mathrm{T} .\left({ }^{\circ} \mathrm{C}\right)=$ Temperatura media anual, $\mathrm{P} .(\mathrm{mm})=$ Precipitaciones promedio anual, Prov. = Provincia fitogeográfica (Cabrera 1971, 1994), Pam. = Provincia fitogeográfica Pampeana, Mont. = Provincia fitogeográfica del Monte, Dom. = Dominio zoogeográfico (Ringuelet 1961), Subt. = Dominio zoogeográfico Subtropical, Pamp. = Dominio zoogeográfico Pampásico, Cent. = Dominio zoogeográfico Central. Ver otras referencias en Tabla 2.2.

\begin{tabular}{cccccccccc}
\hline Reg. & Spp. & Latitud & Longitud & Ap.(m) & Aa. $($ ha) & T. $\left({ }^{\circ} \mathrm{C}\right)$ & P.(mm) & Prov. & Dom. \\
\hline NE & 17 & $33^{\circ} 40^{\prime}-35^{\circ} \mathrm{S}$ & $57^{\circ} 30^{\prime}-62^{\circ} \mathrm{W}$ & 34 & 3200000 & $16-18$ & $900-1000$ & Pam. & Subt. \\
PRA & 9 & $33^{\circ} 20^{\prime} \mathrm{S}$ & $60^{\circ} 13^{\prime} \mathrm{W}$ & 28 & 1500 & 17,1 & 914 & Pam. & Subt. \\
RNO & 8 & $34^{\circ} 13^{\prime} \mathrm{S}$ & $58^{\circ} 53^{\prime} \mathrm{W}$ & 20 & 3000 & 16 & 1000 & Pam. & Subt. \\
RNPL & 14 & $34^{\circ} 46^{\prime} \mathrm{S}$ & $57^{\circ} 57^{\prime} \mathrm{W}$ & 3 & 6000 & 16,2 & 1040 & Pam. & Subt. \\
PCS & 15 & $35^{\circ} 15^{\prime}-35^{\circ} 32^{\prime} \mathrm{S}$ & $57^{\circ} 18^{\prime}-57^{\circ} 20^{\prime} \mathrm{W}$ & 1 & 23500 & 15,1 & 972 & Pam. & Subt. \\
DS & 10 & $35^{\circ} 30^{\prime}-37^{\circ} 40^{\prime} \mathrm{S}$ & $56^{\circ} 50^{\prime}-60^{\circ} 30^{\prime} \mathrm{W}$ & 27 & 5800000 & 15,5 & 934 & Pam. & Pamp. \\
SB & 9 & $36^{\circ} 56^{\prime} \mathrm{S}$ & $60^{\circ} 09^{\prime} \mathrm{W}$ & 242 & 8000 & 13.6 & 892 & Pam. & Pamp. \\
SBM & 11 & $37^{\circ} 40^{\prime}-38^{\circ} \mathrm{S}$ & $57^{\circ} 45^{\prime}-58^{\circ} 15^{\prime} \mathrm{W}$ & 250 & 34000 & 13,6 & 847 & Pam. & Pamp. \\
DC & 13 & $36^{\circ} 25^{\prime}-38^{\circ} 57^{\prime} \mathrm{S}$ & $56^{\circ} 42^{\prime}-61^{\circ} 53^{\prime} \mathrm{W}$ & 1 & 168653 & 13,9 & 700 & Pam. & Pamp. \\
SV & 15 & $37^{\circ} 31^{\prime}-38^{\circ} 23^{\prime} \mathrm{S}$ & $61^{\circ} 13^{\prime}-62^{\circ} 50^{\prime} \mathrm{W}$ & 600 & 710000 & 14 & 800 & Pam. & Cent. \\
SLC & 15 & $38^{\circ} 01^{\prime} \mathrm{S}$ & $65^{\circ} 35^{\prime} \mathrm{W}$ & 300 & 32514 & 15 & 365 & Mont. & Cent. \\
\hline
\end{tabular}

De acuerdo con Ringuelet (1961) el ajuste entre unidades zoo y fitogeográficas es algo esperable y hasta deseable. De hecho, la mayor parte de los pocos intentos zoogeográficos en cuanto a los reptiles argentinos han estado regidos por las divisiones fitogeográficas de base (por ej. Cabrera 1993, 1995, 2001). Justamente, en las regiones comparadas en el presente estudio se observa el "engranaje" de tres dominios zoogeográficos que, de noreste a sudoeste, son el Subtropical, el Pampásico y el Central o Subandino (Ringuelet 1955, 1961, Ringuelet y Arámburu 1957). Estas unidades reproducen aproximadamente el esquema fitogeográfico (Cabrera 1976, 1994) en el mismo orden, provincia Pampeana (dominio Subtropical y Pampásico), del Espinal y del Monte (dominio Central). Sin embargo, es importante destacar que, mientras los dominios Subtropical y Pampásico pertenecen a la subregión Guayano-Brasileña, el dominio Central pertenece a la subregión AndinoPatagónica (Ringuelet 1961).

La mayor similitud biogeográfica de las Sierras de Ventania se presenta con las Sierras de Tandilia (aquí representadas por las Sierras de Balcarce y 
Mar del Plata y por las Sierras Bayas) y con las Dunas Costeras. Estas regiones forman un agrupamiento bien definido según sus ofiofaunas. Ringuelet (1955, 1961) y Ringuelet y Arámburu (1957) no consideran a las Sierras de Ventania parte del dominio Pampásico. Según estos autores, en la provincia de Buenos Aires, la zona desde el río Colorado hasta Ventania inclusive presenta vinculación faunística con el Monte de La Pampa y forma parte del dominio Central (Distrito Sudoriental). Los resultados obtenidos en el presente estudio, vinculan a las Sierras de Ventania con el dominio Pampásico, más precisamente con el sector Tandílico y con el sector Costero (sensu Ringuelet 1961). Además, la unicidad de las Sierras de Ventania como entidad zoogeográfica es discutible. Si bien presenta un taxón exclusivo, Lygophis elegantissimus, están ausentes elementos característicos del dominio Central (por ej. Philodryas p. psamophidea, Erythrolamprus s. sagittifer). Su ensamble de serpientes puede definirse como "pampásico" con algunos elementos propios de hábitats más xéricos (por ej. Epictia australis, Bothrops ammodytoides). Apoyando estos resultados, las Sierras de Lihué Calel, La Pampa, que también fueron incluidas en el domino Central y en la provincia del Monte (Ringuelet 1961, Cabrera 1976, 1994) se separan de las Sierras de Ventania y también del resto de las regiones comparadas a muy bajos valores de similitud biogeográfica. Resultados similares fueron obtenidos en micromamíferos (Pardiñas et al. 2004). Resulta interesante destacar la presencia de Philodryas p. psamophidea, P. trilineata y Pseudotomodon trigonatus al sudoeste de las Sierras de Ventania (ver Composición faunística en Discusión) y en las Sierras de Lihué Calel, lo que aparentemente restringe el límite bonaerense del dominio Central a esta región y confirma en parte las observaciones efectuadas por Ringuelet $(1955,1961)$ y Ringuelet y Arámburu (1957). El resto de las regiones "pampásicas" comparadas en el presente estudio forman otro agrupamiento bien definido en base a sus ofiofaunas. Por un lado, el NE bonaerense presenta elevados valores de similitud biogeográfica con la Reserva Natural Punta Lara y con el Parque Costero del Sur. El subgrupo integrado por estas regiones reconoce claramente el dominio Subtropical (Distrito Mesopotámico, sector Meridional) en la provincia de Buenos Aires, con el límite austral en la costa del río de La Plata (Ringuelet 1955, 1961, Ringuelet y Arámburu 1957), y se diferencia por un conjunto 
exclusivo de serpientes (por ej. Helicops spp., Erythrolamprus semiaureus). Por otro lado, la Depresión del Salado, que forma parte del dominio Pampásico, presenta elevados valores de similitud biogeográfica con el Parque Rafael de Aguiar y con la Reserva Natural Otamendi que forman parte del dominio Subtropical. La vinculación de estas regiones evidencia la presencia de fauna subtropical empobrecida en el dominio Pampásico, como fue mencionado previamente (Ringuelet 1961). Según este autor, no existe una fauna pampeana típica, debido a que los elementos distintivos del dominio Pampásico son todos ajenos, fundamentalmente de retracción faunística del dominio Subtropical.

En conclusión, los resultados obtenidos en este estudio contrastan parcialmente con el esquema zoogeográfico clásico de Ringuelet $(1955,1961)$ y Ringuelet y Arámburu (1957). Los ensambles de serpientes permiten reconocer una división de mayor jerarquía entre el dominio Central o provincia del Monte y el resto de las regiones "pampásicas" consideradas. En este esquema, el engranaje o ecotono entre estos dos bloques faunísticos se desplaza al sudoeste del esquema clásico, y por lo tanto las Sierras de Ventania forman parte del dominio Pampásico. Adicionalmente, el reconocimiento del dominio Subtropical es claro, al igual que su vinculación faunística con el dominio Pampásico por pérdida de especies. 


\section{RELACIONES TRÓFICAS $Y$ ESPACIALES DE LA COMUNIDAD DE SERPIENTES}

\section{INTRODUCCIÓN}

En este capítulo se describe la dieta y el uso del espacio (microhábitat), se analizan diferentes aspectos de la ecología trófica y espacial y el solapamiento del nicho trófico-espacial de la comunidad de serpientes.

\section{METODOLOGÍA}

Para determinar la dieta se utilizaron los ejemplares colectados durante las tareas de campo y los depositados en colecciones (ver Apéndice 1). Para examinar el contenido del tubo digestivo fue realizada una incisión medioventral, desde la garganta hasta la parte anterior de la cloaca, posibilitando el estudio del tracto digestivo completo, esófago, estómago e intestino (Figura 3.1). Se retiró el tubo digestivo, se diseccionó, y se conservó junto con su contenido en cápsulas individuales en una solución de alcohol etílico $70 \%$. Los contenidos digestivos fueron determinados con lupa estereoscópica binocular hasta las categorías taxonómicas más precisas posibles, por medio de comparaciones con material de la colección de referencia del Museo de La Plata (MLP), consulta con especialistas en cada grupo, e identificación a través de claves (Coronado Padilla y Marquez Delgado 1978, Cei 1987, 1993, Fernández et al. 2011).

Se registró el volumen individual y el número de los ítems presa. En aquellas presas que se encontraron poco digeridas (generalmente presentes en el esófago y estómago) se calculó el volumen por medio del método de desplazamiento de agua con ayuda de distintas probetas (con una precisión de $0,01 \mathrm{ml}$ ). En las presas que se encontraban parcialmente digeridas (generalmente en el intestino) fueron tomadas medidas de referencia (por ej. longitud del fémur) para comparar con ejemplares depositados en la colección del MLP y estimar el posible volumen real de la presa ingerida. Los 
invertebrados fueron considerados presas secundarias ingeridas primero por anfibios o saurios, siempre que fueran de pequeño tamaño y se encontraran junto con restos de algún anuro o lagarto. Los restos altamente digeridos (generalmente en intestino) que por su estado no fue posible darles una asignación taxonómica precisa fueron considerados como no identificables.

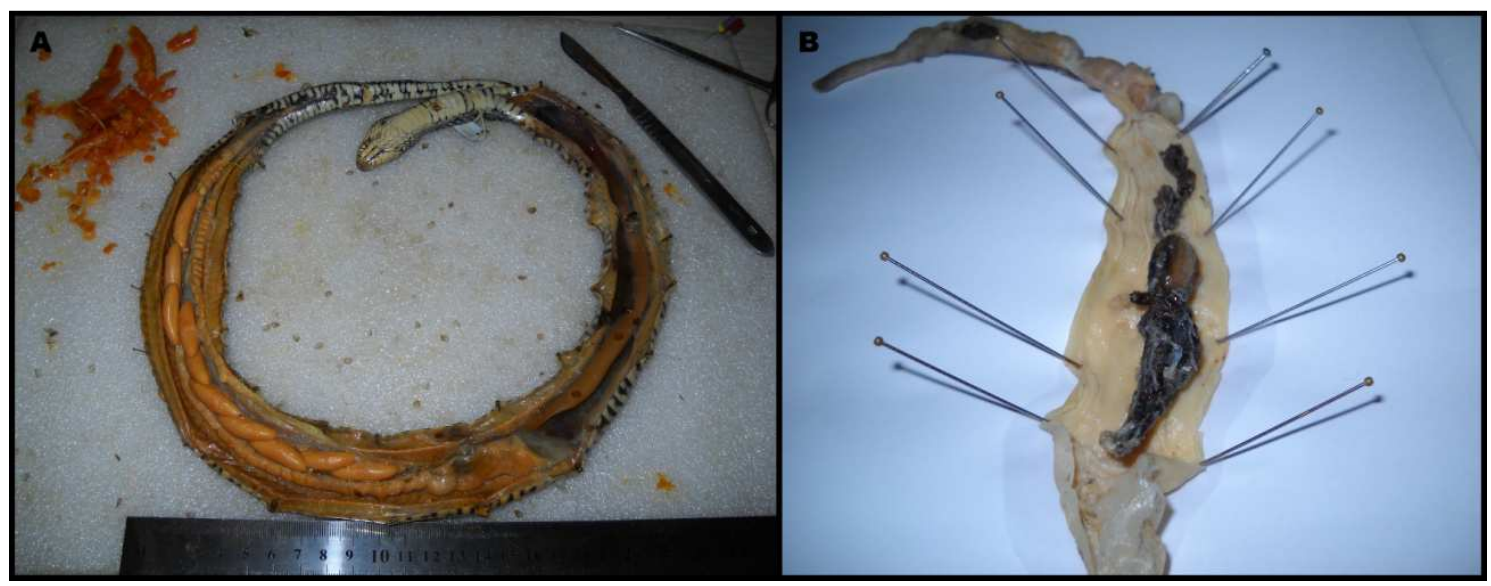

Figura 3.1. Determinación de la dieta. (A) Disección de Erythrolamprus poecilogyrus sublineatus. (B) Detalle del contenido estomacal e intestinal de Philodryas patagoniensis.

Para determinar el uso del microhábitat fueron empleados solo los ejemplares colectados en actividad durante las tareas de campo (ver Metodología del capítulo 2 para detalles del muestreo). No fueron considerados los ejemplares atropellados, las observaciones accidentales (sin captura) y los ejemplares depositados en las colecciones, como un intento de minimizar los posibles errores en las proporciones de las especies en cada uno de los microhábitats. A continuación se describen brevemente cada uno de los hábitats/microhábitats donde fueron registradas las serpientes (Figura 3.2). Para detalles precisos sobre la vegetación véase Frangi y Bottino (1995).

Cursos de agua: los ambientes acuáticos presentes son principalmente lóticos. El tramo superior serrano y temporario de los arroyos puede presentar piletones rocosos a veces profundos. El tramo intraserrano y periserrano está surcado por cursos de agua permanentes. Fueron considerados dos tipos de microhábitat según la presencia de serpientes: Arroyos, cuando los ejemplares 
se hallaron nadando en el cauce; y Bordes de arroyo, cuando los ejemplares se hallaron con parte del cuerpo en el agua y el resto en tierra firme. La vegetación de los cursos de agua ocupa una superficie reducida y por lo general está ocupada por la vegetación aledaña de los pastizales y roquedales. En las cabeceras, márgenes de pequeños cursos de agua y piletas rocosas son frecuentes los carrizales (Phragmites australis), también aparecen juncales (Juncus sp., Scirpus sp.) y totorales (Typha sp.), entre otras especies. En los arroyos permanentes son frecuentes las cortaderas (Cortaderia selloana) y los pequeños bosques marginales de sauces (Salix humboldtiana y S. fragilis).

Pastizal: es el ambiente mejor representado en el área de estudio. Fueron considerados tres tipos de microhábitats según la presencia de serpientes: Pastizal con arbustos, cuando los ejemplares fueron hallados rodeados de arbustos sobre un pastizal sin importar la cobertura del sustrato; Pastizal denso, cuando los ejemplares fueron hallados sobre un sustrato de pastizal completamente cubierto; y Pastizal descubierto, cuando los ejemplares fueron hallados sobre un sustrato de pastizal y tierra. En este último tipo de microhábitat se encuentran además los ejemplares hallados en actividad en el borde de carreteras y caminos rurales. Los pastizales del ambiente serrano están dominados por Briza subaristata y flechillas (Stipa sp. y Piptochaetium sp.). Los prados de altura están dominados por Festuca pampeana y $F$. ventanicola, donde aparece Sorghastrum pellitum como especie codominante. En los pastizales intraserranos y periserranos dominan los pajonales de Stipa caudata y S. ambigua (Pastos tussock). Los principales arbustos son la brusquilla (Discaria americana), la chirca (Eupatorium buniifolium) y la carqueja (Bacchiaris articulata).

Roquedales: están representados aquí por afloramientos de rocas y rocas sueltas. Fueron considerados dos tipos de microhábitats según las presencia de serpientes: Bajo rocas, cuando los ejemplares fueron registrados bajo rocas sueltas sobre tierra desnuda; y Sobre rocas, cuando los ejemplares fueron registrados sobre bloques de roca firme y/o debajo de lajas sobre rocas. Cabe mencionar que el microhábitat bajo rocas sueltas sobre tierra no necesariamente representa un roquedal en sentido estricto, ya que por lo general está inmerso en otro ambiente, como por ejemplo un pastizal 
descubierto o un pastizal con arbustos, sin embargo por fines prácticos fue incluido dentro de este tipo de hábitat. Las principales especies vegetales presentes en los roquedales son los helechos (por ej. Blechnum auriculatum, $B$. chilense, Polystichum elegans, Polypodium argentinum, Adiantum sp. y Anemia tormentosa) la carda (Eryngium stenophyllum), el pino plateado (Plantago bismarckii), los líquenes (Usnea sp., Caloplaca sp.) y cactus (por ej. Parodia sp.).

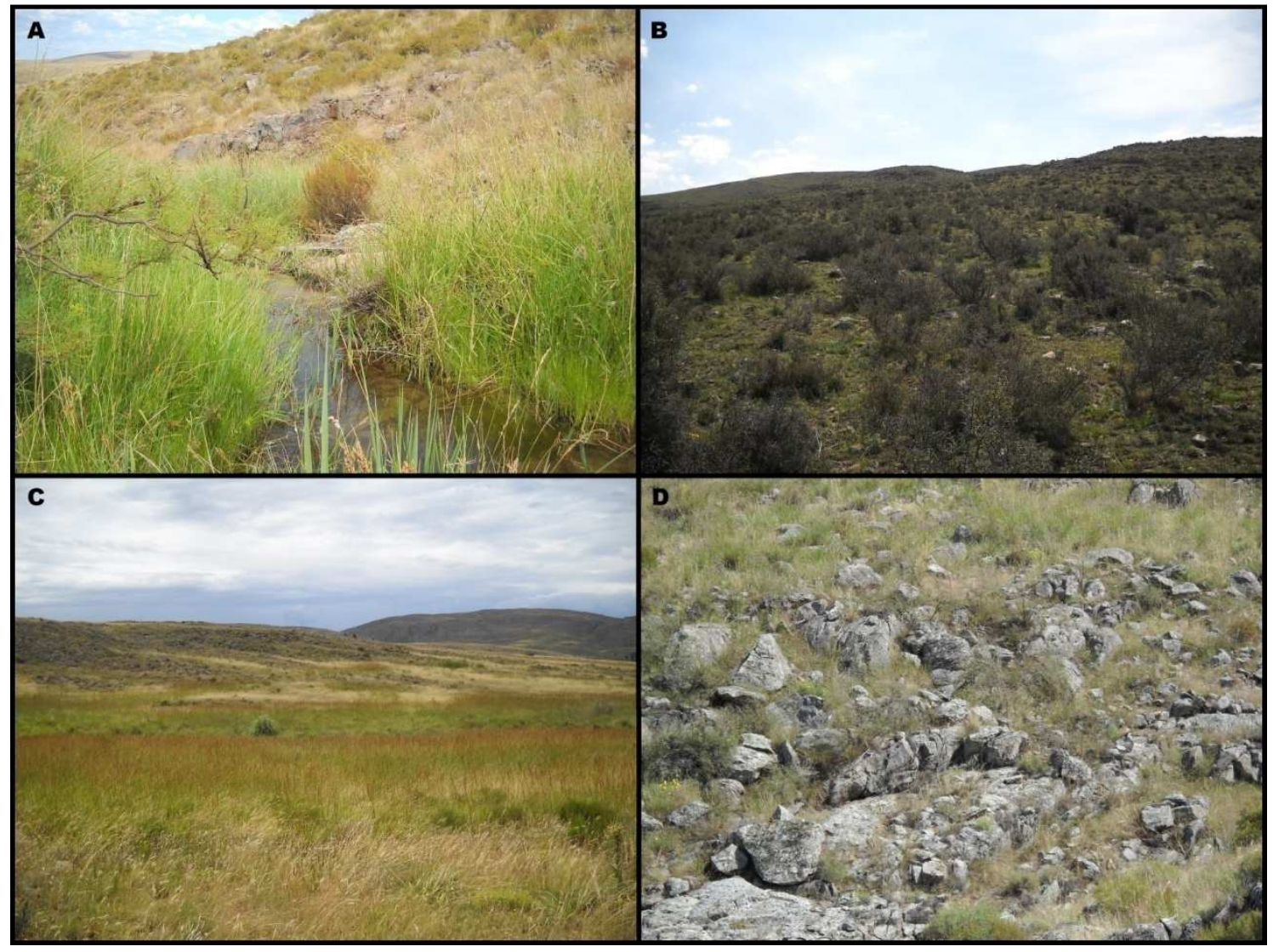

Figura 3.2. Principales tipos de hábitats/microhábitats utilizados por las serpientes en las Sierras de Ventania. (A) Arroyo serrano. (B) Pastizal con arbustos. (C) Pastizal denso. (D) Roquedal.

La diversidad trófica se calculó según el criterio de Hurtubia (1978), que consiste en obtener la diversidad trófica $(H)$ para cada individuo utilizando la formula de Brillouin (1965):

$$
H=(1 / N)\left(\log _{2} N !-\Sigma \log _{2} N_{i} !\right)
$$


donde, $\mathrm{N}$ es el número total de entidades taxonómicas halladas en el estómago de cada individuo y $\mathrm{N}_{\mathrm{i}}$ es el número total de presas de la especie $i$ en cada estómago. Las estimaciones individuales fueron sumadas al azar, obteniéndose la diversidad trófica acumulada $\left(H_{k}\right)$, que fue utilizada para calcular la muestra mínima del número de ejemplares, sobre un gráfico de diversidad trófica acumulada versus número de estómagos (k). La diversidad en el uso del microhábitat para cada una de las especies también fue calculada utilizando la fórmula de Brillouin (1965). Siendo en este caso, $\mathrm{N}$ el número total de ejemplares y $\mathrm{N}_{\mathrm{i}}$ el número de ejemplares en cada microhábitat.

Para determinar el grado de utilización de los recursos disponibles en el ambiente se calculó el índice de Equidad de Pielou (1969) (J’):

$$
J^{\prime}=H^{\prime} / H^{\prime}{ }_{\text {Max }}
$$

donde, $\mathrm{H}^{\prime}=-\Sigma \mathrm{P}_{\mathrm{i}} \log _{2} \mathrm{P}_{\mathrm{i}}$ y $\mathrm{H}_{\text {Max. }}^{\prime}=\log _{2} \mathrm{~S} ; \mathrm{H}^{\prime}$ es el valor del índice de diversidad de Shannon y Weaver (1949) y $S$ representa el número de ítems presa consumidos o de microhábitats utilizados.

Con la finalidad de determinar la importancia de cada ítem presa en la dieta de la especie, se aplicó la fórmula de Biavati et al. (2004):

$$
\text { IPS }=(F O \%+N \%+V \%) / 3
$$

donde, $\mathrm{FO} \%$ es el porcentaje de ocurrencia del ítem presa, $\mathrm{N} \%$ es el porcentaje numérico del ítem presa y $\mathrm{V} \%$ es el porcentaje volumétrico del ítem presa.

La amplitud de nicho de las presas, del volumen, y del microhábitat se calculó utilizando el índice de Levins (1968):

$$
\mathrm{Nb}=\left(\Sigma \mathrm{p}_{\mathrm{ij}}^{2}\right)^{-1}
$$

donde, $\mathrm{p}_{\mathrm{ij}}$ representa la probabilidad de encontrar el ítem presa $i$ en la muestra $j$; o la especie $i$ en el microhábitat $j$.

Se calculó el solapamiento en la dieta (proporción de presas y volumen) y en el microhábitat, utilizando el índice de solapamiento de Pianka (1973): 


$$
O_{j k}=\frac{\sum_{i=1}^{n} P_{i j} P_{i k}}{\sqrt{\sum_{i=1}^{n} P_{i j}^{2} \sum_{i=1}^{n} P_{i k}^{2}}}
$$

donde, $\mathrm{P}_{\mathrm{ij}}$ y $\mathrm{P}_{\mathrm{ik}}$ son las proporciones de utilización de recursos por las especies. Los valores de solapamiento varían entre $0-1$. Valores de solapamiento de 1 indican dietas, volúmenes o microhábitats idénticos, mientras que valores de 0 indican la disimilitud entre dietas, volúmenes o microhábitats. Para determinar si los valores de solapamiento difieren de lo esperado, se realizó un análisis de aleatorización, basado sobre una muestra al azar de los datos y utilizando el programa EcoSim versión 7.71 (Gotelli y Entsminger 2005). EcoSim realiza reasignaciones al azar de los datos observados mediante el método de simulación de Monte Carlo, creando de este modo pseudocomunidades para comparar estadísticamente los patrones de estas comunidades creadas al azar con los datos observados. En este análisis se aplicó el algoritmo RA3 "retained niche breadth / reshuffled zero states" (recomendado por Winemiller y Pianka 1990), y los valores de la matriz original fueron repetidos al azar 1000 veces (creando 1000 pseudomatrices). La amplitud del nicho fue retenida para todas las especies, en otras palabras el algoritmo utilizado permitió retener la especialización de las especies analizadas (Gotelli y Entsminger 2005).

Para determinar la incidencia de una especie sobre la otra se calculó el índice de solapamiento de MacArthur y Levins (1967) para la dieta (proporción de presas y volumen) y el uso del microhábitat:

$$
M_{i y}=\Sigma P_{i} P_{y} / \Sigma P^{2} \text { iy }
$$

donde, $\mathrm{P}_{\mathrm{i}}$ y $\mathrm{P}_{\mathrm{y}}$ son las proporciones de utilización de recursos por las especies. Este índice es asimétrico y otorga dos valores, resultando ser más informativo que el índice de Pianka, al proveer un valor de incidencia de la especie $i$ sobre la $y, y$ otro valor de incidencia de la especie $y$ sobre la $i$.

Para establecer la relación entre la morfología de los depredadores, longitud total del cuerpo (LT) y ancho de la boca $(A B)$, y el volumen de las presas se aplicó el coeficiente de correlación de Pearson con el programa PAST versión 3.04 (Hammer et al. 2001). 


\section{RESULTADOS}

\section{Análisis de la dieta de las especies}

\section{Epictia australis}

Fueron examinados 49 ejemplares de los cuales el 36,7\% (n=18) presentó contenido identificable en el tubo digestivo. El tamaño de la muestra mínima fue de 12 ejemplares (Figura 3.3). La dieta de la especie incluyó solo tres ítems presa de formícidos (Tabla 3.1, Figura 3.4). En orden de importancia numérica y volumétrica fueron los siguientes: Huevo/larva (86,67\%), pupa (8\%) $y$ adulto $(5,33 \%)$. Los ítems presa más frecuentes fueron: Huevo/larva $(54,84 \%)$, adulto $(29,03 \%)$ y pupa $(16,13 \%)$. Considerando los valores del IPS los ítems presa más importantes fueron: Huevo/larva $(76,06)$, adulto $(13,23)$ y pupa $(10,71)$. Se encontraron, además, $0,04 \mathrm{ml}$ de Invertebrados indeterminados en tres estómagos y sedimento en tres estómagos. La diversidad de presas fue de 0,67 y el índice de equidad fue de 0,44. La amplitud del nicho trófico fue de 1,32 para las categorías presa y volumen. La LT promedio de los ejemplares fue de $152,29 \mathrm{~mm} \pm 33,07$ y el peso promedio fue de $1,5 \mathrm{~g} \pm 0,75$. No se halló correlación significativa entre el volumen de las presas y la $L T(r s=3.18477 E-16 ; p=1)$.

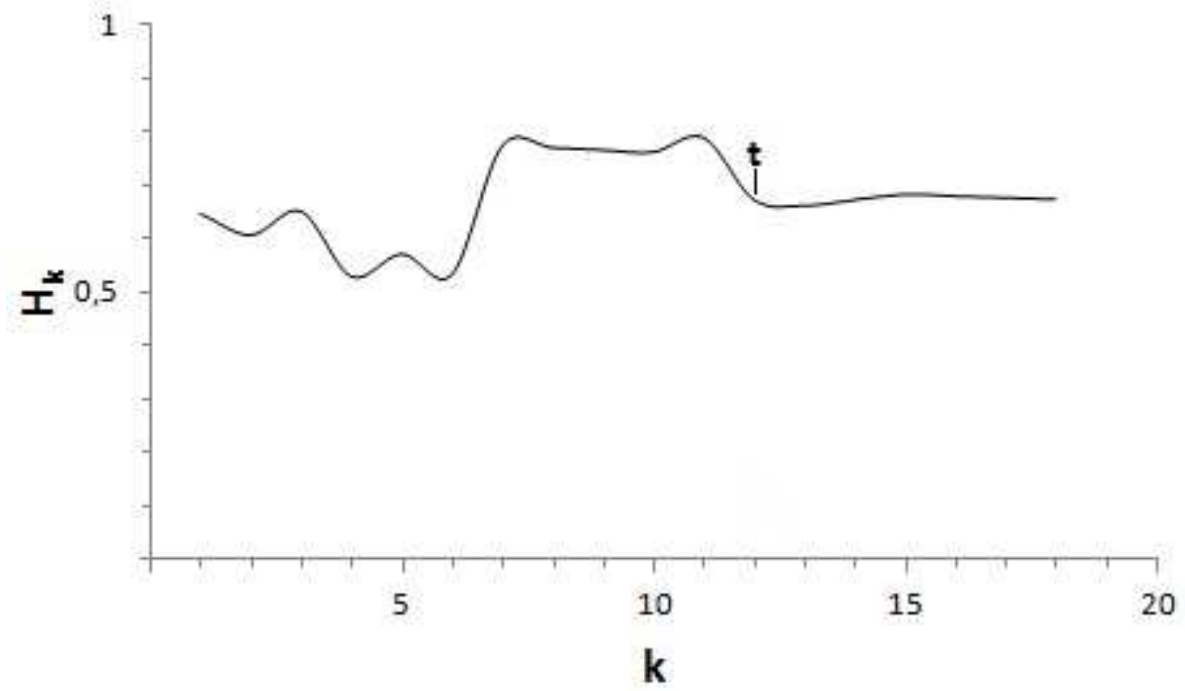

Figura 3.3. Determinación de la muestra mínima para Epictia australis. Referencias: $H_{k}=$ Diversidad trófica acumulada; k= Número de estómagos; $\mathrm{t}=$ Tamaño de la muestra mínima. 
Tabla 3.1. Dieta de Epictia australis. Referencias: $N=$ Número; $\% N=$ Porcentaje del número; $V$ $(\mathrm{ml})=$ Volumen (mililitros); \%V= Porcentaje del volumen; FO= Frecuencia de ocurrencia; \%FO= Porcentaje de la frecuencia de ocurrencia; IPS= Índice de importancia.

\begin{tabular}{lccccccc}
\hline \multicolumn{1}{c}{ ITEMS PRESA } & $\mathbf{N}$ & $\mathbf{\% N}$ & $\mathbf{V}(\mathbf{m l})$ & $\% \mathbf{V}$ & FO & $\%$ FO & IPS \\
\hline $\begin{array}{l}\text { INVERTEBRATA } \\
\text { Insecta }\end{array}$ & & & & & & & \\
Hymenoptera & & & & & & \\
Formicidae & & & & & & & \\
Pheidole sp. & 16 & 5,33 & 0,16 & 5,33 & 9 & 29,03 & 13,23 \\
Adulto & 260 & 86,67 & 2,6 & 86,67 & 17 & 54,84 & 76,06 \\
Huevo/larva & 24 & 8 & 0,24 & 8 & 5 & 16,13 & 10,71 \\
Pupa & 300 & & 3 & & 31 & & \\
TOTAL & & & & & & & \\
\hline
\end{tabular}

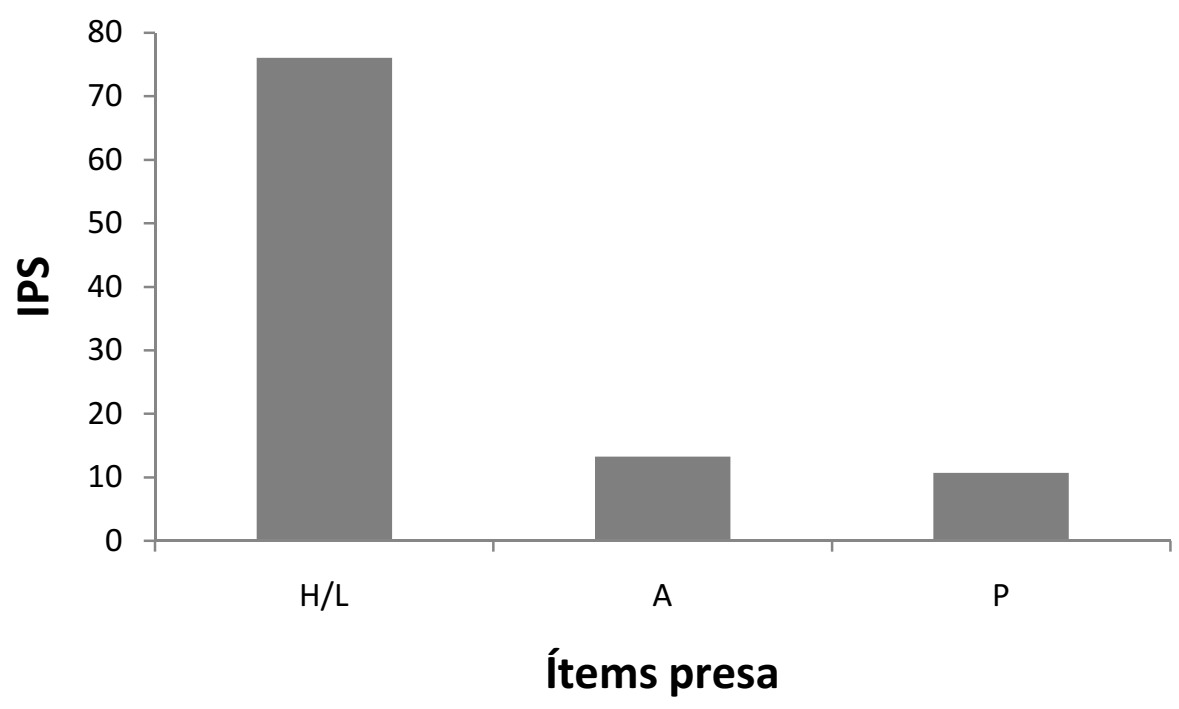

Figura 3.4. Índice de importancia de las categorías de presas consumidas (IPS) por Epictia australis. Referencias: $\mathrm{H} / \mathrm{L}=$ Huevo/larva; $\mathrm{A}=$ Adulto; $\mathrm{P}=\mathrm{Pupa}$.

\section{Erythrolamprus poecilogyrus sublineatus}

Fueron examinados 86 ejemplares de los cuales el 58,1\% $(n=50)$ presentó contenido identificable en el tubo digestivo. El tamaño de la muestra mínima fue de 39 ejemplares (Figura 3.5). La dieta de la especie incluyó nueve ítems presa (Tabla 3.2, Figura 3.6). En orden de importancia numérica se destacan: Larvas Rhinella arenarum (50\%), Jenynsia multidentata adultos $(22,97 \%)$ e Hypsiboas pulchellus (11,49\%). Teniendo en cuenta el volumen 
total, los ítems presa más importantes fueron: Jenynsia multidentata $(31,57 \%)$, Hypsiboas pulchellus $(17,08 \%)$ y Odontophrynus americanus (16,95\%). Los ítems presa más frecuentes fueron: Hypsiboas pulchellus $(33,33 \%)$, larvas Rhinella arenarum (17,65\%), Jenynsia multidentata $(15,69 \%)$ y larvas Hypsiboas pulchellus (11,76\%). Considerando los valores del IPS los ítems presa más importantes fueron: larvas Rhinella arenarum $(25,08)$, Jenynsia multidentata $(23,41)$ e Hypsiboas pulchellus $(20,63)$. Se encontraron además (como presas secundarias y/o indeterminadas), $0,87 \mathrm{ml}$ de Coleópteros en siete estómagos, 0,06 $\mathrm{ml}$ de Dípteros en dos estómagos, 2,4 $\mathrm{ml}$ de Formícidos en siete estómagos, 0,03 $\mathrm{ml}$ de Arácnidos en tres estómagos, 1,92 $\mathrm{ml}$ de Crustáceos en tres estómagos, Vertebrados indeterminados en seis estómagos, Invertebrados indeterminados en dos estómagos, Restos vegetales en 18 estómagos y Sedimento en cuatro estómagos. La diversidad de presas fue de 1,95 y el índice de equidad fue de 0,65. La amplitud del nicho para la categoría presas fue de 3,09 y para el volumen de las mismas fue de 5,48. La LT promedio fue de $472,64 \mathrm{~mm} \pm 150,45$ y el $\mathrm{AB}$ promedio fue de $10,8 \mathrm{~mm} \pm$ 3,11 . El peso promedio de los ejemplares fue de $42,1 \mathrm{~g} \pm 36,35$. No se halló correlación significativa entre el volumen de las presas con el $A B$ ( $r s=-0,07904$; $p=0,58533)$ y tampoco con la LT (rs= -0,00078009; $p=0,99571)$.

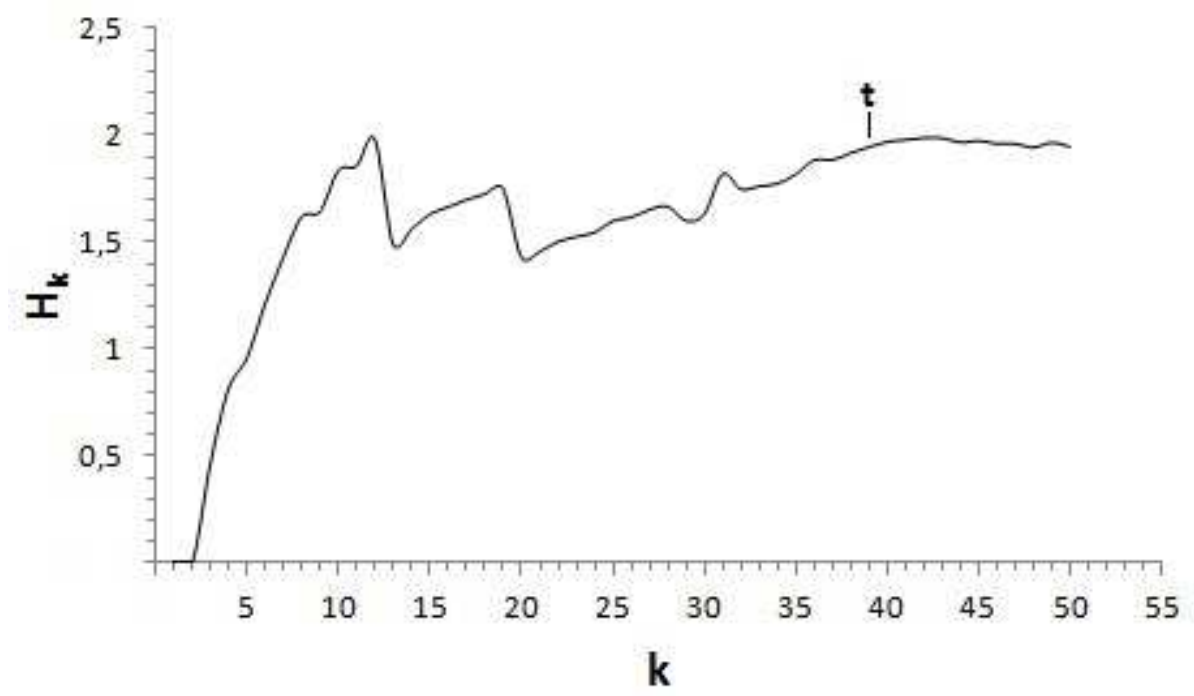

Figura 3.5. Determinación de la muestra mínima para Erythrolamprus poecilogyrus sublineatus. Referencias: $H_{k}=$ Diversidad trófica acumulada; $k=$ Número de estómagos; $t=$ Tamaño de la muestra mínima. 
Tabla 3.2. Dieta de Erythrolamprus poecilogyrus sublineatus. Referencias: $N=$ Número; $\% \mathrm{~N}=$ Porcentaje del número; $\mathrm{V}(\mathrm{ml})=$ Volumen (mililitros); $\% \mathrm{~V}=$ Porcentaje del volumen; $\mathrm{FO}=$ Frecuencia de ocurrencia; \%FO= Porcentaje de la frecuencia de ocurrencia; IPS= Índice de importancia.

\begin{tabular}{|c|c|c|c|c|c|c|c|}
\hline ITEMS PRESA & $\mathbf{N}$ & $\% \mathrm{~N}$ & $V(\mathrm{ml})$ & $\% \mathrm{~V}$ & FO & $\%$ FO & IPS \\
\hline \multicolumn{8}{|l|}{ VERTEBRATA } \\
\hline \multicolumn{8}{|l|}{ Actinopterygii } \\
\hline \multicolumn{8}{|l|}{ Cyprinodontiformes } \\
\hline \multicolumn{8}{|l|}{ Anablepidae } \\
\hline Jenynsia multidentata & 34 & 22,97 & 49,55 & 31,57 & 8 & 15,69 & 23,41 \\
\hline
\end{tabular}

Amphibia

Anura

Bufonidae

Melanophryniscus montevidensis

$\begin{array}{ccccccc}3 & 2,03 & 4,5 & 2,87 & 3 & 5,88 & 3,59 \\ 74 & 50 & 11,9 & 7,58 & 9 & 17,65 & 25,08 \\ & & & & & & \\ 17 & 11,49 & 26,8 & 17,08 & 17 & 33,33 & 20,63 \\ 12 & 8,11 & 13,7 & 8,73 & 6 & 11,76 & 9,53 \\ & & & & & & \\ 1 & 0,68 & 9,5 & 6,05 & 1 & 1,96 & 2,9 \\ & & & & & & \\ 4 & 2,7 & 26,6 & 16,95 & 4 & 7,84 & 9,16\end{array}$

Larvas Rhinella arenarum

Hylidae

Hypsiboas pulchellus

Larvas Hypsiboas pulchellus

Leptodactylidae

Leptodactylus latrans

Odontophrynidae

Odontophrynus americanus

Reptilia

Squamata (Serpentes)

Leptotyphlopidae

Epictia australis

$2 \quad 1,35 \quad 1,4 \quad 0,89 \quad 2 \quad 3,92 \quad 2,05$

Mammalia

Rodentia

Cricetidae

Necromys benefactus

TOTAL

\begin{tabular}{ccccccc}
1 & 0,68 & 13 & 8,28 & 1 & 1,96 & 3,64 \\
148 & & 156,95 & & 51 & & \\
\hline
\end{tabular}




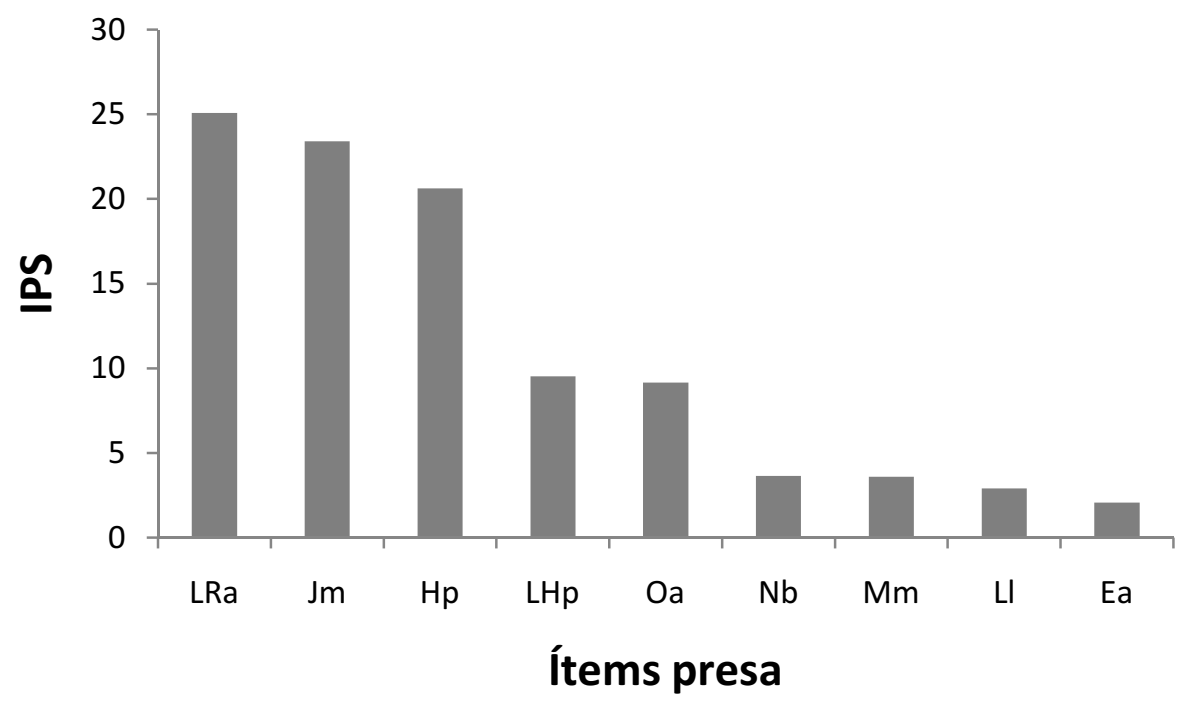

Figura 3.6. Índice de importancia de las categorías de presas consumidas (IPS) por Erythrolamprus poecilogyrus sublineatus. Referencias: LRa= Larvas Rhinella arenarum; Jm= Jenynsia multidentata; $\mathrm{Hp}=$ Hypsiboas pulchellus; LHp= Larvas Hypsiboas pulchellus; $\mathrm{Oa=}$ Odontophrynus americanus; $\mathrm{Nb}=$ Necromys benefactus; $\mathrm{Mm}=$ Melanophryniscus montevidensis; $\mathrm{LI}=$ Leptodactylus latrans; Ea= Epictia australis.

Lygophis elegantissimus

Fueron examinados 70 ejemplares de los cuales el 55,7\% (n=39) presentó contenido identificable en el tubo digestivo. El tamaño de la muestra mínima fue de 29 ejemplares (Figura 3.7). La dieta de la especie incluyó cinco ítems presa (Tabla 3.3, Figura 3.8). En orden de importancia numérica se destacan por igual adultos de Hypsiboas pulchellus $(42,86 \%)$ y larvas de la misma especie $(42,86 \%)$. Teniendo en cuenta el volumen, los ítems presa más importantes fueron: Hypsiboas pulchellus (58,29\%), Rhinella arenarum $(17,83 \%)$ y larvas Hypsiboas pulchellus $(11,41 \%)$. Los ítems presa más frecuentes fueron: Hypsiboas pulchellus (adultos, 57,5\% y larvas, 27,5\%). Considerando los valores del IPS los ítems presa más importantes fueron: Hypsiboas pulchellus (adultos, 52,88\% y larvas, 27,26\%). Se encontraron además, 0,06 $\mathrm{ml}$ de Dípteros en dos estómagos, 0,01 $\mathrm{ml}$ de Formícidos en un estómago, $0,03 \mathrm{ml}$ de Arácnidos en tres estómagos, Vertebrados indeterminados en seis estómagos, Restos vegetales en nueve estómagos y Sedimento en tres estómagos. La diversidad de presas fue de 1,5 y el índice de 
equidad fue de 0,72. La amplitud del nicho para la categoría presas fue de 2,67 y para el volumen de las mismas fue de 2,55 . La LT promedio fue de 513,16 $\mathrm{mm} \pm 123,01$ y el $\mathrm{AB}$ promedio fue de $9,7 \mathrm{~mm} \pm 2,42$. El peso promedio de los ejemplares fue de $27,04 \mathrm{~g} \pm 18,41$. Se halló una correlación significativa entre el volumen de las presas con el $A B(r s=0,39289 ; p=0,014685)$ y con la $L T$ ( $r s=$ $0,63802 ; p=1,6393 E-05)$.

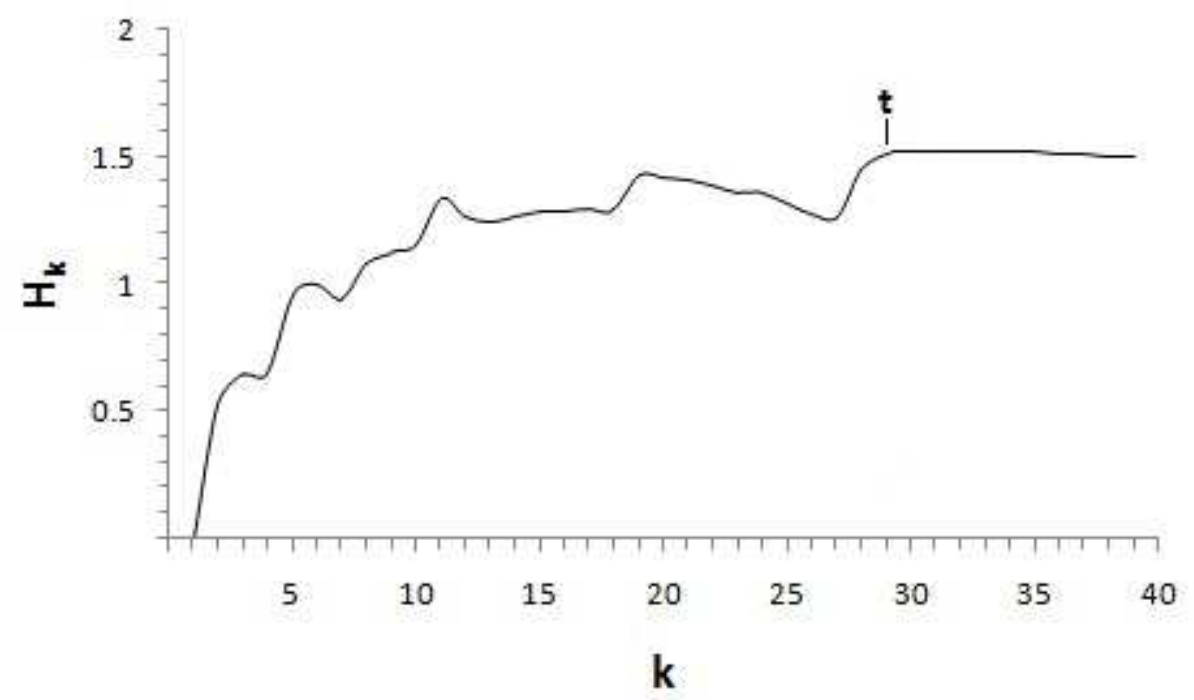

Figura 3.7. Determinación de la muestra mínima para Lygophis elegantissimus. Referencias: $\mathrm{H}_{\mathrm{k}}=$ Diversidad trófica acumulada, $\mathrm{k}=$ Número de estómagos, $\mathrm{t}=$ Tamaño de la muestra mínima. 
Tabla 3.3. Dieta de Lygophis elegantissimus. Referencias: $\mathrm{N}=$ Número; $\% \mathrm{~N}=$ Porcentaje del número; $\mathrm{V}(\mathrm{ml})=$ Volumen (mililitros); $\% \mathrm{~V}=$ Porcentaje del volumen; $\mathrm{FO}=$ Frecuencia de ocurrencia; \%FO= Porcentaje de la frecuencia de ocurrencia; IPS= Índice de importancia.

\begin{tabular}{lllllllll}
\hline ITEMS PRESA (adultos, excepto dde se indica) & $\mathrm{N}$ & $\% \mathrm{~N}$ & $\mathrm{~V}(\mathrm{ml})$ & $\% \mathrm{~V}$ & FO & $\% \mathrm{FO}$ & IPS \\
\hline
\end{tabular} VERTEBRATA

Amphibia

Anura

Bufonidae

Melanophryniscus montevidensis

$\begin{array}{lllllll}4 & 7,14 & 6 & 5,35 & 2 & 5 & 5,83\end{array}$

Rhinella arenarum

$\begin{array}{lllllll}2 & 3,57 & 20 & 17,83 & 2 & 5 & 8,8\end{array}$

Hylidae

Hypsiboas pulchellus

Larvas Hypsiboas pulchellus

$24 \quad 42,86 \quad 65,4 \quad 58,29 \quad 23 \quad 57,5 \quad 52,88$

Odontophrynidae

Odontophrynus americanus

TOTAL

$24 \quad 42,86 \quad 12,8 \quad 11,41 \quad 11 \quad 27,5 \quad 27,26$

$\begin{array}{lllllll}2 & 3,57 & 8 & 7,13 & 2 & 5 & 5,23\end{array}$

$56 \quad 112,2 \quad 40$

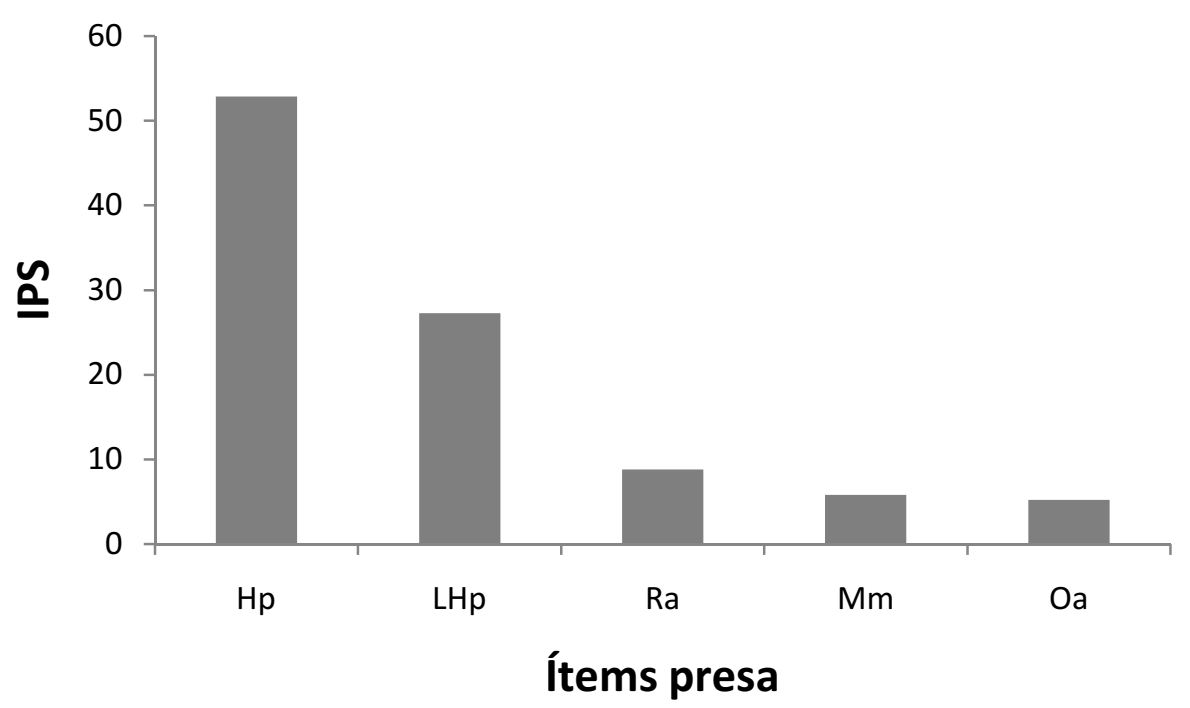

Figura 3.8. Índice de importancia de las categorías de presas consumidas (IPS) por Lygophis elegantissimus. Referencias: $\mathrm{Hp}=$ Hypsiboas pulchellus; $\mathrm{LHp}=$ Larvas Hypsiboas pulchellus; $\mathrm{Ra}=$ Rhinella arenarum; $\mathrm{Mm}=$ Melanophryniscus montevidensis; $\mathrm{Oa}=$ Odontophrynus americanus.

\section{Philodryas patagoniensis}

Fueron examinados 43 ejemplares de los cuales el 46,5\% (n=20) presentó contenido identificable en el tubo digestivo. El tamaño de la muestra 
mínima fue de 15 ejemplares (Figura 3.9). La dieta de la especie incluyó solo cuatro ítems presa (Tabla 3.4, Figura 3.10). En orden de importancia numérica se destacan: Lycosa sp. $(77,08 \%)$ y Calomys sp. $(12,5 \%)$. Teniendo en cuenta el volumen los ítems presa más importantes fueron: Calomys sp. (47,95\%), Necromys benefactus $(31,97 \%)$ y Lycosa sp. $(19,61 \%)$. Los ítems presa más frecuentes fueron: Lycosa sp. (50\%), Calomys sp. (27,27\%) y Necromys benefactus $(18,18 \%)$. Considerando los valores del IPS los ítems presa más importantes fueron: Lycosa sp. $(48,9)$, Calomys sp. $(29,24)$ y Necromys benefactus $(19,49)$. Fueron encontrados además, Vertebrados indeterminados (pelos) en cuatro estómagos, $0,01 \mathrm{ml}$ de Formícidos en un estómago, Invertebrados indeterminados en dos estómagos y Restos vegetales en tres estómagos. La diversidad de presas fue de 0,95 y el índice de equidad fue de 0,54 . La amplitud del nicho para la categoría presas fue de 1,62 y para el volumen de las mismas fue de 2,7. La LT promedio fue de 720,07 $\mathrm{mm} \pm 238,66$ $y$ el $A B$ promedio fue de $13,69 \mathrm{~mm} \pm 3,94$. El peso promedio de los ejemplares fue de $105,72 \mathrm{~g} \pm 65,08$. Se halló una correlación significativa entre el volumen de las presas con el $A B(r s=0,46033 ; p=0,041112)$ y con la $L T$ ( $r=0,54153$; $p=0,01366)$.

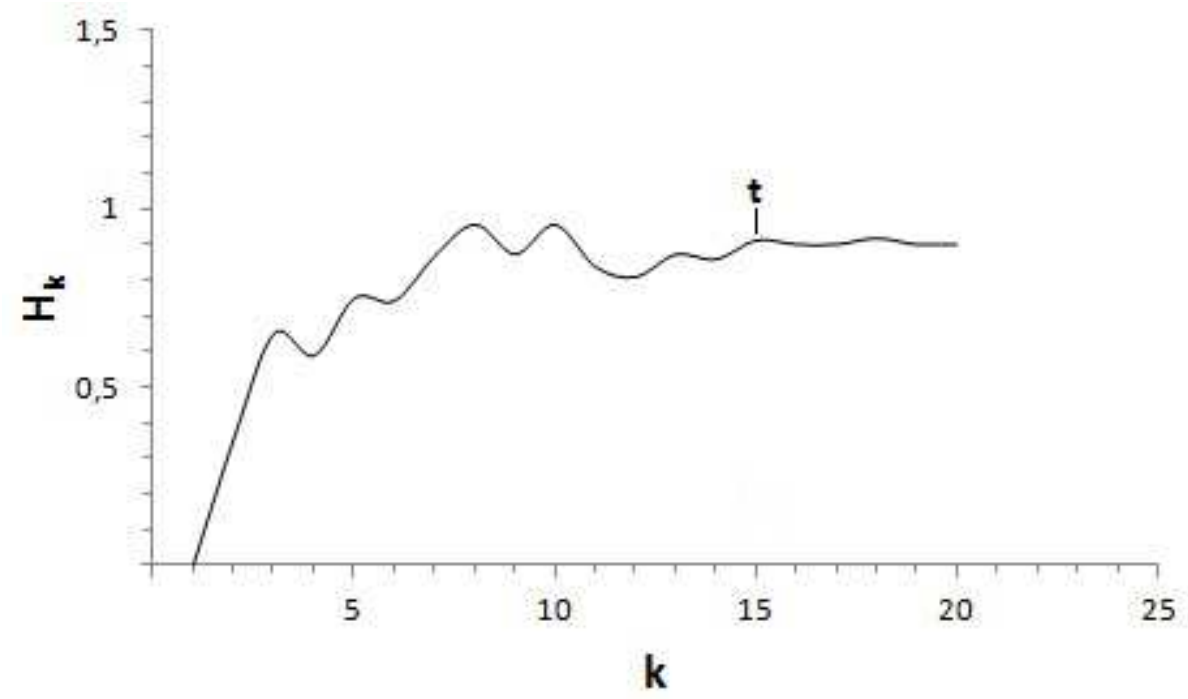

Figura 3.9. Determinación de la muestra mínima para Philodryas patagoniensis. Referencias: $\mathrm{H}_{\mathrm{k}}=$ Diversidad trófica acumulada, $\mathrm{k}=$ Número de estómagos, $\mathrm{t}=$ Tamaño de la muestra mínima. 
Tabla 3.4. Dieta de Philodryas patagoniensis. Referencias: $\mathrm{N}=$ Número; $\% \mathrm{~N}=$ Porcentaje del número; $\mathrm{V}(\mathrm{ml})=$ Volumen (mililitros); $\% \mathrm{~V}=$ Porcentaje del volumen; $\mathrm{FO}=$ Frecuencia de ocurrencia; \%FO= Porcentaje de la frecuencia de ocurrencia; IPS= Índice de importancia.

\begin{tabular}{|c|c|c|c|c|c|c|c|}
\hline $\begin{array}{l}\text { ITEMS PRESA } \\
\end{array}$ & $\mathbf{N}$ & $\% \mathbf{N}$ & $\mathrm{V}(\mathrm{ml})$ & $\% \mathrm{~V}$ & FO & $\%$ FO & IPS \\
\hline \multicolumn{8}{|l|}{ INVERTEBRATA } \\
\hline \multicolumn{8}{|l|}{ Chelicerata } \\
\hline \multicolumn{8}{|l|}{ Araneae } \\
\hline \multicolumn{8}{|l|}{ Lycosidae } \\
\hline Lycosa sp. & 37 & 77,08 & 36,8 & 19,61 & 11 & 50 & 48,9 \\
\hline \multicolumn{8}{|l|}{ Hexapoda } \\
\hline Orthoptera & 1 & 2,08 & 0,9 & 0,48 & 1 & 4,55 & 2,37 \\
\hline \multicolumn{8}{|l|}{ VERTEBRATA } \\
\hline \multicolumn{8}{|l|}{ Mammalia } \\
\hline \multicolumn{8}{|l|}{ Rodentia } \\
\hline \multicolumn{8}{|l|}{ Cricetidae } \\
\hline Calomys sp. & 6 & 12,5 & 90 & 47,95 & 6 & 27,27 & 29,24 \\
\hline Necromys benefactus & 4 & 8,33 & 60 & 31,97 & 4 & 18,18 & 19,49 \\
\hline TOTAL & 48 & & 187,7 & & 22 & & \\
\hline
\end{tabular}

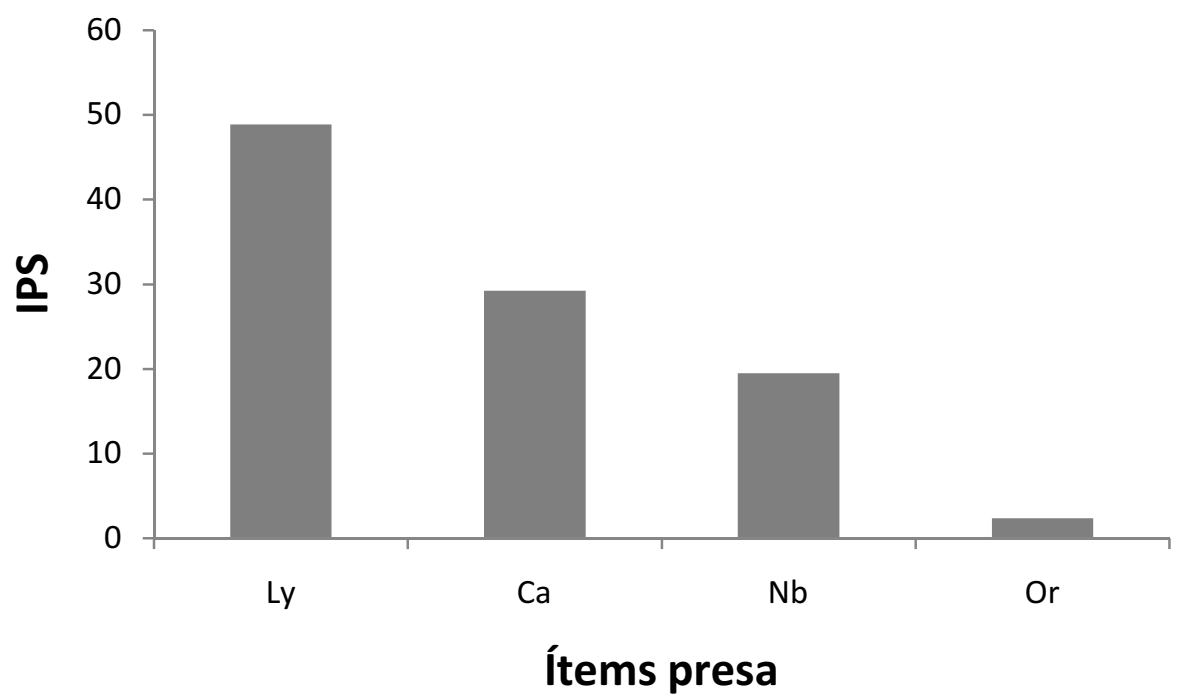

Figura 3.10. Índice de importancia de las categorías de presas consumidas (IPS) por Philodryas patagoniensis. Referencias: $\mathrm{Ly}=$ Lycosa sp.; $\mathrm{Ca}=$ Calomys sp.; $\mathrm{Nb}=$ Necromys benefactus; Or= Orthoptera. 


\section{Bothrops alternatus}

Fueron examinados 58 ejemplares de los cuales el 37,9 \% (n=22) presentó contenido identificable en el tubo digestivo. El tamaño de la muestra mínima fue de 15 ejemplares (Figura 3.11). La dieta de la especie incluyó siete ítems presa de roedores (Tabla 3.5, Figura 3.12). En orden de importancia numérica se destacan: Necromys benefactus (36,36\%), Oligoryzomys flavescens $(18,18 \%)$ y Mus musculus $(18,18 \%)$. Teniendo en cuenta el volumen, los ítems presa más importantes fueron: Necromys benefactus (40,51\%), Oligoryzomys flavescens (18,23\%) y Mus musculus (17,22\%). Los ítems presa más frecuentes fueron: Necromys benefactus $(36,36 \%)$, Oligoryzomys flavescens $(18,18 \%)$ y Mus musculus $(18,18 \%)$. Considerando los valores del IPS los ítems presa más importantes fueron: Necromys benefactus $(37,74)$, Oligoryzomys flavescens $(18,2)$ y Mus musculus $(17,86)$. Fueron encontrados además, Vertebrados indeterminados (pelos) en nueve estómagos, Invertebrados indeterminados en dos estómagos y restos vegetales en siete estómagos. La diversidad de presas fue de 1,98 y el índice de equidad fue de 0,88 . La amplitud del nicho para la categoría presas fue de 4,57 y para el volumen de las mismas fue de 4,12 . La LT promedio fue de $774,04 \mathrm{~mm} \pm 175,89$ y el $\mathrm{AB}$ promedio fue de $25,24 \mathrm{~mm} \pm 6,66$. El peso promedio de los ejemplares fue de $259,84 \mathrm{~g} \pm 142,21$. Se halló una correlación significativa entre el volumen de las presas y la $L T$ ( $r s=0,50687 ; p=0,016062)$ y, no se halló una correlación significativa entre el volumen de las presas y el $A B$ (rs=0,36089; $p=0,098926$ ). 


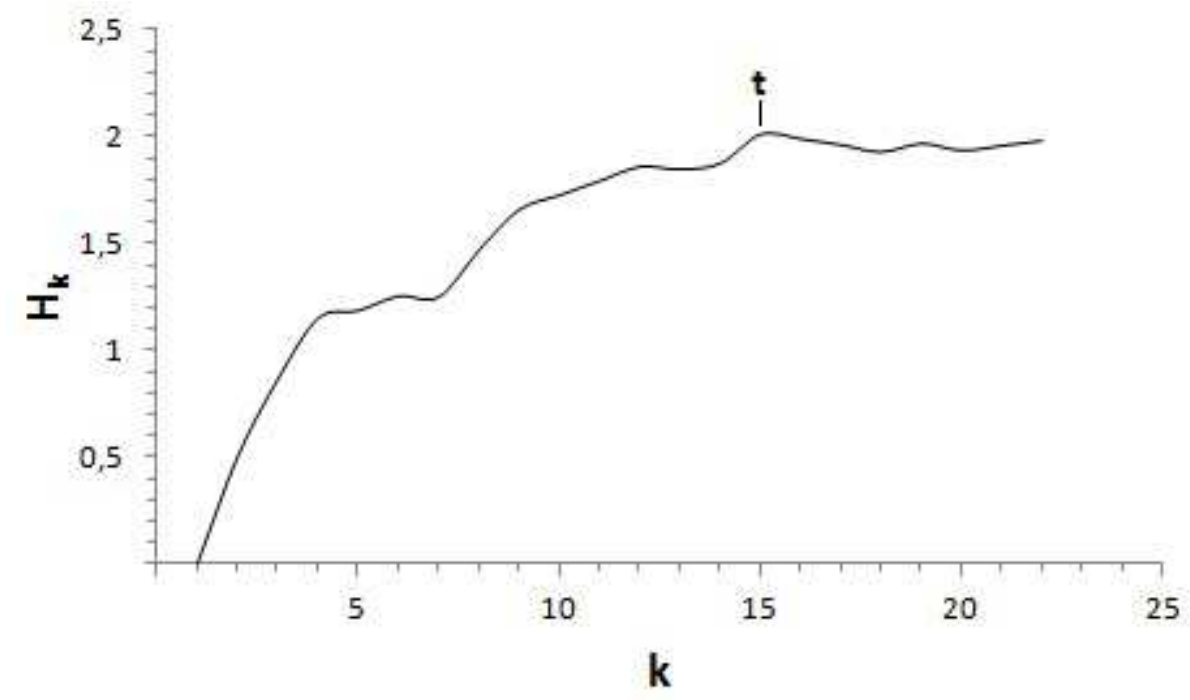

Figura 3.11. Determinación de la muestra mínima para Bothrops alternatus. Referencias: $H_{k}=$ Diversidad trófica acumulada, $\mathrm{k}=$ Numero de estómagos, $\mathrm{t}=$ Tamaño de la muestra mínima.

Tabla 3.5. Dieta de Bothrops alternatus. Referencias: $\mathrm{N}=$ Número; $\% \mathrm{~N}=$ Porcentaje del número; $\mathrm{V}(\mathrm{ml})=$ Volumen (mililitros); $\% \mathrm{~V}=$ Porcentaje del volumen; $\mathrm{FO}=$ Frecuencia de ocurrencia; $\% \mathrm{FO}=$ Porcentaje de la frecuencia de ocurrencia; IPS= Índice de importancia.

\begin{tabular}{lccccccc}
\hline \multicolumn{1}{c}{ ÍTEMS PRESA } & $\mathbf{N}$ & $\mathbf{\% N}$ & $\mathbf{V}(\mathbf{m l})$ & $\% \mathbf{V}$ & FO & $\%$ FO & IPS \\
\hline $\begin{array}{l}\text { VERTEBRATA } \\
\text { Mammalia }\end{array}$ & & & & & & & \\
Rodentia & & & & & & & \\
Cricetidae & & & & & & & \\
Akodon sp. & 2 & 9,09 & 34 & 8,61 & 2 & 9,09 & 8,93 \\
Calomys sp. & 2 & 9,09 & 27 & 6,84 & 2 & 9,09 & 8,34 \\
Necromys benefactus & 8 & 36,36 & 160 & 40,51 & 8 & 36,36 & 37,74 \\
Oligoryzomys flavescens & 4 & 18,18 & 72 & 18,23 & 4 & 18,18 & 18,2 \\
Oxymycterus rufus & 1 & 4,55 & 17 & 4,3 & 1 & 4,55 & 4,46 \\
$\begin{array}{l}\text { Phyllotis xanthopygus } \\
\text { Muridae }\end{array}$ & 1 & 4,55 & 17 & 4,3 & 1 & 4,55 & 4,46 \\
Mus musculus & & & & & & & \\
TOTAL & 4 & 18,18 & 68 & 17,22 & 4 & 18,18 & 17,86 \\
\hline
\end{tabular}




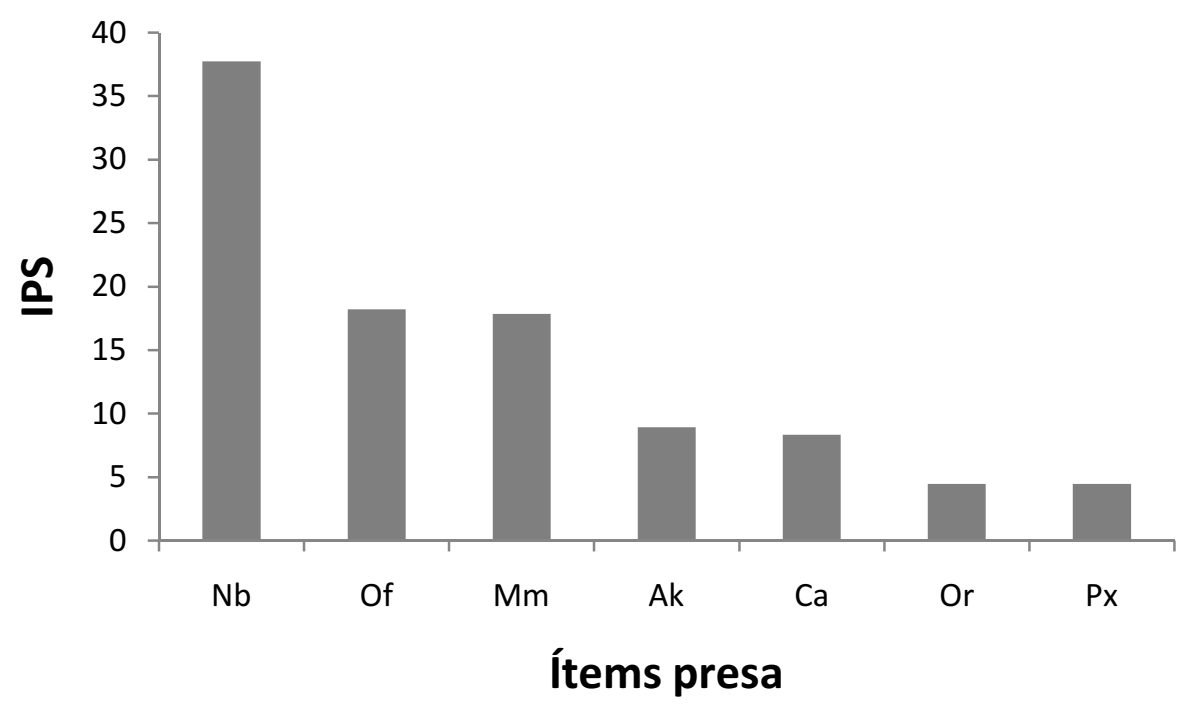

Figura 3.12. Índice de importancia de las categorías de presas consumidas (IPS) por Bothrops alternatus. Referencias: $\mathrm{Nb}=$ Necromys benefactus; $\mathrm{Of}=$ Oligoryzomys flavescens; $\mathrm{Mm}=\mathrm{Mus}$ musculus; $\mathrm{Ak}=$ Akodon sp.; $\mathrm{Ca}=$ Calomys sp.; Or= Oxymycterus rufus; $\mathrm{Px}=$ Phyllotis xanthopygus.

En el resto de las especies de la comunidad, la curva de diversidad trófica acumulada versus número de estómagos no alcanzó la estabilidad por lo que no se pudo calcular la muestra mínima necesaria para que los resultados sean representativos de lo que ocurre en la naturaleza. En la mayoría de estas especies se hallaron restos identificables solo en un estómago. En Lygophis anomalus $(\mathrm{n}=20)$ se halló una Hypsiboas pulchellus $(2,7 \mathrm{ml})$ en un estómago. En Oxyrhopus rhombifer rhombifer $(n=13)$ se halló un Ophiodes vertebralis (3 $\mathrm{ml}$ ) en un estómago. En Paraphimophis rustica $(\mathrm{n}=4)$ se hallaron restos de un ofidio indeterminado en un estómago. En Phalotris bilineatus $(\mathrm{n}=4)$ se halló una Amphisbaena kingii $(6 \mathrm{ml})$ en un estómago. En Philodryas aestiva subcarinata $(\mathrm{n}=4)$ se halló un Necromys benefactus $(13 \mathrm{ml})$ en un estómago. En Xenodon dorbignyi $(\mathrm{n}=8)$ se halló un Odontophrynus americanus $(6,6 \mathrm{ml})$ en un estómago. En Bothrops ammodytoides $(\mathrm{n}=7)$ se halló un Calomys sp. (12 ml) en un estómago. No se hallaron contenidos en el tubo digestivo de Epictia munoai $(\mathrm{n}=2)$, Philodryas agassizii $(\mathrm{n}=3)$ y Xenodon semicinctus $(\mathrm{n}=2)$. 


\section{Análisis del microhábitat de las especies}

\section{Epictia australis}

Fueron registrados en actividad 18 ejemplares $(36,7 \%$ del total). La especie utilizó tres tipos de microhábitats. En orden de importancia numérica fueron los siguientes (Figura 3.13): Bajo rocas $(88,89 \%)$, Borde de arroyos $(5,56 \%)$ y Pastizal denso (5,56\%). Los ejemplares fueron hallados a una altura promedio de 294,8 $\mathrm{m} \pm 122,1$. La diversidad de microhábitats utilizados por la especie fue de 0,46 y el índice de equidad fue de 0,39. La amplitud del nicho en su dimensión espacial fue de 1,26.

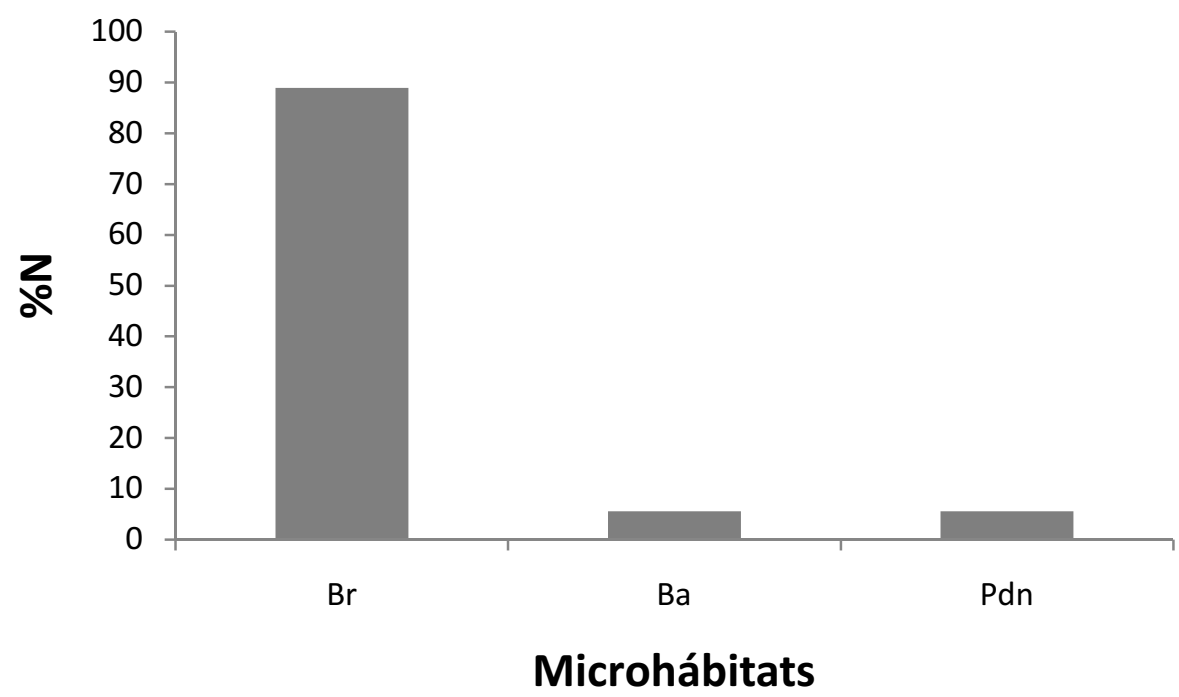

Figura 3.13. Microhábitats utilizados por Epictia australis. Referencias: $\mathrm{Br}=\mathrm{Bajo}$ rocas; $\mathrm{Ba}=$ Borde de arroyos; Pdn= Pastizal denso.

Erythrolamprus poecilogyrus sublineatus

Fueron registrados en actividad 43 ejemplares (50\% del total). La especie utilizó cinco tipos de microhábitats. En orden de importancia numérica fueron los siguientes (Figura 3.14): Arroyos (46,51\%), Pastizal descubierto $(18,6 \%)$, Bajo rocas $(16,28 \%)$, Borde de arroyos $(11,63 \%)$ y Pastizal denso $(6,98 \%)$. Los ejemplares fueron hallados a una altura promedio de 412,2 m \pm 
216,8. La diversidad de microhábitats utilizados por la especie fue de 1,79 y el índice de equidad fue de 0,87 . La amplitud del nicho en su dimensión espacial fue de 3,38 .

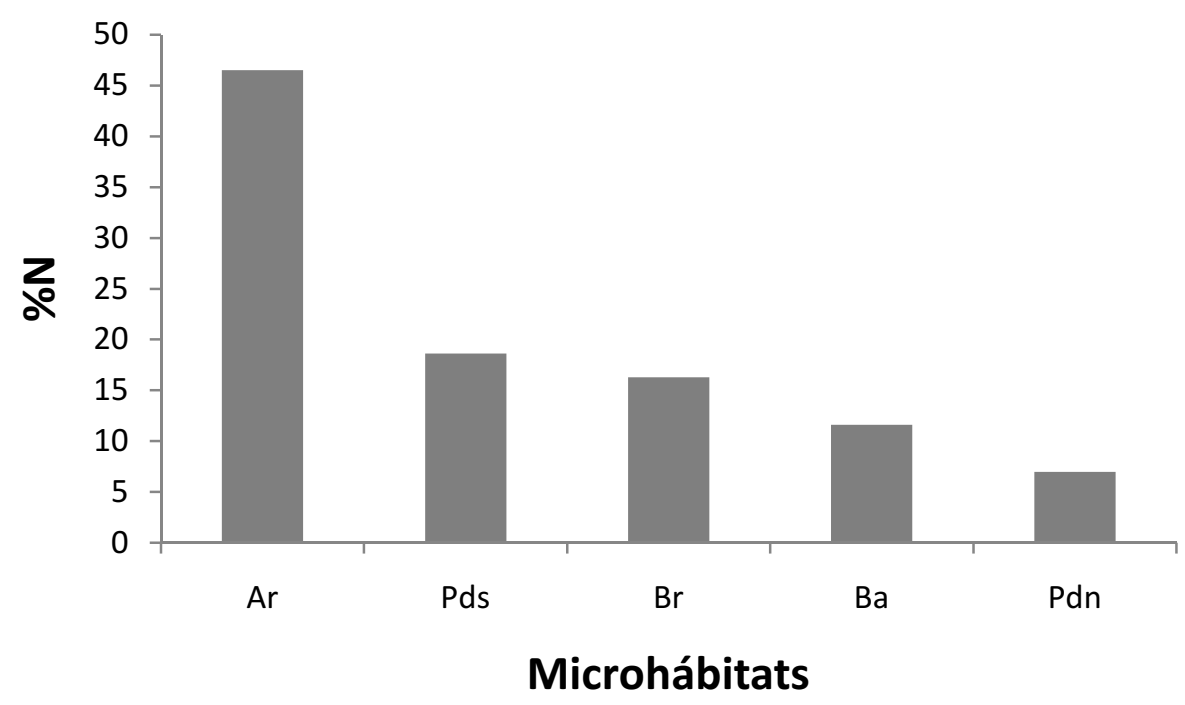

Figura 3.14. Microhábitats utilizados por Erythrolamprus poecilogyrus sublineatus. Referencias: $\mathrm{Ar}=$ Arroyos; $\mathrm{Pds}=$ Pastizal descubierto; $\mathrm{Br}=$ Bajo rocas; $\mathrm{Ba}=$ Borde de arroyos; $\mathrm{Pdn}=$ Pastizal denso.

\section{Lygophis elegantissimus}

Fueron registrados en actividad 29 ejemplares $(41,43 \%$ del total). La especie utilizó siete tipos de microhábitats. En orden de importancia numérica fueron los siguientes (Figura 3.15): Arroyos (41,38\%), Borde de arroyos $(20,69 \%)$, Pastizal descubierto $(20,69 \%)$, Bajo rocas $(6,9 \%)$, Pastizal denso $(3,45 \%)$, Pastizal con arbustos $(3,45 \%)$ y Sobre rocas $(3,45 \%)$. Los ejemplares fueron hallados a una altura promedio de 384,7 $\mathrm{m} \pm 166,7$. La diversidad de microhábitats utilizados por la especie fue de 1,86 y el índice de equidad fue de 0,8. La amplitud del nicho en su dimensión espacial fue de 3,77. 


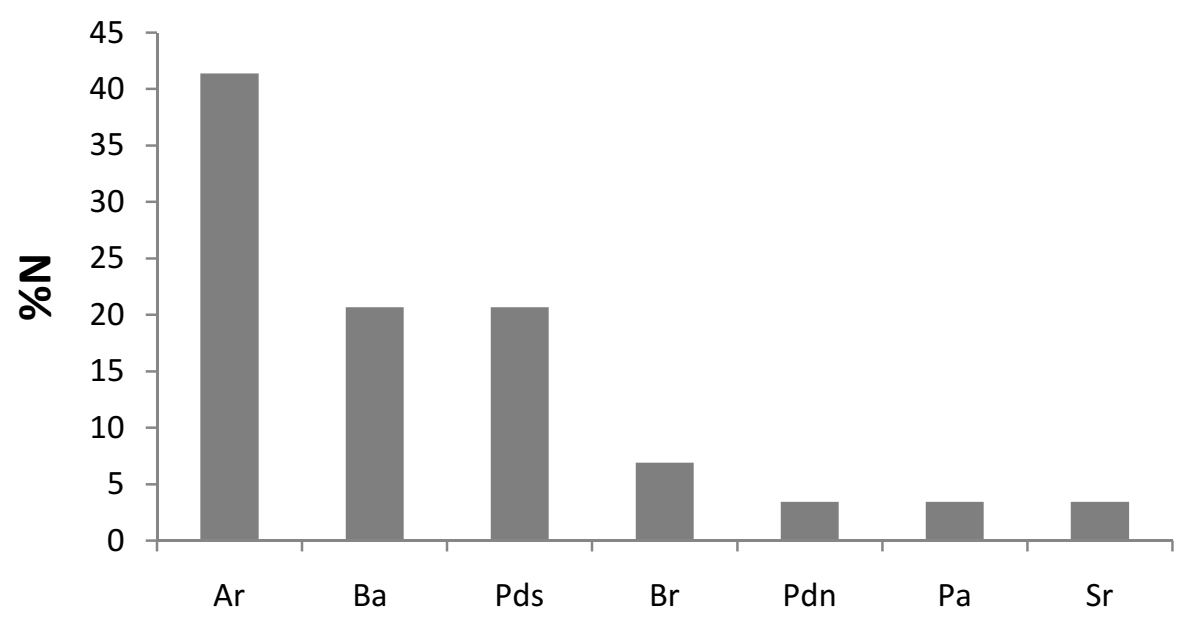

Microhábitats

Figura 3.15. Microhábitats utilizados por Lygophis elegantissimus. Referencias: Ar= Arroyos; $\mathrm{Ba}=$ Borde de arroyos; $\mathrm{Pds}=$ Pastizal descubierto; $\mathrm{Br}=$ Bajo rocas; $\mathrm{Pdn}=$ Pastizal denso; $\mathrm{Pa}=$ Pastizal con arbustos; $\mathrm{Sr}=$ Sobre rocas.

Philodryas patagoniensis

Fueron registrados en actividad 16 ejemplares (37,2\% del total). La especie utilizó cuatro tipos de microhábitats. En orden de importancia numérica fueron los siguientes (Figura 3.16): Pastizal descubierto $(56,25 \%)$, Pastizal denso $(31,25 \%)$, Pastizal con arbustos $(6,25 \%)$ y Sobre rocas $(6,25 \%)$. Los ejemplares fueron hallados a una altura promedio de 356,7 $\mathrm{m} \pm 126,6$. La diversidad de microhábitats utilizados por la especie fue de 1,18 y el índice de equidad fue de 0,75. La amplitud del nicho en su dimensión espacial fue de 2,37 . 


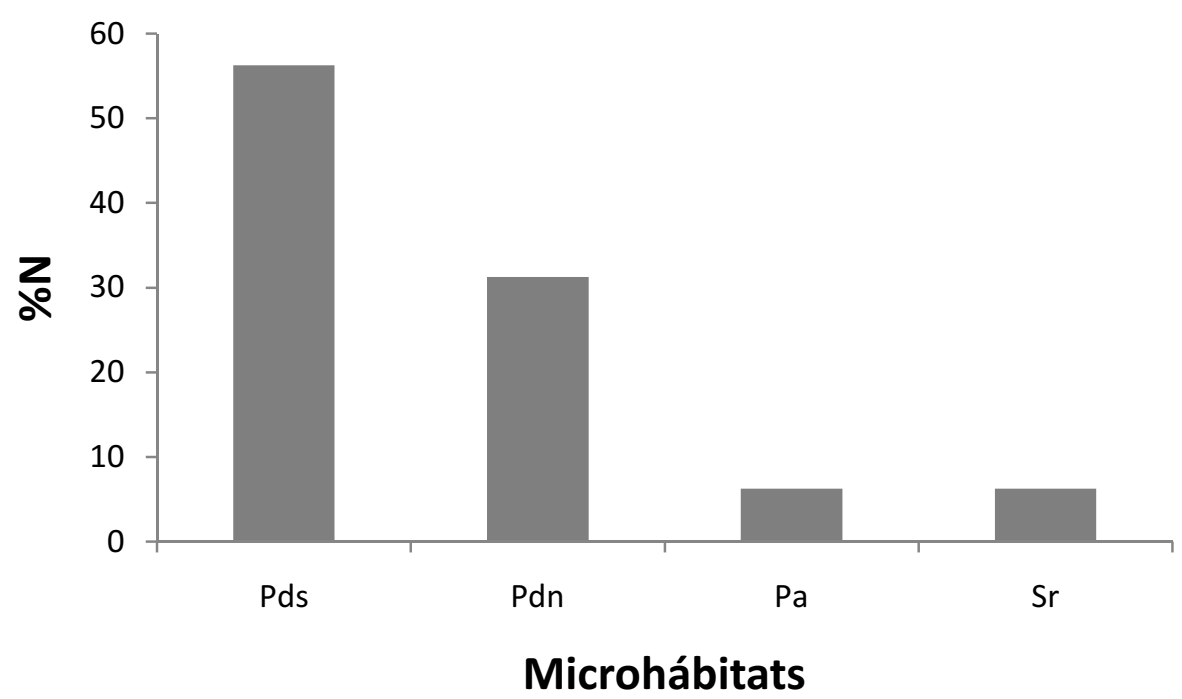

Figura 3.16. Microhábitats utilizados por Philodryas patagoniensis. Referencias: $P d s=P a s t i z a l$ descubierto; $\mathrm{Pdn}=$ Pastizal denso; $\mathrm{Pa}=$ Pastizal con arbustos; $\mathrm{Sr}=$ Sobre rocas.

Bothrops alternatus

Fueron registrados en actividad 20 ejemplares (34,5\% del total). La especie utilizó seis tipos de microhábitats. En orden de importancia numérica fueron los siguientes (Figura 3.17): Pastizal denso (40\%), Pastizal descubierto $(35 \%)$, Arroyos (10\%), Borde de arroyos (5\%), Pastizal con arbustos $(5 \%)$ y Sobre rocas $(5 \%)$. Los ejemplares fueron hallados a una altura promedio de $416,7 \mathrm{~m} \pm 149,6$. La diversidad de microhábitats utilizados por la especie fue de 1,62 y el índice de equidad fue de 0,79. La amplitud del nicho en su dimensión espacial fue de 3,33 . 


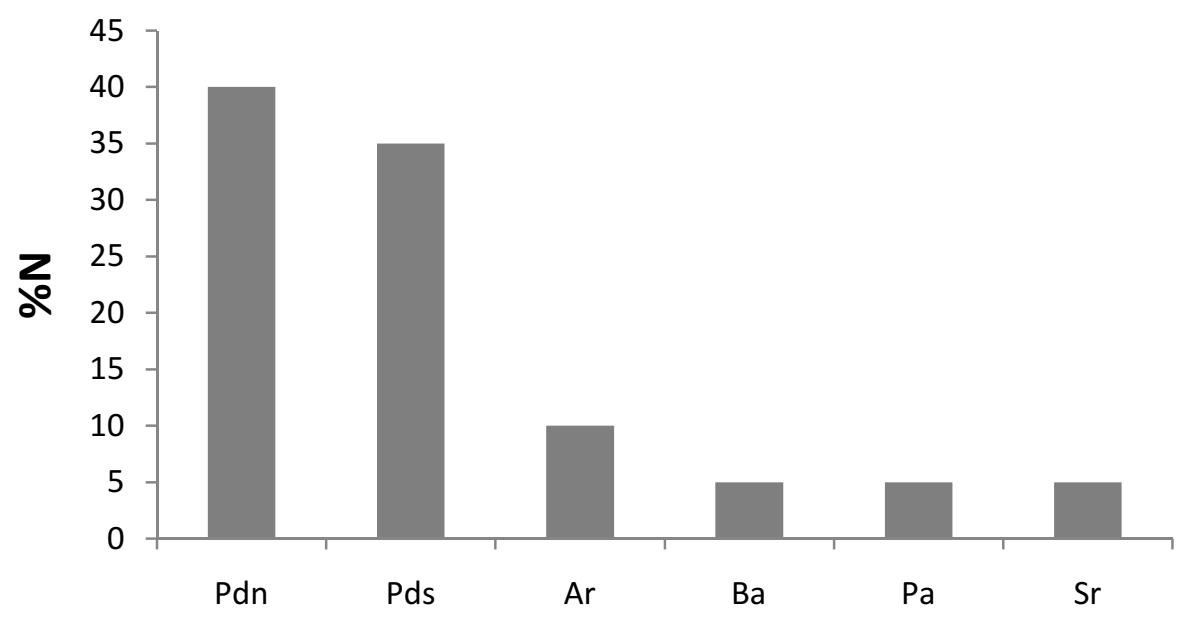

Microhábitats

Figura 3.17. Microhábitats utilizados por Bothrops alternatus. Referencias: $P d n=P a s t i z a l$ denso; $\mathrm{Pds}=$ Pastizal descubierto; $\mathrm{Ar}=$ Arroyos; $\mathrm{Ba}=$ Borde de arroyos; $\mathrm{Pa}=$ Pastizal con arbustos; $\mathrm{Sr}=$ Sobre rocas.

En el resto de las especies menos de 10 ejemplares fueron hallados en actividad en el campo por lo que no son tratados en detalle. A continuación se presentan algunos resultados. No se hallaron durante las tareas de campo Philodryas aestiva subcarinata $(\mathrm{n}=4)$ y $P$. agassizii $(\mathrm{n}=4)$. Epictia munoai $(\mathrm{n}=3)$ solo se halló en actividad un ejemplar bajo rocas sueltas sobre tierra. Lygophis anomalus $(n=20)$ se hallaron en actividad seis ejemplares ( $30 \%$ del total) en Arroyos (50\%), Borde de arroyos (33,3\%) y Pastizal descubierto (16,7\%). Oxyrhopus rhombifer rhombifer $(n=13)$ se hallaron en actividad tres ejemplares (23,08\% del total) en el Pastizal descubierto $(66,7 \%)$ y Bajo rocas $(33,3 \%)$. Paraphimophis rustica $(n=4)$ se hallaron en actividad dos ejemplares en el Pastizal descubierto. Phalotris bilineatus $(n=4)$ se hallaron en actividad dos ejemplares, Bajo rocas $(50 \%)$ y en el Pastizal descubierto (50\%). Xenodon dorbignyi $(n=8)$ se hallaron en actividad seis ejemplares $(75 \%$ del total) en el Pastizal descubierto $(83,3 \%)$ y Bajo rocas $(16,7 \%)$. Xenodon semicinctus $(\mathrm{n}=2)$ solo se halló un ejemplar en actividad en el Pastizal descubierto. Bothrops ammodytoides $(\mathrm{n}=7)$ solo se halló un ejemplar en actividad en el Pastizal descubierto. 


\section{Relaciones tróficas y espaciales}

Se analizaron las relaciones del solapamiento de nicho trófico (proporción y volumen de las presas) y espacial (uso del microhábitat) (ver Tabla 3.6). Se observó que respecto a la proporción de las presas la recombinación al azar de los datos produjo un bajo solapamiento significativo en ocho de los 10 pares de especies comparadas, en donde la media observada fue menor o igual a la esperada. Considerando el volumen de las presas la recombinación al azar de los datos produjo un bajo solapamiento significativo en seis de los 10 pares de especies comparadas, en donde la media observada fue menor o igual a la esperada. Respecto al uso del microhábitat, la recombinación al azar de los datos produjo un elevado solapamiento significativo en dos de los 10 pares de especies comparadas, en donde la media observada fue mayor o igual a la esperada.

En la Tabla 3.7 se observan las relaciones establecidas por el índice de MacArthur y Levins (1967) para los pares de especies comparadas. Considerando los valores de solapamiento elevados y significativos, se observa una incidencia de $L$. elegantissimus sobre E. p. sublineatus y también de $B$. alernatus sobre $P$. patagoniensis en el uso del microhábitat (Tabla 3.7). 
Tabla 3.6. Relaciones interespecíficas entre Epictia australis (Ea), Erythrolamprus poecilogyrus sublineatus (Ep), Lygophis elegantissimus (Le), Philodryas patagoniensis (Pp) y Bothrops alternatus $(\mathrm{Ba})$ : Valores de solapamiento de Pianka $\left(O_{J K}\right)$, significancia del solapamiento $\left(P_{o} \geq e ; P_{o} \leq e\right)$, promedios observados $\left(X_{o b s}\right)$ y esperados $\left(X_{\text {esp }}\right)$ de la proporción de ítems presa consumidos, volumen de las presas y microhábitats utilizados. En rojo se indican los valores de significancia menores a 0,05.

\begin{tabular}{|c|c|c|c|c|c|c|c|c|c|c|c|c|c|c|c|}
\hline \multirow[b]{2}{*}{ Especies } & \multicolumn{5}{|c|}{ Proporción de las presas } & \multicolumn{5}{|c|}{ Volumen de las presas } & \multicolumn{5}{|c|}{ Microhábitat } \\
\hline & $O_{J K}$ & $P_{0 \geq e}$ & $P_{o \leq e}$ & $X_{o b s}$ & $X_{e s p}$ & $O_{J K}$ & $P_{0 \geq e}$ & $P_{0 \leq e}$ & $X_{o b s}$ & $X_{e s p}$ & $O_{J K}$ & $P_{o \geq e}$ & $P_{0 \leq e}$ & $X_{o b s}$ & $X_{e s p}$ \\
\hline Ea-Ep & 0,00 & 1,000 & 0,006 & 0,00 & 0,16 & 0,00 & 1,000 & 0,009 & 0,00 & 0,28 & 0,31 & 0,572 & 0,428 & 0,31 & 0,41 \\
\hline Ea-Le & 0,00 & 1,000 & 0,019 & 0,00 & 0,23 & 0,00 & 1,000 & 0,021 & 0,00 & 0,36 & 0,16 & 0,564 & 0,436 & 0,16 & 0,32 \\
\hline Ea-Pp & 0,00 & 1,000 & 0,028 & 0,00 & 0,22 & 0,00 & 1,000 & 0,023 & 0,00 & 0,36 & 0,02 & 0,912 & 0,088 & 0,02 & 0,29 \\
\hline Ea-Ba & 0,00 & 1,000 & 0,006 & 0,00 & 0,24 & 0,00 & 1,000 & 0,010 & 0,00 & 0,46 & 0,05 & 0,913 & 0,087 & 0,05 & 0,29 \\
\hline Ep-Le & 0,24 & 0,403 & 0,597 & 0,24 & 0,27 & 0,17 & 0,725 & 0,275 & 0,17 & 0,33 & 0,95 & 0,014 & 0,986 & 0,95 & 0,51 \\
\hline Ep-Pp & 0,001 & 0,998 & 0,002 & 0,001 & 0,18 & 0,51 & 0,177 & 0,823 & 0,51 & 0,25 & 0,35 & 0,517 & 0,483 & 0,35 & 0,41 \\
\hline Ep-Ba & 0,009 & 0,995 & 0,005 & 0,009 & 0,25 & 0,32 & 0,568 & 0,432 & 0,32 & 0,35 & 0,48 & 0,406 & 0,594 & 0,48 & 0,47 \\
\hline Le-Pp & 0,00 & 1,000 & 0,007 & 0,00 & 0,22 & 0,00 & 1,000 & 0,005 & 0,00 & 0,28 & 0,39 & 0,555 & 0,445 & 0,39 & 0,43 \\
\hline Le-Ba & 0,00 & 1,000 & 0,001 & 0,00 & 0,28 & 0,00 & 1,000 & 0,003 & 0,00 & 0,36 & 0,50 & 0,474 & 0,526 & 0,50 & 0,51 \\
\hline $\mathrm{Pp}-\mathrm{Ba}$ & 0,11 & 0,792 & 0,208 & 0,11 & 0,28 & 0,52 & 0,472 & 0,528 & 0,52 & 0,44 & 0,92 & 0,048 & 0,952 & 0,92 & 0,46 \\
\hline
\end{tabular}


Tabla 3.7. Valores de solapamiento de MacArthur y Levins (1967) para la proporción de las presas, volumen de las presas y microhábitats entre Epictia australis (Ea), Erythrolamprus poecilogyrus sublineatus (Ep), Lygophis elegantissimus (Le), Philodryas patagoniensis (Pp) y Bothrops alternatus (Ba). En rojo se indican los pares de especies que presentaron valores significativos en el análisis anterior.

\begin{tabular}{cccccc}
\hline \multicolumn{2}{c}{ Proporción de las presas } & \multicolumn{2}{c}{ Volumen de las presas } & \multicolumn{2}{c}{ Microhábitat } \\
\hline $\mathrm{Ea} / \mathrm{Ep}$ & $\mathrm{Ep} / \mathrm{Ea}$ & $\mathrm{Ea} / \mathrm{Ep}$ & $\mathrm{Ep} / \mathrm{Ea}$ & $\mathrm{Ea} / \mathrm{Ep}$ & $\mathrm{Ep} / \mathrm{Ea}$ \\
0 & 0 & 0 & 0 & 0,195 & 0,524 \\
$\mathrm{Ea} / \mathrm{Le}$ & $\mathrm{Le} / \mathrm{Ea}$ & $\mathrm{Ea} / \mathrm{Le}$ & $\mathrm{Le} / \mathrm{Ea}$ & $\mathrm{Ea} / \mathrm{Le}$ & $\mathrm{Le} / \mathrm{Ea}$ \\
0 & 0 & 0 & 0 & 0,094 & 0,282 \\
$\mathrm{Ea} / \mathrm{Pp}$ & $\mathrm{Pp} / \mathrm{Ea}$ & $\mathrm{Ea} / \mathrm{Pp}$ & $\mathrm{Pp} / \mathrm{Ea}$ & $\mathrm{Ea} / \mathrm{Pp}$ & $\mathrm{Pp} / \mathrm{Ea}$ \\
0 & 0 & 0 & 0 & 0,022 & 0,041 \\
$\mathrm{Ea} / \mathrm{Ba}$ & $\mathrm{Ba} / \mathrm{Ea}$ & $\mathrm{Ea} / \mathrm{Ba}$ & $\mathrm{Ba} / \mathrm{Ea}$ & $\mathrm{Ea} / \mathrm{Ba}$ & $\mathrm{Ba} / \mathrm{Ea}$ \\
0 & 0 & 0 & 0 & 0,031 & 0,083 \\
$\mathrm{Ep} / \mathrm{Le}$ & $\mathrm{Le} / \mathrm{Ep}$ & $\mathrm{Ep} / \mathrm{Le}$ & $\mathrm{Le} / \mathrm{Ep}$ & $\mathrm{Ep} / \mathrm{Le}$ & $\mathrm{Le} / \mathrm{Ep}$ \\
0,267 & 0,230 & 0,108 & 0,268 & 0,908 & 1,013 \\
$\mathrm{Ep} / \mathrm{Pp}$ & $\mathrm{Pp} / \mathrm{Ep}$ & $\mathrm{Ep} / \mathrm{Pp}$ & $\mathrm{Pp} / \mathrm{Ep}$ & $\mathrm{Ep} / \mathrm{Pp}$ & $\mathrm{Pp} / \mathrm{Ep}$ \\
0,002 & 0,001 & 0,625 & 0,432 & 0,427 & 0,300 \\
$\mathrm{Ep} / \mathrm{Ba}$ & $\mathrm{Ba} / \mathrm{Ep}$ & $\mathrm{Ep} / \mathrm{Ba}$ & $\mathrm{Ba} / \mathrm{Ep}$ & $\mathrm{Ep} / \mathrm{Ba}$ & $\mathrm{Ba} / \mathrm{Ep}$ \\
0,008 & 0,011 & 0,833 & 0,126 & 0,491 & 0,484 \\
$\mathrm{Le} / \mathrm{Pp}$ & $\mathrm{Pp} / \mathrm{Le}$ & $\mathrm{Le} / \mathrm{Pp}$ & $\mathrm{Pp} / \mathrm{Le}$ & $\mathrm{Le} / \mathrm{Pp}$ & $\mathrm{Pp} / \mathrm{Le}$ \\
0 & 0 & 0 & 0 & 0,496 & 0,312 \\
$\mathrm{Le} / \mathrm{Ba}$ & $\mathrm{Ba} / \mathrm{Le}$ & $\mathrm{Le} / \mathrm{Ba}$ & $\mathrm{Ba} / \mathrm{Le}$ & $\mathrm{Le} / \mathrm{Ba}$ & $\mathrm{Ba} / \mathrm{Le}$ \\
0 & 0 & 0 & 0 & 0,533 & 0,471 \\
$\mathrm{Pp} / \mathrm{Ba}$ & $\mathrm{Ba} / \mathrm{Pp}$ & $\mathrm{Pp} / \mathrm{Ba}$ & $\mathrm{Ba} / \mathrm{Pp}$ & $\mathrm{Pp} / \mathrm{Ba}$ & $\mathrm{Ba} / \mathrm{Pp}$ \\
0,068 & 0,190 & 1,112 & 0,244 & $\mathbf{0 , 7 7 8}$ & 1,094 \\
\hline
\end{tabular}

\section{DISCUSIÓN}

\section{Composición de la dieta}

El $36,7 \%$ de los ejemplares examinados de Epictia australis presentó contenido identificable en el tubo digestivo. La especie consumió exclusivamente hormigas del género Pheidole. Se registraron tres ítems presa. Según los valores del IPS los huevos/larvas son los ítems presa más importantes en la dieta de $E$. australis, quedando muy relegados en importancia los adultos y por último las pupas. En este estudio se presenta la primera información no-anecdótica sobre la dieta de la especie. La especialización mirmecófaga, además, ha sido mencionada en otras especies de Leptotyphlopidae. Por ejemplo, Vaz-Ferreira et al. (1970) obtienen contenido 
gástrico de Epictia munoai constituido exclusivamente por larvas de hormigas cortadoras del género Acromyrmex. Sin embargo, posteriormente Carreira (2002) en base a una completa revisión bibliográfica y de ejemplares depositados en colecciones, indica que E. munoai se alimenta de huevos, larvas y adultos de termitas, y larvas y probablemente adultos de hormigas. Webb et al. (2000) notaron en Leptotyphlops scutifrons que, a diferencia de las menciones previas sobre hormigas y termitas en su dieta, la especie se alimentó exclusivamente de huevos, larvas, pupas y adultos de hormigas. Al carecer de menciones bibliográficas sobre la dieta de $E$. australis no queda claro si la especie se alimenta exclusivamente de hormigas en toda su distribución. El hecho de que en el área de estudio las termitas son abundantes (obs. pers.) y que los contenidos gástricos examinados fueron exclusivamente hormigas indicaría una preferencia de la especie por este ítem.

El $58,1 \%$ de los ejemplares examinados de Erythrolamprus poecilogyrus sublineatus presentó contenido identificable en el tubo digestivo. La especie consumió una gran variedad de presas. Se registraron nueve categorías de presas. Según los valores del IPS, larvas de anuros Rhinella arenarum, peces Jenynsia multidentata y adultos de anuros Hypsiboas pulchellus son los ítems presa más importantes en la dieta de E. p. sublineatus. La especie es considerada por muchos autores como generalista (por ej. Serié 1919, Gallardo 1977, Lema et al. 1983, Michaud y Dixon 1989, Cei 1986, 1993). No obstante, otros autores mencionan que E. poecilogyrus se alimenta exclusivamente de anfibios (por ej. Vitt 1983, Vitt y Vangilder 1983, Dixon y Markezich 1992, Pinto y Fernandes 2004) o que los anfibios son predominantes en la dieta de la especie (Carreira 2002, Prieto et al. 2012). Los resultados obtenidos en este estudio coinciden con estos últimos autores.

El $55,7 \%$ de los ejemplares examinados de Lygophis elegantissimus presentó contenido identificable en el tubo digestivo. La especie consumió exclusivamente larvas, juveniles y adultos de anfibios anuros. Se registraron cinco categorías de presas. Según los valores del IPS, adultos y larvas de Hypsiboas pulchellus son los ítems presa más importantes. En este estudio se presenta la primera información detallada sobre la dieta de L. elegantissimus. Miranda et al. (1983) y Williams y Scrocchi (1994) mencionan que esta especie 
se alimenta de anuros y saurios. Se coincide con estos autores en la alimentación en base de anuros, aunque no fueron registrados saurios en los contenidos gástricos examinados. La importancia de los anuros en la dieta ha sido reportada en otras especies del género (por ej. Vitt 1983, Vitt y Vangilder 1983, Michaud y Dixon 1989, Carreira 2002, Panzera y Maneyro 2014). Resulta interesante el hecho de que la anurofagia ha sido considerada como un rasgo conservativo entre los xenodontinos (ver Cadle y Greene 1993). Los resultados aquí obtenidos corroboran estas observaciones para L. elegantissimus.

Es importante destacar la presencia de Melanophryniscus montevidensis en la dieta de E. p. sublineatus y L. elegantissimus. Los anuros del género Melanophryniscus presentan diferentes estrategias para evitar la depredación, tales como defensa química (alcaloides en la piel), coloración aposemática y comportamiento unkenreflex (ver Daly et al. 2008). Aquí se aporta información inédita a los escasos registros publicados sobre depredación del género Melanophryniscus por serpientes (M. moreirae por Thamnodynastes strigatus en Brasil, Winkler et al. 2011; M. montevidensis y M. atroluteus por Xenodon dorbignyi en Uruguay, Orejas-Miranda 1966). De igual forma, fueron registrados en los tubos digestivos examinados de $L$. elegantissimus anuros adultos del género Rhinella, que también producen secreciones toxicas (ver Mebs 2002). A diferencia de lo que sucede con el género Melanophryniscus, los bufónidos del género Rhinella han sido reportados como presas frecuentes de varias especies de serpientes (por ej. Erythrolamprus miliaris, Michaud y Dixon 1989; Xenodon dorbignyi, Oliveira et al. 2001; Erythrolamprus poecilogyrus poecilogyrus, Pinto y Fernandes 2004; Erythrolamprus reginae semilineatus, Albarelli y Santos-Costa 2010; Erythrolamprus poecilogyrus, Prieto et al. 2012; Lygophis anomalus, Panzera y Maneyro 2014).

El $46,5 \%$ de los ejemplares examinados de Philodryas patagoniensis presentó contenido identificable en el tubo digestivo. La especie consumió poca variedad de presas. Se registraron cuatro categorías. Según los valores del IPS, las arañas Lycosa sp. y los roedores Calomys sp. y Necromys benefactus son los ítems presa más importantes en la dieta de $P$. patagoniensis. Si consideramos solo el volumen de las presas, estos valores se invierten y los roedores presentan mayor importancia. Según varios autores, $P$. patagoniensis 
se alimenta de una gran variedad de presas y por lo tanto puede considerarse como un depredador generalista (por ej. Gallardo 1977, Cei 1986, 1993, Gonzaga et al. 1997, Carreira 2002, López 2003, Hartmann y Marques 2005, López y Giraudo 2008). Como fue notado previamente por López y Giraudo (2008), la dieta de Philodryas patagoniensis varía geográficamente y está relacionada con la disponibilidad de las presas. Estos autores indican que la población del Noreste de la Argentina se alimenta principalmente de reptiles. Mientras que, Carreira (2002) y Hartmann y Marques (2005) hallaron que las poblaciones de Uruguay y el Sur de Brasil, respectivamente, se alimentan mayormente de anfibios. Los resultados aquí obtenidos indican que la población del área de estudio se alimenta principalmente de arañas y roedores. Solo Carreira (2002) menciona invertebrados en la dieta de $P$. patagoniensis (arañas Lycosa sp. y hormigas Ectatoma sp.). López y Giraudo (2008) consideran los invertebrados como presas secundarias en la dieta de $P$. patagoniensis, debido a su pequeño tamaño y que supuestamente fueron ingeridos primero por lagartijas o anfibios. Los resultados obtenidos en este estudio apoyan las observaciones realizadas por Carreira (2002) sobre la presencia de invertebrados en la dieta de la especie, ya que los artrópodos hallados en este trabajo (arañas y ortópteros) presentaron gran tamaño (mayores a $1 \mathrm{ml}$ ) y no fueron registrados junto a otros restos (Figura 3.1B). Sin embargo, las hormigas (Vol. 0,01 ml) fueron consideradas como presas secundarias siguiendo el criterio de López y Giraudo (2008). Resulta interesante que, las arañas del género Lycosa también fueron mencionadas como presas primarias de $P$. agassizii (ver Viñas 1985, Carreira 2002, Marques et al. 2006). Estas especies están relacionadas filogenéticamente y forman un clado bien soportado (ver Zaher et al. 2009). Por lo tanto, la alimentación de invertebrados en este caso podría tener una raíz filogenética.

El 37,9\% de los ejemplares de Bothrops alternatus presentó contenido identificable en el tubo digestivo. La especie consumió exclusivamente roedores. Se registraron siete categorías de presas. Según los valores del IPS, Necromys benefactus, Oligoryzomys flavescens y Mus musculus son los ítems presa más importantes en la dieta de la especie. Como fue indicado previamente, $B$. alternatus se alimenta exclusivamente de mamíferos, lo que 
indicaría una especialización en la dieta (Cei 1986, 1993, Martins et al. 2002, Giraudo et al. 2008). Según Martins et al. (2002) esta especialización podría representar una sinapomorfía del clado de $B$. alternatus. El gran tamaño de $B$. alternatus y la elevada toxicidad para los mamíferos del veneno de los juveniles son factores que favorecen dicha especialización (ver Giraudo et al. 2008). Los resultados obtenidos en este estudio confirman las menciones previas sobre la dieta de la especie.

\section{Estrategias de forrajeo}

En el análisis de la dieta de Epictia australis fueron hallados exclusivamente formícidos, donde los huevos y larvas de éstos presentaron elevada proporción numérica $(86,67 \%)$, mientras que los índices de diversidad de presas y de amplitud de nicho trófico (número y volumen) fueron muy bajos (Tabla 3.8). Estas características sugieren una alimentación de tipo especialista. Una dieta de tipo especialista, está relacionada con una estrategia de forrajeo de búsqueda activa, widely foraging, caracterizada por la obtención de muchas presas, de pequeño tamaño, con alto costo energético de búsqueda y de digestión, pero con un bajo gasto energético en la captura (ver Toft 1980, 1981, 1985, Huey y Pianka 1981). El gremio de los especialistas en este tipo de presas (hormigas y/o termitas) se alimentan de un recurso sedentario y distribuido en grupos en el espacio y tiempo que sólo los depredadores activos pueden aprovechar (Gerritsen y Strickler 1977, Krebs 1978, Eckhardt 1979, Huey y Pianka 1981, Basso 1990). Por otra parte, la ausencia de correlación entre el volumen promedio de las presas consumidas, que se mantuvo relativamente constante $(0,01 \mathrm{ml})$, y la LT indica que los ejemplares de $E$. australis estudiados no consumen presas más grandes a medida que aumentan de tamaño.

Por lo general, las serpientes que emplean una táctica trófica de forrajeo activo utilizan la quimiorrecepción mediante el órgano vomeronasal para discriminar a las presas y la visión para localizarlas y finalmente capturarlas (Greene 1997, Mullin y Cooper 1998). Sin embargo las serpientes como $E$. australis, presentan los ojos reducidos sin la capacidad de localizar a las 
presas visualmente (Greene 1997). Resulta particularmente interesante que solo en el leptotiflópido norteamericano Rena dulcis fueron reportadas secreciones cloacales para repeler el ataque dentro de los hormigueros (Gehlbach et al. 1968, Watkins et al. 1969). El hecho de que $R$. dulcis es considerado como un depredador generalista (Punzo 1974, Webb et al. 2000) y que $E$. australis se alimentó casi exclusivamente de huevos y larvas de hormigas podría indicar la presencia de algún tipo de adaptación similar, sin embargo se desconoce su existencia. Este interrogante queda planteado para futuros estudios.

Las observaciones personales realizadas durante las tareas de campo y el tipo y naturaleza de las presas consumidas por la especie permiten corroborar en parte lo expuesto. Fueron registrados varios ejemplares de $E$. australis bajo rocas sueltas sobre tierra y alimentándose de huevos y larvas de hormigas, mientras que las hormigas adultas aparentemente no notaban su presencia dentro del hormiguero. Inclusive fue registrado más de un ejemplar dentro del mismo hormiguero. Un ejemplar regurgitó varios huevos/larvas de hormigas al ser capturado (Figura 3.18). 


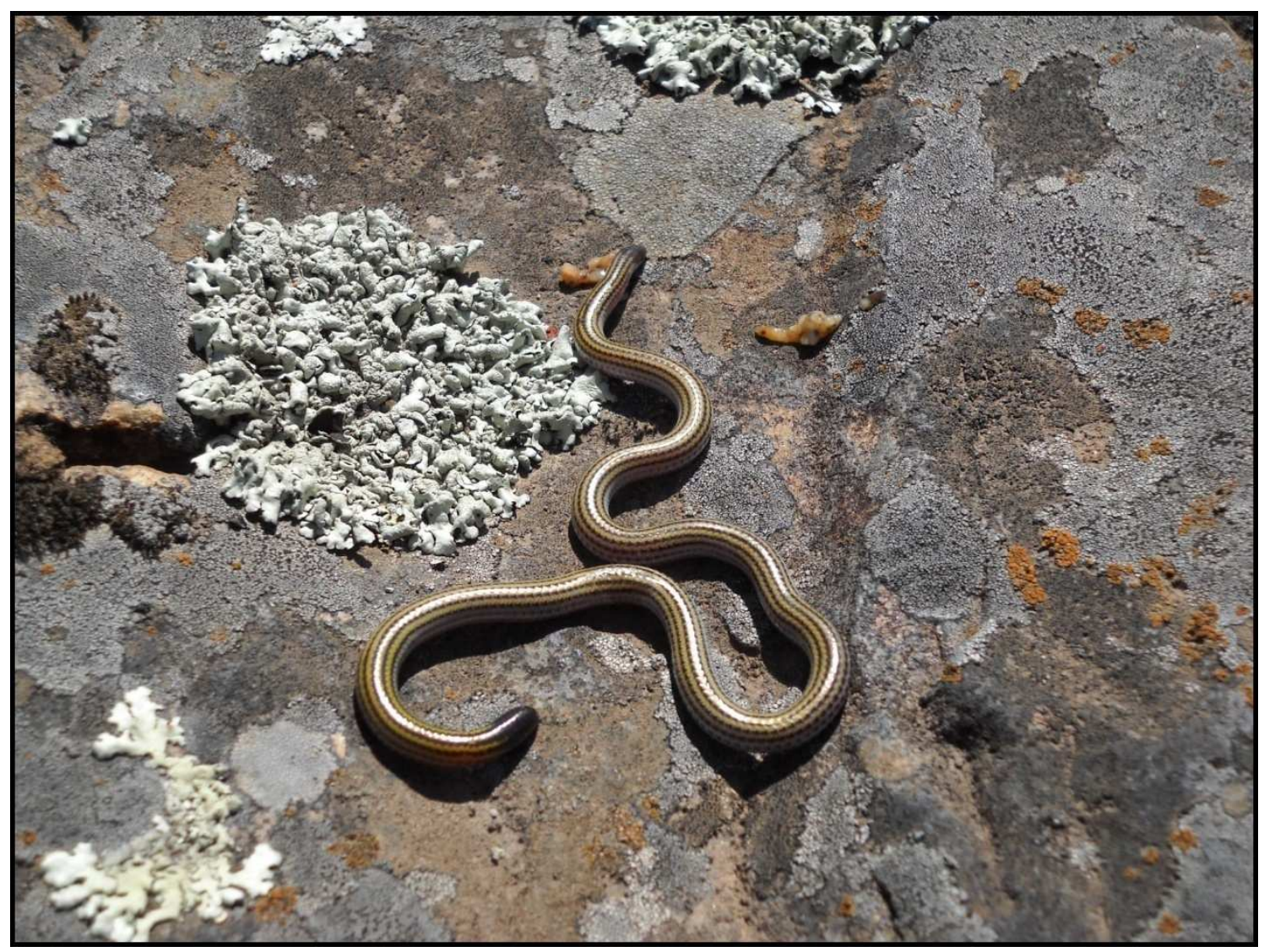

Figura 3.18. Epictia australis regurgitando huevos/larvas de hormigas.

Por lo tanto, se concluye que $E$. australis utiliza una estrategia de forrajeo activo (widely foraging) con elevada selectividad por los huevos y larvas de formícidos (Pheidole sp.) lo que sustenta una dieta del tipo especialista, con bajos valores en los índices de diversidad de presas y de amplitud del nicho trófico (Tabla 3.8).

En el análisis de la dieta de Erythrolamprus poecilogyrus sublineatus, los valores en los índices de diversidad de presas y de amplitud del nicho trófico (número y volumen) fueron elevados (Tabla 3.8). Estas características sugieren una dieta de tipo generalista, que habitualmente está relacionada con una táctica trófica de captura al acecho, sit and wait (ver Huey y Pianka 1985). Sin embargo, esto no queda del todo claro a la luz de los resultados.

Con respecto al tipo de dieta, las larvas de Rhinella arenarum presentaron elevadas proporciones numéricas (50\%), y agrupando los diferentes ítems presa, los anfibios (larvas y adultos) presentaron proporciones 
numéricas del $75 \%$, los peces del $22,97 \%$, los reptiles del $1,35 \%$ y los mamíferos del $0,68 \%$, lo que revela una tendencia a la especialización (o preferencia) por los anfibios y sus larvas. Resultados similares fueron obtenidos por Carreira (2002) para las poblaciones de E. p. sublineatus de Uruguay. Además, Prieto et al. (2012) consideran las poblaciones de E. poecilogirus del Noreste de la Argentina como especialistas en la alimentación de anfibios. Cabe mencionar aquí que en el Noreste de la Argentina habitan en simpatría tres de las cuatro subespecies de E. poecilogirus reconocidas (Dixon y Markezich 1992). Por lo tanto, se puede considerar que la población de E. p. sublineatus del área de estudio presenta una dieta generalista, pero con una tendencia a la especialización por los anfibios (larvas y adultos).

Con respecto a la estrategia de forrajeo, la ausencia de correlación entre el volumen de las presas consumidas y el AB y la LT indica que los ejemplares de E. $p$ sublineatus se alimentan de presas de tamaño variable y no consumen presas más grandes a medida que aumenta de tamaño, sugiriendo que (1) las serpientes de pequeño tamaño son capaces de ingerir presas grandes, y (2) las serpientes de mayor tamaño no rechazan las presas pequeñas. Shine (1987) interpreta esta ausencia de correlación como una consecuencia del forrajeo generalizado "searching". Según este autor, en los forrajeros "searching" sería de esperar que consuman todos los ítems presa que encuentran, incluso los de pequeño tamaño, debido a que los costos de tiempo, el riesgo y la energía empleada en capturar y tragar a las presas serían triviales (Schoener 1971, Pough y Andrews 1985). Además, la preferencia por los anfibios que indica una tendencia a la especialización en la dieta, la elevada frecuencia de alimentación (determinada aquí por la elevada proporción de ejemplares con contenido gástrico) y la presencia de presas de pequeño tamaño son características de especies con una táctica trófica de búsqueda activa (ver Toft 1980, 1981, 1985, Huey y Pianka 1981). Por lo tanto, se puede considerar que la población de E. p. sublineatus del área de estudio presenta una estrategia de forrajeo activo.

Por otro lado, las observaciones personales realizadas durante las tareas de campo y el tipo y naturaleza de las presas consumidas por la especie permiten corroborar en parte lo expuesto. El tipo de presas nos indica que la 
especie en el área de estudio se alimenta tanto en los ambientes terrestres (ej. Epictia australis) como en los acuáticos (ej. Jenynsia multidentata), a diferencia de las poblaciones del Noreste de la Argentina que se alimentaron de presas terrestres (sensu Prieto et al. 2012). Una elevada proporción de larvas de anfibios y peces de hábitos gregarios fueron registrados en los contenidos gástricos de la especie en este estudio, generalmente más de una presa por estómago. Fueron registrados varios eventos de depredación en relación con este tipo de presas, en arroyos serranos de agua clara y poco profunda lo que permitió observar el comportamiento en este ambiente, donde E. p. sublineatus persiguió larvas de Rhinella arenarum realizando movimientos bruscos bajo el agua con la boca completamente abierta. Es de esperar que realice el mismo comportamiento con los peces gregarios Jenynsia multidentata. Shine et al. (2004) registraron en condiciones de laboratorio un comportamiento similar para capturar pequeños peces en la serpiente acuática Enhydris polylepis (Homalopsinae). Estos autores notaron que las señales utilizadas por esta especie para localizar sus presas eran visuales, en especial el movimiento de la presa, y para lanzar el ataque el disparador era táctil, por contacto directo con la presa o el movimiento del agua. Probablemente, E. p. sublineatus utiliza las mismas señales para localizar y capturar presas acuáticas. Fuera del agua fue registrado durante las tareas de campo un evento de depredación sobre la rana criolla Leptodactylus latrans (Figura 3.19), donde E. p. sublineatus capturó a la presa tomándola por los miembros posteriores, probablemente debido a un fallido modo de escape (saltación sensu Toft 1980). Sería de esperar que fuera del agua esta especie utilice la quimiorrecepción para discriminar a sus presas y la visión para localizarlas y finalmente capturarlas, como es común en los buscadores activos (Greene 1997). 


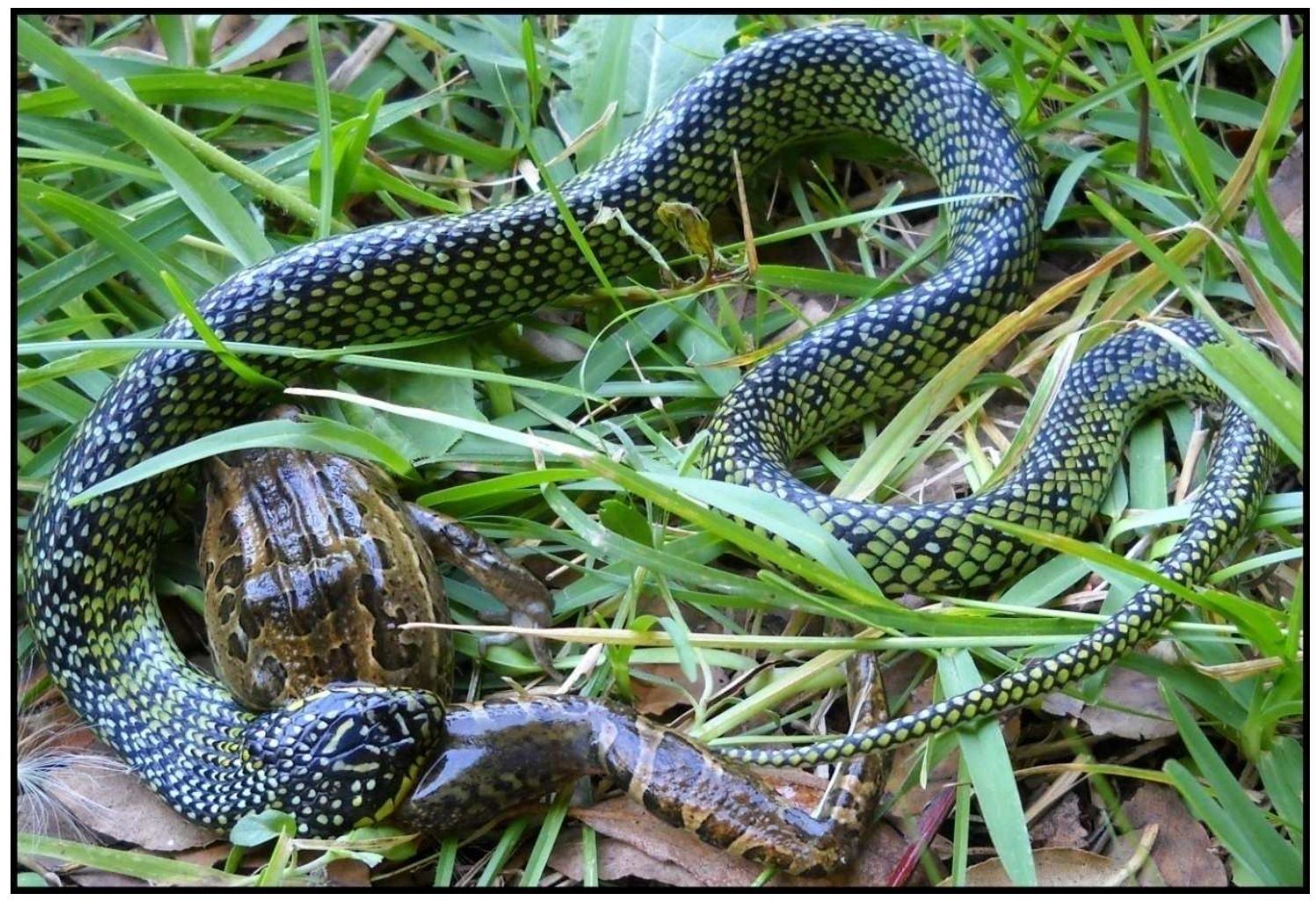

Figura 3.19. Depredación de Erythrolamprus poecilogyrus sublineatus sobre Leptodactylus latrans.

Por lo tanto, se concluye que E. p. sublineatus es una subespecie que utiliza una estrategia de forrajeo activo (widely foraging), con selectividad moderada por los anfibios (en general) que sustenta una tendencia a la especialización (preferencia) trófica, pero con una dieta generalista con una gran amplitud de nicho trófico (número y volumen) y diversidad de presas (Tabla 3.8).

En el análisis de la dieta de Lygophis elegantissimus fueron hallados exclusivamente anfibios, donde las larvas y adultos de Hypsiboas pulchellus presentaron en conjunto elevada proporción numérica $(85,71 \%)$, mientras que los índices de diversidad de presas y de amplitud de nicho trófico (número y volumen) fueron relativamente bajos. Estas características sugieren una alimentación del tipo especialista, que generalmente está relacionada con una estrategia de forrajeo de búsqueda activa, widely foraging (ej. Toft 1980, 1981, Huey y Pianka 1981). Como fue mencionado por estos autores, y es fácilmente identificable en $L$. elegantissimus, los depredadores activos que deben 
desplazarse para capturar sus presas y están más expuestos a los ataques de los depredadores pueden presentar coloraciones especiales (por ej. aposemática) y/o toxinas para evitar la depredación. Se desconoce la presencia de toxinas exocorpóreas de este tipo en ofidios.

Por otra parte, la correlación significativa entre el volumen promedio de las presas consumidas y el $A B$ y la LT nos indica que esta especie consume presas más grandes a medida que aumenta de tamaño. Recientemente, Panzera y Maneyro (2014) en base a una completa revisión bibliográfica y de ejemplares depositados en colecciones indicaron en $L$. anomalus, una especie cercana filogenéticamente a L. elegantissimus (ver Zaher et al. 2009), una especialización en la dieta de anuros adultos y estrategia de forrajeo activo "searching" similar al reportado en E. p. sublinetus (presente trabajo). A diferencia de estas especies, L. elegantissimus presenta mayor selectividad por el tipo y tamaño óptimo de sus presas.

Las observaciones realizadas en el campo y en el laboratorio permiten corroborar lo expuesto. Las presas consumidas por esta especie se encuentran frecuentemente en los arroyos serranos y sus cercanías (obs. pers.). Fueron registrados en el campo varios eventos de depredación sobre adultos de $H$. pullchelus que se encontraban posados sobre la vegetación del borde de arroyo, donde se observó que L. elegantissimus se acercó (desde el agua o por el margen del arroyo) y capturó a las ranas por la cabeza, también fue observado un comportamiento similar pero con la captura por los miembros posteriores (Figura 3.20), probablemente debido a un fallido intento de escape de la rana (saltación sensu Toft 1980). Además, fue registrado en este ambiente un evento de depredación sobre Melanophryniscus montevidensis, donde se observó que $L$. elegantissimus capturó el sapo desde la cabeza y éste disponía sus miembros perpendiculares al sentido de la alimentación, probablemente para dificultar la ingesta por parte de la serpiente. Posteriormente, para confirmar las observaciones de campo, se registraron en experimentos en cautiverio varios eventos de depredación sobre $M$. montevidensis $(n=5)$. En el terrario la serpiente se acercó con movimientos repetidos de la lengua y tomó (en todas las réplicas) al sapo desde la cabeza, al mismo tiempo éste disponía los miembros en sentido perpendicular como fue 
observado en el campo (Figura 3.21). No fue desplegado el comportamiento típico de unkenreflex. La ingesta siguió el método descripto en la literatura como inercial (Gans 1961). Se observó que los sapos al ser capturados comienzan a secretar una sustancia mucosa por su piel (que podría incluir alcaloides, ver Daly et al. 2008) que aparentemente no afecta a la serpiente (Figura 3.21). Durante las tareas de campo no fue registrado un comportamiento trófico similar al observado en E. p. sublineatus dentro del medio acuático (presente trabajo). El tipo de presas consumidas por esta especie dentro del agua parece indicar la ausencia de dicho comportamiento, ya que consumió larvas de $H$. pulchellus en avanzado estado de desarrollo, que generalmente presentan comportamiento solitario. Además, se encontraron pocas de estas larvas por tubo digestivo examinado, a diferencia de lo observado en E. p. sublineatus. Futuros estudios de laboratorio permitirán corroborar la presencia/ausencia de dicho comportamiento alimentario.

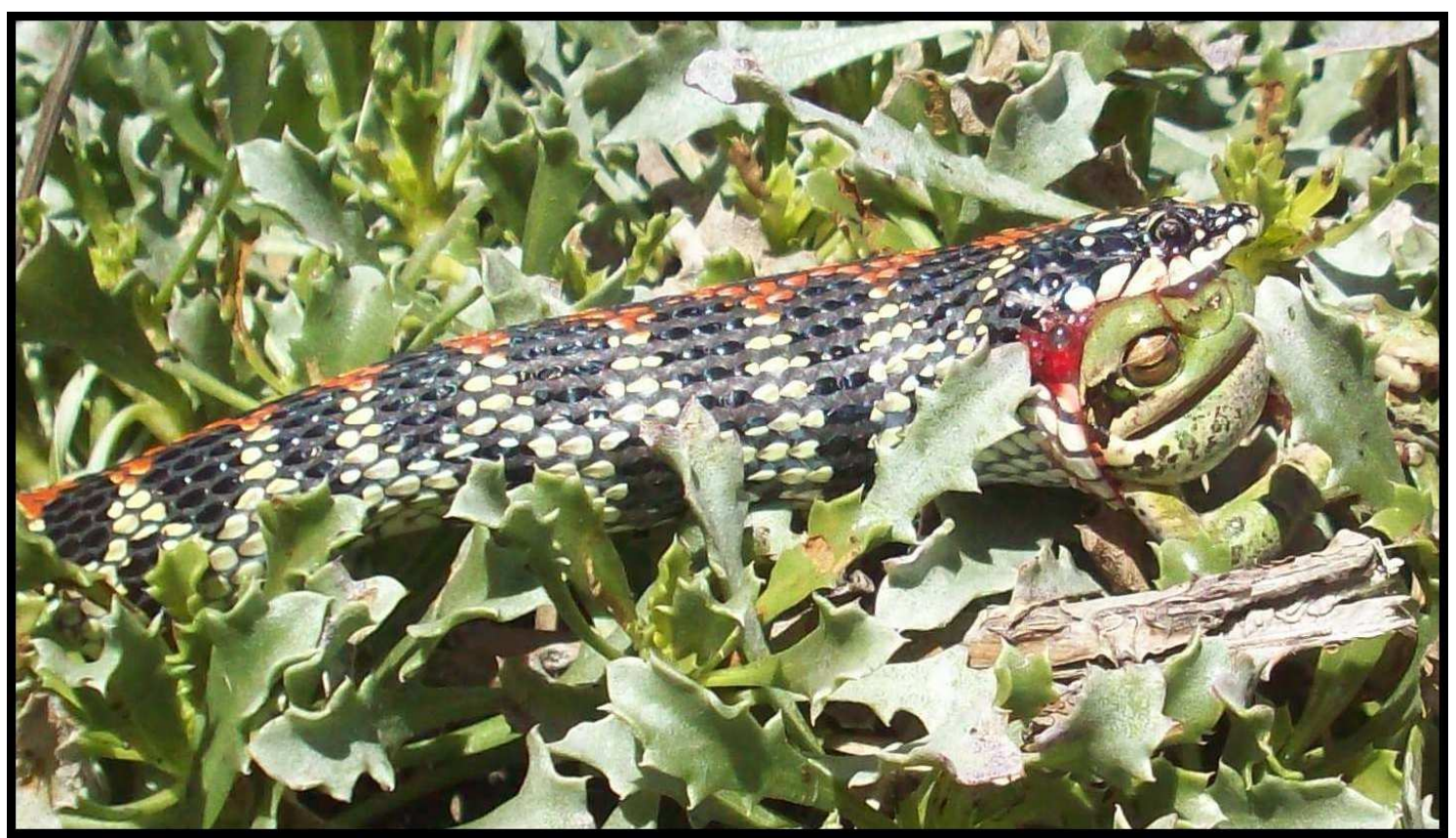

Figura 3.20. Depredación de Lygophis elegantissimus sobre Hypsiboas pulchellus. 


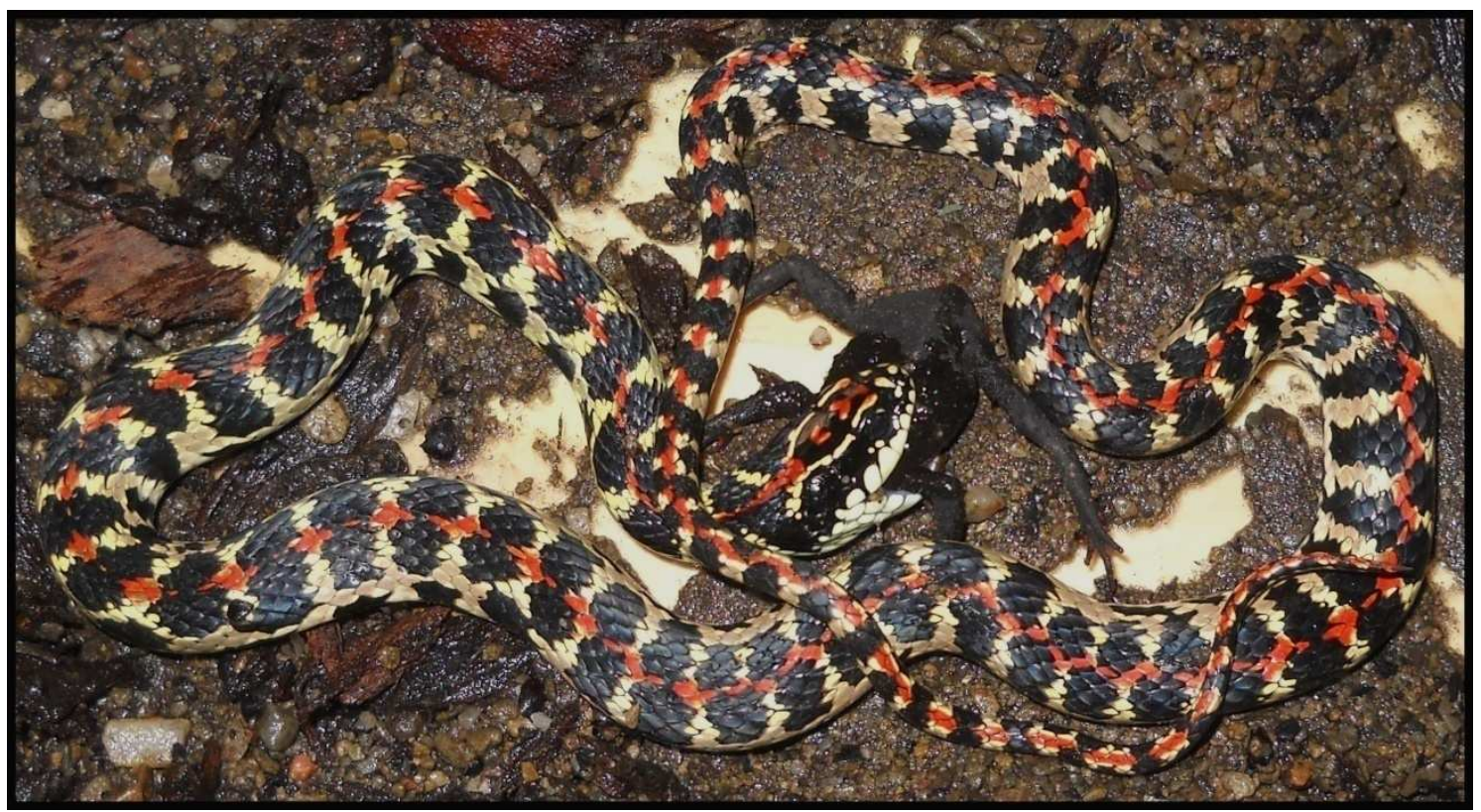

Figura 3.21. Depredación en cautiverio de Lygophis elegantissimus sobre Melanophryniscus montevidensis. Note la disposición de los miembros posteriores y la presencia de secreciones en la presa.

Por lo tanto, se concluye que L. elegantissimus, es una especie que utiliza una estrategia de forrajeo activo (widely foraging), con elevada selectividad por las larvas y adultos de Hypsiboas pulchellus y exclusividad en la alimentación de anfibios anuros que sustenta una dieta de tipo especialista con relativamente bajos valores de amplitud del nicho trófico (número y volumen) y diversidad de presas (Tabla 3.8).

En el análisis de la dieta de Philodryas patagoniensis, las arañas del género $L y c o s a$ presentaron elevada proporción numérica $(77 \%)$, los valores en los índices de diversidad de presas y amplitud del nicho trófico (número y volumen) fueron bajos. Estas características sugieren una dieta del tipo especialista. No obstante, la especialización podría ser aparente, ya que esta especie se considera comúnmente en la literatura como un depredador generalista, con una alimentación que varía geográficamente y está relacionada con la disponibilidad de presas (Hartmann y Marques 2005, López y Giraudo 2008). Por ejemplo, Lema (1973) indica que se alimenta de toda presa potencial que encuentra en el ambiente. En el área de estudio, las arañas del género Lycosa son muy abundantes en el microhábitat que 
frecuenta esta especie (obs. pers.) lo que podría explicar la presencia de este ítem presa en proporciones numéricas elevadas. Como fue mencionado anteriormente, sólo Carreira (2002) indica la presencia de artrópodos en los contenidos gástricos de $P$. patagoniensis. Analizando en detalle los datos publicados por este autor, las arañas del género Lycosa son el ítem presa mejor representado numéricamente $(n=17)$ y fue hallado solo en ocho ejemplares procedentes de localidades próximas entre sí del sur de Uruguay. De igual forma, esta elevada proporción numérica podría deberse a la disponibilidad en el ambiente. A diferencia de las menciones bibliográficas sobre la dieta de $P$. patagoniensis (ver arriba) no fueron registrados anfibios, reptiles y aves en los contenidos gástricos examinados, sin embargo es probable que la especie también consuma este tipo de presas en el área de Sierra de la Ventana (según las menciones de Koslowsky 1895). Por lo tanto, se puede considerar que la especie presenta una dieta del tipo generalista, aunque la elevada proporción numérica de arañas parece sugerir una tendencia a la especialización (o preferencia) por este tipo de presas debido a la disponibilidad en el área de estudio. Por otra parte, la correlación significativa entre el volumen promedio de las presas consumidas y el AB y la LT nos indica que esta especie consume presas más grandes a medida que aumenta de tamaño, no obstante, los ejemplares de gran tamaño no rechazaron las presas pequeñas.

Con respecto a la estrategia de forrajeo, una dieta del tipo generalista habitualmente está relacionada con una táctica trófica de captura al acecho, sit and wait (ver Huey y Pianka 1985). Sin embargo, esto no queda del todo claro en $P$. patagoniensis al considerar las presas más importantes halladas en los contenidos gástricos. La presencia de estas presas de pequeño tamaño, como las arañas, requiere un bajo costo energético de captura, pero un elevado costo energético en la digestión, debido a los exoesqueletos quitinosos (Figura 3.1B). El consumo de este tipo de presas, sumado a la elevada frecuencia de alimentación (determinado aquí por la proporción de ejemplares con contenido gástrico) indicaría el empleo de una estrategia de forrajeo activo (Toft 1980, 1981, 1985, Huey y Pianka 1981). Lamentablemente, no fueron registrados eventos de depredación en el campo que permitan corroborar lo expuesto, sin 
embargo, considerando el tipo y naturaleza de las presas más importantes de la especie en el área de estudio y las menciones previas que indican que la búsqueda activa es la táctica trófica más frecuente entre las culebras (ver revisión de Luiselli 2006) se puede suponer el empleo de esta estrategia de forrajeo en la especie.

Por lo tanto, se concluye que $P$. patagoniensis es una especie que utiliza una estrategia de forrajeo activo (widely foraging) y que presenta una dieta generalista con una selectividad moderada por las arañas del género Lycosa que sustenta una tendencia a la especialización (preferencia) trófica, con bajos valores en los índices de diversidad de presas y de amplitud del nicho (Tabla 3.8).

En el análisis de la dieta de Bothrops alternatus fueron hallados exclusivamente roedores lo que sustenta una dieta del tipo especialista. Los índices de diversidad de presas y de amplitud de nicho trófico fueron relativamente elevados, debido a las distintas especies de roedores consideradas en este estudio como ítems presa independientes. En una revisión sobre dieta de ofidios, Luiselli (2006) notó que los vipéridos en general presentan una estrategia de forrajeo pasivo sit and wait, caracterizada por la obtención de pocas presas, de gran tamaño, con bajo costo energético de búsqueda y de digestión, pero con un elevado gasto en la captura (ver Toft 1980, 1981, Huey y Pianka 1981). Según estos autores, los cazadores al acecho, en general, presentan coloración criptica, carecen de toxinas en la piel, se desplazan poco y esperan el paso de presas. Huey y Pianka (1981) mencionan al vipérido Bitis caudalis como un típico depredador pasivo sit and wait ya que sus presas más frecuentes (lagartijas en este caso) son a su vez depredadores activos widely foraging. Todas estas características son muy notables en $B$. alternatus. Los vipéridos que emplean una táctica de forrajeo pasivo, por lo general utilizan la quimiorrecepción para detectar el sitio de emboscada y luego utilizan la termorrecepción (mediante los receptores de la foseta loreal) para detectar el paso de las presas (Clark 2004, Colston et al. 2010). Sazima (1992) indica en $B$. jararaca una estrategia de forrajeo pasivo "strike-release-track" sobre mamíferos terrestres. Para la depredación sobre aves, ha sido mencionada una estrategia de forrajeo pasivo algo diferente en $B$. 
insularis ya que esta especie retiene las presas en la boca luego del ataque (Wüster et al. 2005). Es de esperar en B. alternatus una táctica trófica de búsqueda pasiva del tipo "strike-release-track" debido a su dieta exclusiva de roedores.

Por otra parte, la correlación significativa entre la LT y el volumen promedio de las presas consumidas indica que los ejemplares aquí estudiados consumen presas más grandes a medida que aumentan de tamaño. La ausencia de correlación entre el $A B$ y el volumen promedio de las presas podría ser un artefacto debido al empleo de algunos ejemplares atropellados.

La especie se alimentó de gran parte de los micromamíferos citados para el área de Sierra de la Ventana (ver Pardiñas et al. 2004 para detalles). Durante las tareas de campo no fueron registrados directamente eventos de depredación. Sin embargo, en varias oportunidades luego de observar la presencia de roedores en el campo, inclusive muertos, fueron capturados ejemplares de esta especie al acecho entre los pastizales y también desplazándose en las cercanías.

Por lo tanto, se concluye que Bothrops alternatus en el área de estudio utiliza una táctica trófica de forrajeo pasivo (sit and wait), con elevada selectividad por los roedores (en general), que sustenta una dieta del tipo especialista, con elevados valores en los índices de diversidad de presas y de amplitud del nicho (Tabla 3.8) debido al consumo de diversas especies de roedores.

Finalmente, resulta interesante destacar aquí el entrecruzamiento entre los modos de forrajeo en los distintos niveles tróficos del área de estudio, ya que los buscadores activos consumieron presas primarias que generalmente presentan una táctica trófica de búsqueda pasiva, y viceversa. Por ejemplo, el buscador activo $L$. elegantissimus se alimentó primariamente de $H$. pulchellus, una especie que presenta una táctica trófica pasiva (ver Basso 1990). Este entrecruzamiento entre los niveles tróficos fue mencionado previamente en la literatura para diversas especies (por ej. Gerritsen y Strickler 1977, Huey y Pianka 1981). 
Tabla 3.8. Amplitud del nicho ( $\mathrm{N}=$ número, $\mathrm{V}=$ volumen), diversidad de presas, tipo de dieta, estrategias de forrajeo y selectividad en Epictia australis (Ea), Erythrolamprus poecilogyrus sublineatus (Ep), Lygophis elegantissimus (Le), Philodryas patagoniensis (Pp) y Bothrops alternatus $(\mathrm{Ba})$.

\begin{tabular}{ccccccc}
\hline Especie & Amplitud del nicho & \multicolumn{2}{c}{ Diversidad de presas } & Tipo de dieta & Forrajeo & Selectividad \\
\hline & $\mathbf{N}$ & $\mathbf{V}$ & & & & \\
Ea & 1,32 & 1,32 & 0,67 & Especialista & Activo & Alta \\
Ep & 3,09 & 5,48 & 1,95 & Generalista & Activo & Media \\
Le & 2,67 & 2,55 & 1,5 & Especialista & Activo & Alta \\
Pp & 1,62 & 2,7 & 0,95 & Generalista & Activo & Media \\
Ba & 4,57 & 4,12 & 1,98 & Especialista & Pasivo & Alta \\
\hline
\end{tabular}

\section{Uso del microhábitat}

Las descripciones sobre la preferencia del hábitat actualmente están disponibles para unas pocas especies de serpientes (Reinert 1993). En la mayoría de los trabajos sobre comunidades de serpientes los resultados sobre el uso del microhábitat están limitados por sesgos de muestreo (ver Martins y Oliveira 1998). Este estudio no escapa de estas observaciones debido a que muchas especies fueron registradas ocasionalmente durante las tareas de campo. Por lo tanto, para evitar errores u omisiones en el uso del microhábitat se tratan en detalle las especies frecuentes (más de 10 ejemplares) y solo aquellas registradas en actividad durante los muestreos (ver metodología).

De una manera general, se pueden agrupar las entidades taxonómicas de acuerdo a parámetros del nicho ecológico en lo que se llama ensambles funcionales (por ej. Jaksic 1981, Di Fonzo de Abalos y Bucher 1983, Yanosky 1989). Según este criterio y considerando solo el microhábitat más utilizado, ya que muchas especies utilizan más de un microhábitat cuando están en actividad (Figura 3.13 a 3.17 ), $40 \%$ de las especies son primariamente terrestres, $26,6 \%$ son semifosoriales, $20 \%$ son semiacuáticas y $13,3 \%$ son fosoriales. Al comparar estos valores con los de otras regiones se observan algunas diferencias y/o similitudes en el uso del microhábitat. Por ejemplo, en el ensamble de la Reserva Ecológica El Bagual, Formosa (Yanosky 1989), 60\% de las especies fueron terrestres, $20 \%$ fueron semiacuáticas, $10 \%$ fueron arborícolas y $10 \%$ fueron semifosoriales. Estas claras diferencias en el uso del 
microhábitat pueden simplemente reflejar diferencias en la composición específica de estos ensambles, es decir, la contribución relativa de cada linaje filogenético, cada uno con sus propias limitaciones en relación con el uso del microhábitat (ver Cadle y Greene 1993). Sin embargo, algunas de estas diferencias también pueden ser consecuencia de las diferencias en las presiones de depredación, la disponibilidad de presas en cada microhábitat, y/o la disponibilidad de microhábitats (ver Martins y Oliveira 1998). Por ejemplo, la presencia de especies fosoriales en Ventania y la presencia de especies arborícolas en el Bagual. De igual forma, en comunidades que presentan elevada similitud biogeográfica con Ventania (ver capítulo 2) se observa una elevada semejanza en los ensambles faunísticos funcionales. Por ejemplo, en las Sierras de Tandilia (Vega y Bellagamba 1990) $40 \%$ de las especies fueron terrestres, $30 \%$ fueron semifosoriales, $20 \%$ fueron semiacuáticas y $10 \%$ fueron fosoriales.

En la comunidad de serpientes de Ventania las preferencias en el uso del microhábitat parecen estar relacionadas con el hallazgo local de las presas. Esta relación ha sido mencionada previamente en la literatura para diversas especies de serpientes (por ej. Henderson y Binder 1980, Reinert 1993, Hartmann y Marques 2005).

El $36,7 \%$ de los ejemplares examinados de Epictia australis fueron registrados en actividad (exclusivamente diurna) durante las tareas de campo. La especie utilizó tres tipos de microhábitats. Los ejemplares fueron registrados principalmente bajo rocas sueltas sobre tierra $(88,89 \%)$, quedando muy relegados en importancia numérica los ejemplares hallados en otros tipos de sustratos (Figura 3.13). Los datos previos sobre las preferencias en el uso del microhábitat de esta especie provienen de las menciones generales brindadas por Cei $(1986,1993)$. Según este autor, E. australis presenta hábitos subterráneos, y se encuentra bajo rocas en diferentes biotopos. Vega y Bellagamba (1990) registraron en las Sierras de Tandilia 33 ejemplares de $E$. munoai exclusivamente bajo rocas sueltas sobre tierra. Resultados similares fueron obtenidos en el presente estudio para $E$. australis en las Sierras de Ventania. Además, se confirman las costumbres gregarias en esta especie, ya que varios ejemplares fueron hallados bajo la misma roca. Las costumbres 
gregarias fueron mencionadas previamente en la literatura para otras especies del género Epictia (por ej. E. munoai, Vega y Bellagamba 1990; E. diaplocia, Martins y Oliveira 1998).

Por lo tanto, se concluye que E. australis presenta elevada selectividad por el tipo de microhábitat (bajo rocas sueltas sobre tierra), lo que sustenta una especialización en el uso del sustrato con bajos valores en los índices de diversidad y amplitud espacial (Tabla 3.9).

El $50 \%$ de los ejemplares examinados de Erythrolamprus p. sublineatus fueron registrados en actividad (tanto diurna como nocturna) durante las tareas de campo. La especie utilizó cinco tipos de microhábitats. Los ejemplares fueron registrados principalmente en arroyos serranos y en menor medida en otros tipos de microhábitats (Figura 3.14). Al considerar los arroyos serranos y sus bordes como un único tipo de microhábitat las preferencias son más notables $(58,14 \%)$. Resultados similares fueron mencionados previamente de manera general por Gallardo (1977) y Miranda et al. (1983). Según estos autores, E. p. sublineatus en los alrededores de Buenos Aires habita cerca del agua de ríos, lagunas y arroyos. En el área de Sierra de la Ventana, Koslowsky (1895) indica que esta especie se encuentra en los valles de las sierras a lo largo de los arroyos. Mientras que, Vega y Bellagamba (1990) mencionan en las Sierras de Tandilia distintos tipos de microhábitats para esta especie (zonas inundadas, pastizal y bajo rocas). Los resultados obtenidos en este estudio corroboran y amplían las observaciones previas sobre el uso del microhábitat de esta especie.

Por lo tanto, se concluye que E. p. sublineatus presenta una selectividad moderada por el tipo de sustrato, lo que sustenta hábitos generalistas con relativamente altos valores en los índices de diversidad y amplitud espacial (Tabla 3.9), aunque la elevada proporción de ejemplares hallados en el agua o cerca de ella indican una preferencia por este tipo de medio.

El $41,43 \%$ de los ejemplares examinados de Lygophis elegantissimus fueron registrados en actividad exclusivamente diurna durante las tareas de campo. La especie utilizó siete tipos de microhábitats. Los ejemplares fueron hallados principalmente en arroyos serranos y en menor medida en otros tipos 
de sustratos (Figura 3.15). Aunque, al considerar los arroyos serranos y sus bordes como un único tipo de microhábitat las preferencias son notables $(62,07 \%)$. Los datos previos sobre el uso del microhábitat de L. elegantissimus provienen de las menciones generales brindadas por Williams y Scrocchi (1994). Según estos autores, esta especie endémica de Ventania, se observa cerca de los arroyos que bajan de las sierras y en los pastizales al pie de las mismas. Los resultados aquí obtenidos confirman y amplían aquellas menciones previas sobre el uso del microhábitat de esta especie.

Por lo tanto, se concluye que $L$. elegantissimus presenta una selectividad moderada por el tipo de sustrato lo que sustenta hábitos generalistas con valores relativamente altos en los índices de diversidad y amplitud del nicho espacial (Tabla 3.9), aunque la elevada proporción de ejemplares hallados en los arroyos serranos y sus márgenes sugieren una preferencia por este microambiente.

El $37,2 \%$ de los ejemplares examinados de Philodryas patagoniensis fueron registrados en actividad exclusivamente diurna durante las tareas de campo. La especie utilizó cuatro tipos de microhábitats. Los ejemplares fueron hallados principalmente en el pastizal descubierto, y en menor medida en otros tipos de pastizales (Figura 3.16). Solo un ejemplar fue hallado sobre rocas. Al considerar el pastizal en general como un único tipo de sustrato la especialización es evidente (93,75\%). A pesar de ser una especie común y ampliamente distribuida en la mayoría de las provincias argentinas (ver distribución en Giraudo et al. 2012) los datos previos sobre las preferencias en el uso del microhábitat son escasos o provenientes de observaciones casuales. Por ejemplo, Gallardo $(1970,1977)$ indica que esta especie, en los alrededores de Buenos Aires, se encuentra en campo abierto en pastizales y vizcacheras, y Vega y Bellagamba (1990) mencionan a esta especie, en las Sierras de Tandilia, sobre pastizal entre rocas. En el sur de Brasil, Hartmann y Marques (2005) indican que $P$. patagoniensis habita frecuentemente en áreas abiertas y exclusivamente sobre el sustrato pastizal. Según estos últimos autores, las preferencias en el uso del microhábitat de esta especie están relacionadas con la disponibilidad y abundancia de sus presas en los pastizales. Resultados similares fueron obtenidos en el presente estudio. 
Por lo tanto, se concluye que $P$. patagoniensis en el área de estudio presenta elevada selectividad por el tipo de sustrato (pastizal en general), lo que sustenta una especialización en el uso del microhábitat con relativamente bajos valores en los índices de diversidad y amplitud espacial (Tabla 3.9).

El $34,5 \%$ de los ejemplares examinados de $B$. alternatus fueron hallados en actividad (tanto diurna, como crepuscular y nocturna) durante las tareas de campo. La especie utilizó seis tipos de microhábitats. Los ejemplares fueron registrados principalmente en el pastizal denso (Figura 3.17), y en menor medida en otros tipos de sustratos. Al considerar el pastizal en general como un único tipo de microhábitat las preferencias son más claras (80\%). En las Sierras de Ventania esta especie ha sido mencionada previamente en los pajonales de arroyos y en los roquedales rodeados por pastizales arbustivos (Koslowsky 1985, Cei 1986, 1993, respectivamente). Mientras que, en las Sierras de Tandilia fue registrada sobre bloques rocosos y en el pastizal con arbustos (Vega y Bellagamba 1990). Los resultados obtenidos en el presente estudio corroboran y amplían las observaciones previas sobre el uso del microhábitat de esta especie.

Por lo tanto, se concluye que $B$. alternatus presenta una selectividad moderada por el tipo de sustrato, lo que sustenta hábitos generalistas con relativamente altos valores en los índices de diversidad y amplitud del nicho espacial (Tabla 3.9), aunque la elevada proporción de ejemplares hallados en los pastizales en general sugieren una preferencia por este tipo de sustrato.

Tabla 3.9. Amplitud del nicho, diversidad espacial, tipo de microhábitat y selectividad en Epictia australis (Ea), Erythrolamprus poecilogyrus sublineatus (Ep), Lygophis elegantissimus (Le), Philodryas patagoniensis (Pp) y Bothrops alternatus (Ba).

\begin{tabular}{ccccc}
\hline Especie & Amplitud del nicho & Diversidad espacial & Tipo de microhábitat & Selectividad \\
\hline Ea & 1,26 & 0,46 & Especialista & Alta \\
Ep & 3,38 & 1,79 & Generalista & Media \\
Le & 3,77 & 1,86 & Generalista & Media \\
Pp & 2,37 & 1,18 & Especialista & Alta \\
Ba & 3,33 & 1,62 & Generalista & Media \\
\hline
\end{tabular}




\section{Relaciones trófico-espaciales}

Se registró un bajo solapamiento significativo en la proporción de presas consumidas entre $E$. australis y el resto de las especies comparadas, E. $p$. sublineatus y $P$. patagoniensis, E. p. sublineatus y $B$. alternatus, y también entre $L$. elegantissimus y $P$. patagoniensis, y $L$. elegantissimus y $B$. alternatus (o sea, las especies están particionando el recurso). Considerando el volumen de las presas se registró un bajo solapamiento significativo entre $E$. australis y el resto de las especies comparadas, $L$. elegantissimus y $P$. patagoniensis, y $L$. elegantissimus y $B$. alternatus (las especies están particionando el recurso; Tabla 3.6).

Ningún parámetro ecológico simple modela todo un ensamble. Las comunidades de cualquier grupo de organismos probablemente están influenciadas por más factores de los que aquí se analizan. Por ejemplo, las limitaciones fisiológicas y morfológicas, la respuesta a los depredadores (Toft 1985) y las limitaciones históricas (Brooks y McLennan 1991, Cadle y Greene 1993). De hecho, Cadle y Greene (1993) indican que es importante analizar la relación de los factores ecológicos y evolutivos, ya que especies cercanamente emparentadas tienden a compartir características a partir de ancestros comunes y no como causa de evolución independiente o como adaptación a la condición ambiental. No obstante, las comparaciones entre las principales dimensiones del nicho ecológico (dieta y hábitat) permiten inferir cuantitativamente qué factores tienen mayor efecto sobre la estructura de la comunidad (Pianka, 1973, 1974). Aquí, la dieta parece ser más importante en la divergencia ecológica, ya que se encontró particionada en la mayoría de los pares de especies comparadas. Este análisis coincide con las menciones previas que indican que la mayoría de los ensambles de serpientes están estructurados por la dieta (Arnold 1972, Schoener 1977, Toft 1985, Luiselli 2006, Goodyear y Pianka 2008).

Por otra parte, en el uso del microhábitat se registró un elevado solapamiento significativo entre E. p. sublineatus y L. elegantissimus, y también entre $P$. patagoniensis y $B$. alternatus (o sea, las especies están compartiendo el recurso; Tabla 3.6 y 3.7). El índice de solapamiento de MacArthur y Levins 
(1967) mostró una mayor influencia de L. elegantissimus sobre E. $p$. sublineatus y también de $B$. alternatus sobre $P$. patagoniensis. Teniendo en cuenta este análisis, E. p. sublineatus se vería afectada por L. elegantissimus, y $P$. patagoniensis se vería afectada por $B$. alternatus ante la escasez de recursos, ya que el solapamiento elevado y significativo implicaría una potencial competencia, que aún no ha dado lugar a divergencias en el uso de los recursos (Sale 1974, Conell 1980).

Finalmente, es interesante señalar que un mismo recurso puede compartirse por ser abundante en el medio o por su explotación diferencial en espacio y tiempo (ver revisión de Toft 1985). Los resultados obtenidos en el presente estudio muestran que los elevados valores de solapamiento observados en el uso del microhábitat se hallaron compensados por los bajos valores de solapamiento observados en la dieta. La hipótesis de complementariedad de nichos (Schoener 1974) establece que para que la coexistencia ocurra, una elevada superposición en una dimensión del nicho debe ser compensada por la baja superposición en otra dimensión. Por lo tanto, se concluye que las especies analizadas utilizan nichos complementarios con una alta superposición en una dimensión y una baja superposición en otra lo que permite que coexistan en simpatría (y/o sintopía) evitando la exclusión competitiva. 


\section{ÁREAS PRIORITARIAS PARA LA CONSERVACIÓN DE LA COMUNIDAD DE SERPIENTES}

\section{INTRODUCCIÓN}

En este capítulo se analiza la distribución de la comunidad de serpientes a través de herramientas de modelaje del nicho ecológico, con el propósito de completar los vacíos de información existentes en los patrones de distribución y estimar el hábitat de ocurrencia para cada especie. Finalmente, se integra esta información para generar propuestas para la conservación y determinar la representación del sistema actual de Áreas Naturales Protegidas.

\section{METODOLOGÍA}

\section{Modelos de distribución potencial}

Datos de ocurrencia: Se emplearon los ejemplares colectados durante las tareas de campo y los procedentes de la revisión de colecciones de museos (ver Apéndice 1 para detalles). Se georreferenciaron los registros de campo utilizando GPS Garmin eTrex Vista y las coordenadas de localidades de museos se obtuvieron mediante el programa Google Earth Pro. Para comparar la distribución de los datos de ocurrencia, se tuvo en cuenta la distribución de frecuencias del número de sitios donde fueron colectadas las serpientes. Se consideran especies de distribución restringida aquellas presentes en el primer cuartil de frecuencias, de distribución intermedia entre el primer y el último cuartil y de distribución extendida en el último cuartil, siguiendo criterios similares empleados para comparar localidades dentro de un mismo grupo taxonómico (Langhammer et al. 2007).

Selección de variables predictivas: Fueron utilizadas las variables ambientales del proyecto Worldclim (www.worldclim.org) con la mayor resolución posible (30 Arc segundos, cerca de $1 \mathrm{~km}^{2}$ por celda). El banco de datos del proyecto consiste de una variable de altitud y 19 variables bioclimáticas que representan tendencias anuales, estacionales y valores 
climáticos extremos (Tabla 4.1). Los valores se derivan de mediciones mensuales de temperatura y precipitación obtenidas por estaciones meteorológicas durante el periodo 1950-2000 e interpolados con el programa Anusplin (sensu Hijmans et al. 2005). Todas las variables fueron procesadas y dimensionadas de acuerdo con el área de estudio (Figura 4.1, latitud variando de -38.880043 a -36.872821 y longitud de -63.458333 a -60.633857 ) utilizando el programa DIVA-GIS versión 7.5 (Hijmans et al. 2012). Debido a que no es aconsejable utilizar todas las variables climáticas juntas ya que la correlación de las mismas puede tener efectos adversos en el desempeño del modelo (ver Seoane y Bustamante 2001, Sillero et al. 2010), se utilizó un set de 1000 puntos aleatorios dentro del área de estudio (Figura 4.1) para extraer los valores de las 20 variables ambientales con el programa DIVA-GIS versión 7.5 (Hijmans et al. 2012) y posteriormente seleccionar aquellas variables menos correlacionadas entre sí y con el resto de las variables ambientales (coeficiente de correlación de Pearson $r<0,7$ ) empleando el programa PAST versión 3.04 (Hammer et al. 2001).

Tabla 4.1. Variables ambientales empleadas para construir los modelos de distribución.

\begin{tabular}{|c|c|}
\hline Nombre & Descripción \\
\hline $\mathrm{ALT}$ & Altitud \\
\hline $\mathrm{BIO1}$ & Temperatura media anual \\
\hline $\mathrm{BIO} 2$ & Variación diurna promedio (media mensual de temp. máxima - mínima) \\
\hline $\mathrm{BIO}$ & Isotermalidad o índice de variabilidad de la temperatura (BIO2/BIO7 * 100) \\
\hline $\mathrm{BIO} 4$ & Estacionalidad de la temperatura (desviación estándar * 100) \\
\hline $\mathrm{BIO5}$ & Temperatura máxima del mes más cálido \\
\hline $\mathrm{BIO6}$ & Temperatura mínima del mes más frío \\
\hline $\mathrm{BIO}$ & Variación anual de temperatura (BIO5 - BIO6) \\
\hline $\mathrm{BIO}$ & Temperatura media del trimestre más húmedo \\
\hline $\mathrm{BIO9}$ & Temperatura media del trimestre más seco \\
\hline $\mathrm{BIO} 10$ & Temperatura media del trimestre más cálido \\
\hline BIO11 & Temperatura media del trimestre más frío \\
\hline $\mathrm{BIO} 12$ & Precipitación anual \\
\hline $\mathrm{BIO} 13$ & Precipitación del mes más húmedo \\
\hline $\mathrm{BIO} 14$ & Precipitación del mes más seco \\
\hline $\mathrm{BIO} 15$ & Estacionalidad de las precipitaciones (coeficiente de variación) \\
\hline $\mathrm{BIO} 16$ & Precipitación del trimestre más húmedo \\
\hline $\mathrm{BIO} 17$ & Precipitación del trimestre más seco \\
\hline $\mathrm{BIO} 18$ & Precipitación del trimestre más cálido \\
\hline $\mathrm{BIO} 19$ & Precipitación del trimestre más frío \\
\hline
\end{tabular}




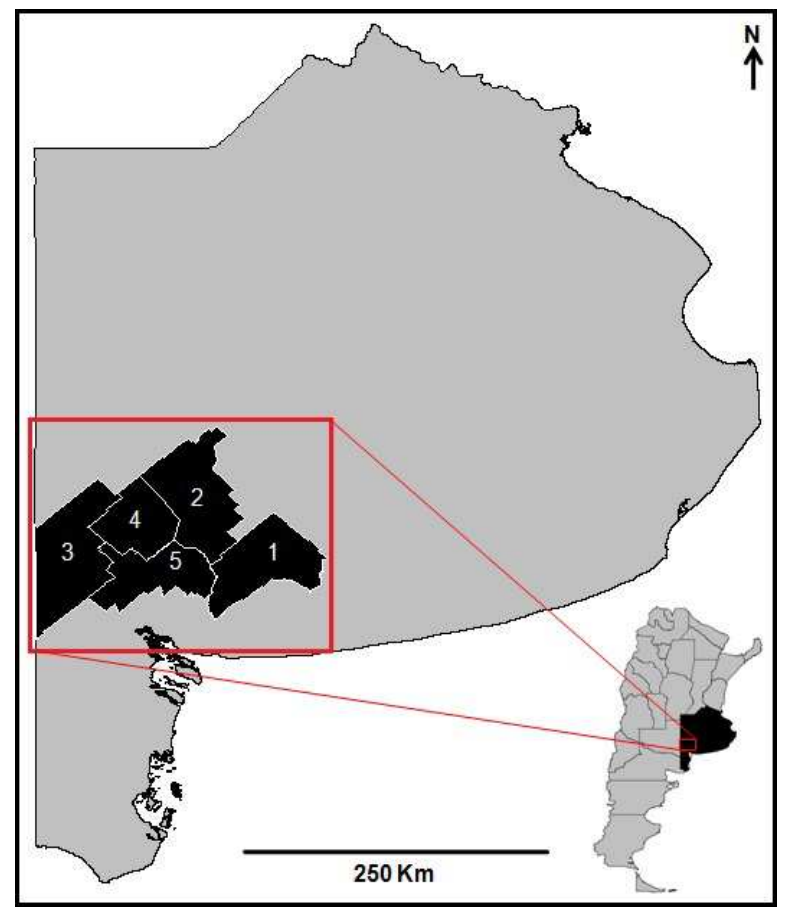

Figura 4.1. Área seleccionada en la provincia de Buenos Aires para generar los modelos de distribución potencial. Referencias (Partidos): Cnel. Pringles (1), Cnel. Suárez (2), Puan (3), Saavedra (4) y Tornquist (5).

Modelo y validación: Los modelos de distribución potencial de las especies en el área de estudio fueron generados con el programa Maxent versión 3.3.3k (Phillips et al. 2006, Phillips y Dudík 2008) que utiliza un algoritmo basado en el concepto de máxima entropía. Este principio plantea que la mejor aproximación a una distribución desconocida es aquella mas expandida, pero sujeta a restricciones conocidas. Aplicado a la modelación de distribución de especies, este programa estima, a partir de un conjunto de variables ambientales predictivas, la distribución de máxima entropía (la más expandida posible) pero que se ajusta a los valores de variables predictivas en las localidades de presencia conocida de la especie (Phillips et al. 2006). El resultado expresa para cada unidad de paisaje cuan apropiado es el hábitat para la especie según un modelo matemático. Respecto a otras técnicas de modelación de distribución geográfica, el algoritmo de Maxent ha mostrado un desempeño cuantitativamente superior (Elith et al. 2006, Elith y Leathwick 2009) y entre sus ventajas está el hecho de que solo requiere datos de presencia (otros algoritmos necesitan además datos de ausencia, que son muy 
difíciles de confirmar y necesitan de un gran esfuerzo de muestreo) y que puede arrojar resultados confiables a partir de un reducido número de observaciones (Franklin 2011). Si bien el algoritmo de Maxent es uno de los más utilizados a nivel global, en los últimos años no está exento de críticas (ver recomendaciones en Merow et al. 2013).

Para disminuir el efecto de la autocorrelación espacial de los datos de ocurrencia se removieron por especie los puntos duplicados por cada celda como recomiendan Phillips et al. (2006). Dado que el número de puntos de presencia empleados influye en la eficiencia de los algoritmos de modelación (Franklin 2011), para la construcción de los modelos de distribución en el área de estudio fueron analizadas solo aquellas especies que, luego de la remoción de duplicados, quedaron representadas en cinco o más celdas, tamaño de muestra para el cual se ha demostrado que el programa Maxent proporciona modelos confiables (Elith et al. 2006, Pearson et al. 2007). Con el fin de maximizar la capacidad predictiva de los modelos, considerando las características de los datos de ocurrencia obtenidos y el tamaño del área de estudio, fueron seleccionadas las opciones de ajuste lineal y cuadrático (juntas) de las variables ambientales, 10000 puntos de trasfondo como máximo (background o pseudoausencias) y una constante de regularización de 0,5 (ver Anderson y Gonzalez Jr. 2011, Shcheglovitova y Anderson 2013). Además, teniendo en cuenta el relativo éxito del re-muestreo en el modelaje de distribuciones con una muestra reducida, fue utilizado el método de validación cruzada del modelo (ver Pearson et al. 2007). Fueron realizadas tantas réplicas como cantidad de celdas ocupadas por cada especie para evaluar el ajuste del modelo y para obtener una predicción de consenso que represente confiablemente la distribución geográfica (ver Dormann 2007, Elith et al. 2011). Para probar el ajuste de las réplicas de los modelos fue estimado el valor promedio del área bajo la curva $(A \cup C)$ de la característica operativa del receptor (ROC), tanto para los datos de prueba (AUCp) como para los de entrenamiento (AUCe), que ofrece una medida de la capacidad predictiva de los modelos. Los modelos con una capacidad predictiva aleatoria tienen valores promedios de $A U C=0,5$ y con capacidad predictiva perfecta valores de $A U C=$ 1 (máximo valor). Usualmente, valores de AUC de 0,5 - 0,7 son tomados como 
una confiabilidad pobre del modelo, valores de 0,7 - 0,9 indican una aplicación útil del modelo y valores mayores a 0,9 indican una confiabilidad de buena a excelente (Broennimann et al. 2007).

Los resultados de los modelos fueron expresados en formato logístico, que da un estimado de la probabilidad de presencia con valores que van de cero para hábitats inapropiados a uno para los hábitats más apropiados (Phillips y Dudík 2008). Esta salida es de fácil interpretación, es independiente de la escala del estudio y además mejora la calibración de los modelos, de modo que las grandes variaciones en los valores de salida responden realmente a grandes variaciones en cuanto a la calidad del hábitat o la probabilidad de presencia (Phillips y Dudík 2008). Adicionalmente, para estimar la extensión de presencia de cada especie en el área de estudio, los mapas con valores continuos de probabilidad de presencia fueron convertidos en mapas con valores binarios (hábitat apropiado/inapropiado) con el programa DIVA-GIS versión 7.5 (Hijmans et al. 2012). Para ello se empleó como umbral de corte el percentil 10 de los valores de probabilidad logística registrados para las celdas con datos de presencia, con lo cual se clasifican como hábitat inapropiados aquellas celdas con probabilidad de presencia inferior al $10 \%$ de estos valores, que pudieran representar condiciones extremas de hábitat o poblaciones efímeras. Este valor de umbral es bastante conservador y ha sido empleado con fines similares en diversos estudios de modelación de la distribución de especies (por ej. Buckley et al. 2010, Morueta-Holme et al. 2010). Dado que la resolución de los modelos fue de cerca de $1 \mathrm{~km}^{2}$ por celda, un conteo de las celdas permitió estimar la extensión de la distribución de cada especie en el área de estudio.

La contribución relativa de cada una de las variables ambientales a los modelos de distribución de las especies fue estimada en porcentaje a partir de su contribución al incremento de ganancia producido en la fase de entrenamiento u optimización del modelo durante las iteraciones del algoritmo de máxima entropía. La ganancia es un parámetro que indica qué tan concentrado está el modelo alrededor de los datos de presencia. Adicionalmente, se evaluó la contribución de cada una de las variables al modelo mediante el método de Jackknife, que calcula la ganancia en modelos 
producidos con todas las variables menos una y luego en modelos que incluyan una sola variable (Phillips et al. 2006). Los resultados finales de los análisis de modelación (tanto los mapas de distribución potencial, como la evaluación de los modelos y la contribución de las variables) representan el promedio de las distintas réplicas efectuadas para cada una de las especies.

\section{Áreas prioritarias de conservación}

Para identificar las áreas prioritarias para la conservación de la comunidad de serpientes, se integraron los mapas de distribución geográfica, tanto los de distribución potencial como los de puntos de presencia. Para ello se empleó el programa Zonation versión 4, apropiado para el análisis de la planificación espacial de áreas de conservación (Moilanen et al. 2014 y literatura allí citada). Con el fin de mantener la conectividad del paisaje, este algoritmo trabaja desde la periferia del área de interés y de forma iterativa va removiendo las celdas de menor valor (Moilanen et al. 2014). El valor de las celdas está definido por el número de especies presentes y su importancia relativa. En cada iteración del programa se re-calculan los valores de las celdas restantes y se estima para cada especie el porcentaje de área removida. De esta manera se obtiene una ordenación del paisaje donde reciben mayor valor las regiones con mayor presencia de especies importantes (Moilanen et al. 2014).

En este análisis se le asignó una importancia relativa mayor a las especies endémicas y/o amenazadas según la reciente categorización de serpientes a nivel nacional (Giraudo et al. 2012), para ello se empleó una escala de valoración logarítmica, otorgándole un peso diez veces mayor al micro-endemismo Lygophis elegantissimus y cinco veces mayor a las especies endémicas parciales o amenazadas a nivel nacional, como Epictia australis y Philodryas agassizii, respectivamente. Estudios anteriores con el programa Zonation (por ej. Fiorella et al. 2010) han demostrado que la escala logarítmica responde mejor a las necesidades de priorización de especies endémicas y amenazadas. Las especies cuya distribución no pudo ser modelada, por estar representadas en menos de cinco celdas, fueron incluidas como especies de 
especial interés (SSI) y sus coordenadas son manejadas por el programa de manera equivalente a las celdas de los mapas de distribución potencial. Fueron comparadas dos reglas o algoritmos diferentes de remoción de celdas con Zonation para determinar la mejor propuesta de conservación en el área de interés (sensu Moilanen et al. 2014). La regla "Core-area Zonation (CAZ)", basada en Moilanen et al. (2005) y Moilanen (2007), utiliza una lógica de disminuir la pérdida biológica retirando las celdas que presentan los menores valores de ocurrencia para cada especie. Esto significa que se retienen en el paisaje solo las áreas núcleo de la distribución geográfica de todas las especies consideradas. De este modo, en un primer momento las celdas con ocurrencias de especies comunes son removidas y gradualmente las celdas antes comunes se tornan más raras, comenzando a ser removidas, y por último permanecen en el paisaje solo las celdas más importantes para cada especie. Esta propuesta fue comparada con una "Additive benefit function $(A B F)$ ", basada en Moilanen (2007), que prioriza las áreas que mantengan la riqueza específica, incluso si para esto se pierden áreas de especies en particular. Este algoritmo minimiza la tasa de extinción a través de la curva especie-área. Esta interpretación surge porque la forma matemática del $A B F$ es igual a la curva canónica de especie-área originada de la teoría biogeográfica de islas. Debido a que el $A B F$ suma todas las especies, el número de especies en una celda tiene un significado mayor en comparación con el CAZ.

Para analizar la correspondencia entre las áreas prioritarias de conservación de la comunidad de serpientes y las reservas naturales existentes en el área de estudio, se sigue el criterio de Prendergast et al. (1993), escogiendo para proteger al menos el $5 \%$ de las áreas prioritarias obtenidas en cualquiera de sus posibilidades. Posteriormente, se cuantificó mediante un SIG qué porcentaje de éstas áreas prioritarias están representadas dentro del sistema actual de Áreas Naturales Protegidas del Organismo Provincial para el Desarrollo Sostenible (ANP, OPDS - www.opds.gba.gov.ar). En el caso del área de estudio, estas son el Monumento Natural Cerro Ventana (Ley 11750/1995, 680 ha.) dentro del Parque Provincial Ernesto Tornquist (PPET) (Ley 18818/2001, 6147 ha.) y la Reserva Natural Privada Educativa y Botánica Sierras Grandes (RPSG), recientemente creada (Decreto 526/2013, 2742 ha.). 


\section{RESULTADOS}

\section{Modelos de distribución potencial}

Luego del análisis de correlación pareado, ocho variables resultaron menos correlacionadas entre sí y con el resto de las variables ambientales $(r<$ $0,7)$ y por lo tanto más informativas para generar los modelos de distribución potencial en el área de interés. De éstas, siete fueron bioclimáticas: isotermalidad o índice de variabilidad de la temperatura, temperatura máxima del mes más cálido, temperatura mínima del mes más frío, temperatura promedio del trimestre más húmedo, estacionalidad de las precipitaciones, precipitación del trimestre más cálido y precipitación del trimestre más frío; y una variable ambiental fue topográfica: altitud (Tabla 4.2).

De acuerdo con el material examinado ( $\mathrm{n}=376$ ejemplares) la comunidad de serpientes fue registrada en 157 sitios o celdas diferentes (Tabla 4.3, ver Apéndice 1). En cuanto al número de sitios por especie, el análisis comparativo reveló que seis taxones (Xenodon semicinctus, Epictia munoai, Paraphimophis rustica, Phalotris bilineatus, Philodryas aestiva subcarinata y Philodryas agassizii) presentaron una distribución restringida (2-4 celdas), cinco taxones (Xenodon dorbignyi, Bothrops ammodytoides, Oxyrhopus rhombifer rhombifer, Epictia australis y Lygophis anomalus) presentaron una distribución intermedia (5-13 celdas), y cuatro taxones (Philodryas patagoniensis, Bothrops alternatus, Erythrolamprus poecilogyrus sublineatus y Lygophis elegantissimus) presentaron una distribución más extendida (16-31 celdas). La mayoría de las especies con una distribución restringida, como $P$. bilineatus, $P$. agassizii, $P$. a. subcarinata y $X$. semicinctus, fueron registradas en localidades muy próximas entre sí, mientras que $E$. munoai y $P$. rustica también fueron registradas en pocos sitios aunque de localidades relativamente distantes (ver Apéndice 1). Las especies con una distribución de intermedia a extendida cumplieron los requisitos para generar los modelos de distribución potencial, al quedar representadas entre cinco y 31 sitios diferentes (media $=15,1)$. Los modelos de máxima entropía obtenidos para estos taxones revelaron una capacidad predictiva elevada, con valores del estadístico AUC entre 0,9 y 0,96 (media $=$ 
0,93 ) para los datos de entrenamiento y entre 0,8 y 0,94 (media $=0,89$ ) para los datos de prueba (Tabla 4.3).

Al proyectar los modelos en el área de interés se obtuvieron las distribuciones potenciales de las nueve especies y subespecies de serpientes incluidas en estos análisis (Figura 4.2 a 4.10). La probabilidad de presencia de la mayoría de las especies es muy elevada en las Sierras de Ventania, tanto en el ambiente serrano como en el intraserrano (valles serranos) y disminuye gradualmente hacia el ambiente periserrano y la llanura circundante a las sierras. Este patrón de distribución es evidente en la mayoría de las especies, excepto en $B$. ammodytoides y $L$. anomalus donde la probabilidad de presencia es más elevada en la llanura circundante y el ambiente periserrano y disminuye hacia el ambiente serrano y el intraserrano (Figura 4.3 y 4.6). Es notable en $P$. patagoniensis y $X$. dorbignyi la extensión hacia el sur de los partidos relevados a través del Río Sauce Grande (Figura 4.9 y 4.10 ).

Con respecto al hábitat apropiado o área de ocupación para la comunidad de serpientes (Tabla 4.3, Figura 4.2 B a $4.10 \mathrm{~B}$ ), los taxones individuales analizados presentaron áreas de hábitat relativamente similares $\left(\right.$ media $\left.=16311,6 \mathrm{~km}^{2}\right)$, donde E. p. sublineatus presentó el menor valor de ocurrencia (9692 $\left.\mathrm{km}^{2}\right)$, seguido por $B$. alternatus $\left(11472 \mathrm{~km}^{2}\right.$ ) y $L$. elegantissimus (12118 $\left.\mathrm{km}^{2}\right)$, mientras que $E$. australis presentó el mayor valor de ocurrencia $\left(25436 \mathrm{~km}^{2}\right)$, seguido por O. r. rhombifer $\left(21932 \mathrm{~km}^{2}\right)$. 
Tabla 4.2. Resultados del análisis de correlación espacial realizado con las variables ambientales. Se ilustra en cada caso los valores del coeficiente de correlación de Pearson $(r)$, destacando en rojo los valores mayores de 0,7 . Se indican en negrita las variables mas informativas y menos correlacionadas entre sí y con el resto de las variables, que fueron empleadas para generar los modelos de distribución potencial. Ver referencias en Tabla 4.1.

\begin{tabular}{|c|c|c|c|c|c|c|c|c|c|c|c|c|c|c|c|c|c|c|c|c|}
\hline Var. & ALT. & $\mathrm{BIO} 1$ & $\mathrm{BlO} 2$ & BlO3 & $\mathrm{BIO} 4$ & BIO5 & BIO6 & $\mathrm{BlO} 7$ & BIO8 & $\mathrm{BIO9}$ & BIO10 & BIO11 & $\mathrm{BIO} 12$ & $\mathrm{BIO} 13$ & $\mathrm{BIO} 14$ & BI015 & BIO16 & $\mathrm{BIO} 17$ & BIO18 & $\mathrm{BIO}$ \\
\hline ALT. & & - & - & - & - & - & - & - & - & - & - & - & - & - & - & - & - & - & - & - \\
\hline BIO1 & $-0,86$ & - & - & - & - & - & - & - & - & - & - & - & - & - & - & - & - & - & - & - \\
\hline $\mathrm{BIO} 2$ & $-0,06$ & 0,45 & - & - & - & - & - & - & - & - & - & - & - & - & - & - & - & - & - & - \\
\hline BIO3 & 0,07 & $-0,12$ & 0,21 & - & - & - & - & - & - & - & - & - & - & - & - & - & - & - & - & - \\
\hline $\mathrm{BIO} 4$ & $-0,09$ & 0,52 & 0,94 & $-0,08$ & - & - & - & - & - & - & - & - & - & - & - & - & - & - & - & - \\
\hline BIO5 & $-0,47$ & 0,79 & 0,85 & $-0,14$ & 0,90 & - & - & - & - & - & - & - & - & - & - & - & - & - & - & - \\
\hline BIO6 & $-0,54$ & 0,17 & $-0,78$ & $-0,26$ & $-0,70$ & $-0,38$ & - & - & - & - & - & - & - & - & - & - & - & - & - & - \\
\hline $\mathrm{BIO} 7$ & $-0,08$ & 0,48 & 0,98 & 0,03 & 0,98 & 0,90 & $-0,75$ & - & - & - & - & - & - & - & - & - & - & - & - & - \\
\hline BIO8 & $-0,06$ & 0,15 & 0,16 & $-0,02$ & 0,14 & 0,22 & $-0,02$ & 0,17 & - & - & - & - & - & - & - & - & - & - & - & - \\
\hline BIO9 & $-0,97$ & 0,88 & 0,01 & $-0,11$ & 0,07 & 0,44 & 0,59 & 0,03 & 0,12 & - & - & - & - & - & - & - & - & - & - & - \\
\hline BIO10 & $-0,65$ & 0,93 & 0,71 & $-0,15$ & 0,79 & 0,94 & $-0,16$ & 0,75 & 0,18 & 0,66 & - & - & - & - & - & - & - & - & - & - \\
\hline BIO11 & $-0,97$ & 0,89 & 0,02 & $-0,12$ & 0,08 & 0,45 & 0,58 & 0,04 & 0,12 & 1,00 & 0,66 & - & - & - & - & - & - & - & - & - \\
\hline BIO12 & 0,40 & $-0,51$ & $-0,29$ & $-0,27$ & $-0,25$ & $-0,28$ & 0,09 & $-0,24$ & 0,07 & $-0,44$ & $-0,43$ & $-0,44$ & - & - & - & - & - & - & - & - \\
\hline $\mathrm{BlO} 13$ & 0,39 & $-0,53$ & $-0,41$ & $-0,31$ & $-0,37$ & $-0,38$ & 0,19 & $-0,36$ & 0,15 & $-0,41$ & $-0,50$ & $-0,41$ & 0,96 & - & - & - & - & - & - & - \\
\hline BIO14 & 0,36 & $-0,59$ & $-0,62$ & $-0,32$ & $-0,57$ & $-0,56$ & 0,35 & $-0,57$ & $-0,10$ & $-0,36$ & $-0,63$ & $-0,36$ & 0,80 & 0,82 & - & - & - & - & - & - \\
\hline BI015 & 0,14 & 0,28 & 0,73 & $-0,04$ & 0,82 & 0,64 & $-0,62$ & 0,75 & 0,09 & $-0,11$ & 0,56 & $-0,10$ & 0,01 & $-0,14$ & $-0,37$ & - & - & - & - & - \\
\hline BIO16 & 0,38 & $-0,44$ & $-0,21$ & $-0,25$ & $-0,16$ & $-0,20$ & 0,05 & $-0,17$ & 0,07 & $-0,41$ & $-0,35$ & $-0,41$ & 0,99 & 0,93 & 0,75 & 0,14 & - & - & - & - \\
\hline $\mathrm{BIO} 17$ & 0,20 & $-0,56$ & $-0,69$ & $-0,19$ & $-0,72$ & $-0,63$ & 0,47 & $-0,67$ & 0,04 & $-0,26$ & $-0,69$ & $-0,26$ & 0,68 & 0,80 & 0,79 & $-0,69$ & 0,58 & - & - & - \\
\hline BI018 & 0,42 & $-0,47$ & $-0,19$ & $-0,25$ & $-0,14$ & $-0,20$ & 0,01 & $-0,14$ & 0,09 & $-0,45$ & $-0,35$ & $-0,45$ & 0,98 & 0,91 & 0,72 & 0,18 & 0,99 & 0,54 & - & - \\
\hline BI019 & 0,20 & $-0,56$ & $-0,69$ & $-0,19$ & $-0,72$ & $-0,63$ & 0,47 & $-0,67$ & 0,04 & $-0,25$ & $-0,69$ & $-0,26$ & 0,68 & 0,80 & 0,79 & $-0,69$ & 0,58 & 1,00 & 0,54 & - \\
\hline
\end{tabular}


Tabla 4.3. Resultados obtenidos durante el modelaje con el algoritmo de máxima entropía. Para cada especie se presenta el número de sitios de colecta ( $\mathrm{n}$ ), los valores del índice del área bajo la curva para los datos de entrenamiento (AUCe) y de prueba (AUCp), el área de ocupación estimada (AO), y la contribución porcentual de las variables ambientales ( $\mathrm{ALT}$, BIO3, BIO5, BIO6, BIO8, BIO15, BIO18 y BIO19; ver referencias en Tabla 4.1) indicando entre paréntesis la ganancia porcentual de los modelos obtenida durante la prueba de Jackknife (solo con la variable/sin la variable).

\begin{tabular}{|c|c|c|c|c|c|c|c|c|c|c|c|}
\hline Especies (n) & AUCe & AUCp & AO (km2) & ALT & $\mathrm{BIO3}$ & $\mathrm{BIO5}$ & BIO6 & $\mathrm{BIO8}$ & BIO15 & BI018 & BIO19 \\
\hline B. alternatus (18) & 0,96 & 0,94 & 11472 & $50,1(92,9 / 97,6)$ & $0,7(5,9 / 99,4)$ & $23,9(58,8 / 99,4)$ & $23,5(33,5 / 95,9)$ & $0,3(2,4 / 99,4)$ & $0,9(0,6 / 99,4)$ & $0.6(14,1 / 99,4)$ & $0(20,6 / 100)$ \\
\hline B. ammodytoides (7) & 0,9 & 0,8 & 16848 & $58(41,1 / 51,8)$ & $2,1(3,6 / 98,2)$ & $0(0 / 100)$ & $9,9(16,1 / 94,6)$ & $13,8(10,7 / 82,1)$ & $0,7(5,4 / 100)$ & $5,5(3,6 / 92,9)$ & $10(10,7 / 98,2)$ \\
\hline E. australis (10) & 0,91 & 0,86 & 25436 & $68,4(92,2 / 98,1)$ & $0,2(5,8 / 99)$ & $24,6(69,9 / 93,2)$ & $6(30,1 / 98,1)$ & $0,7(1 / 98,1)$ & $0(0 / 99)$ & $0,1(4,9 / 99)$ & $0(2,9 / 99)$ \\
\hline E. munoai (3) & - & - & - & - & - & - & - & - & - & - & - \\
\hline E. p. sublineatus (27) & 0,95 & 0,94 & 9692 & $44,4(88,5 / 97,8)$ & $0(15,4 / 100)$ & $38,2(72,5 / 98,8)$ & $16,4(33,5 / 96,7)$ & $0,1(3,8 / 100)$ & $0,5(1,6 / 95,5)$ & $0,2(21,4 / 99,5)$ & $0,1(33 / 100)$ \\
\hline L. anomalus (13) & 0,9 & 0,86 & 16085 & $6,8(34,5 / 96,4)$ & $0,1(1,2 / 100)$ & $32(17,9 / 78,6)$ & $9,3(13,1 / 91,7)$ & $18,5(10,7 / 70,2)$ & $3,1(1,2 / 100)$ & $25,3(25 / 91,7)$ & $4,9(1,2 / 97,6)$ \\
\hline L. elegantissimus (31) & 0,94 & 0,91 & 12118 & $42,4(82,8 / 95,1)$ & $0,1(10,4 / 100)$ & $33,2(59,5 / 100)$ & $17,6(24,5 / 92,6)$ & $2,8(0,6 / 99,4)$ & $0,9(4,3 / 100)$ & $2,2(30,7 / 100)$ & $0,8(34,4 / 99,4)$ \\
\hline O. r. rhombifer (9) & 0,95 & 0,92 & 21932 & $60,6(85 / 100)$ & $1,4(3,2 / 98,4)$ & $12,6(60,4 / 94,1)$ & $18,9(48,1 / 94,1)$ & $1(9,6 / 99,5)$ & $0,4(1,6 / 99,5)$ & $5,1(8,6 / 98,9)$ & $0(0,5 / 100)$ \\
\hline P. rustica (4) & - & - & - & - & - & - & - & - & - & - & - \\
\hline P. bilineatus (4) & - & - & - & - & - & - & - & - & - & - & - \\
\hline P. a. subcarinata (4) & - & - & - & - & - & - & - & - & - & - & - \\
\hline P. agassizii (4) & - & - & - & - & - & - & - & - & - & - & - \\
\hline P. patagoniensis (16) & 0,92 & 0,91 & 17820 & $56,3(81,7 / 98,5)$ & $0,2(8,4 / 100)$ & $24,7(46,6 / 90,8)$ & $5,8(22,9 / 99,2)$ & $0,1(2,3 / 100)$ & $7,1(3,8 / 96,9)$ & $5,9(13 / 99,2)$ & $0(13 / 100)$ \\
\hline X. dorbignyi (5) & 0,92 & 0,88 & 15401 & $44,9(80 / 100)$ & $2,9(8,8 / 96)$ & $44,5(72,8 / 84)$ & $5,3(23,2 / 97,6)$ & $0,9(3,2 / 98,4)$ & $1,2(0 / 99,2)$ & $0,2(4,8 / 100)$ & $0(3,2 / 100)$ \\
\hline X. semicinctus (2) & - & - & - & - & - & - & - & - & - & - & - \\
\hline Promedio & 0,93 & 0,89 & 16311,6 & $48(75,4 / 92,8)$ & $0,9(7 / 99)$ & $26(50,9 / 93,2)$ & $12,5(27,2 / 95,6)$ & $4,2(4,9 / 94,1)$ & $1,6(2,1 / 99,3)$ & $5(14 / 97,8)$ & $1,8(13,3 / 99,4)$ \\
\hline
\end{tabular}




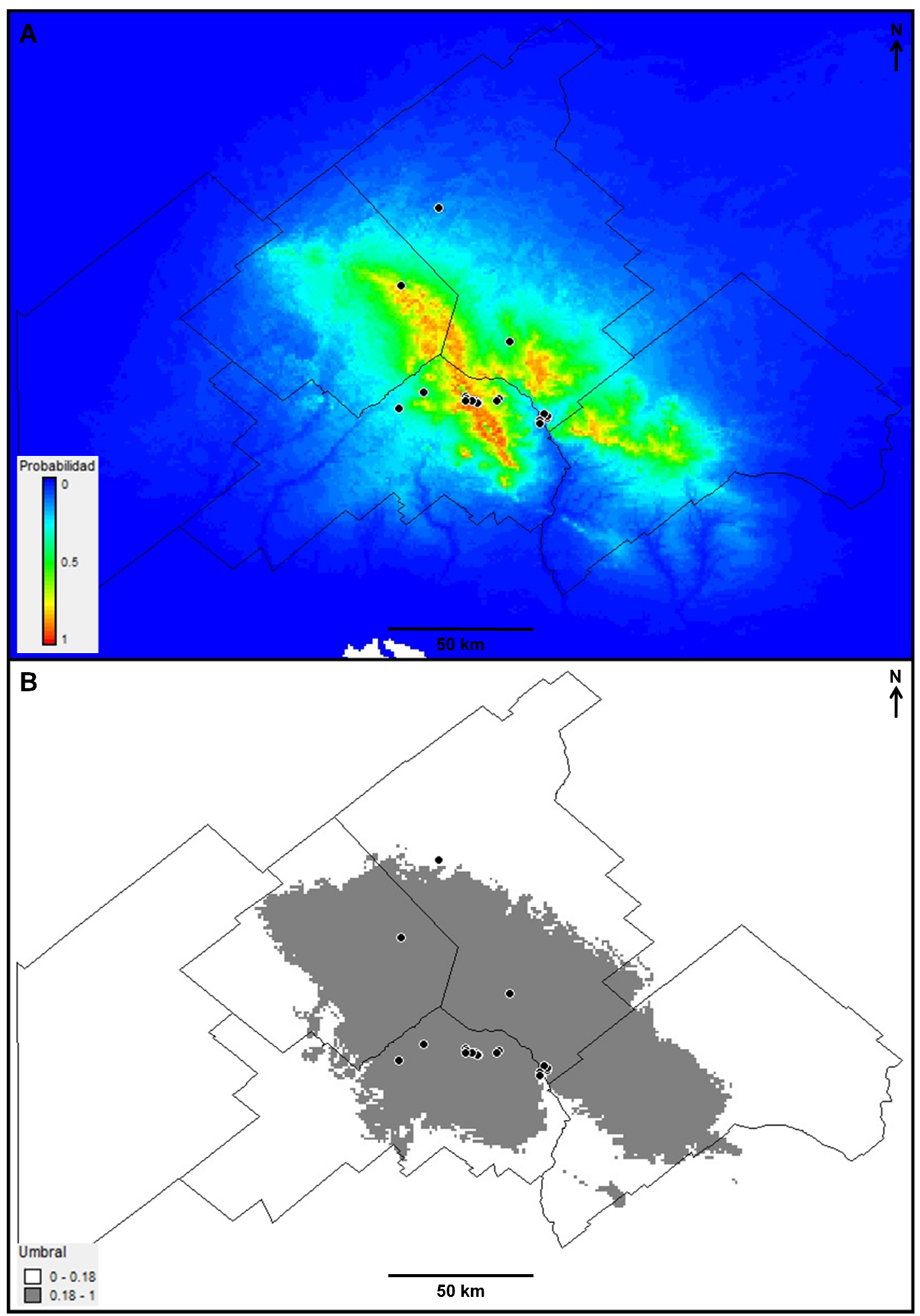

Figura 4.2. Modelo de distribución potencial de Bothrops alternatus en el área de estudio generado con Maxent en escala logística (A) y binaria (B). Los círculos negros indican las localidades conocidas de la especie que fueron empleadas en la construcción del modelo. 

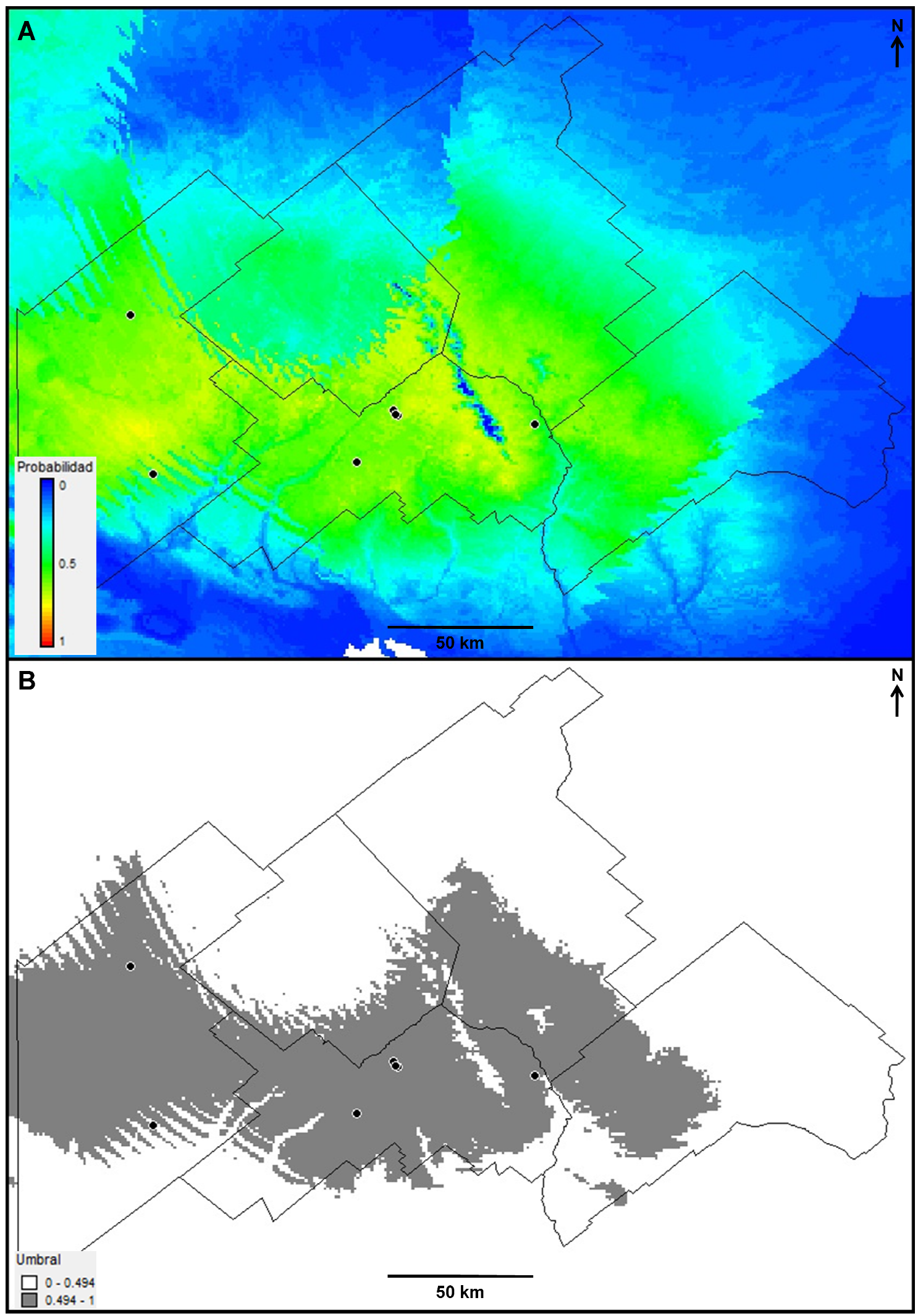

Figura 4.3. Modelo de distribución potencial de Bothrops ammodytoides en el área de estudio generado con Maxent en escala logística (A) y binaria (B). Los círculos negros indican las localidades conocidas de la especie que fueron empleadas en la construcción del modelo. 


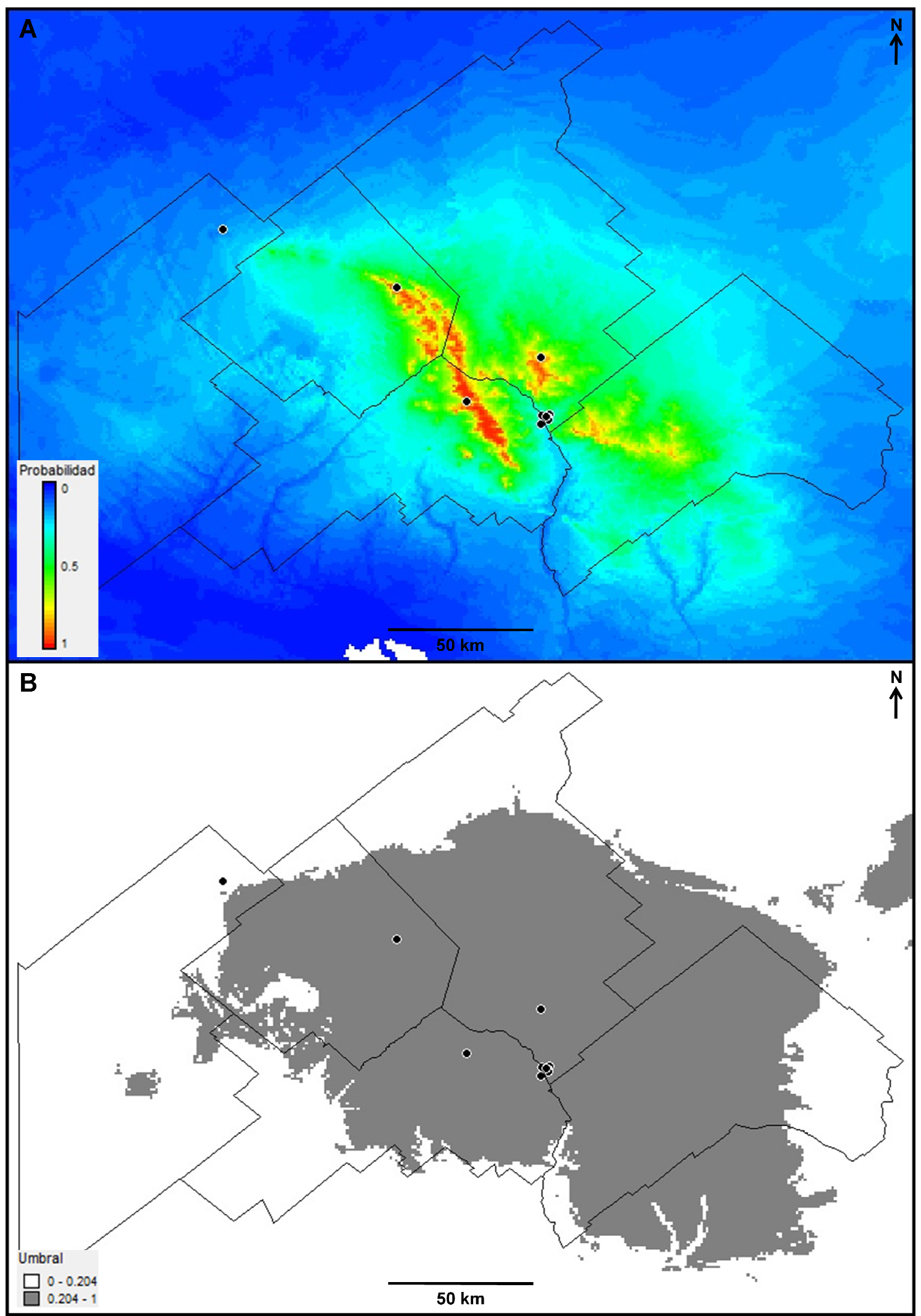

Figura 4.4. Modelo de distribución potencial de Epictia australis en el área de estudio generado con Maxent en escala logística (A) y binaria (B). Los círculos negros indican las localidades conocidas de la especie que fueron empleadas en la construcción del modelo. 


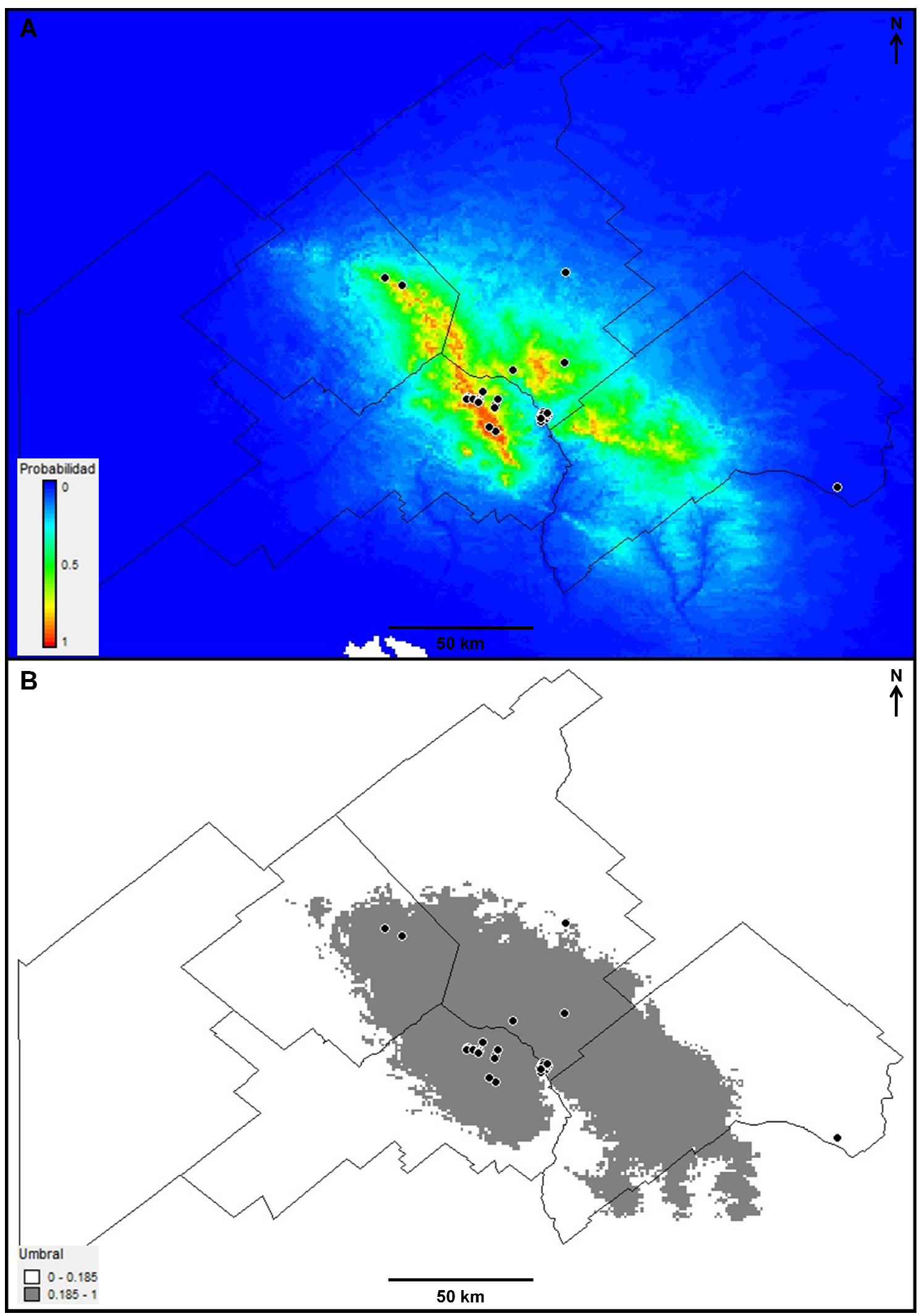

Figura 4.5. Modelo de distribución potencial de Erythrolamprus poecilogyrus sublineatus en el área de estudio generado con Maxent en escala logística $(A)$ y binaria (B). Los círculos negros indican las localidades conocidas de la especie que fueron empleadas en la construcción del modelo. 


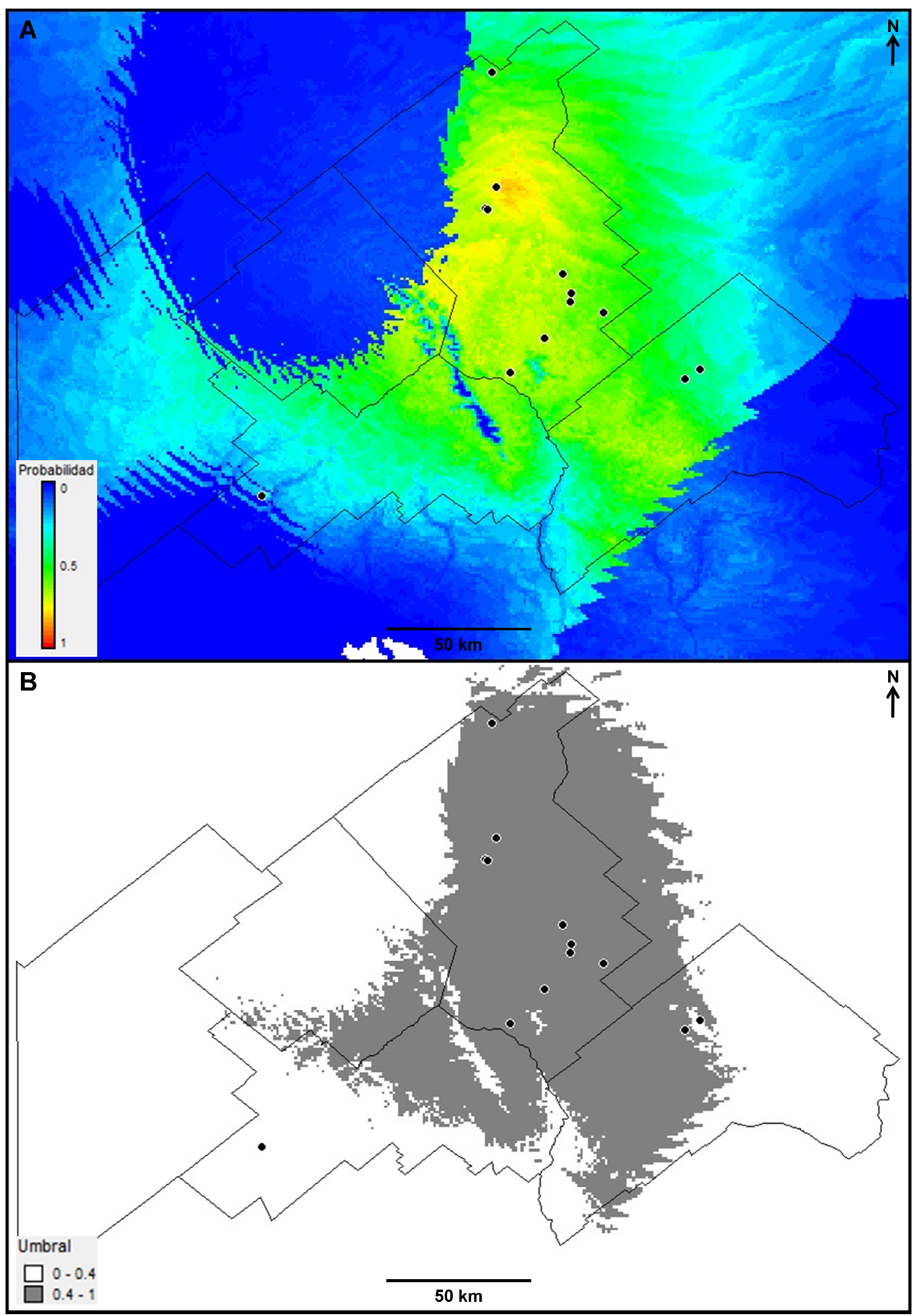

Figura 4.6. Modelo de distribución potencial de Lygophis anomalus en el área de estudio generado con Maxent en escala logística (A) y binaria (B). Los círculos negros indican las localidades conocidas de la especie que fueron empleadas en la construcción del modelo. 


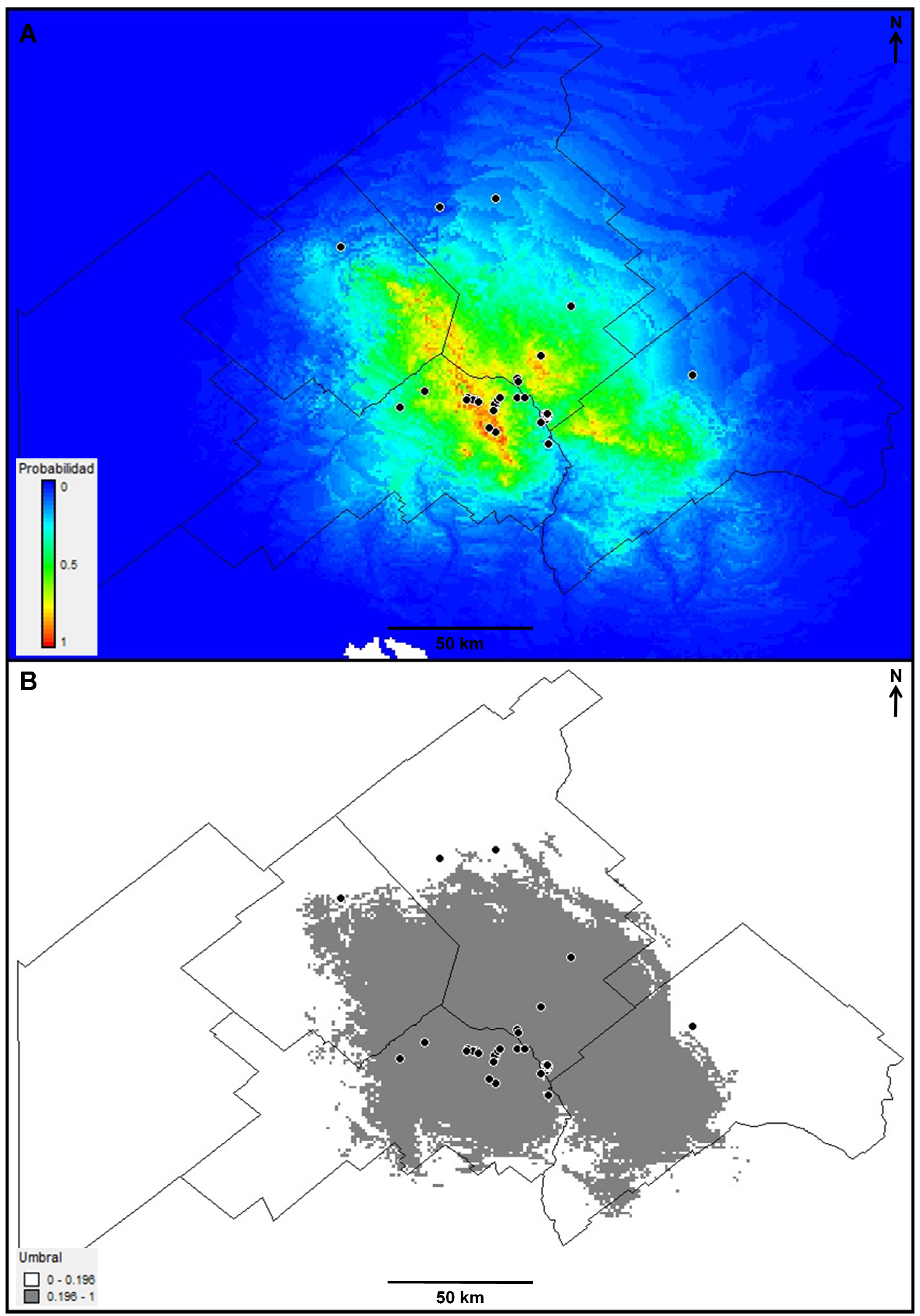

Figura 4.7. Modelo de distribución potencial de Lygophis elegantissimus en el área de estudio generado con Maxent en escala logística (A) y binaria (B). Los círculos negros indican las localidades conocidas de la especie que fueron empleadas en la construcción del modelo. 


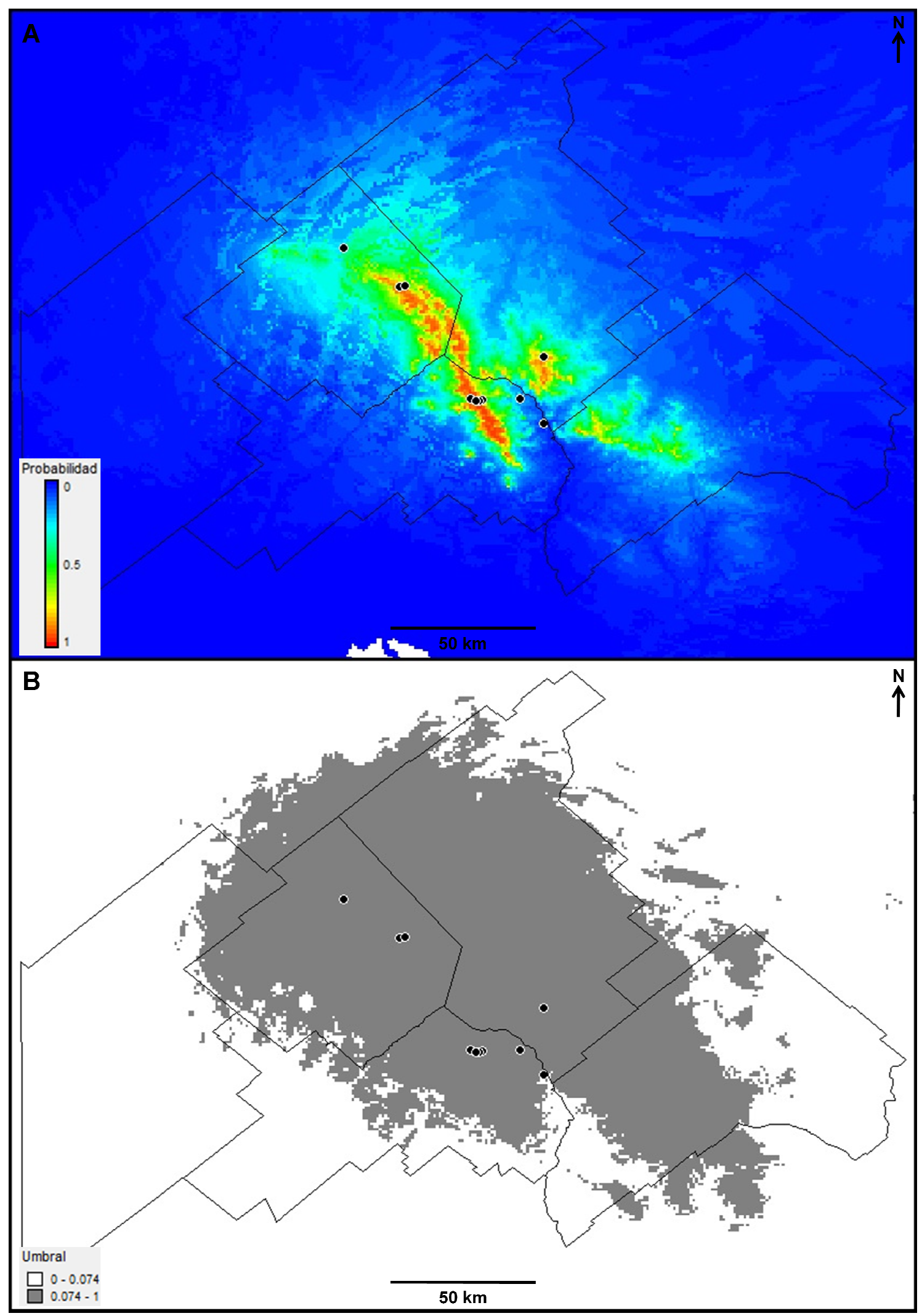

Figura 4.8. Modelo de distribución potencial de Oxyrhopus rhombifer rhombifer en el área de estudio generado con Maxent en escala logística (A) y binaria (B). Los círculos negros indican las localidades conocidas de la especie que fueron empleadas en la construcción del modelo. 


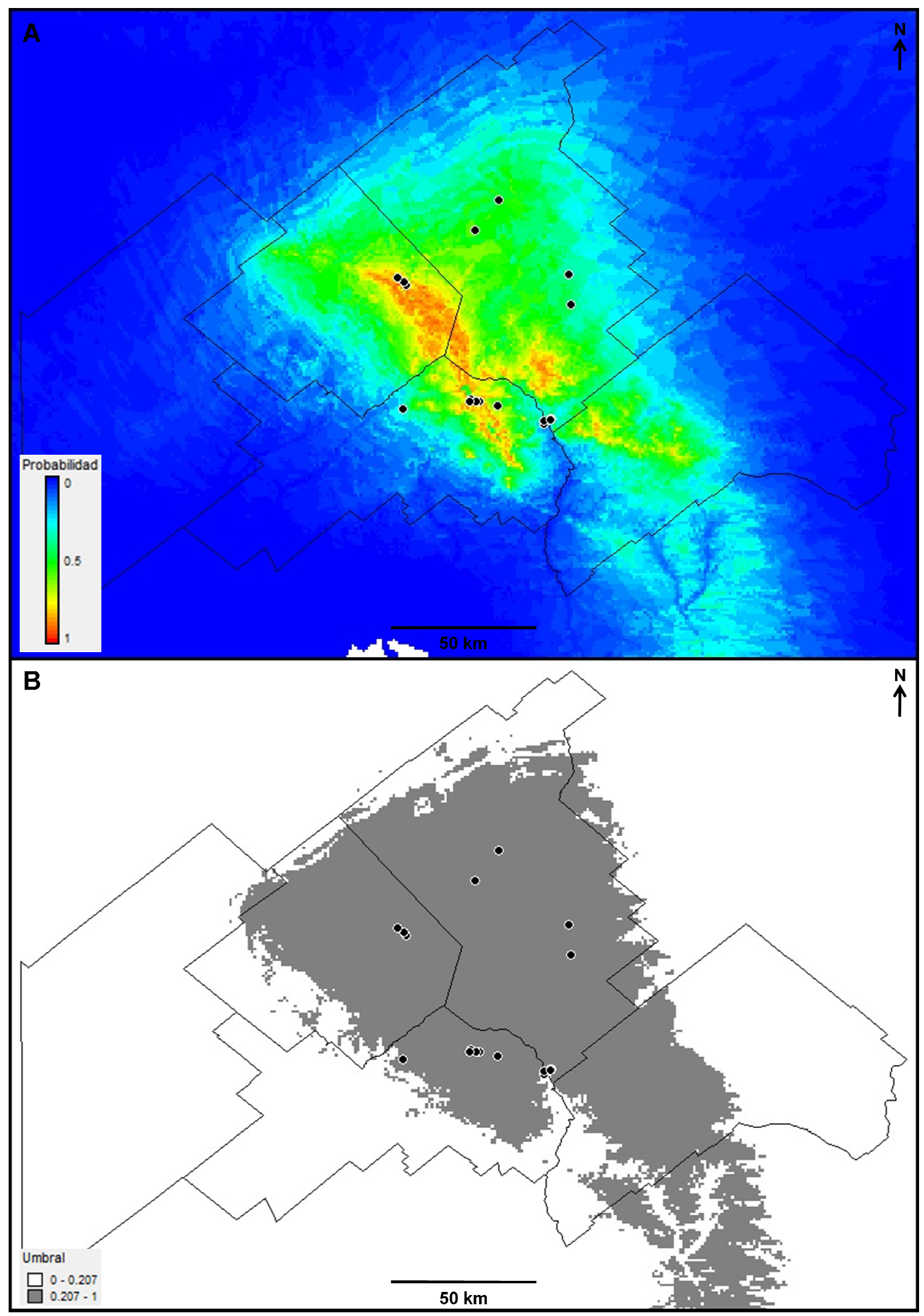

Figura 4.9. Modelo de distribución potencial de Philodryas patagoniensis en el área de estudio generado con Maxent en escala logística (A) y binaria (B). Los círculos negros indican las localidades conocidas de la especie que fueron empleadas en la construcción del modelo. 


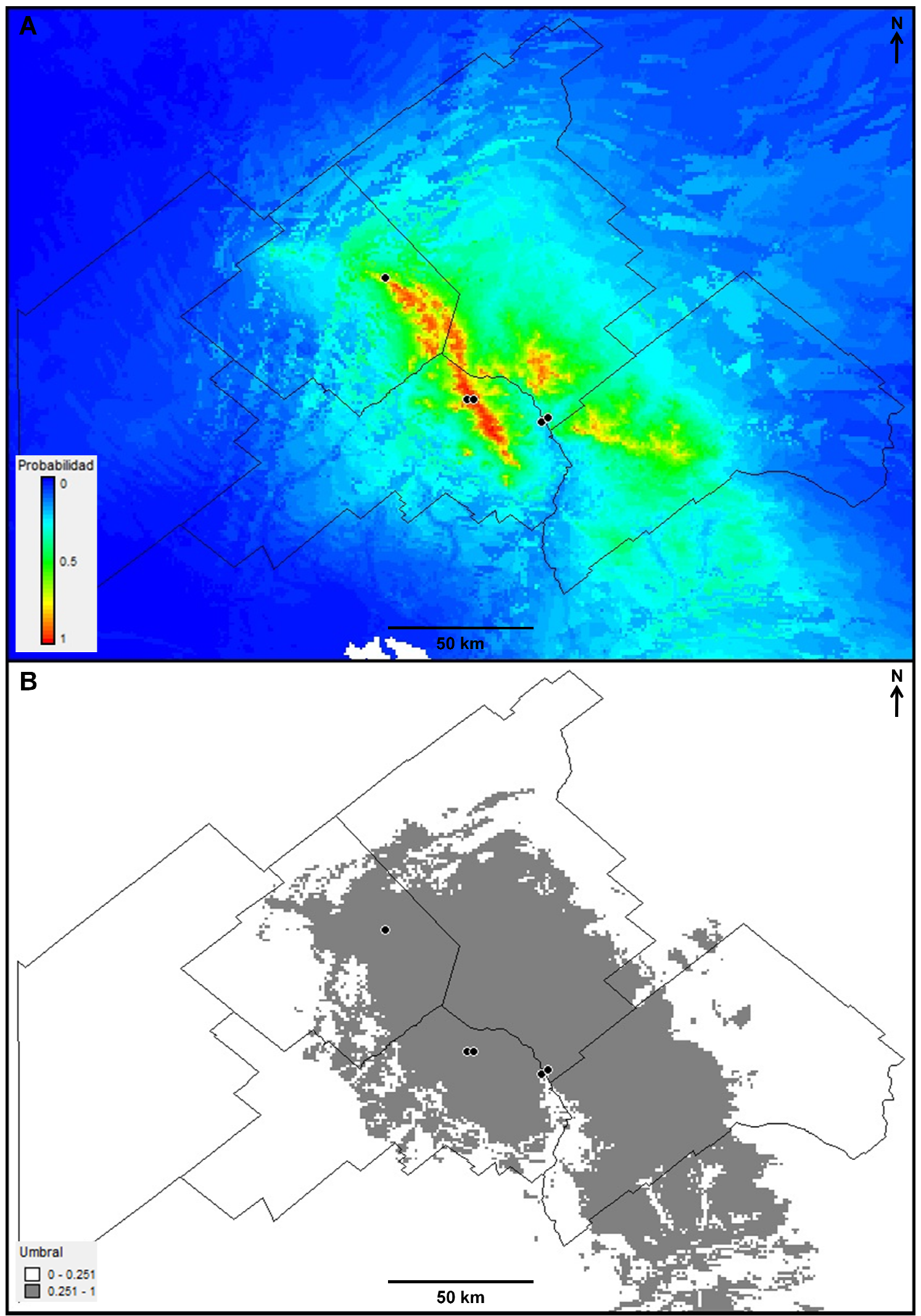

Figura 4.10. Modelo de distribución potencial de Xenodon dorbignyi en el área de estudio generado con Maxent en escala logística (A) y binaria (B). Los círculos negros indican las localidades conocidas de la especie que fueron empleadas en la construcción del modelo. 
El análisis de la contribución relativa de las variables ambientales a la construcción de los modelos reveló que, como promedio, la variable más importante fue la altitud, con valores entre 6,8\% a 68,4\% (media $=48 \%$ ), seguida de la temperatura máxima del mes más cálido, con valores entre $0 \%$ a $44,5 \%$ (media $=26 \%$ ) y de la temperatura mínima del mes más frío, con valores entre $5,3 \%$ a $23,5 \%$ (media $=12,5 \%$ ). El resto de las variables presentaron menor contribución porcentual ( $\leq 5 \%$, Tabla 4.3, Figura 4.11 A). Analizando por especie la contribución de las variables, en $L$. anomalus la variable más importante fue la temperatura máxima del mes más cálido, mientras que en el resto de las especies fue la altitud (Tabla 4.3). Un patrón muy similar se observa en los análisis de Jackknife (Tabla 4.3, Figura 4.11 B). De estos análisis se desprende que, como promedio, la altitud es la variable con mayor ganancia cuando se utiliza aislada, con valores entre $34,5 \%$ a 92,9\% (media = $75,4 \%$ ), seguida de la temperatura máxima del mes más cálido, con valores entre $0 \%$ a $72,8 \%$ (media $=50,9 \%$ ), y de la temperatura mínima del mes más frío, con valores entre $13,1 \%$ a $48,1 \%$ (media $=27,2 \%$ ). El resto de las variables ambientales presentaron menor ganancia cuando se utilizan aisladas ( $\leq 14 \%$, Tabla 4.3, Figura 4.11 B). Aunque la omisión alternativa de las variables no afectó sustancialmente el resultado de los modelos, la altitud también presenta, como promedio, la mayor disminución de ganancia cuando se omite y por lo tanto la mayor información que no está presente en el resto de las variables, con valores entre $51,8 \%$ a $100 \%$ (media $=92,8 \%$ ), seguida de la temperatura máxima del mes más cálido, con valores entre $78,6 \%$ a $100 \%$ ( media $=93,2 \%)$, y de la temperatura media del trimestre más húmedo, con valores entre $70,2 \%$ a $100 \%$ (media $=94,1 \%$ ). Analizando por especie la ganancia de los modelos, para todas las especies la altitud fue la variable que presenta la mayor ganancia por sí sola. Con respecto a la variable que presenta la mayor información cuando se omite, en $E$. australis, $P$. patagoniensis y $X$. dorbignyi fue la temperatura máxima del mes más cálido; en B. alternatus, E. p. sublineatus, L. elegantissimus y O. r. rhombifer fue la temperatura mínima del mes más frío; en $B$. ammodytoides fue la altitud; y en L. anomalus fue la temperatura media del trimestre más húmedo (Tabla 4.3). 
De acuerdo a los predictores empleados para modelar la distribución geográfica de cada especie existen tendencias diferentes entre la probabilidad de presencia y las variables identificadas como más informativas. Por ejemplo, considerando solo la variable más informativa, es notable en $E$. australis, O. $r$. rhombifer, y $X$. dorbignyi que la probabilidad de presencia aumenta de forma sigmoidal a medida que aumenta la altitud, mientras que para el resto de las especies la probabilidad de presencia alcanza un máximo a diferentes alturas (basales en $L$. anomalus y $B$. ammodytoides e intermedias en $B$. alternatus, $E$. p. sublineatus, L. elegantissimus y $P$. patagoniensis) y luego disminuye mostrando una función de respuesta normal más o menos acampanada, según la especie (Figura 4.12). 

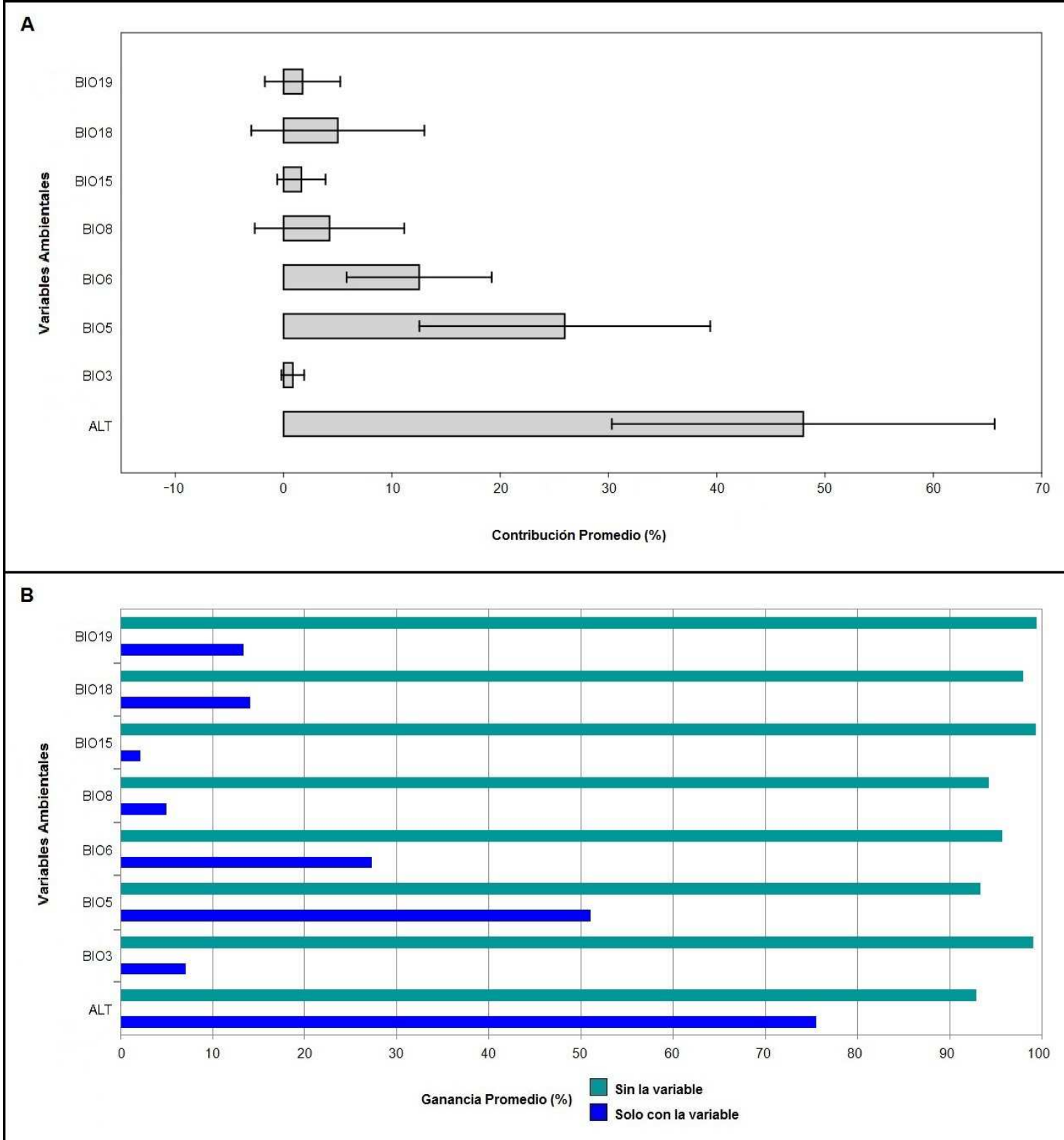

Figura 4.11. Aporte de las variables ambientales a los modelos de distribución potencial. (A) Contribución porcentual de las variables ambientales, las barras representan el promedio y las líneas el desvío estándar. (B) Resultados de la prueba de Jackknife, las barras representan la ganancia promedio de los modelos sin la variable (verde) y solo con la variable (azul). 


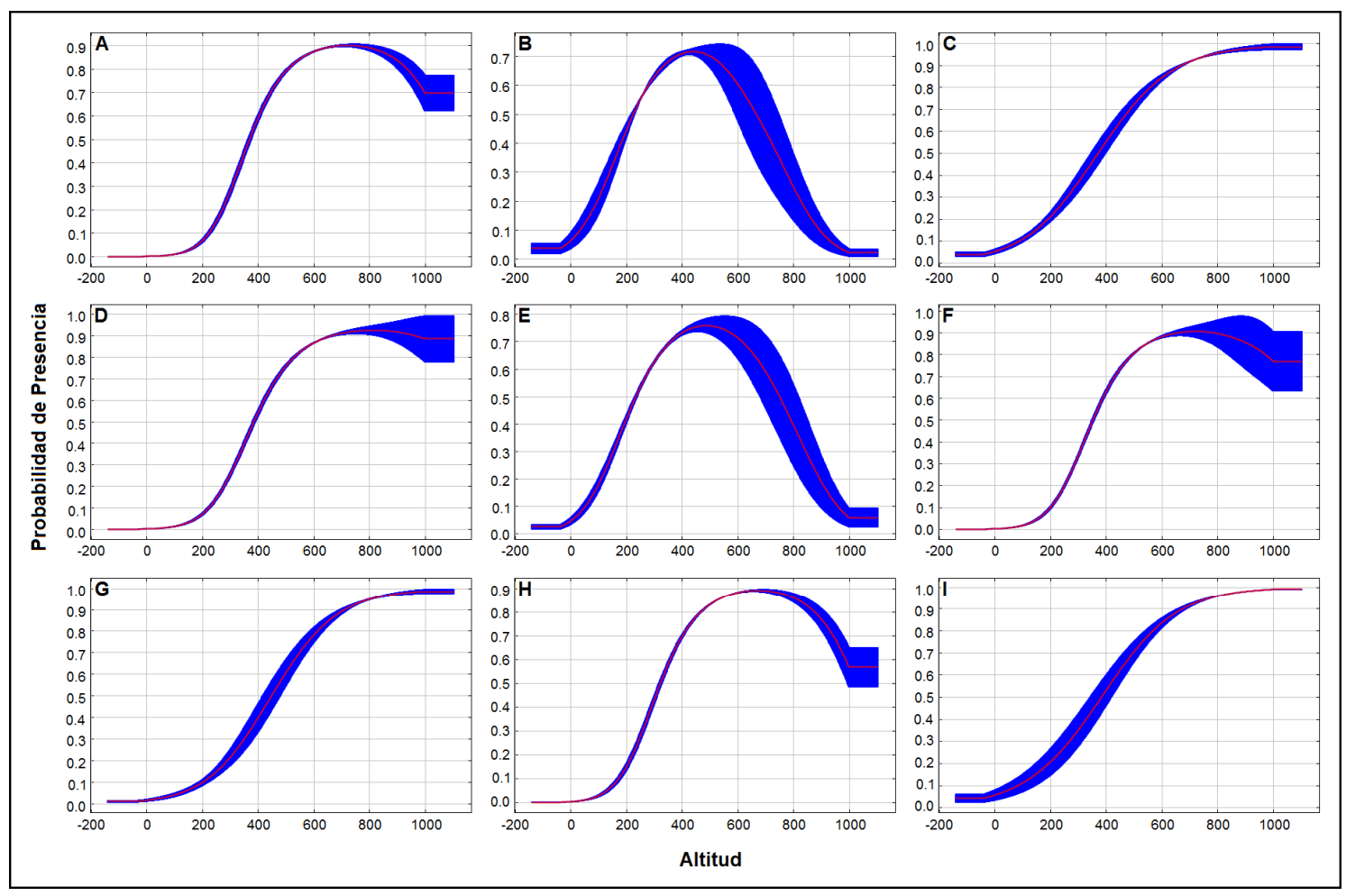

Figura 4.12. Curvas de respuesta de Bothrops alternatus (A), B. ammodytoides (B), Epictia australis (C), Erythrolamprus poecilogyrus sublineatus (D), Lygophis anomalus (E), L. elegantissimus $(\mathrm{F})$, Oxyrhopus rhombifer rhombifer $(\mathrm{G})$, Philodryas patagoniensis $(\mathrm{H})$ y Xenodon dorbignyi (I) empleando solo la variable altitud como predictor de la distribución. Las lineas rojas indican el promedio y la zona sombreada en azul el desvio estándar.

\section{Propuesta de conservación}

Fueron generadas dos propuestas de áreas prioritarias para la conservación basadas en diferentes algoritmos de remoción de celdas con Zonation ( $A B F$ y $C A Z$, Figura 4.13 y 4.14). Estos análisis revelaron que las mejores áreas para la conservación de la comunidad de serpientes (áreas con valores entre 0,95 a 1 ) abarcan una superficie total de $4176 \mathrm{Km}^{2}$ (1,3\% del territorio provincial). En el caso de la propuesta empleando $A B F$ las áreas de mayor importancia para la conservación se distribuyen asociadas a las Sierras de Ventania (sur de Cnel. Suárez, oeste de Cnel. Pringles, este de Saavedra y noreste de Tornquist, Figura 4.13). Mientras que, en la propuesta empleando $C A Z$ las áreas de mayor importancia para la conservación también se encuentran distribuidas en las mencionadas sierras, aunque con menor superficie de extensión a expensas de ampliar el área prioritaria a sectores 
particulares de la llanura circundante (centro de Cnel. Suárez y de Puan, Figura 4.14). La distribución de estas áreas, en ambas propuestas, está fuertemente influenciada por la presencia de especies endémicas y/o amenazadas (i. e., $L$. elegantissimus, $E$. australis y $P$. agassizii), las cuales recibieron un mayor coeficiente de priorización.

El análisis de correspondencia entre las áreas prioritarias de conservación seleccionadas y el PPET, única entidad de conservación funcionando actualmente en el área de estudio, reveló que solo el 1,6\% de estas áreas prioritarias están representadas en el PPET. Si consideramos además la RPSG, recientemente creada y aun sin vías de acceso, este valor aumenta al $2,2 \%$. Aunque la superficie destinada para la conservación en el área de estudio resultó escasa, ambas reservas naturales se encuentran emplazadas en zonas prioritarias para la conservación de la comunidad de serpientes (Figura 4.13 B y 4.14 B). 

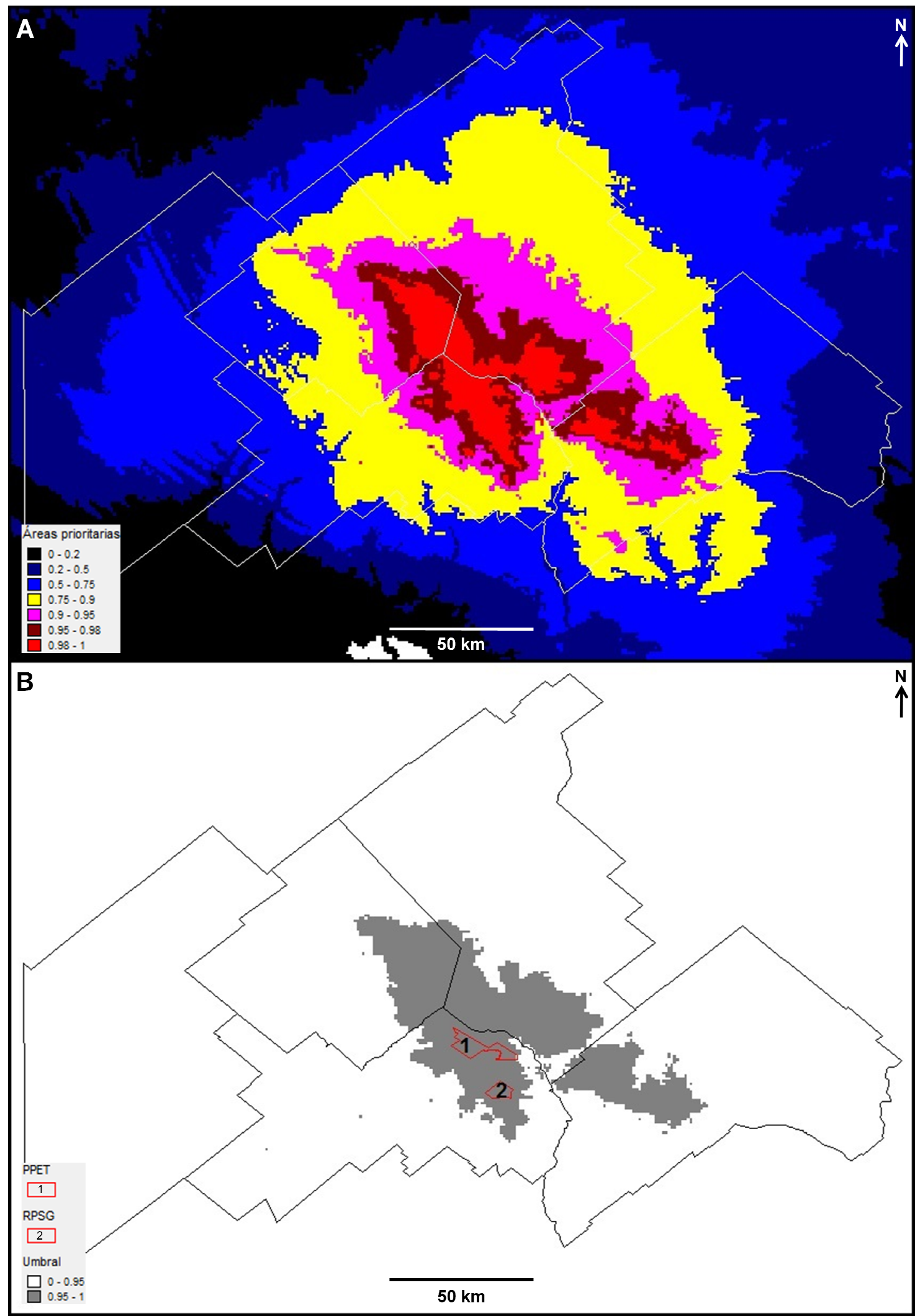

Figura 4.13. Modelo de áreas prioritarias para la conservación de la comunidad de serpientes basado en el algoritmo $A B F$ de Zonation, los valores próximos a uno indican áreas más prioritarias (A). Modelo de las mejores áreas para la conservación indicando en gris los valores de importancia mayores a 0,95 y en rojo las Áreas Naturales Protegidas del OPDS (B). 

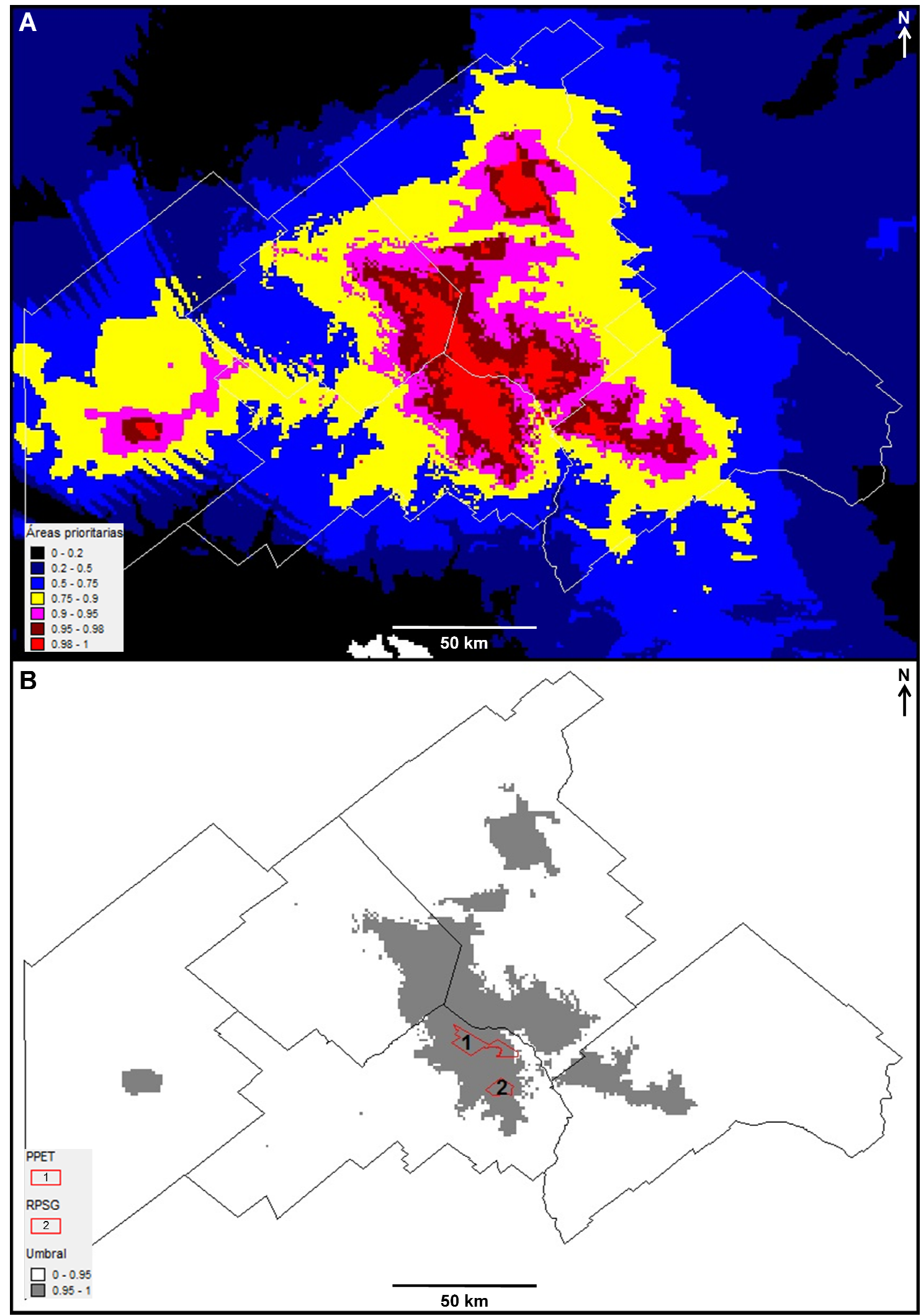

Figura 4.14. Modelo de áreas prioritarias para la conservación de la comunidad de serpientes basado en el algoritmo $C A Z$ de Zonation, valores próximos a uno indican áreas más prioritarias (A). Modelo de las mejores áreas para la conservación indicando en gris los valores de importancia mayores a 0,95 y en rojo las Áreas Naturales Protegidas del OPDS (B). 


\section{DISCUSIÓN}

\section{Modelos de distribución potencial}

El análisis comparativo en cuanto al número de sitios de colecta por especie reveló que las serpientes con una distribución considerada de intermedia a extendida (cinco o más celdas, Tabla 4.3) cumplieron los requisitos mínimos para generar los modelos de distribución potencial (Elith et al. 2006, Pearson et al. 2007). Los modelos obtenidos para estas nueve de las 15 especies que componen la comunidad de serpientes mostraron una capacidad predictiva que puede considerarse elevada según los valores del AUC (Philips et al. 2006). Se ha indicado que los modelos más precisos pueden ser generados para especies con nichos ecológicos estrechos, como las microendémicas, ya que poseen menores intervalos de distribución (ver Urbina-Carbona y Flores-Villela 2010). De hecho, los valores del AUC varían con el tamaño de área de estudio, y por lo tanto, este estadístico no es recomendable para comparar modelos de distribución en diferentes áreas (Jiménez-Valverde et al. 2008, VanDerWal et al. 2009). En este estudio, empleando el mismo área para modelar la distribución de todas las especies (Figura 4.1), los valores predictivos del AUC resultaron relativamente similares, como así también el área de ocupación o hábitat apropiado para cada especie (Tabla 4.3). Con respecto a esto último, sin embargo, se debe mencionar que las especies de hábitos primarios fosoriales o semifosoriales (por ej. $E$. australis y 0 . $r$. rhombifer, Tabla 4.3, Figura 4.4 B y 4.8 B) presentaron relativamente mayores áreas de ocupación, que aquellas especies de hábitos primarios semiacuáticos (por ej. E. p. sublineatus y L. elegantissimus, Tabla 4.3, Figura 4.5 B y 4.7 B). Esto probablemente se encuentra relacionado con la disponibilidad de hábitats para las serpientes, ya que de los principales tipos de hábitats mencionados en el área de Sierras de Ventania (roquedales, suelos cubiertos por pastizales y cursos de agua), el ambiente acuático resulta de menor importancia en la región serrana, ya que está formado principalmente por arroyos temporarios (ver Kristensen y Frangi 1995b). La disponibilidad de hábitats, o de tiempo suficiente para colonizarlos, junto con las interacciones bióticas, como la capacidad competitiva de las especies, han sido indicados 
previamente para explicar patrones biogeográficos de este tipo en diferentes grupos de organismos (ver Losos y Ricklefs 2009).

El modelado de una comunidad combina datos de muchas especies y produce información adicional sobre los patrones espaciales en la distribución de la diversidad a nivel de la comunidad en conjunto, además de a nivel de las especies individuales (revisado en Ferrier y Guisan 2006). Considerando esto, al proyectar los modelos en el espacio geográfico se observan básicamente dos patrones de distribución (Figura 4.2 a 4.10), que corroboran las observaciones realizadas utilizando solo los datos de ocurrencia de las especies (ver patrones de distribución y abundancia en capítulo 2): (1) el hábitat apropiado es elevado en las Sierras de Ventania, tanto en el ambiente serrano como en el intraserrano (valles serranos), y disminuye gradualmente hacia el ambiente periserrano y la llanura circundante (en $B$. alternatus, $E$. australis, E. p. sublineatus, L. elegantissimus, O. r. rhombifer, P. patagoniensis y $X$. dorbignyi) y (2) el hábitat apropiado es elevado en la llanura circundante y el ambiente periserrano y disminuye hacia el ambiente serrano (en $B$. ammodytoides y L. anomalus). El primer patrón, tipo islote zoogeográfico, confirma las menciones previas sobre la presencia de serpientes endémicas o poblaciones aparentemente aisladas en el área de estudio, como tempranamente indicaron Cranwell (1942) para L. elegantissimus, Barrio (1961) y Barrio y Miranda (1966) para B. alternatus, y Scrocchi (1990) y Williams (1991) para E. australis. Una situación similar podría ocurrir con $P$. aestiva subcarinata y P. agassizii (Couturier y Grisolía 1989, Viñas et al. 1989, respectivamente), aunque no pudo ser confirmado con modelos precisos en el presente estudio, debido a su distribución restringida (cuatro o menos celdas, Tabla 4.3). El resto de las especies aquí asignables a este patrón de distribución (i. e. E. p. sublineatus, O. r. rhombifer, $P$. patagoniensis y $X$. dorbignyi) fueron indicadas para toda la provincia de Buenos Aires, sin mencionar localidades concretas y material de referencia (ver Miranda et al. 1983, Varela de Olmedo y Carrizo 1987, Williams 1991), lo que dificulta realizar comparaciones, y aún más al considerar la escala local de este estudio. Sería necesario efectuar estudios adicionales para determinar la distribución de éstas y otras especies de serpientes referidas para toda la provincia, ya que 
aparentemente están ausentes en algunas regiones, como por ej. O. $r$. rhombifer, $X$. semicinctus y $X$. dorbignyi (ver capítulo 2). Estos interrogantes quedan planteados para futuros estudios. No obstante, resulta interesante destacar en $P$. patagoniensis y $X$. dorbignyi la extensión hacia el sur de los partidos relevados, mayormente a través del Río Sauce Grande (Figura 4.9 y 4.10). Estas áreas de sobrepredicción, zonas sin registros puntuales pero con elevada probabilidad de presencia en los modelos, en organismos de poca capacidad de dispersión como los lagartos parecen estar provocadas por los elementos físicos como los ríos, ya que representan barreras geográficas (Pearson et al. 2007, Raxworthy et al. 2007). En este estudio, la sobrepredicción asociada al Río Sauce Grande, podría indicar una posible vía de dispersión para las serpientes, como tempranamente propuso Barrio (1961) para explicar el origen de las poblaciones aisladas de $B$. alternatus en las Sierras de Ventania. Con respecto al segundo patrón de distribución, los modelos obtenidos también fueron similares, en términos generales, a los mapas presentados por Dixon (1985) y Williams (1991) para L. anomalus, y por Barrio (1961) para B. ammodytoides. Sin embargo, a diferencia de los mapas presentados por estos autores, los modelos predictivos extienden el área de distribución de $L$. anomalus, y restringen la de $B$. ammodytoides; es notable en ambas especies que la probabilidad de presencia disminuye considerablemente en el ambiente serrano en particular (ver Figura 4.3 y 4.6). Con respecto a $B$. ammodytoides, una situación similar fue observada en varias localidades de las Sierras de Tandilia, donde esta especie no fue registrada (ver Nágera 1915, Vega y Bellagamba 1990). Se debe señalar que los mapas presentados previamente por Nori et al. (2013a) para $B$. alternatus y $B$. ammodytoides pierden detalle en las Sierras de Ventania, debido al amplio rango geográfico modelado, lo que no invalida las observaciones brindadas por estos autores. Este es uno de los primeros estudios que modela la distribución de una comunidad de serpientes a escala local y resolución detallada (ver Jenkins et al. 2009).

La altitud resultó la variable más informativa para la construcción de los modelos de distribución, seguida de la temperatura máxima del mes más cálido y la mínima del más frio (Tabla 4.3, Figura 4.11). Esta variable, típicamente, 
implica cambios no aleatorios en numerosos componentes del clima y el ambiente local, que finalmente determinan los patrones de diversidad a lo largo del gradiente altitudinal (Lomolino 2001). Según los datos disponibles para este estudio, en las Sierras de Ventania y alrededores, la altitud está fuertemente correlacionada con tres variables climáticas, la temperatura media anual, la temperatura media del trimestre más seco y del más frío (Tabla 4.2). Estas variables reflejan, en conjunto, las características ambientales sugeridas como determinantes en la distribución potencial de diversas especies de serpientes (por ej. Urbina-Cardona y Flores-Villela 2010, Paredes-García et al. 2011, Rivera et al. 2011, Mesquita et al. 2013, Nori et al. 2013b, González-Maya et al. 2014). No obstante, la selección de variables estuvo limitada por la disponibilidad de los datos y su resolución. Se debe mencionar que la disminución de la temperatura con el aumento en la altitud ha sido indicado previamente en el área de Sierra de la Ventana (Kristensen y Frangi 1995a). Según estos autores, y aceptando las zonas de vida propuestas por Holdridge (1978), las localidades basales (por ej. Sierra de la Ventana, Tornquist) se corresponden con el Bosque seco templado cálido, mientras que el límite inferior $\left(12^{\circ} \mathrm{C}\right)$ del Piso montano se encuentra a los $750 \mathrm{msnm}$, y a partir de allí son más importantes las comunidades exclusivas de pastizal de las sierras, como los prados de altura y los pastizales de Festuca pampeana y $F$. ventanicola. En este estudio, considerando solo la altitud como variable predictora de la distribución (Figura 4.12), la probabilidad de presencia de la mayoría de las especies $(66,6 \%$ del total), incluyendo la especie microendémica $L$. elegantissimus y la población aislada de B. alternatus, alcanza un pico máximo en altitudes basales o intermedias, en concordancia con el Bosque seco templado cálido (aproximadamente $400 \mathrm{msnm}$ en $B$. ammodytoides y $L$. anomalus y 700 msnm en B. alternatus, E. p. sublineatus, $L$. elegantissimus y $P$. patagoniensis), y luego disminuye mostrando una curva de respuesta normal más o menos acampanada según la especie (Figura 4.12 A, $B, D, E, F y H)$. La relación unimodal entre la riqueza de especies y la elevación, con un pico a bajas o medias altitudes, parece ser un patrón general en una gran variedad de taxa, inclusive en serpientes (Lomolino 2001, Fu et al. 2007, McCain 2010). En el resto de las especies modeladas, incluyendo el endemismo parcial $E$. australis, la probabilidad de presencia muestra una 
función de respuesta de tipo sigmoidea, alcanzando un máximo a mayores altitudes en concordancia con el Piso montano templado cálido (aproximadamente $1000 \mathrm{msnm}$ en E. australis, O. r. rhombifer y X. dorbignyi, Figura $4.12 \mathrm{C}, \mathrm{G}$ e I). En este estudio, solo estas últimas especies de serpientes apoyan la propuesta de una unidad bioclimática exclusiva en la provincia de Buenos Aires sobre los 750 msnm (ver Kristensen y Frangi 1995a).

\section{Propuesta de conservación}

Como consecuencia de la heterogeneidad física, las zonas de montaña presentan mayor diversidad que las llanuras adyacentes, haciendo posible conservar grandes cantidades de diversidad en un área relativamente pequeña (Lafon 2004, Fu et al. 2007). En el presente estudio fueron comparadas dos propuestas de conservación, basadas en diferentes algoritmos o reglas de remoción de celdas, para determinar la opción más apropiada en el área de interés (sensu Moilanen et al. 2014). En la propuesta de áreas prioritarias empleando el algoritmo $A B F$, todas las celdas que contienen las especies que ocupan el ambiente de llanura circundante (en menor número que las especies que ocupan el ambiente serrano, intraserrano y periserrano) se pierden primero en el análisis, ya que este algoritmo minimiza la tasa de extinción priorizando áreas que mantengan la riqueza especifica (Figura 4.13). Por otro lado, la propuesta empleando el algoritmo $C A Z$, prioriza la ocurrencia de todas las especies, dando importancia a las áreas núcleo de su distribución geográfica (o sea, con elevada probabilidad de presencia), y por lo tanto, indica además áreas puntuales de baja riqueza específica en la llanura circundante, minimizando así la pérdida biológica (Figura 4.14). Debido a las características particulares del área de estudio, ya que las Sierras de Ventania fueron consideradas como una isla biogeográfica (por ej. Cranwell 1942, Kristensen y Frangi 1995b), y de los objetivos de conservación, ya que las serpientes fueron consideradas muy buenas especies subrogadas de la biodiversidad (por ej. Giraudo 2001, Arzamendia y Giraudo 2004), y además, esperando un alto retorno de la inversión en la conservación, la propuesta de áreas prioritarias 
empleando el algoritmo $A B F$ se considera la opción más adecuada para la conservación de la comunidad de serpientes (ver Moilanen et al. 2014). Se debe mencionar que en esta propuesta se pierden ambientes de algunas especies en la llanura circundante (i. e., B. ammodytoides, L. anomalus y $X$. semicinctus), que fueron incluidos en el análisis empleando el algoritmo CAZ. Sin embargo, el algoritmo $A B F$ representa mejor el hábitat de las especies endémicas y/o amenazadas (i. e., L. elegantissimus, E. australis y $P$. agassizii), las cuales recibieron un mayor coeficiente de priorización. Adicionalmente, esta propuesta de conservación se corresponde con los objetivos de tamaño, forma y distancia entre reservas fijados en la teoría del equilibrio de biogeografía de islas y teorías biogeográficas asociadas (MacArthur y Wilson 1967, Diamond 1975, Wilson y Willis 1975).

Independientemente del algoritmo de remoción de celdas empleado para generar las propuestas de conservación, los resultados aquí obtenidos indican que las ANP existentes en las Sierras de Ventania son poco efectivas en la protección de la comunidad de serpientes. Las ANP juegan un rol fundamental para su preservación, ya que la mayoría de las personas mata a las serpientes cuando las encuentra debido al exacerbado temor cultural y bajo la presunción de que todas las especies son peligrosas (Giraudo 2001, Arzamendia y Giraudo 2004, 2012). Sin embargo, y como se observa en el presente estudio, los límites de las ANP han sido establecidos fundamentalmente siguiendo razones logísticas, a partir de elementos antrópicos o geográficos, que no necesariamente delimitan los hábitats y las condiciones propicias para las especies (Araújo y Williams 2000, Küper et al. 2004). Aquí, protegiendo únicamente las áreas con valores entre 0,95 a 1 (o sea, al menos el 5\% de las áreas con mayor riqueza específica en el caso del $A B F$, o al menos el $5 \%$ del área núcleo de la distribución geográfica de todas las especies en el caso del $C A Z$ ) se observa que solo el $1,6 \%$ de estas áreas prioritarias están representadas en el PPET, única entidad de conservación funcionando actualmente en el área de estudio. Si consideramos además la RPSG, recientemente creada y aun sin vías de acceso, este valor aumenta al $2,2 \%$. Se debe mencionar que, aunque la superficie destinada para la conservación en el área de estudio resulta escasa para cumplir con el objetivo propuesto de 
conservación, ambas reservas naturales se encuentran emplazadas en zonas prioritarias para la conservación de la comunidad de serpientes (Figura 4.13 B y $4.14 \mathrm{~B})$. Los resultados obtenidos en el presente estudio aportan más evidencia que apoya la hipótesis de que más área es requerida para alcanzar los objetivos de conservación, inclusive los menos ambiciosos (por ej. UrbinaCardona y Flores-Villela 2010, Tognelli et al. 2011, Corbalán et al. 2011, Nori et al. 2013a).

Finalmente, aunque en el presente estudio se implementó un enfoque desarrollado para el diseño de áreas prioritarias bajo un objetivo específico, y considerando que los resultados pueden ser relevantes para las políticas de conservación, se es consciente que algunos aspectos adicionales deben ser considerados a la hora de tomar decisiones. Por ejemplo, el área identificada como prioritaria representa una porción continua de terreno (ver Figura 4.13 B) y es poco probable que su totalidad pueda ser asignada para la conservación, principalmente, debido a que la mayor parte de estas tierras son privadas. EI objetivo de este estudio, sin embargo, es identificar las áreas de interés para la conservación de la comunidad de serpientes y así colaborar con los agentes de conservación en la toma de decisiones. Si los objetivos de conservación propuestos se quieren alcanzar, la protección debe tener lugar tanto dentro como fuera de las ANP. Para lograr esto, se deben proporcionar incentivos sociales y económicos apropiados, además de una gestión innovadora de sistemas agrícolas más amigables con la biodiversidad (ver Tognelli et al. 2011). Otro aspecto interesante a tener en cuenta es que, a pesar de que las serpientes son muy buenas especies subrogadas de la biodiversidad en las Sierras de Ventania ya que, por ej., son elementos característicos de todos los hábitats/microhábitats presentes en la región, y además depredan sobre una gran variedad de presas, incluyendo todos los anuros y la mayoría de los roedores citados (ver capítulo 3), estudios adicionales considerando otros grupos de organismos como subrogados de la biodiversidad serían muy interesantes a fin de complementar y apoyar los resultados aquí obtenidos. 


\section{CONCLUSIONES}

\section{Composición taxonómica y similitud biogeográfica}

- El material examinado permite confirmar la presencia de 15 especies y subespecies de serpientes en el área de estudio, que representan el $50 \%$ del total de ofidios citados para la provincia de Buenos Aires, y el $11 \%$ del total citado para la República Argentina.

- Independiente del método empleado para la obtención de los ejemplares, las especies más abundantes en las Sierras de Ventania son, en orden decreciente, Erythrolamprus poecilogyrus sublineatus, Lygophis elegantissimus, Bothrops alternatus, Epictia australis y Philodryas patagoniensis. El resto de las especies son poco frecuentes.

- Las localidades y partidos del centro del área de estudio presentan mayor riqueza y abundancia de serpientes que las localidades y partidos periféricos. Este patrón de distribución podría estar relacionado con las diferencias significativas halladas en la distribución altitudinal de la comunidad de serpientes, o bien debido a las diferencias en la utilización de los ambientes en términos productivos.

- El área de sintopía estricta entre los ofidios congéneres Lygophis elegantissimus - L. anomalus, Epictia australis - E. munoai y Bothrops alternatus - $B$. ammodytoides, se observa en el noreste, este y sudoeste de las Sierras de Ventania, respectivamente.

- La disminución de la riqueza con el aumento de la latitud sur y la disminución de la temperatura se observa, levemente, al comparar la comunidad de serpientes del Noreste bonaerense y el resto de las regiones. En las Sierras de Ventania, otros factores independientes de la latitud, como la mayor altitud, deben estar influenciando la elevada riqueza específica.

- La mayor similitud biogeográfica de las Sierras de Ventania se presenta con las Dunas Costeras, con las Sierras de Balcarce y Mar del Plata y con las Sierras Bayas. Estas regiones forman un agrupamiento bien definido en base a sus ofiofaunas. 
- Las comunidades de serpientes contrastan parcialmente con el esquema zoogeográfico clásico. Se reconoce una división de mayor jerarquía entre el dominio Central o provincia del Monte y el resto de las regiones del dominio Pampásico. En este esquema, el ecotono entre estos dos bloques faunísticos se desplaza al sudoeste del esquema clásico, y por lo tanto, las Sierras de Ventania forman parte del dominio Pampásico. Adicionalmente, el reconocimiento del dominio Subtropical es claro, al igual que su vinculación faunística con el dominio Pampásico por pérdida de especies.

\section{Relaciones tróficas y espaciales}

- $\quad$ Epictia australis utiliza una estrategia de forrajeo activo (widely foraging) con elevada selectividad por los huevos y larvas de formícidos (Pheidole sp.) lo que sustenta una dieta del tipo especialista, con bajos valores en los índices de diversidad de presas y de amplitud del nicho trófico.

- Erythrolamprus poecilogyrus sublineatus es una subespecie que utiliza una estrategia de forrajeo activo (widely foraging), con selectividad moderada por los anfibios (en general) que sustenta una tendencia a la especialización (preferencia) trófica, pero con una dieta generalista con una gran amplitud de nicho trófico (número y volumen) y diversidad de presas.

- Lygophis elegantissimus utiliza una estrategia de forrajeo activo (widely foraging), con elevada selectividad por las larvas y adultos de Hypsiboas pulchellus y exclusividad en la alimentación de anfibios anuros que sustenta una dieta de tipo especialista con relativamente bajos valores de amplitud del nicho trófico (número y volumen) y diversidad de presas.

- $\quad$ Philodryas patagoniensis utiliza una estrategia de forrajeo activo (widely foraging) y presenta una dieta generalista con una selectividad moderada por las arañas del género Lycosa, que sustenta una tendencia a la especialización (preferencia) trófica, con bajos valores en los índices de diversidad de presas y de amplitud del nicho. 
- Bothrops alternatus utiliza una táctica trófica de forrajeo pasivo (sit and wait), con elevada selectividad por los roedores (en general), que sustenta una dieta del tipo especialista, con elevados valores en los índices de diversidad de presas y de amplitud del nicho debido al consumo de diversas especies de roedores.

- Los buscadores activos consumen presas primarias que generalmente presentan una táctica trófica de búsqueda pasiva, y viceversa, evidenciando el entrecruzamiento entre modos de forrajeo.

- En la comunidad de serpientes de las Sierras de Ventania las preferencias en el uso del microhábitat parecen estar relacionadas con el hallazgo local de las presas. El $40 \%$ de las especies son primariamente terrestres, $26,6 \%$ son semifosoriales, $20 \%$ son semiacuáticas y $13,3 \%$ son fosoriales.

- Epictia australis presenta elevada selectividad por el tipo de microhábitat (bajo rocas sueltas sobre tierra), lo que sustenta una especialización en el uso del sustrato, con bajos valores en los índices de diversidad y amplitud espacial.

- Erythrolamprus poecilogyrus sublineatus presenta una selectividad moderada por el tipo de sustrato, lo que sustenta hábitos generalistas con relativamente altos valores en los índices de diversidad y amplitud espacial, aunque la elevada proporción de ejemplares hallados en el agua o cerca de ella indican una preferencia por este tipo de medio.

- $\quad$ Lygophis elegantissimus presenta una selectividad moderada por el tipo de sustrato lo que sustenta hábitos generalistas con valores relativamente altos en los índices de diversidad y amplitud del nicho espacial, aunque la elevada proporción de ejemplares hallados en los arroyos serranos y sus márgenes sugiere una preferencia por este microambiente.

- Philodryas patagoniensis presenta elevada selectividad por el tipo de sustrato (pastizal en general), lo que sustenta una especialización en el uso del microhábitat con relativamente bajos valores en los índices de diversidad y amplitud espacial. 
- Bothrops alternatus presenta una selectividad moderada por el tipo de sustrato, lo que sustenta hábitos generalistas con relativamente altos valores en los índices de diversidad y amplitud del nicho espacial, aunque la elevada proporción de ejemplares hallados en los pastizales en general sugiere una preferencia por este tipo de sustrato.

- Se observa un bajo solapamiento significativo en la proporción de presas consumidas entre E. australis y el resto de las especies comparadas, E. $p$. sublineatus y $P$. patagoniensis, E. p. sublineatus y $B$. alternatus, y también entre L. elegantissimus y $P$. patagoniensis, y L. elegantissimus y B. alternatus.

- Se registra un bajo solapamiento significativo en el volumen de las presas consumidas entre $E$. australis y el resto de las especies comparadas, $L$. elegantissimus y $P$. patagoniensis, y L. elegantissimus y $B$. alternatus.

- Se registra un elevado solapamiento significativo en el uso del microhábitat entre E. p. sublineatus y L. elegantissimus, y también entre $P$. patagoniensis y $B$. alternatus. Ante la escasez de recursos, E. p. sublineatus se vería afectada por $L$. elegantissimus, y $P$. patagoniensis se vería afectada por $B$. alternatus, ya que el solapamiento elevado y significativo en el uso del microhábitat implicaría una potencial competencia, que aún no ha dado lugar a divergencias en el uso de los recursos.

- La dieta parece ser más importante que el microhábitat en la divergencia ecológica, ya que se encuentra particionada en la mayoría de los pares de especies comparadas. La comunidad de serpientes se encuentra estructurada por la dieta.

- Las especies analizadas utilizan nichos complementarios con una alta superposición en una dimensión del nicho (microhábitat) y una baja superposición en otra (proporción y volumen de las presas consumidas) lo que permite que coexistan en simpatría y/o sintopía evitando la exclusión competitiva. 


\section{Áreas prioritarias para la conservación}

- Los modelos obtenidos, para nueve de las 15 especies que componen la comunidad de serpientes, revelan una capacidad predictiva elevada según los valores del AUC, y además, confirman los patrones de distribución empleando solo los registros de ocurrencia de las especies.

- Al proyectar los modelos en el espacio geográfico se observan básicamente dos patrones de distribución: (1) tipo islote zoogeográfico, donde el hábitat apropiado es elevado en las Sierras de Ventania, tanto en el ambiente serrano como en el intraserrano (valles serranos), y disminuye gradualmente hacia el ambiente periserrano y la llanura (en la mayoría de las especies) y (2) el hábitat apropiado es elevado en la llanura circundante y el ambiente periserrano y disminuye hacia el ambiente serrano (exclusivo de Bothrops ammodytoides y Lygophis anomalus).

- La altitud resulta la variable más informativa para la construcción de los modelos de distribución, seguida de la temperatura máxima del mes más cálido y la mínima del más frio. Sin embargo, la selección de variables ambientales estuvo limitada en este trabajo por la disponibilidad y resolución de los datos.

- Las áreas prioritarias para la conservación de la comunidad de serpientes abarcan una superficie total de $4176 \mathrm{Km}^{2}(1,3 \%$ del territorio provincial). En la propuesta empleando el algoritmo $A B F$, se priorizan áreas de elevada riqueza específica, minimizando la tasa de extinción. Mientras que, en la propuesta empleando $C A Z$, se priorizan las áreas núcleo de la distribución geográfica de todas las especies, minimizando la pérdida biológica.

- Debido a las características biogeográficas del área de estudio, de los objetivos de conservación, y esperando un alto retorno de la inversión en la conservación, la propuesta empleando el algoritmo $A B F$ se considera la opción más adecuada para la conservación de la comunidad de serpientes.

- Independientemente del algoritmo de remoción de celdas empleado, las Áreas Naturales Protegidas (ANP) existentes en las Sierras de Ventania son poco efectivas en la protección de la comunidad de serpientes (solo representan el $2,2 \%$ de las áreas prioritarias). Aunque la superficie destinada 
para la conservación en el área de estudio resulta escasa, las ANP se encuentran emplazadas en zonas prioritarias para la conservación.

- Si los objetivos de conservación se quieren alcanzar, la protección debe tener lugar tanto dentro como fuera de las ANP. Para lograr esto, se deben proporcionar incentivos sociales y económicos apropiados, además de una gestión innovadora de sistemas agrícolas más amigables con la biodiversidad. 


\section{BIBLIOGRAFÍA}

Abalos J. W. y Mischis C. C. 1975. Elenco sistemático de los ofidios argentinos. Bol. Acad. Nac. Cs. Córdoba, Argentina 51: 55-76.

Adalsteinsson S. A. Branch W. R. Trape S. Vitt L. J. y Hedges S. B. 2009. Molecular phylogeny, classification, and biogeography of snakes of the Family Leptotyphlopidae (Reptilia, Squamata). Zootaxa 2244: 1-50.

Albarelli L. P. P. y Santos Costa M. C. 2010. Feeding ecology of Liophis reginae semilineatus (Serpentes: Colubridae: Xenodontinae) in Eastern Amazon, Brazil. Zoologia 27: 87-91.

Amaral A. 1926. Sobre a invalidez de um genero e algunas especies de ophidios sul-americanos. Primera nota de ophiologia. Rev. Mus. Paulista 14: 17-33.

Anderson R. P. y Gonzalez Jr. I. 2011. Species-specific tuning increases robustness to sampling bias in models of species distributions: An implementation with Maxent. Ecological Modelling 222: 2796-2811.

Araújo M. B. y Guisan A. 2006. Five (or so) challenges for species distribution modelling. Journal of Biogeography 33: 1677-1688.

Araújo M. B. y Williams P. H. 2000. Selecting areas for species persistence using occurrence data. Biol. Conserv. 96: 331-345.

Arnold S. J. 1972. Species densities of predators and their prey. Am. Nat. 106: 220-236.

Arzamendia V. y Giraudo A. R. 2004. Usando patrones de biodiversidad para la evaluación y diseño de áreas protegidas: las serpientes de la provincia de Santa Fe (Argentina) como ejemplo. Rev. Chil. Hist. Nat. 77: 335-348.

Arzamendia V. y Giraudo A. R. 2012. A panbiogeographical model to prioritize areas for conservation along large rivers. Divers. Distrib. 18: 168-179.

Barrio A. 1961. Distribución del género Bothrops Wagler (Ophidia, Crotalidae) en la provincia de Buenos Aires. Physis 22: 211-215.

Barrio A. y Miranda M. E. 1966. Las diferentes poblaciones de Bothrops alternata Dúmeril y Bibron (Ophidia, Crotalidae) de la Argentina, consideraciones desde el punto de vista Morfológico y Antigénico. Mem. Inst. Butantan 33:887-892.

Basso N. G. 1990. Estrategias adaptativas en una comunidad subtropical de anuros. Cuad. Herpetol. (Serie Monográfica) 1: 1-70.

Bellini G. P. Giraudo A. R. Arzamendia V. y Etchepare E. G. 2015. Temperate snake community in South America: Is diet determined by phylogeny or ecology? PLOS ONE 10: 1-15.

Berg C. 1898. Contribuciones al conocimiento de la fauna erpetológica argentina y de los países limítrofes. An. Mus. Nac. Hist. Nat. Buenos Aires 6: 135.

Bernarde P. S. y Abe A. S. 2006. A snake community at Espigão do Oeste, Rondônia, southwestern Amazon, Brazil. South American J. Herpetol. 1: 102-113.

Biavati G. Wiederhecker H. y Colli G. R. 2004. Diet of Epipedobates flavopictus (Anura: Dendrobatidae) in a Netropical savanna. Journal of Herpetology 38: 510-518.

Bilenca D. y Miñarro F. 2004. Identificación de Áreas Valiosas de Pastizal (AVPs) en las Pampas y Campos de Argentina, Uruguay y sur de Brasil. Fundación Vida Silvestre, Argentina. 
Brillouin L. 1965. Science and information theory. Academic Press, New York, USA.

Broennimann O. Treier U. A. Müller-Schärer H. Thuiller W. Peterson A. T. y Guisan A. 2007. Evidence of climatic niche shift during biological invasion. Ecology Letters 10: 701-709.

Brooks D. R. y McLennan D. A. 1991. Phylogeny, Ecology, and Behavior. University of Chicago Press, Chicago, USA.

Brooks T. M. Mittermeier R. A. da Fonseca G. A. Gerlach J. Hoffmann M. Lamoreux J. F. Mittermeier C. G. Pilgrim J. D. y Rodrigues A. S. 2006. Global biodiversity conservation priorities. Science 313: 58-61.

Bruner A. G. Gullison R. E. Rice R. E. y da Fonseca G. A. B. 2001. Effectiveness of Parks in Protecting Tropical Biodiversity. Science 291: 125128.

Buckley L. B. Urban M. C. Angilletta M. J. Grozier L. G. Rissler L. J. y Sears M. W. 2010. Can mechanism inform species' distribution models. Ecology Letters 13: 1041-1054.

Burgos J. J. 1968. El clima de la provincia de Buenos Aires en relación con la vegetación y el suelo. Pp. 101-123. En: Cabrera A. L. (ed.). Flora de la Provincia de Buenos Aires, Parte I. Colección Científica del INTA. Buenos Aires, Argentina.

Butchart S. H. M. Walpole M. Collen B. van Strien A. Scharlemann J. P. W. Almond R. E. A. Baillie J. E. M. Bomhard B. Brown C. Bruno J. Carpenter K. E. Carr G. M. Chanson J. Chenery A. M. Csirke J. Davidson N. C. Dentener F. Foster M. Galli A. Galloway J. N. Genovesi P. Gregory R. D. Hockings M. Kapos V. Lamarque J. F. Leverington F. Loh J. McGeoch M. A. McRae L. Minasyan A. Morcillo M. H. Oldfield T. E. E. Pauly D. Quader S. Revenga C. Sauer J. R. Skolnik B. Spear D. Stanwell-Smith D. Stuart S. N. Symes A. Tierney M. Tyrell T. D. Vie J. C. y Watson R. 2010. Global biodiversity: indicators of recent declines. Science 328: 1164-1168.

Cabrera A. L. 1976. Regiones fitogeográficas argentinas. Pp. 1-85. En: Kugler WF (Ed.) Enciclopedia argentina de agricultura y jardinería. Tomo 2. Fasciculo 1. $2^{\circ}$ edición. Acme. Buenos Aires, Argentina.

Cabrera A. L. 1994. Regiones fitogeográficas argentinas. Pp. 1-85. En: Kugler WF (Ed.) Enciclopedia argentina de agricultura y jardinería. Tomo 2. Fasciculo $1.2^{\circ}$ edición. $1^{\circ}$ reimpresión. Acme. Buenos Aires, Argentina.

Cabrera M. R. 1993. Los saurios del Espinal y su presencia en provincias biogeográficas vecinas. Rev. Mus. Argentino Cienc. Nat. 4: 17-34.

Cabrera M. R. 1995. Comparative composition of turtle species in four natural regions of the Chacoan Domain, South America. An Mus. Hist. Nat. Valparaíso 23: 41-52.

Cabrera M. R. 2001. Composición comparativa de la fauna de serpientes (Reptilia, Squamata) de cuatro provincias biogeográficas del Dominio Chaqueño. Rev. Mus. Argentino Cienc. Nat. 3 (2): 109-118.

Cadle J. E. y Greene H. W. 1993. Phylogenetic patterns, biogeography, and the ecological structure of neotropical snake assemblages. Pp. 281-293. En: Ricklefs R. E. y Schluter D. (eds.). Species diversity in ecological communities. Univ. of Chicago Press, Chicago, USA.

Campbell H. W. y Christman S. P. 1982. Field techniques for herpetofaunal community analysis. Pp. 193-200. En: Scott Jr. N. J. (ed.). 
Herpetological communities. Wildlife Research Report 13, US Department of Interior, Fish and Wildlife Service, USA.

Campbell J. A. y Lamar A. A. 2004. The venemous reptiles of the Western Hemisphere. Comstock Publishing Associates, Ithaca, USA.

Cappannini D. Scoppa C. O. y Vargas-Gil J. R. 1971. Suelos de las Sierras Australes de la Provincia de Buenos Aires. Pp. 203-234 En: Reunión Geología Sierras Australes. Comisión de Investigaciones Científicas. La Plata, Argentina.

Carrasco P. A. Mattoni C. I. Leynaud G. C. y Scrocchi G. J. 2012. Morphology, phylogeny and taxonomy of South American bothropoid pitvipers (Serpentes, Viperidae). Zoologica Scripta 41: 109-124.

Carreira S. 2002. Alimentación de los ofidios de Uruguay. Asociación Herpetológica Española (AHE), Monografías de Herpetología, Barcelona, España.

Carroll C. 2010. Role of climatic niche models in focal-species-based conservation planning: assessing potential effects of climate change on Northern Spotted Owl in the Pacific Northwest, USA. Biol. Conserv. 143: 14321437.

Cei J. M. 1986. Reptiles del Centro, Centro-Oeste y Sur de la Argentina. Herpetofauna de Zonas Áridas y Semiáridas. Museo Regionale di Scienze Naturali Torino, Monografie 4: 112-120.

Cei J. M. 1987. Additional Notes to Amphibians of Argentina. An Update, 1980-1986. Monitore Zool ital 21: 209-272.

Cei J. M. 1993. Reptiles del noroeste, nordeste y este de la Argentina. Museo Regionale Scienze Naturale Torino, Monografie 14: 1-949.

Celsi C. E. Monserrat A. L. y Kacoliris F. P. 2008. Reptilia, Colubridae, Philodryas aestivus: Distribution extension. Check List 4: 12-14.

Clark R. W. 2004. Timber rattlesnakes (Crotalus horridus) use chemical cues to select ambush sites. Journal of Chemical Ecology 30: 607-617.

Colston T. J. Costa G. C. y Vitt L. J. 2010. Snake diets and the deep history hypothesis. Biological Journal of the Linnean Society. 101: 476-486.

Connell J. H. 1980. Diversity and the coevolution of competitors, or the ghost of competition past. Oikos 35: 131-138.

Cooper W. E. 1994. Chemical discrimination by tongue-flicking in lizards: A review with hypotheses on its origin and its ecological and phylogenetic relationships. Journal of Chemical Ecology 20: 439-487.

Cooper W. E. 1995. Foraging mode, prey chemical discrimination, and phylogeny in lizards. Animal Behaviour 50: 973-985.

Corbalán V. Tognelli M. F. Scolaro J. A. y Roig-Juñent S. A. 2011. Lizards as conservation targets in Argentinean Patagonia. J. Nat. Conserv. 19: 60-67.

Coronado Padilla R. y Marquez Delgado A. 1978. Introducción a la Entomología. Morfología y Taxonomía de los Insectos. Limusa, México.

Couturier G. A. y Grisolia C. 1989. Presencia de Philodryas aestivus (Duméril, Bibron y Duméril, 1854) en Sierra de la Ventana (Provincia de Buenos Aires). Bol. Asoc. Herpetol. Arg. 5: 13.

Cranwell J. A. 1942. Consideraciones sobre Rhadinaea elegantissima Koslowsky. Rev. Argent. Zoogeogr. 2: 143-146. 
Crisci J. V. Katinas L. y Posadas P. 2000. Introducción a la teoría y práctica de la biogeografía histórica. Sociedad Argentina de Botánica, Buenos Aires.

Daly J. W. Garraffo H. M. Spande T. F. Yeh H. J. C. Peltzer P. M. Cacivio P. Baldo D. y Faivovich J. 2008. Indolizidine 239Q and Quinolizidine 275l. Major alkaloids in two Argentinian bufonid toads (Melanophryniscus). Toxicon 52: 858-870.

De la Sota E. R. 1967. Composición, origen y vinculaciones de la flora pteridológica de las Sierras de Buenos Aires (Argentina). Bol. Soc. Argentina de Botánica 11:105-128.

de Roodt A. R. Lanari L. C. Laskowicz R. D. Botassi S. Rocco D. M. de Oliveira V. C. y Regner P. I. 2012. Comparación de caracteres corporales y del veneno de Bothrops alternatus entre poblaciones de las provincias de Buenos Aires y Entre Ríos, Argentina. Cuad. Herpetol. 26: 5-12.

Diamond J. M. 1975. The island dilema: lessons of modern biogeographic studies for the design of natural reserves. Biol. Conserv. 7:129146.

Di Fonzo de Abalos A. y Bucher E. H. 1983. La fauna de serpientes de la provincia de Córdoba, Argentina. II. Comunidades asociadas a las formaciones vegetales. Ecosur 10: 19-35.

Di Pietro D. O. y Nenda S. J. 2007. Geographic distribution. Serpentes: Thamnodynastes strigatus (NCN). Herpetological Review 38: 491.

Di Pietro D. O. Williams J. D. y Nenda S. J. 2012. Lygophis elegantissimus (Koslowsky, 1896), Culebra serrana. En: Categorización del Estado de Conservación de la Herpetofauna de la República Argentina. Ficha de los Taxones. Serpientes. Cuadernos de Herpetología 26 (supl.1): 355.

Dixon J. R. 1985. A review of Liophis anomalus and Liophis elegantissimus, and the description of a new species (Serpentes: Colubridae). Copeia 1985: 565-573.

Dixon J. R. y Hendricks F. S. 1979. The Wormsnakes (Family Typhlopidae) of the Neotropics, exclusive of the Antilles. Zoologische Verhandelingen 173: 1-39.

Dixon J. R. y Markezich A. L. 1992. Taxonomy and geographic variation of Liophis poecilogyrus (Wied) from South America (Serpentes: Colubridae). Texas Journal of Science 44:131-166.

Dodd Jr. C. K. 1993. Strategies for snake conservation. Pp. 363-393. En: Seigel R. A. y Collins J. T. (eds.). Snakes: Ecology and behavior. Mc GrawHill, New York, USA.

Dormann C. F. 2007. Promising the future? Global change projections of species distributions. Basic and Applied Ecology 8:387-397.

Duellman W. E. 1979. The herpetofauna of the Andes: Patterns of distribution, origin, differentiation and present communities. Pp. 371-459. En: Duellman W. E. (ed.). The South American Herpetofauna: Its Origin Evolution and Dispersal. Mus. Nat. Hist. Univ. Kansas. Monogr. 7. USA.

Duellman W. E. 1990. Herpetofaunas in Neotropical rainforests: comparative composition, history, and resource use. Pp. 455-505. En: Gentry A. H. (ed.). Four Neotropical Rainforests. Yale University Press, New Haven, USA.

Eckhardt R. C. 1979. The adaptive syndromes of two guilds of insectivorous birds in the Colorado Rocky Mountains. Ecological Monographs 49: 129-149. 
Eken G. Bennun L. Brooks T. M. Darwall W. Fishpool L. D. C. Foster M. Knox D. Langhammer P. Matiku P. Radford E. Salaman P. Sechrest W. Smith M. L. Spector S. y Tordoff A. 2004. Key biodiversity areas as site conservation targets. BioScience 54: 1110-1118.

Elith J. Graham C. H. Anderson R. P. Dudík M. Ferrier S. Guisan A. Hijmans R. J. Huettmann F. Leathwick J. R. Lehmann A. Li J. Lohmann L. G. Loiselle B. A. Manion G. Moritz C. Nakamura M. Nakazawa Y. Overton J. M. Peterson A. T. Phillips S. J. Richardson K. Scachetti-Pereira R. Schapire R. E. Soberón J. Williams S. Wisz M. S. y Zimmermann N. E. 2006. Novel methods improve prediction of species' distributions from ocurrence data. Ecography 29: 129-151.

Elith J. y Leathwick J. R. 2009. Species Distribution Models: ecological explanation and prediction across space and time. Ann. Rev. Ecol. Evol. Syst. 40: 677-697.

Elith J. Phillips S. J. Hastie T. Dudík M. Chee Y. E. y Yates C. J. 2011. A statistical explanation of Maxent for ecologists. Diversity and Distributions 17:43-57.

Felicísimo A. M. Gómez A. y Muñoz J. 2005. Potencial distribution of forest species in dehesas of Extremadura (Spain). Advances in GeoEcology 37: 231-246.

Fernández F. J. Ballejo F. Moreira G. J. Tonni E. P. y De Santis L. J. M. 2011. Roedores cricétidos de la Provincia de Mendoza, guía cráneo-dentaria orientada para su aplicación en estudios zooarqueológicos. Universitas, Sociedad Antropológica Argentina. Argentina.

Ferrier S. y Guisan A. 2006. Spatial modelling of biodiversity at the community level. Journal of Applied Ecology 43: 393-404.

Fiorella K. Cameron A. Sechrest W. Winfree R. y Kremen C. 2010. Methodological considerations in reserve system selection: a case study of malagasy lemurs. Biol. Conserv. 143: 963-973.

Frangi J. L. y Barrera M. D. 1996. Biodiversidad y dinámica de los pastizales en la Sierra de la Ventana, Provincia de Buenos Aires. Pp. 134-162 En: Sarmiento G. y Cabido M. (eds.). Biodiversidad y funcionamiento de pastizales y sabanas en América Latina. Mérida: Cyted y Cielat. Argentina.

Frangi J. L y Bottino O. J. 1995. Comunidades vegetales de la Sierra de la Ventana, Provincia de Buenos Aires. Rev. Fac. Agron. (La Plata). 71: 93133.

Franklin J. 2011. Mapping species distribution: spatial inference and prediction. Cambridge University Press, New York, USA.

Fu C. Wang J. Pu Z. Zhang S. Chen H. Zhao B. Chen J. y Wu J. 2007. Elevational gradients of diversity for lizards and snakes in the Hengduan Mountains, China. Biodiv. Conserv. 16: 707-726.

Gallardo J. M. 1970. Estudio ecológico sobre los anfibios y reptiles del sudoeste de la provincia de Buenos Aires, Argentina. Rev. Mus. Argentino Cienc. Nat. 10 (3): 27-63.

Gallardo J. M. 1973. Conservación de la fauna: vertebrados, reptiles y anfibios. Museo Argentino Ciencias Naturales "Bernardino Rivadavia". Publicaciones de Extensión Cultural y Didáctica 20: 1-15.

Gallardo J. M. 1976. Estudio ecológico sobre los anfibios y reptiles de la Depresión del Salado, provincia de Buenos Aires, Argentina. Rev. Mus. Argentino Cs. Nat. Ecologia, Tomo II, n¹: 1-26. 
Gallardo J. M. 1977. Reptiles de los Alrededores de Buenos Aires. EUDEBA. Buenos Aires, Argentina.

Gallardo J. M. 1980a. Estudio ecológico sobre los anfibios y reptiles del noreste de la provincia de Buenos Aires, Argentina. Pp. 331-349. I Reunión Iberoamer. Zool. Vert. La Rábida.

Gallardo J. M. 1980b. Los reptiles y el control de los roedores en la provincia de Buenos Aires, República Argentina. Revista de Ciencias Agrarias 3: 107-110.

Gallardo J. M. 1987. Anfibios y Reptiles del Partido de Magdalena (Provincia de Buenos Aires). Fund. E. S. de Pearson. Buenos Aires, Argentina.

Gans C. 1961. The feeding mechanism of snakes and its possible evolution. Am. Zool. 1: 217-227.

Gehlbach F. R. Watkins J. F. y Reno H. 1968. Blind snake defensive behaviour elicited by ant attacks. Bioscience 18: 784-785.

Gerritsen J. y Strickler J. R. 1977. Encounter probabilities and community structure in zooplankton: a mathematical model. Journal of the Fisheries Research Board of Canada 34: 73-82.

Giambelluca L. A. 2015. Serpientes bonaerenses. EDULP, La Plata, Buenos Aires, Argentina (version electrónica).

Gibbons J. W. Scott D. E. Ryan T. J. Buhlmann K. A. Tuberville T. D. Metts B. S. Greene J. L. Mills T. Leiden Y. Poppy S. y Winne C. T. 2000. The global decline of reptiles, déjà vu amphibians. BioScience 50: 653-666.

Giraudo A. R. 2001. Serpientes de la Selva Paranaense y del Chaco Húmedo. LOLA, Buenos Aires, Argentina.

Giraudo A. R. Arzamendia V. y Bellini G. 2011. Las especies amenazadas como hipótesis: problemas y sesgos en su categorización ejemplificados con las serpientes de la Argentina. Cuadernos de Herpetología 25: 43-54.

Giraudo A. R. Arzamendia V. Bellini G. P. Bessa C. A. Calamante C. C. Cardozo G. Chiaraviglio M. Constanzo M. B. Etchepare E. Di Cola V. Di Pietro D. Kretzchmar S. Palomas S. Nenda S. Rivera P. C. Rodríguez M. E. Scrocchi G. J. y Williams J. D. 2012. Categorización del estado de conservación de las Serpientes de la República Argentina. Cuad. Herpetol. 26 (Supl. 1): 303-326.

Giraudo A. R. Arzamendia V. Lopez S. M. Quaini R. O. Prieto Y. A. Leiva L. A. Regner S. A. y Urban J. M. 2008. Serpientes venenosas de Santa Fe, Argentina: conocimientos sobre su historia natural aplicados para la prevención de ofidismo. FABICIB 12: 69-89.

Giraudo A. R. y Scrocchi G. J. 2002. Argentinean snakes: an annotated checklist. Smithsonian Herpetological Information Service 132: 1-53.

Gonzaga L. A. P. Castiglioni G. D. A. y Alves M. A. 1997. Philodryas patagoniensis. (NCN). Diet. Herp. Rev. 28: 154.

González-Maya J. F. Castañeda F. González R. Pacheco J. y Ceballos G. 2014. Distribution, range extension, and conservation of the endemic black-headed bushmaster (Lachesis melanocephala) in Costa Rica and Panama. Herpetol. Conserv. Biol. 9: 369-377.

Goodyear S. E. y Pianka E. R. 2008. Sympatric ecology of five species of fossorial snakes (Elapidae) in Western Australia. Journal of Herpetology 42: 279-285. 
Gotelli N. J. y Entsminger G. L. 2005. EcoSim: Null Models Software for Ecology, Version 7. Acquired Intelligence Inc. y Kesey-Bear, Burlington, Vermont, USA.

Grazziotin F. G. Zaher H. Murphy R. W. Scrocchi G. Benavides M. A. Zhang Y. P. y Bonatto S. L. 2012. Molecular phylogeny of the New World Dipsadidae (Serpentes: Colubroidea): a reappraisal. Cladistics 1: 1-23.

Greene H. W. 1997. Snakes. The evolution of mystery in nature. University of California Press, Berkeley, USA.

Grinnell J. 1917. The niche relationship of the California Thrasher. Auk 34: 427-433.

Guisan A. y Zimmermann N. E. 2000. Predictive habitat distribution models in ecology. Ecol. Model. 135: 147-186.

Hammer Ø. Harper D. A. T. y Ryan P. D. 2001. PAST: Paleontological Statistics Software Package for Education and Data Analysis. Palaeontologia Electronica. National University of Ireland, Galway, Ireland.

Harrington H. J. 1947. Explicación de las Hojas Geológicas 33m (Sierra de Curamalal) y $34 \mathrm{~m}$ (Sierra La Ventana). Provincia de Buenos Aires. Boletín de la Dirección de Minería y Geología 61, Buenos Aires, Argentina.

Harrington H. J. 1980. Sierras Australes de Buenos Aires. Pp. 967-983. En: Leanza A. F. (ed.). Geología Regional Argentina. Academia Nacional de Ciencias, Córdoba, Argentina.

Hartmann P. A. y Marques O. A. V. 2005. Diet and habitat use of two sympatric species of Philodryas (Colubridae), in south Brazil. Amphibia-Reptilia 26: 25-31.

Henderson R. W. 1974a. Resource partitioning among the snakes of the University of Kansas Natural History Reservation: a preliminary analysis. Milwaukee Public Museum Contributions in Biology and Geology 1:1-11.

Henderson R. W. 1974b. Aspects of the ecology of the Neotropical vine snake, Oxybelis aeneus (Wagler). Herpetologica, 30 (1): 19-24.

Henderson R. W. y Binder M. H. 1980. The ecology and behavior of the vine snakes (Ahaetulla, Oxybelis, Thelotornis, Uromacer): a review. Milwaukee Publ. Mus. Contrib. Biol. Geol. 37:1-38.

Heyer W. R. 1988. On frog distribution patterns East of the Andes. Pp. 245-273. En: Heyer W. R. y Vanzolini P. E. (eds.). Proceedings of the Workshop on Neotropical Distribution Patterns. Academia Brasileira de Ciências, Rio de Janeiro, Brasil.

Hijmans R. J. Cameron S. E. Parra J. L. Jones P. G. y Jarvis A. 2005. Very high resolution interpolated climate surfaces for global land areas. Int. J. Climatol. 25: 1965-1978.

Hijmans R. J. Guarino L. y Mathur P. 2012. DIVA-GIS. Version 7.5. User Manual. University of California. California, USA.

Holdridge L. 1978. Ecología basada en Zonas de Vida. Inst. Iteram. De Cs. Agr. San Jose, Costa Rica.

Huey R. B. y Pianka E. R. 1981. Ecological consequences of foraging modes. Ecology 62: 991-999.

Hurtubia J. 1978. Trophic diversity measurement in sympatric species. Ecology 54: 885-890.

Hutchinson G. E. 1957. Concluding remarks. Cold Spring Harbour symposium on quantitative biology: 415-427. 
Jaksic F. M. 1981. Abuse and misuse of the term "guild" in ecological studies. OIKOS 37: 397-400.

Jaksic F. M. Greene H. W. y Yáñez J. L. 1981. The Guild Structure of a Community of Predatory Vertebrates in Central Chile. Oecologia 49: 21-28.

Jenkins C. L. Peterson C. R. y Kingsbury B. A. 2009. Modeling Snake Distribution and Habitat. Pp. 123-148. En: Mullin S. J. y Seigel R. A. (Eds.). Snakes: ecology and conservation. Cornell University Press, Ithaca, USA.

Jenkins C. N. y Joppa L. 2009. Expansion of the global terrestrial Protected Area system. Biol. Conserv. 142: 2166-2174.

Jiménez-Valverde A. Lobo J. M. y Hortal J. 2008. Not as good as they seem: the importance of concepts in species distribution modelling. Diversity and Distributions 14: 885-890.

Kacoliris F. P. Horlent N. y Williams J. D. 2006. Herpetofauna, Coastal Dunes, Buenos Aires Province, Argentina. Check List: 2: 15-21.

Kearney M. 2006. Habitat, environment and niche: what are we modelling? OIKOS 115: 186-191.

Koslowsky J. 1895. Reptiles y batracios de la Sierra de la Ventana (Provincia de Buenos Aires). Rev. Mus. La Plata 7: 151-156.

Koslowsky J. 1896. Enumeración sistemática y distribución geográfica de los reptiles argentinos. Rev. Mus. La Plata 8:161-200.

Kremen C. Cameron A. Moilanen A. Phillips S. J. Thomas C. D. Beentje H. Dransfield J. Fisher B. L. Glaw F. Good T. C. Harper G. J. Hijmans R. J. Lees D. C. Louis Jr. E. Nussbaum R. A. Raxworthy C. J. Razafimpahanana A. Schatz G. E. Vences M. Vieites D. R. Wright P. C. y Zjhra M. L. 2008. Aligning conservation priorities across taxa in Madagascar with high-resolution planning tools. Science 320: 222-226.

Krebs J. R. 1978. Optimal foraging: decision rules for predators. Pp. 2363. En: Krebs J. R. y Davies N. B. (eds.). Behavioural ecology: an evolutionary approach. Sinauer Associates, Sunderland, Massachusetts, USA.

Kristensen M. J. y Frangi J. L. 1995a. Mesoclimas de pastizales de la Sierra de la Ventana. Ecol. Austral 5: 55-64.

Kristensen M. J. y Frangi J. L. 1995b. La Sierra de la Ventana: Una isla de biodiversidad. Ciencia Hoy 5 (30): 25-34.

Küper W. Sommer J. H. Lovett J. C. Mutke J. Linder H. P. Beentje H. J. van Rompaey R. Chatelain C. Sosef M. y Barthlott W. 2004. Africa's hotspots of biodiversity redefined. Annals of the Missouri Botanical Garden 91: 525-535.

Lafon C. W. 2004. High biodiversity: an assessment of mountain biodiversity. Diversity and Distributions 10: 75-76.

Langhammer P. F. Bakarr M. I. Bennun L. A. Brooks T. M. Clay R. P. Darwall W. De Silva N. Edgar G. J. Eken G. Fishpool L. D. C. da Fonseca G. A. B. Foster M. N. Knox D. H. Matiku P. Radford E. A. Rodrigues A. S. L. Salaman P. Sechrest W. y Tordoff A. W. 2007. Identification and gap analysis of key biodiversity areas: targets for comprehensive protected area systems (Best Practice Protected Area Guidelines Series 15). Gland, Switzerland, IUCN.

Laurent R. F. 1973. Una nueva subespecie de culebra del Noroeste argentino y de Bolivia. Acta Zoológica Lilloana 26: 293-297.

Leach K. Zalat S. y Gilbert F. 2013. Egypt's Protected Area network under future climate change. Biol. Conserv. 159: 490-500. 
Leathwick J. R. Moilanen A. Ferrier S. y Julian K. 2010. Complementarity-based conservation prioritization using a community classification, and its application to riverine ecosystems. Biol. Conserv. 143: 984-991.

Leathwick J. R. Moilanen A. Francis M. Elith J. Taylor P. Julian K. Hastie T. y Duffy C. 2008. Novel methods for the design and evaluation of marine Protected Areas in offshore waters. Conserv. Lett. 1: 91-102.

Lema T. de 1973. As serpentes do estado do Rio Grande do Sul. Iheringia 3: 19-33.

Lema T. de 1984. Sobre o genero Elapomorphus Wiegmann, 1843 (Serpentes, Colubridae, Elapomorphinae). Iheringia 64: 53-86.

Lema T. de. Araujo de M. L. y Azevedo A. C. P. 1983. Contribuição ao conhecimento da alimentação e do modo alimentar de serpentes do Brasil. Comun. Mus Cs. PUCRS, Porto Alegre 26: 41-121.

Levins R. 1968. Evolution in Changing Environments: Some Theoretical Explorations. Princeton University Press, Princeton, USA.

Lizzi J. M. Garbulsky M. F. Golluscio A. y Deregibus A. V. 2007. Mapeo indirecto de la vegetación de Sierra de la Ventana, provincia de Buenos Aires. Ecología Austral 17: 217-230.

Lomolino M. V. 2001. Elevational gradients of species diversity: historical and prospective views. Global Ecol. Biogeogr. 10: 3-13.

López M. S. 2003. Philodryas patagoniensis (NCN). Diet. Herpetological Review. 34: 71-72.

López M. S. y Giraudo A. R. 2008. Ecology of the Snake Philodryas patagoniensis (Serpentes, Colubridae) from Northeast Argentina. Journal of Herpetology 42: 474-48.

Losos J. B. y Ricklefs R. E. 2009. The theory of island biogeography revisited. Princeton University Press, New Jersey y Oxfordshire, USA.

Luiselli L. 2006. Resource partitioning and interspecific competition in snakes: the search for general geographical and guild patterns. Oikos 114:193211.

MacArthur R. H. 1971. Patterns in terrestrial bird communities. Pp 189221. En: Farner D. S. y King J. R. (eds.), Avian Biology. Vol. 1. Academic Press, New York, USA.

MacArthur R. H. y Levins R. 1967. The limiting similarity, convergence and divergence of coexisting species. Am. Nat. 101: 377-385.

MacArthur R. H. y Wilson E. O. 1967. The theory of Island Biogeography. Princeton University Press, Princeton, N. J., USA.

Manzanilla J. y Péfaur J. E. 2000. Consideraciones sobre métodos y técnicas de campo para el estudio de anfibios y reptiles. Rev. Ecol. Lat. Am. 7 (1-2): 17-30.

Marelli C. A. 1924. Batracios y Reptiles. Pp. 594-596. En: Elenco Sistemático de la Fauna de la Provincia de Buenos Aires (Procordados y Vertebrados). Rosso L. J. (ed.). Buenos Aires, Argentina.

Marques O. A. V. Sawaya R. J. Stender-Oliveira F. M. y Franca F. G. R. 2006. Ecology of the Colubrid snake Pseudablabes agassizii in southeastern South America. Herpetological Journal 16: 37-45.

Martins M. Marques O. A. V. y Sazima I. 2002. Ecological and phylogenetic correlates of feeding habits in neotropical pitvipers of the genus Bothrops. Pp. 307-328. En: Schuett G. W. Hoggren M. Douglas M. E. y Greene 
H. W. (eds). Biology of the vipers. Eagle Mountain Publishing, Eagle Mountain, USA.

Martins M. y Oliveira M. E. 1998. Natural history of snakes in forests of the Manaus region, central Amazonia, Brazil. Herpetol. Nat. Hist. 6: 78-150.

Mateo R. G. Felicísimo A. M. y Muñoz J. 2011. Modelos de distribución de especies: Una revisión sintética. Rev. Chil. Hist. Nat. 84: 217-240.

McCain C. M. 2010. Global analysis of reptile elevational diversity. Global Ecology and Biogeography 19: 541-553

Mebs D. 2002. Venomous and Poisonous Animals. CRC Press, Boca Raton, USA.

Merow C. Smith M. J. Silander J. A. 2013. A practical guide to MaxEnt for modeling species' distributions: what it does, and why inputs and settings matter. Ecography 36: 1058-1069.

Mesquita P. C. M. D. Pinheiro-Mesquita S. F. y Pietczak C. 2013. Are common species endangered by climate change? Habitat suitability projections for the royal ground snake, Liophis reginae (Serpentes, Dipsadidae). NorthWest. J. Zool. 9: 51-53.

Michaud E. J. y Dixon J. R. 1989. Prey items of 20 species of Neotropical Colubrid snakes genus Liophis. Herpetological Review 20:39-41.

Milanovich J. R. Peterman W. E. Nibbelink N. P. y Maerz. J. C. 2010. Projected loss of a salamander diversity hotspot as a consequence of projected global climate change. PLOS ONE 5: e12189.

Miranda M. Couturier G. y Williams J. D. 1983. Guía de los Ofidios Bonaerenses. Asoc. Coop. J. Zool. La Plata, Buenos Aires, Argentina.

Moilanen A. 2007. Landscape zonation, benefit functions and targetbased planning: Unifying reserve selection strategies. Biological Conservation 134: 571-579.

Moilanen A. Franco A. M. A. Early R. Fox R. Wintle B. y Thomas C. D. 2005. Prioritising multiple-use landscapes for conservation: methods for large multispecies planning problems. Proceedings of the Royal Society of London, Series B, Biological Sciences 272: 1885-1891.

Moilanen A. Pouzols F. M. Meller L. Veach V. Arponen A. Leppänen J. y Kujala H. 2014. Zonation - Spatial conservation planning methods and software. Version 4. User Manual. University of Helsinki. Finland.

Morrone J. J. 2001. Biogeografía de America Latina y el Caribe. M\&TManuales \& Tesis CEA. Zaragoza, España.

Morueta-Holme N. Fløjgaard y Svenning J. 2010. Climate change risks and conservation implications for a threatened small-range mammal. Plos One 5: e10360.

Mullin S. J. y Cooper R. J. 1998. The foraging ecology of the snake Elaphe obsoleta spiloides - visual stimuli facilitate location of arboreal prey. Amer. Midl. Nat. 140: 397-401.

Mullin S. J. y Seigel R. A. 2009. Snakes: ecology and conservation. Cornell University Press. Ithaca, USA.

Myers N. Mittermeier R. A. Mittermeier C. G. Da Fonseca G. A. B. y Kent J. 2000. Biodiversity hotspots for conservation priorities. Nature 403: 853858.

30.

Nágera J. J. 1915. Batracios y Reptiles de la Sierra Baya. Physis 2: 23- 
Nenda S. J. y Di Pietro D. O. 2009. Serpentes, Dipsadidae, Echinantherini, Taeniophallus poecilopogon (Cope, 1863): Rediscovery in Argentina. Check List 5: 503-506.

Nori J. Carrasco P. A. y Leynaud G. C. 2013a. Venomous snakes and climate change: ophidism as a dynamic problema. Climatic Change DOI 10.1007/s10584-013-1019-6.

Nori J. Lescano J. N. Illoldi-Rangel P. Frutos N. Cabrera M. R. y Leynaud G. C. 2013b. The conflict between agricultural expansion and priority conservation areas: Making the right decisions before it is too late. Biological Conservation 159: 507-513.

Oliveira R. B. Di-Bernardo M. Pontes G. M. F. Maciel A. P. y Krause L. 2001. Dieta e comportamento alimentar da cobra-nariguda, Lystrophis dorbignyi (Duméril \& Duméril, 1854), no Litoral Norte do Rio Grande do Sul, Brasil. Cuad. Herpetol. 14: 117-122.

Olson D. M. Dinerstein E. Wikramanayake E. Burgess N. D. Powell G. V. N. Underwood E. C. D'amico J. A. Itoua I. Strand H. Morrison J. C. Loucks C. Allnutt T. F. Ricketts T. H. Kura Y. Lamoreux J. F. Wettengel W. W. Hedao P. y Kassem K. R. 2001. Terrestrial ecoregions of the world: a new map of life on earth. BioScience 51: 933-938.

Orejas Miranda B. R. 1961. Una nueva especie de ofidio de la familia Leptotyphlopidae. Acta Biológica Venezuélica 3: 83-97.

Orejas Miranda B. R. 1966. The snake genus Lystrophis in Uruguay. Copeia 1966:193-205.

Orrego Aravena R. 1971. Reptiles de La Pampa. Biblioteca Pampeana Serie Folletos 14: 168.

Orrego Aravena R. 1979. Reptiles de la provincia de La Pampa. Acta Zool. Lilloana 35:679-682.

Panzera A. y Maneyro R. 2014. Feeding Biology of Lygophis anomalus (Dipsadidae, Xenodontinae). South American Journal of Herpetology 9: 75-82.

Pardiñas U. F. J. Abba A. M. y Merino M. L. 2004. Micromamíferos (Didelphimorphia y Rodentia) del sudoeste de la provincia de Buenos Aires (Argentina): Taxonomía y distribución. Mastozoología Neotropical 11: 211-232.

Paredes-García D. M. Ramírez-Bautista A. y Martínez-Morales M. A. 2011. Distribución y representatividad de las especies del género Crotalus en las áreas naturales protegidas de México. Rev. Mex. Biodiv. 82: 689-700.

Pearson R. G. Raxworthy C. J. Nakamura M. y Peterson A. T. 2007. Predicting species distributions from small numbers of occurrence records: a test case using cryptic geckos in Madagascar. Journal of Biogeography 34: 102-117.

Perez C. A. y Frangi J. L. 2000. Grassland biomass dynamics an altitudinal gradient in the Pampa. J. Range Manag. 53: 518-528.

Pereira J. y Haene H. 2003. Reptiles de la Reserva Natural Otamendi. Pp. 37-46. En: Haene H. y Pereira J. (eds.). Fauna de Otamendi. Inventario de los animales vertebrados de la Reserva Natural Otamendi, Campana, Buenos Aires, Argentina. Temas de Naturaleza y Conservación 3. Aves Argentina/AOP, Buenos Aires, Argentina.

Perry G. y Pianka E. R. 1997. Animal foraging: past, present and future. Tree 12: 360-363.

Peters J. y Orejas Miranda B. 1970. Catalogue of the Neotropical Squamata. Part. I. Snakes. Bull. U S Nat. Mus. 297: 347 pp. 
Peterson A. T. 2006. Uses and requirements of ecological niche models and related distributional models. Biodiversity Informatics 3: 59-72.

Phillips S. J. Anderson R. P. y Schapire R. E. 2006. Maximum entropy modelling of species geographic distributions. Ecol. Model. 190: 231-259.

Phillips S. J. y Dudík M. 2008. Modeling of species distributions with Maxent: new extensions and a comprehensive evaluation. Ecography 31: 161175.

Pianka E. R. 1966. Convexity, desert lizards and spatial heterogeneity. Ecology 47: 1055-1059.

Pianka E. R. 1973. The structure of lizard communities. Ann. Rev. Ecol. Syst. 4: 53-74.

Pianka E. R. 1974. Niche overlap and diffuse competition. Proc. Nat. Acad. Sci. 71 (5): 2141-2145.

Pianka E. R. 1975. Niche relationships of desert lizards. Pp. 292-314. En: Cody M. L. y Diamong J. M. (eds.). Ecology and evolution of communities. Harvard Univ. Press, USA.

Pianka E. R. 1982. Ecología evolutiva. Omega, Barcelona, España.

Pianka E. R. 1986. Ecology and natural history of desert lizards. Princeton Univ. Press, New Jersey, USA.

Pielou E. C. 1969. An introduction to mathematical ecology. Wiley, New York, USA.

Pimm S. L Russell G. J Gittleman J. L y Brooks T. M. 1995. The future of biodiversity. Science 269: 347-350.

Pinto R. R. y Fernandes R. 2004. Reproductive biology and diet of Liophis poecilogyrus poecilogyrus (Serpentes, Colubridae) from southeastern Brazil. Phyllomedusa 3: 9-14.

Pisani G. R. y Villa J. 1974. Guía de técnicas de preservación de anfibios y reptiles. SSAR Publicaciones Misceláneas, Kansas, USA.

Pleguezuelos J. M. Márquez R. y Lizana M. 2002. Atlas y libro rojo de los anfibios y reptiles de España. Asociación Herpetológica Española. Madrid, España.

Pough F. H. y Andrews R. M. 1985. Energy costs of subduing and swallowing prey for a lizard. Ecology 66:1525-1533.

Prendergast J. R. Quinn R. M. Lawton J. H. Eversham B. C. y Gibbons D. W. 1993. Rare species the coincidence of diversity hotspots and conservation strategies. Nature 365: 335-337.

Pressey R. L. 1994. Ad hoc reservations: Forward or backward steps in developing representative reserve systems. Conservation Biology 8: 662-668.

Prieto Y. A. Giraudo A. R. y López M. S. 2012. Diet and Sexual Dimorphism of Liophis poecilogyrus (Serpentes, Dipsadidae) from the Wetland Regions of Northeast Argentina. J. Herpetol. 46: 402-406.

Pulliam R. H. 2000. On the relationship between niche and distribution. Ecology Letters 3: 349-361.

Punzo F. 1974. Comparative analysis of the feeding habits of two species of Arizona blind snakes, Leptotyphlops $h$. humilis and Leptotyphlops $d$. dulcis. J. Herp. 8: 153-156.

Ramos B. Gallardo F. B. Baldo J. L. 2013. Tantilla melanocephala (Linnaeus, 1758) - (Serpentes: Colubridae). Primeros registros para la Provincia de Jujuy y confirmación de su presencia en el noroeste argentino. Cuad. Herpetol. 27 (1): 81-83. 
Rapoport E. H. 1975. Areografía: estrategias geográficas de las especies. Fondo de Cultura Económica, México.

Raxworthy C. J. Ingram C. M. Rabibisoa N. y Pearson R. G. 2007. Applications of ecological niche modeling for species delimitation: a review and empirical evaluation using day Geckos (Phelsuma) from Madagascar. Systematic Biology 56: 907-923.

Reading C. J. Luiselli L. M. Akani G. C. Bonnet X. Amori G. Ballouard J. M. Filippi E. Naulleau G. Pearson D. y Rugiero L. 2010. Are snake populations in widespread decline? Biology letters doi:10.1098/rsbl.2010.0373.

Rebelo A. G. 1994. Iterative selection procedures: centres of endemism and optimal placement of reserves. Strelitzia 1: 231-257.

Reinert H. K. 1993. Habitat selection in snakes. Pp. 201-240. En: Seigel R. A. y Collins J. T. (eds.). Snakes: Ecology and Behavior. MacGraw-Hill, New York, USA.

Ricketts T. H. Dinerstein E. Boucher T. Brooks T. M. Butchart S. H. M. Hoffmann M. Lamoreux J. F. Morrison J. Parr M. Pilgrim J. D. Rodrigues A. S. L. Sechrest W. Wallace G. E. Berlin K. Bielby J. Burgess N. D. Church D. R. Cox N. Knox D. Loucks C. Luck G. W. Master L. L. Moore R. Naidoo R. Ridgely R. Schatz G. E. Shire G. Strand H. Wettengel W. y Wikramanayake E. 2005. Pinpointing and preventing imminent extinctions. Proc. Nac. Acad. Sci. 51: 18497-18501.

Ringuelet R. A. 1955. Panorama Zoogeográfico de la provincia de Buenos Aires. Rev. Museo de La Plata 17: 1-15.

Ringuelet R. A. 1961. Rasgos fundamentales de la Zoogeografía de la Argentina. Physis 22: 151-170.

Ringuelet R. A. y Arámburu R. H. 1957. Enumeración sistemática de los vertebrados de la provincia de Buenos Aires. Ministerio de Asuntos Agrarios de la Provincia de Buenos Aires 119: 1-94.

Rissler L. J. y Smith W. H. 2010. Mapping amphibian contact zones and phylogeographical break hotspots across the United States. Mol. Ecol. 19: 5404-5416.

Rivera P. C. Di Cola V. Martínez J. J. Gardenal C. N. y Chiaraviglio M. 2011. Species delimitation in the continental forms of the genus Epicrates (Serpentes, Boidae) intergrating phylogenetics and environmental niche models. PLOS ONE 6 (9): E 22199.

Saibene P. E. Cajade R. Pagano L. G. y Herrera R. 2012. Reptiles de la Reserva Natural Punta Lara. Pp. 83-96. En: Roesler I. y Agostini G. (eds). Inventario de los Vertebrados de la Reserva Natural Punta Lara, provincia de Buenos Aires, Argentina. Temas de Naturaleza y Conservación 8. Aves Argentina/AOP, Buenos Aires, Argentina.

Sale P. F. 1974. Overlap in resource use, and interspecific competition. Oecologia 17: 245-256.

Sazima I. 1992. Natural history of the jararaca pitviper, Bothrops jararaca, in southeastern Brazil. Pp. 199-216. En: Campbell J. A. y Brodie Jr. E. D. (eds). Biology of the Pitvipers. Univ. Texas, Arlington, USA.

Sawaya R. J. Marques O. A. V. y Martins M. 2008. Composition and natural history of a Cerrado snake assemblage at Itirapina, São Paulo state, southeastern Brazil. Biota Neotropica 8: 129-151. 
Scanferla C. A. y Nenda S. J. 2005. El registro más antiguo del género Bothrops (Serpentes, Viperidae), proveniente del Pleistoceno inferior a medio de Argentina. Rev. Mus. Arg. Cs. Nat. 7: 177- 181.

Shcheglovitova M. y Anderson R. P. 2013. Estimating optimal complexity for ecological niche models: Ajackknife approach for species with small sample sizes. Ecological Modelling 269: 9-17

Schoener T. W. 1971. Theory of feeding strategies. Annual Review of Ecology and Systematics 2: 369-404.

Schoener T. W. 1974. Resource partitioning in ecological communities. Science 185: 27-39.

Schoener T. W. 1977. Competition and the niche. Pp. 35-136. En: Tinkle D. W. y Gans C. (eds.). Biology of the Reptilia Vol. 7, Academic Press, New York, USA.

Schoener T. W. 1983. Field experiments on interspecific competition. Amer. Natur. 122: 240-285.

Schwenk K. 1995. Of tongues and noses: Chemoreception in lizards and snakes. Trends in Ecology and Evolution 10: 7-12.

Scrocchi G. J. 1990. Contribución al conocimiento de los Leptotyphlopidae de Argentina. II. Nuevos datos sobre Leptotyphlops australis Freiberg y Orejas Miranda. Acta zool. lilloana 39: 113-114.

Scrocchi G. J. 1991. Las colecciones de ejemplares y el concepto de "voucher". Boletín del Colegio de Graduados en Ciencias Biológicas de Tucumán 9: 8-10.

Scrocchi G. J. Aguer I. Arzamendia V. Cacivio P. Carcacha H. Chiaraviglio M. Giraudo A. R. Kretzschmar S. Leynaud G. López M. S. Rey L. Waller T. y Williams J. 2000. Categorización de las serpientes de Argentina. Pp. 75-93. En: Lavilla E. Richard E. y Scrocchi G. (eds.). Categorización de los anfibios y reptiles de la República Argentina. Asociación Herpetológica Argentina. Tucumán, Argentina.

Scrocchi G. J. y Cruz F. 1993. Description of a new species of the genus Lystrophis Cope and a revalidation of Lystrophis pullcher (Jan 1863) (Serpentes: Colubridae). Papéis Avulsos de Zoologia. Museu de Zoologia da Universidade de São Paulo 38: 171-186.

Scrocchi G. J. y Kretzschmar S. 1996. Guía de métodos de captura y preparación de anfibios y reptiles para estudios científicos y manejos de colecciones herpetológicas. Miscelanea 102, Fundación Miguel Lillo, Tucuman, Argentina.

Scrocchi G. J. y Giraudo A. R. 1997. El género Psomophis (Serpentes: Colubridae) en la Argentina. Cuadernos de Herpetología 11: 63-68.

Scrocchi G. J. y Giraudo A. R. 2005. Reptiles de la Reserva El Bagual. Pp. 155-198. En: Di Giacomo A. G y Krapovickas S. F. (eds.). Historia Natural y paisaje de la Reserva El Bagual, Provincia de Formosa, Argentina. Temas de Naturaleza y Conservación 4, Aves Argentina/AOP, Buenos Aires, Argentina.

Scrocchi G. J. y Viñas M. 1991. El género Clelia (Serpentes: Colubridae) en la República Argentina: revisión y comentarios. Boll. Mus. Reg. Sci. Nat. Torino 8: 487-499.

Sellés-Martínez J. 2001. Geología de la Ventania (Provincia de Buenos Aires (Argentina). Journal of Iberian Geology 27: 43-69.

Seoane J. y Bustamante J. 2001. Modelos predictivos de la distribución de especies: una revisión de sus limitaciones. Ecología 15: 9-21. 
Serié P. 1915. Suplemento a la fauna herpetológica argentina. Anales del Museo de Historia Natural de Buenos Aires 27: 93-109.

Serié P. 1919. Notas sobre la alimentación de algunos afidios. Rev. J. Zool. Buenos Aires 60: 307-328.

Serié P. 1921. Catálogo de los ofidios argentinos. Anales de la Soc. Cient. Arg. 92: 145-175.

Serié P. 1936. Nueva enumeración sistemática y distribución geográfica de los ofidios argentinos. Museo de La Plata. Obra cincuentenario: 33-68.

Seymour C. L. De Klerk H. M. Channing A. y Crowe T. M. 2001. The biogeography of the Anura of Subequatorial Africa and the prioritisation of areas for their conservation. Biodiversity and Conservation 10: 2045-2076.

Shannon C. E. y Weaver W. 1949. The mathematical theory of communications. University Illinois Press, Urbana, Illinois, U.S.A., 144 pp.

Shine R. 1987. Ecological ramifications of prey size: food habits and reproductive biology of Australian copperhead snakes (Austrelaps, Elapidae). Journal of Herpetology 21: 21-28.

Shine R. y Bonnet X. 2000. Snakes: A new "model organism" in ecological research? Trends Ecol. Evol. 15: 221-222.

Shine R. Brown G. P. y Elphick M. J. 2004. Field experiments on foraging in free-ranging water snakes Enhydris polylepis (Homalopsinae). Animal Behaviour 68: 1313-1324.

Sillero N. Barbosa A. M. Martínez-Freiría F. y Real R. 2010. Los modelos de nicho ecológico en la herpetología ibérica: pasado, presente y futuro. Bol. Asoc. Herpetol. Esp. 21: 2-24.

Stattersfield A. J. Crosby M. J. Long A. J. y Wege D. C. 1998. Endemic Bird Areas of the World: Priorities for Biodiversity Conservation. Cambridge, U.K.

Sutherland W. J. Bardsley S. Bennun L. Clout M. Côté I. M. Depledge M. H. Dicks L. V. Dobson A. P. Fellman L. y Fleishman 2010. A horizon scan of global conservation issues for 2011. Trends in Ecology and Evolution 26: 1016.

Thorpe R. S. Brown R. P. Day M. Malhotra A. McGregor D. P. y Wuster W. 1994. Testing ecological and phylogenetic hypothesis in microevolutionary studies. Pp. 189-206. En: Eggleton P. y Vane-Wright R. (eds.). Phylogenetics and Ecology. Academy Press, New York, USA.

Tiranti S. I. y Avila L. J. 1997. Reptiles of La Pampa Province, Argentina: An annotated checklist. Bull. Maryland Herpetol. Soc. 33: 97-117.

Thomas R. A. 1976. A revision of the South American Colubrid snake genus Philodryas Wagler 1830. Phd. Dissertation, Texas A\&M University, USA.

Thomas R. A. y Johnson J. D. 1984. Philodryas varius (Jan, 1863), A Senior Synonym of Philodryas borelli Peracca (Serpentes: Colubridae). J. Herpetol. 18: 80.

Thomas R. A. Laurent R. F. y Barrio A. 1977. Philodryas borellii Peracca (Serpentes: Colubridae), a Distinct species. Herpetologica 33: 82-86.

Toft C. A. 1980. Feeding ecology of thirteen syntopic species of anurans in a seasonal tropical environment. Oecologia 45: 131-141.

Toft C. A. 1981. Feeding ecology of Panamanian litter anurans: patterns in diet and foraging mode. J. Herpetol. 15:139-144.

Toft C. A. 1985. Resource partitioning in amphibians and reptiles. Copeia 1985: 1-21. 
Tognelli M. F. Abba A. M. Bender J. B. y Seitz V. P. 2011. Assessing conservation priorities of xenarthrans in Argentina. Biodivers. Conserv. 20:141151.

Urbina-Cardona J. N. 2008. Conservation of Neotropical herpetofauna: research trends and challenges. Trop. Conserv. Sci. 1: 359-375.

Urbina-Cardona J. N. y Flores-Villela O. 2010. Ecological-niche modeling and prioritization of conservation-area networks for Mexican Herpetofauna. Conserv. Biol. 24: 1031-1041.

Urbina-Cardona J. N. y Loyola R. D. 2008. Applying niche-based models to predict endangered-hylid potential distributions: are neotropical protected areas effective enough? Trop. Conserv. Sci. 1: 417-445.

VanDerWal J. Shoo L. P. Graham C. y Williams S. E. 2009. Selecting pseudo-absence data for presence-only distribution modeling: How far should you stray from what you know? Ecological Modelling 220: 589-594.

Varela de Olmedo E. A. y Carrizo G. R. 1987. Ofidios de la provincia de Buenos Aires. El Naturalista 3 (Supl. 3): 1-8.

Vargas Gil J. R. y Scoppa C. O. 1973. Suelos de la Provincia de Buenos Aires. Rev. Inv. Agrop. 10: 57-79.

Vaz Ferreira R. Covello de Zolessi L. y Achaval F. 1970. Ovoposición y desarrollo de ofidios y lacertilios en hormigueros de Acromyrmex. Physis 29: 431-459.

Vega L. y Bellagamba P. 1990. Lista comentada de la Herpetofauna de las Sierras de Balcarce y Mar del Plata, Buenos Aires, Argentina. Cuad. Herp. 5: 10-14.

Viñas M. 1985. Notas sobre la biología de Pseudablabes agassizii Jan. Boletín de la Asociación Herpetológica Argentina 1: 16.

Viñas M. Daneri G. y Gnida G. 1989. Presencia de Pseudablabes agassizii (Jan, 1863) en Sierra de la Ventana (provincia de Buenos Aires), y confirmación para la provincia de la Pampa. Bol. Asoc. Herpetol. Arg. 5: 13-14.

Vitt L. J. 1983. Ecology of an anuran-eating guild of terrestrial tropical snakes. Herpetologica 39:52-66.

Vitt L. J. 1987. Communities. Pp. 335-365. En: Seigel R. A. Collins J. T. y Novak S. S. (eds.). Snakes: Ecology and Evolutionary Biology. Macmillan, New York, USA.

Vitt L. J. y Pianka E. R. 2005. Deep history impacts present-day ecology and biodiversity. Proc. Nat. Acad. Sci. 102: 7877-7881.

Vitt L. J. y Vangilder L. D. 1983. Ecology of a snake community in northeastern Brazil. Amphibia-Reptilia 4:273-296.

Vitt L. J. y Zani P. A. 1996. Organization of a taxonomically diverse lizard assemblage in Amazonian Ecuador. Can. J. Zool. 74: 1313-1335.

Vitt L. J. y Zani P. A. 1998. Prey use among sympatric lizard species in lowland rain forest of Nicaragua. J. Trop. Ecol. 14: 537-559.

Voglino D. Herrera R. y Maugeri G. 2001. Descripción Biológica y Ambiental del Parque Regional, Forestal y Botánico "Rafael de Aguiar" de San Nicolás (Pcia. De Buenos Aires). La Plata, Argentina.

Vuoto J. A. 1996. Ampliación del área de distribución de Waglerophis merremii (Wagler 1824) (Serpentes: Colubridae) sobre las provincias de Entre Ríos, Santa Fe y Buenos Aires. Cuad. Herpetol. 10: 67-70. 
Watkins J. F. Gehlbach F. R. y Kroll J. C. 1969. Attractant-repellent secretions in blind snakes (Leptotyphlops dulcis) and army ants (Neivamyrmex nigrescens). Ecology 50: 1098-1102

Webb J. K. Shine R. Branch W. R. y Harlow P. S. 2000. Life-history strategies in basal snakes: reproduction and dietary habits of the African thread snake Leptotyphlops scutifrons (Serpentes: Leptotyphlopidae). J. Zool. 250: 321-327.

White M. y Kolb J. A. 1974. A preliminary study of Thamnophis near Sagehen Creek, California. Copeia 1974:126-136.

Williams J. D. 1991. Anfibios y Reptiles. Pp. 1-21. En: López H. y Toni E. (eds.). Situación ambiental de la Provincia de Buenos Aires. A. Recursos y rasgos naturales en la evaluación ambiental. Comisión de Investigaciones Científicas de la Provincia de Buenos Aires, La Plata, Argentina.

Williams J. D. 2013. Asociación Herpetológica Argentina: Treinta años de esfuerzos y resultados. Cuad. Herpetol. 27: 7-14.

Williams J. D. y Kacoliris F. P. 2009. Anfibios y Reptiles del Parque Costero del Sur (Buenos Aires). Pp. 247-261. En: Athor J. (ed.). Parque Costero del Sur. Naturaleza, conservación y patrimonio cultural. Fundación de Historia Natural Félix de Azara, Buenos Aires, Argentina.

Williams J. W. y Francini F. 1991. A checklist of the Argentina snakes. Boll Mus. Reg. Sci. Nat. Torino 9: 55-90.

Williams J. D. y Scrocchi G. J. 1994. Ofidios de agua dulce de la República Argentina. Pp. 1-52. En: de Castellanos Z. A. (dir.). Fauna de Agua Dulce de la República Argentina. CIC, Buenos Aires, Argentina.

Wilson E. O y Willis E. O. 1975. Aplied biogeography. Pp. 522-534. En: Cody M. L. y Diamond (eds.). Ecology and Evolution of Communities. Harvard University Press, USA.

Winck G. R. Dos Santos T. G. y Cechin S. Z. 2007. Snakes assemblages in a disturbed grassland environment in Rio Grande do Sul State, Southern Brazil: population fluctuations of Liophis poecilogyrus and Pseudablabes agassizii. Annales Zoologici Fennici 44: 321-332.

Winemiller K. O. y Pianka E. R. 1990. Organization in natural assemblages of desert lizards and tropical fishes. Ecol. Monogr. 60: 27-55.

Winkler F. J. M. Waltenberg L. M. Santos P. A. Nascimento D. S. Vrcibradic D. y Sluys M. V. 2011. New records of anuran prey for Thamnodynastes strigatus (Günther, 1858) (Serpentes: Colubridae) in a highelevation area of southeast Brazil. Herpetology Notes 4: 123-124.

Wüster W. Duarte M. R. y Salomão M. G. 2005. Morphological correlates of incipient arboreality and ornithophagy in island pitvipers, and the phylogenetic position of Bothrops insularis. J. Zool. Lond. 266: 1-10.

Yanosky A. A. 1989. La ofidiofauna de la reserva ecológica El Bagual, Formosa: Abundancia, utilización de los hábitats y estado de situación. Cuad. Herpetol. 4: 11-14.

Zaher H. Grazziotin F. G. Cadle J. E. Murphy R. W. Moura-Leite J. C. y Bonatto S. L. 2009. Molecular phylogeny of advanced snakes (Serpentes, Caenophidia) with an emphasis on South American Xenodontines: a revised classification and descriptions of new taxa. Papéis Avulsos de Zoologia. Museu de Zoologia da Universidade de São Paulo 49: 115-153.

Zunino M. y Zullini A. 1995. Biogeografía: la dimensione spaziale dell'evoluzione. Casa Editrice Ambrosiana, Milano, Italia. 


\section{APÉNDICE 1}

Lista del material examinado. Los acrónimos pertenecen a las siguientes colecciones: Centro Nacional de Investigaciones lológicas (ex CENAI, actualmente MACN, Buenos Aires), Museo Argentino de Ciencias Naturales "Bernardino Rivadavia" (MACN, Buenos Aires), Museo de La Plata (MLP.R; MLP.JW, Buenos Aires) y Fundación Miguel Lillo (FML, Tucumán). En todos los casos, las determinaciones taxonómicas de catálogo o etiqueta fueron contrastadas con el examen directo del material.

Epictia australis (Freiberg y Orejas Miranda 1968). 50 ejemplares. Buenos Aires: Partido de Coronel Suárez (18 ejemplares), Villa Arcadia, alrededores del Cerro Ceferino, MLP.R.6217-18, 6221-35; Sierra de las Tunas y RP76, Estancia la Morocha, MACN 34548. Partido de Puan (2), Cerritos de Puan, MACN 36774A, B. Partido de Saavedra (1), Cerro Cura Malal, 10 km al Este de Dufaur, MACN 36773. Partido de Tornquist (29), Sierra de la Ventana, MACN 25080, 32564, 32909-17, 32942-54, 34521, 36775, FML 01609 A,B; Parque Provincial Ernesto Tornquist, base del Cerro Ventana y RP76, MLP.R.6219.

Epictia munoai (Orejas Miranda 1961). 3 ejemplares. Buenos Aires: Partido de Coronel Suárez (1), Villa Arcadia, alrededores del Cerro Ceferino, MLP.R.6220. Partido de Saavedra (1), Saavedra, MLP.JW.1018. Partido de Tornquist (1), Sierra de la Ventana, MACN 12487 (paratipo).

Erythrolamprus poecilogyrus sublineatus (Cope 1860). 86 ejemplares. Buenos Aires: Partido de Coronel Pringles (1), Indio Rico, MLP.R.6163. Partido de Coronel Suárez (23), Quiñihual, naciente del arroyo Quiñihual, MACN 27316; D'Orbigny, MACN 28811, 32261; Sierra de las Tunas y RP76, MLP.R.6173; Villa Arcadia, alrededores del Cerro Ceferino, MLP.R.6138, 614849, 6152-53, 6157-58, 6164-65, 6169-70, 6174, 6177, 6180, 6182-84, 6186-87. Partido de Saavedra (2), Cerro Cura Malal Chico, MLP.JW.0309; base del 
Cerro Cura Malal Grande, MLP.R.6189. Partido de Tornquist (60), Abra de la Ventana, MACN 7442, 20830, MLP.JW.0751; Cerro Tres Picos, MACN 24873, 25885-86; Piletas del Cerro Tres Picos, MACN 9689; Parque Provincial Ernesto Tornquist, MLP.JW.0442, MLP.R.6151, 6156, 6162, 6167-68, 6175-76, 6181; Parque Provincial Ernesto Tornquist, base del Cerro Bahía Blanca y RP76, MLP.R.6155, 6185,6188; Parque Provincial Ernesto Tornquist, base del Cerro Ventana y RP76, MLP.R.6150, 6160; Parque Provincial Ernesto Tornquist, camino a la Cueva del Toro, MACN 32820, 32822; Parque Provincial Ernesto Tornquist, Villa Ventana, Arroyo Belisario, MLP.R.6166; Parque Provincial Ernesto Tornquist, entre la cuesta de la mesa y el refugio, MACN 32819, 32828-29; Sierra de la Ventana, MACN 22168, 34476, 34488, 34505A, B, MLP.JW.0156, 0474, 0811, 1515, 1529, 1545, 1561, 1593, 1695, 1715, 1801, 1866, 1868, MLP.R.6161, 6172; Sierra de la Ventana, Abra de los Vascos, MACN 28810; Sierra de la Ventana, Arroyo Atravesado, MACN 28813; Sierra de la Ventana, Camping El Paraíso, MLP.R.6159; Sierra de la Ventana, Camping Sierra Ventura, MLP.R. 6154; Sierra de la Ventana, Camping Yamila, MLP.R.6179; Sierra de la Ventana, Río Sauce Grande, MACN 7341-42, MLP.JW.1502-03, MLP.R.6171, 6178; Villa Ventana, camino al viejo Hotel Provincial, MLP.JW.0961; Villa Ventana, represa Arroyo Belisario, MACN 14279.

Lygophis anomalus (Günther 1858). 20 ejemplares. Buenos Aires: Partido de Coronel Pringles (2), Coronel Pringles, Arroyo Pillahuincó, MLP.R.5503, 6119. Partido de Coronel Suárez (17), Arroyo Las Tunas, cruce RP76, MLP.R.611618, 6133; D’Orbignyi, MACN 24469, 31303, 31438, 32262, 32279-80; Estancia El Relincho, MACN 36079; Estancia El Triunfo, MACN 27841-42, 28799; Huanguelen, Estancia Las Nenas, MACN 24444; naciente del Arroyo Las Tunas, MACN 27315; Quiñihual, Remonta del Ejército, MACN 28305. Partido de Tornquist (1), Chasicó, MLP.JW.0856.

Lygophis elegantissimus (Koslowsky 1895). 70 ejemplares. Buenos Aires: Partido de Coronel Pringles (1), Coronel Pringles, Arroyo Pillahuincó y RP51, 
MLP.R.6216. Partido de Coronel Suárez (30), Arroyo Las Tunas y RP85, MLP.R.6195; Cerro Las Tunas, MACN 24470, 33009; Cerro Las Tunas, Estancia El Relincho, MACN 32956-57; Coronel Suárez, MLP.JW.0097; Cura Malal, MACN 195A; Sierra de las Tunas, MACN 29185; Sierra de las Tunas, naciente del Arroyo las Tunas, Estancia Peñaflor, MACN 27315; Sierra de Las Tunas y RP76, MLP.R.6191; Sierra de Las Tunas, RP76, Estancia El Perdido, MACN 34563; Sierra de Las Tunas, RP76, Estancia El Relincho, MACN 34564; Villa Arcadia, alrededores del Cerro Ceferino, MLP.R. 6005, 6192-93, 6197-02, 6204, 6206-11, 6213, R.6241. Partido de Saavedra (2), Pigüé, MACN 2747; Pigüé, Sierra de Cura Malal, Estancia La Bloqueada, MACN 34540. Partido de Tornquist (35), Abra de la Ventana, MACN 7440-41, 20829; Cerro Tres Picos, MACN 24874; Piletas del Cerro Tres Picos, MACN 9691; Cordón Esmeralda, RP72 cruce RP76, MLP.R.6205, MACN 32541-42; Parque Provincial Ernesto Tornquist, MLP.JW.0946, MLP.R.6215; Parque Provincial Ernesto Tornquist, base del Cerro Bahía Blanca y RP76, MLP.R. 6196; Parque Provincial Ernesto Tornquist, base del Cerro Ventana y RP76, MLP.R.6203, 6214; Parque Provincial Ernesto Tornquist, Cordón Esmeralda, MLP.R.6194; Parque Provincial Ernesto Tornquist, Villa Ventana, Arroyo Belisario, MLP.R.6212; Saldungaray, MACN 6446; Sierra de la Ventana, MACN 195B, 2658, 3007, 6447, 16775, 27305, 34504, MLP.JW.0713, 0715, 0835,1930, MLP.R.6190; Sierra de la Ventana, Estancia Fortín Chaco, MACN 30303; Sierra de la Ventana, Estancia Montoriano, MLP.JW.0714; Tornquist, MACN 1259; Villa Ventana, MACN 32832; Villa Ventana, represa Arroyo Belisario, MACN 14280; Villa Ventana, Hotel Provincial, MLP.JW.0472-73. Sin localidad específica de colecta (2), MACN 0850, 30008.

Oxyrhopus rhombifer rhombifer (Duméril, Bibron y Duméril 1854). 13 ejemplares. Buenos Aires: Partido de Coronel Suárez (2), Sierra de Las Tunas, MACN 29626, 33464. Partido de Saavedra (3), Pigüé, MACN 44822; Sierra de Cura Malal, 46 km al Este de Saavedra, MACN 29059; base del Cerro Cura Malal Grande, MLP.R.6132. Partido de Tornquist (8), Abra de la Ventana, MACN 9690, 20832-33; Parque Provincial Ernesto Tornquist, MACN 12783; Parque Provincial Ernesto Tornquist, base del Cerro Bahía Blanca, 
MLP.R.6120; Sierra de la Ventana, MACN 34497; Sierra de la Ventana, Cordón Esmeralda, MLP.R.5504; Sierra de la Ventana, Estancia Laurina, MACN 37232.

Paraphimophis rustica (Cope 1878). 4 ejemplares. Buenos Aires: Partido de Coronel Suárez (1), Sierra de Las Tunas y RP76, MLP.R.6127. Partido de Saavedra (1), base del Cerro Cura Malal Grande, MLP.R.6128. Partido de Tornquist (2), Cerro Tres Picos, MACN 33555; Sierra de la Ventana, MACN 34583.

Phalotris bilineatus (Duméril, Bibron y Duméril 1854). 4 ejemplares. Buenos Aires: Partido de Tornquist (4), Parque Provincial Ernesto Tornquist, MACN 32886; Sierra de la Ventana, MLP.JW.0620, MLP.R.5640; Sierra de la Ventana, balneario El Dique, MLP.R.6129.

Philodryas aestiva subcarinata Boulenger 1902. 4 ejemplares. Buenos Aires: Partido de Tornquist (4), Complejo Turístico el Pinar, MACN 33197; Hotel La Espadaña, MACN 31675; Sierra de la Ventana, MACN 37430, MLP.R.6051.

Philodryas agassizii (Jan 1863). 4 ejemplares. Buenos Aires: Partido de Tornquist (4), Parque Provincial Ernesto Tornquist, FML 16269, MACN 31773; Sierra de la Ventana, MACN 31772, 31774.

Philodryas patagoniensis (Girard 1857). 43 ejemplares. Buenos Aires: Partido de Coronel Suárez (18), Bajo del Cura, entre arroyo Sauce Corto y Cura Malal, MACN 27840; Coronel Suárez, MACN 28117, 38737; Cruce RP76 y RP85, MLP.R.6140; D’Orbigny, MACN 14281, 23527, 27467, 32236, 35339, 35742-43; D’Orbigny, Estancia Sauce Corto, MACN 18575; D’Orbigny, Estancia Santa Marta, MACN 21728; D’Orbigny, Estancia San Pablo, MACN 27317; Villa Arcadia, alrededores Cerro Ceferino, MLP.R.5926, 5955, 6136-37. 
Partido de Saavedra (5), base del Cerro Cura Malal, MLP.R.6142-44, 6146-47. Partido de Tornquist (20), Abra de la Ventana, MACN 20831, 30012; Parque Provincial Ernesto Tornquist, base del Cerro Bahía Blanca y RP76, R.6240; Parque Provincial Ernesto Tornquist, base del Cerro Ventana y RP76, MLP.R.6134-35, 6139, 6141; Parque Provincial Ernesto Tornquist, entre la cuesta de la mesa y el refugio, MACN 32830-31; Sierra de la Ventana, MACN 32941, 35401, 38705, MLP.JW.1901-03, 1905, MLP.R.6145; Sierra de la Ventana, Estancia Laurina, MACN 38694; Tornquist, MLP.JW.1655; Villa Ventana, MACN 34822.

Xenodon dorbignyi (Duméril, Bibron y Duméril 1854). 8 ejemplares. Buenos Aires: Partido de Coronel Suárez (1), Villa Arcadia, basural, MLP.R.6125. Partido de Saavedra (1), Cerro Cura Malal Chico, MLP.JW.0508. Partido de Tornquist (6), Parque Provincial Ernesto Tornquist, base del Cerro Bahía Blanca, MLP.R.6121, 6124, 6126; Parque Provincial Ernesto Tornquist, base del Cerro Ventana y RP76, MLP.R.6122-23; Sierra de la Ventana, Estancia El Pantanoso, MACN 44543.

Xenodon semicinctus (Duméril, Bibron y Duméril 1854). 2 ejemplares. Buenos Aires: Partido de Tornquist (2), Chasicó, MACN 27451; Tornquist y RN33, MLP.R.6239.

Bothrops alternatus (Duméril, Bibron y Duméril 1854). 58 ejemplares. Buenos Aires: Partido de Coronel Suárez (7), Cura Malal, MACN 0189; Sierra de Las Tunas y RP76, MLP.R.6108, 6113; Villa Arcadia, Alrededores del Cerro Ceferino, MLP.R.6105, 6109, 6114-15. Partido de Saavedra (2), base del Cerro Cura Malal, MLP.R.6130-31. Partido de Tornquist (49), Abra de la Ventana, MACN 7439, 20834, 27318, MLP.JW.1740, MLP.R.5875; Parque Provincial Ernesto Tornquist, MACN 9692A, B, MLP.JW.0039, 0470, 0749, MLP.R.6104, 6110-12; Parque Provincial Ernesto Tornquist, base del Cerro Bahía Blanca, MLP.R.6106-07, 6098; Parque Provincial Ernesto Tornquist, base del Cerro 
Ventana, MACN 43252, MLP.R.6099, 6101, 6103; Parque Provincial Ernesto Tornquist, Cordón Esmeralda, MLP.R.6100; Parque Provincial Ernesto Tornquist, junto al refugio, MLP.JW.0750; Parque Provincial Ernesto Tornquist, Villa Ventana, MLP.R.6102; Sierra de la Ventana, MACN 6905-07, 33463, 40018, 43088, 43268, 44202, MLP.JW.0484, 0773; Sierra de la Ventana, Estancia Laurina, MACN 39209; Sierra de la Ventana, Fortín Chaco, MACN 26097, Sierra de la Ventana, Río Sauce Grande, MACN 7340, 33029; Sierra de la Ventana, Campo Vineto, MLP.JW.0507; Sierra de la Ventana, Vivero Agrario, MLP.JW.0781; Tornquist, MLP.JW.0710-11, 0783, 0793, 0899-02, 1578.

Bothrops ammodytoides (Leybold 1873). 7 ejemplares. Buenos Aires: Partido de Puan (2), Bordenave, Estancia Las Glicinas, MACN 34371; San Germán, MLP.JW.0595. Partido de Tornquist (5), Sierra de la Ventana, MACN 44276; Tornquist, MACN 34648, 39068, 46306, Tornquist y RN33, MLP.R.6238. 


\section{APÉNDICE 2}

Fotografías de las serpientes de presencia confirmada: Epictia australis (A), E. munoai (B), Erythrolamprus poecilogyrus sublineatus (C), Lygophis anomalus (D), L. elegantissimus (E), Oxyrhopus rhombifer rhombifer (F), Paraphimophis rustica (G), Phalotris bilineatus (H), Philodryas aestiva subcarinata (I), P. agassizii (J), P. patagoniensis (K), Xenodon dorbignyi (L), $X$. semicinctus (M), Bothrops alternatus $(\mathrm{N})$ y B. ammodytoides $(\tilde{\mathrm{N}})$.

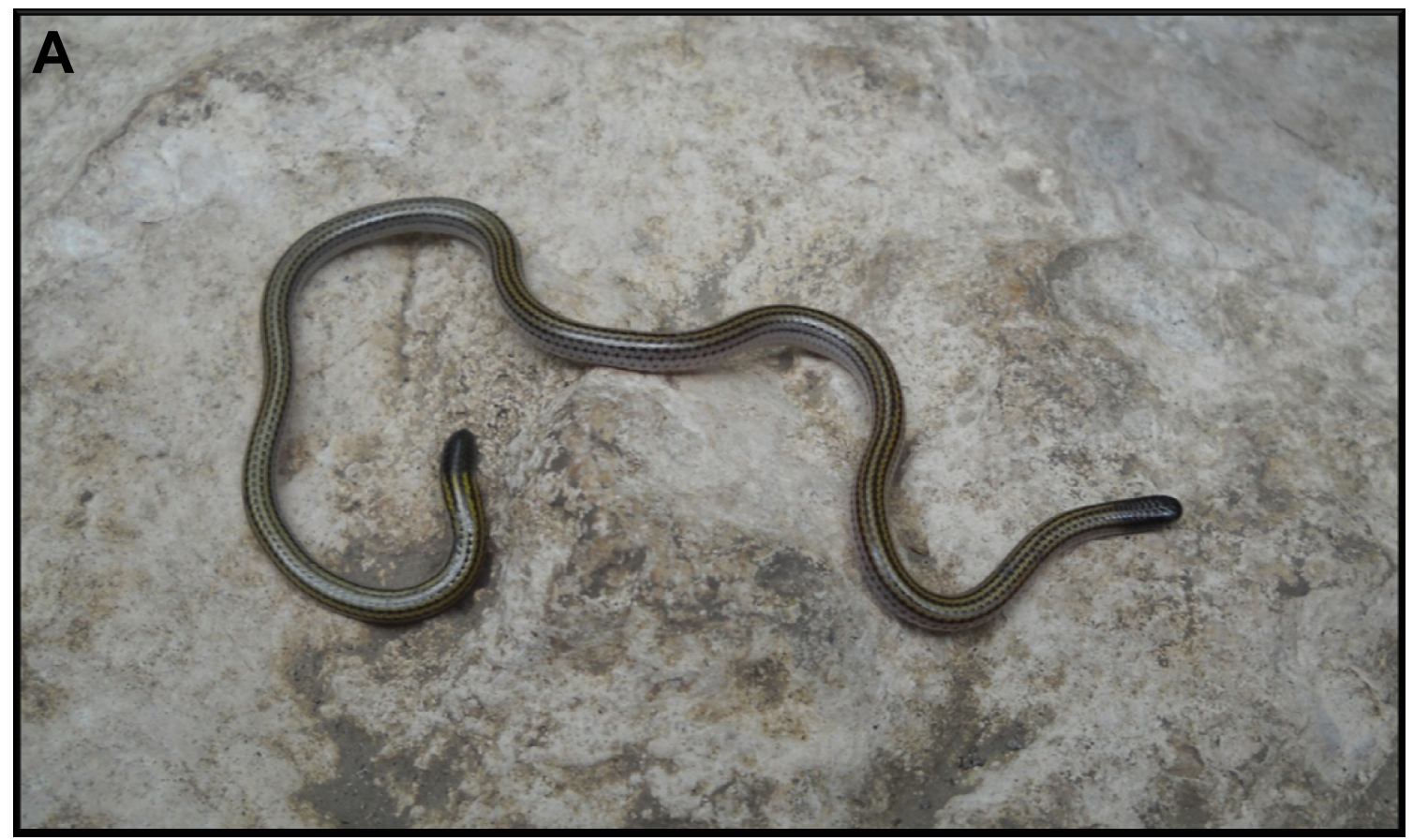



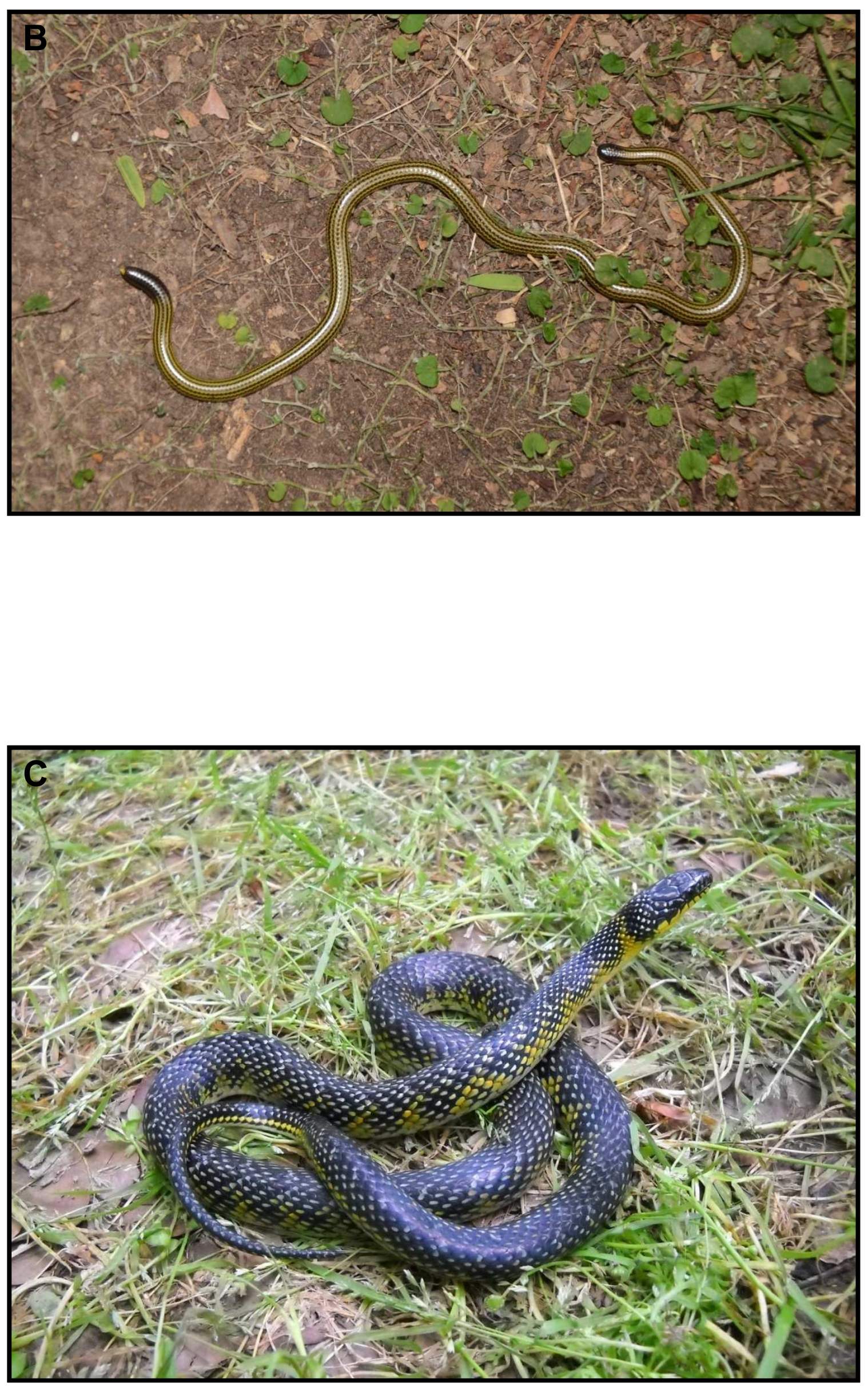

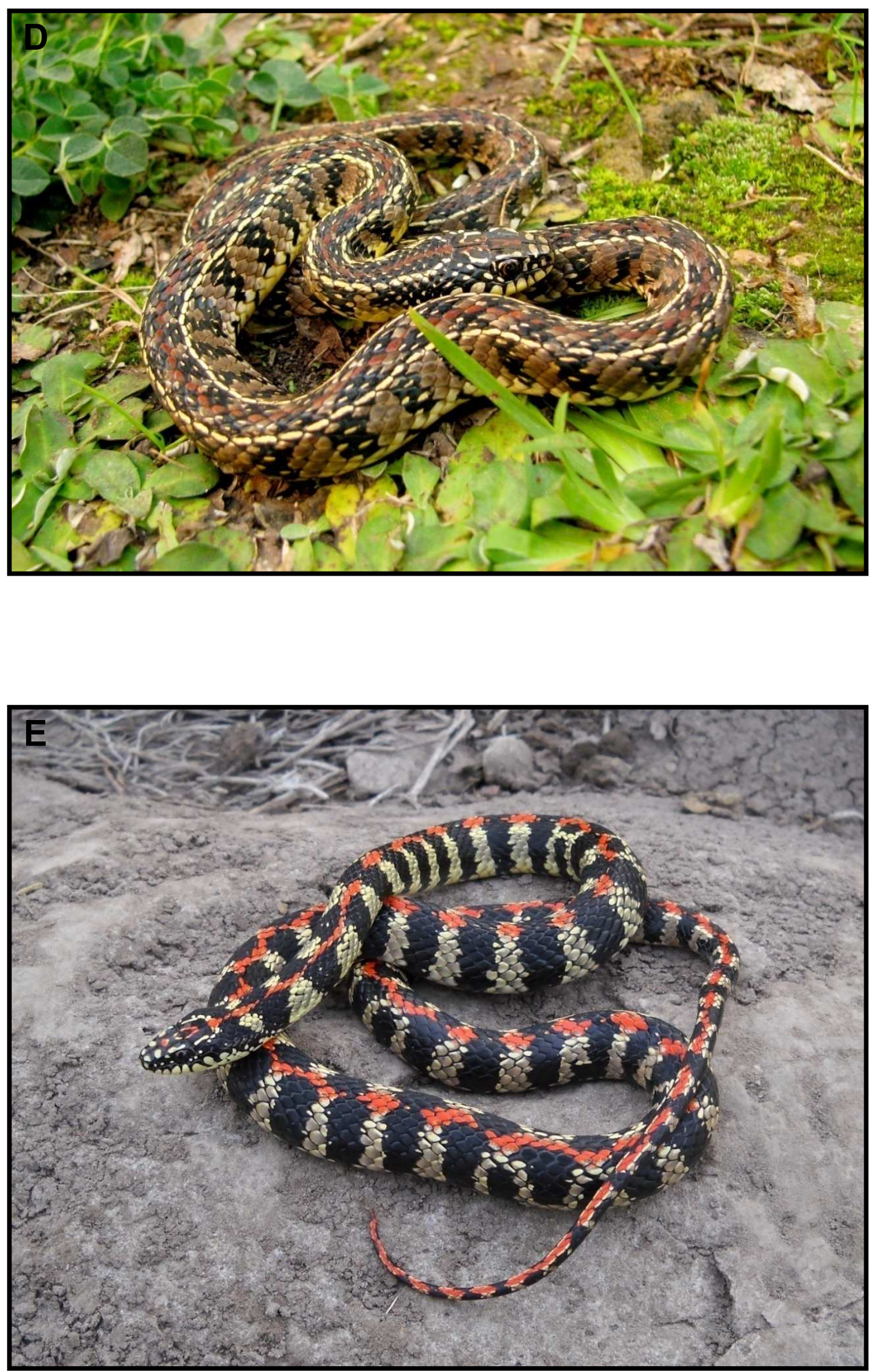

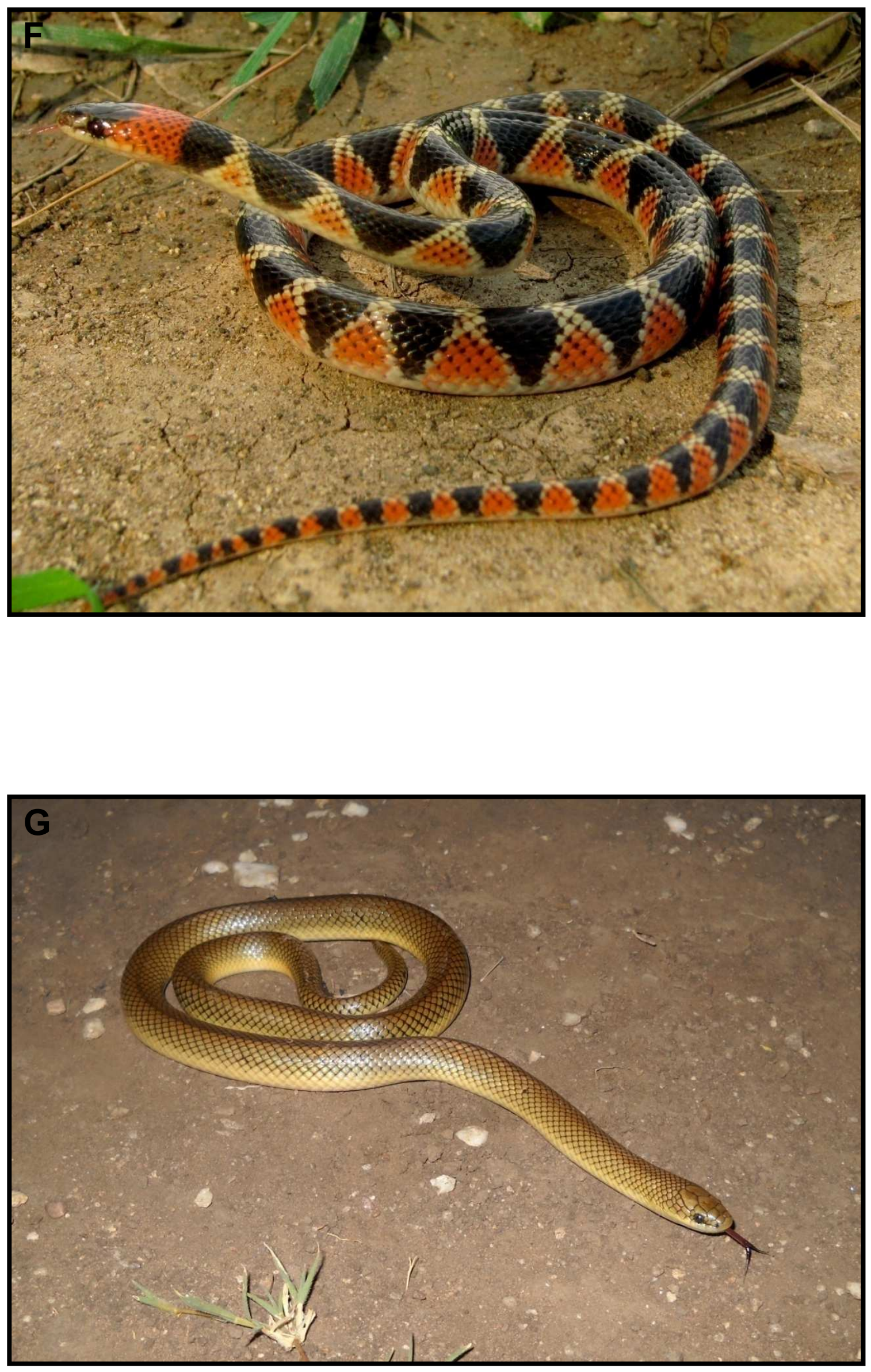

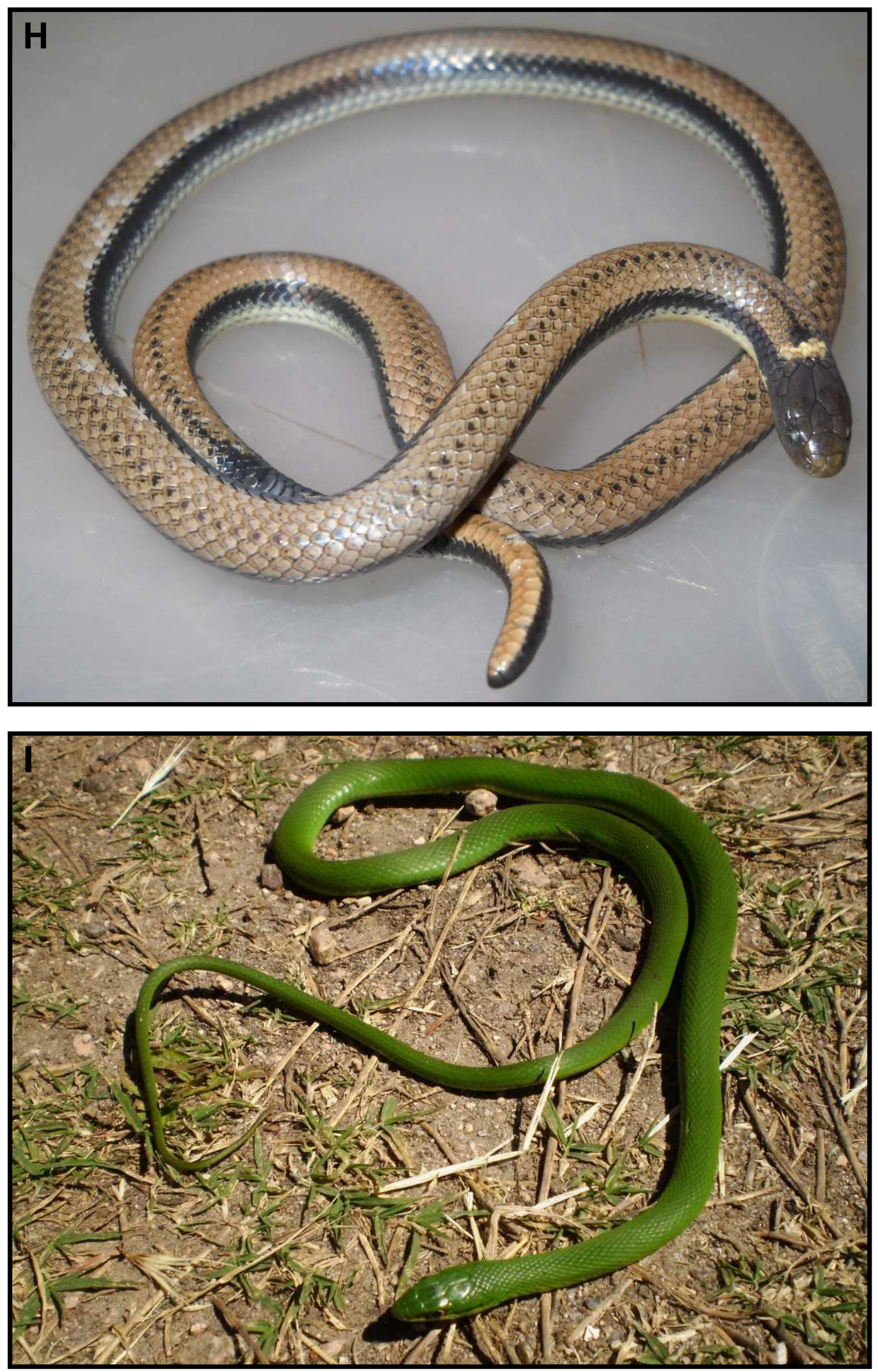

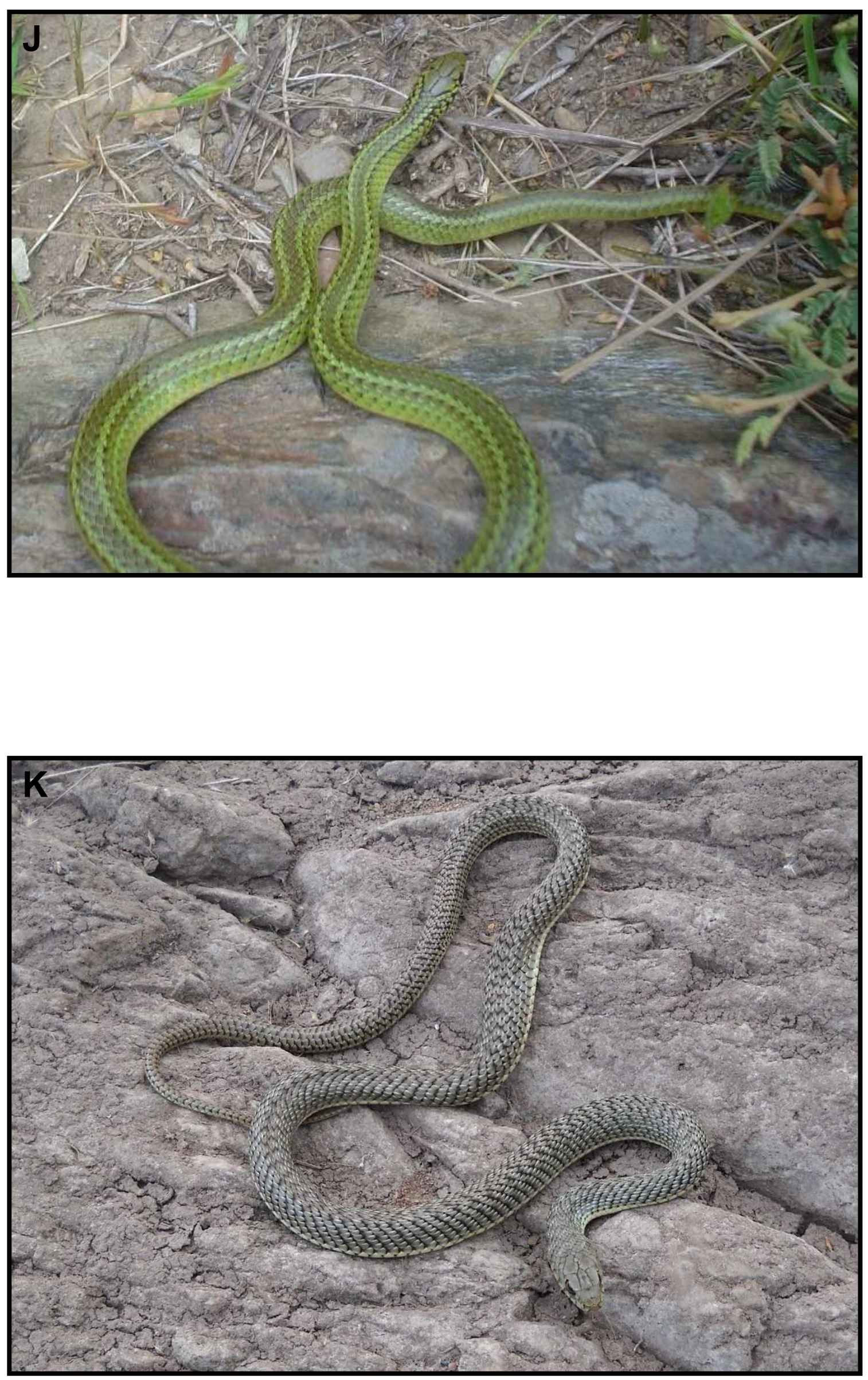

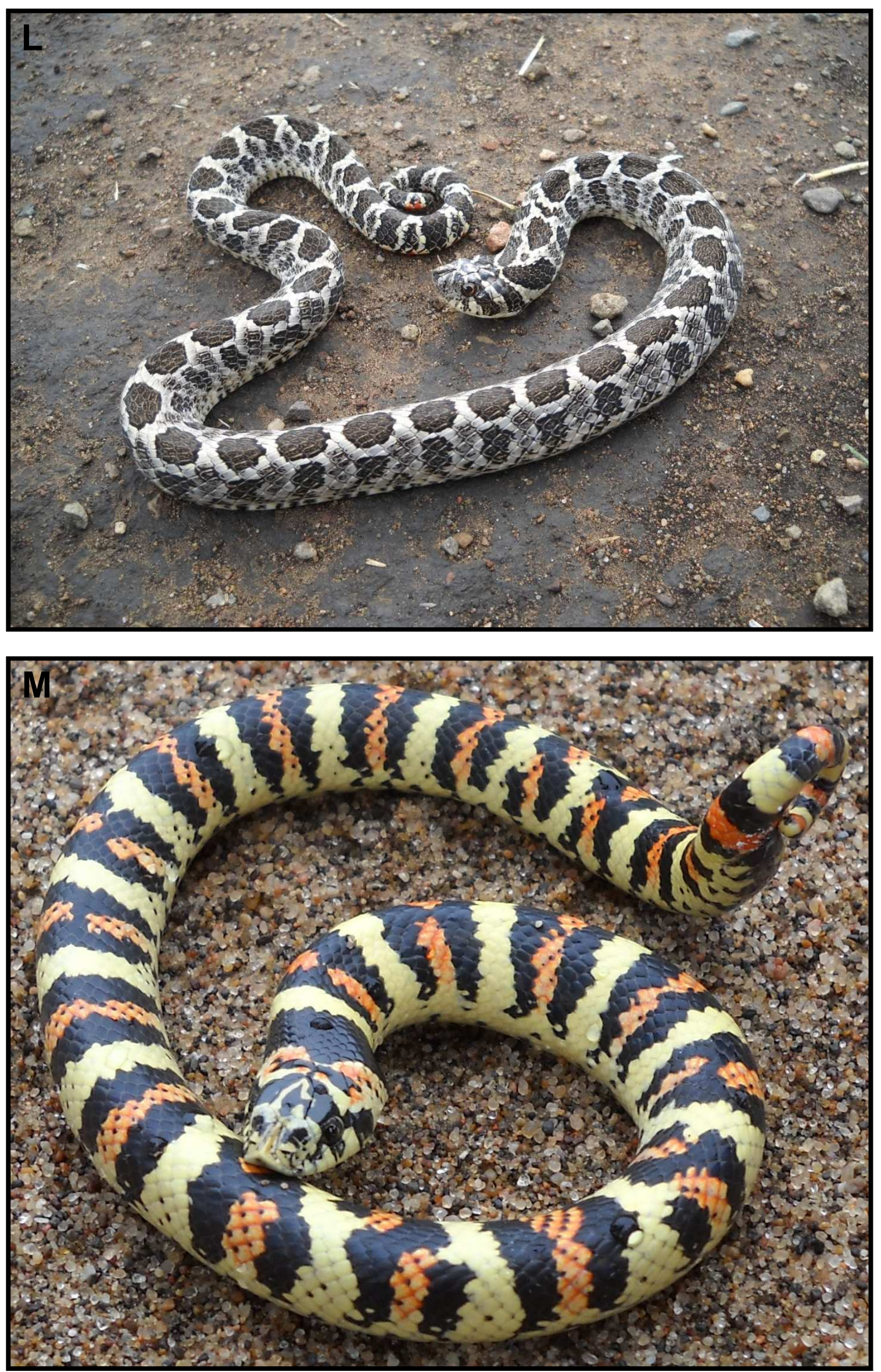

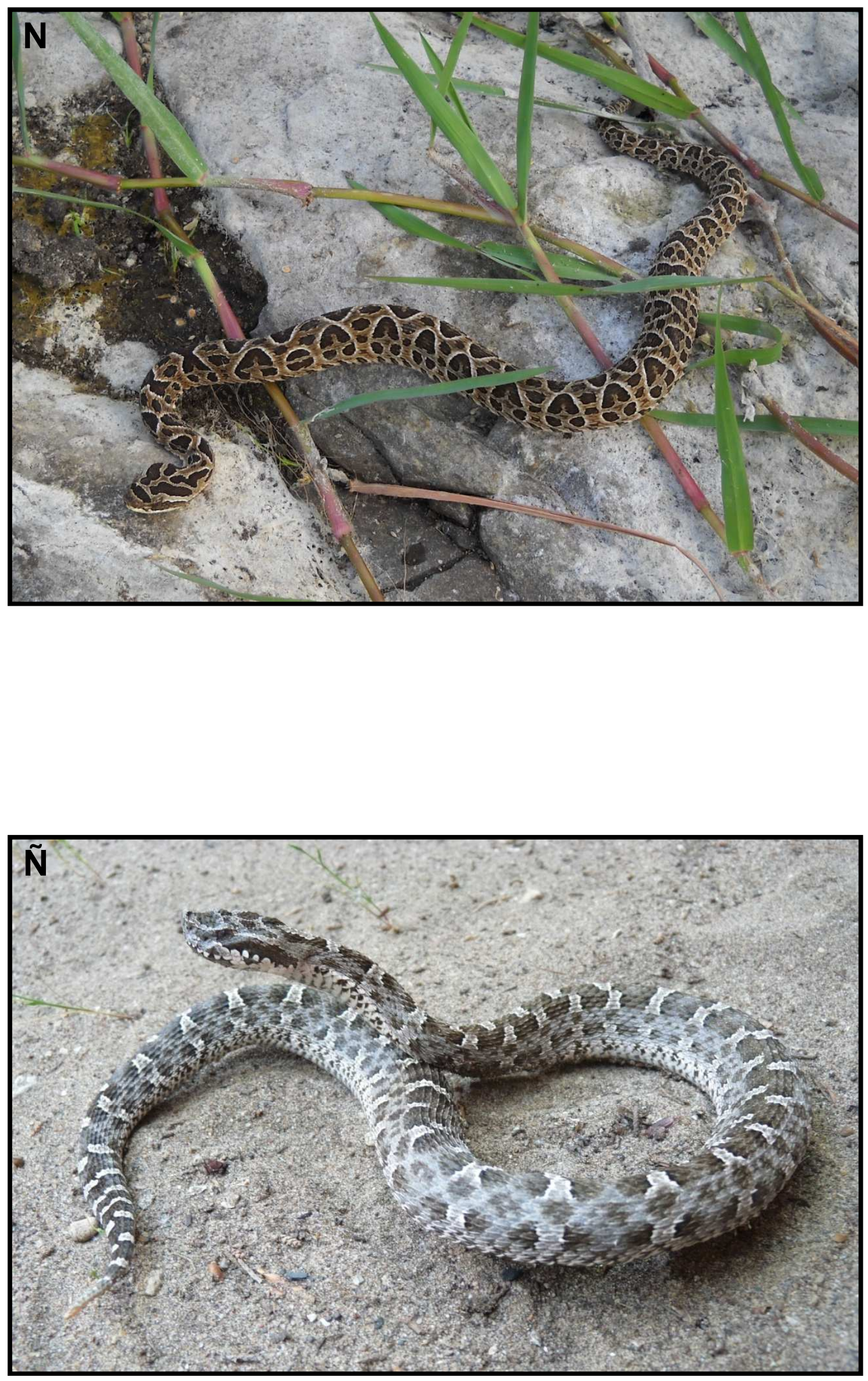